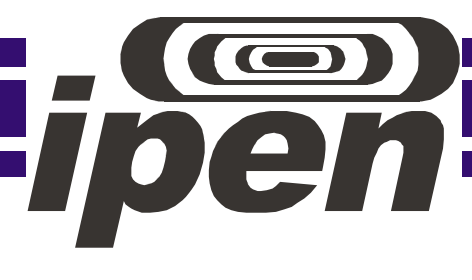

AUTARQUIA ASSOCIADA À UNIVERSIDADE DE SÃO PAULO

ESTABELECIMENTO DE PADRONIZAÇÃO PRIMÁRIA E DE MÉTODOS RELATIVOS COM O USO DE TÉCNICAS LUMINESCENTES EM DOSIMETRIA DA RADIAÇÃO BETA

Patrícia de Lara Antonio

Tese apresentada como parte dos requisitos para obtenção do Grau de Doutor em Ciências na Área de Tecnologia Nuclear - Aplicações

Orientadora:

Profa. Dra. Linda V. E. Caldas 
INSTITUTO DE PESQUISAS ENERGÉTICAS E NUCLEARES

Autarquia associada à Universidade de São Paulo

ESTABELECIMENTO DE PADRONIZAÇÃO PRIMÁRIA E DE MÉTODOS RELATIVOS COM O USO DE TÉCNICAS LUMINESCENTES EM DOSIMETRIA DA RADIAÇÃO BETA

Patrícia de Lara Antonio

Tese apresentada como parte dos requisitos para obtenção do Grau de Doutor em Ciências na Área de Tecnologia Nuclear - Aplicações

Orientadora:

Profa. Dra. Linda V. E. Caldas

Versão Corrigida

Versão Original disponível no IPEN

São Paulo

2013 
DEDICATÓRIA

Àqueles que me apoiaram em todo o tempo: Meus pais, Omar e Marisa, com gratidão e todo amor, Dra. Linda, com carinho e admiração, e Senhor Jesus, Emanuel, que sempre esteve comigo. 


\section{AGRADECIMENTOS}

À minha querida orientadora Dra. Linda V. E. Caldas, por ter me ensinado quão prazeroso e ao mesmo tempo desafiador é trabalhar com radiação beta e com câmara de extrapolação. Muito obrigada pela oportunidade de trabalhar com assuntos e instrumentos dos quais eu adorei e aprendi tanto. Entretanto, acima de tudo, eu gostaria de agradecê-la por ser quem a Sra. é. Eu serei sempre grata por todo amor e carinho, amizade e companhia, toda compreensão e paciência, e também por cada sorriso, que mesmo nos momentos mais difíceis, de alguma forma me motivava. Eu também não poderia deixar de agradecê-la por todo cuidado, pelos momentos de desabafo, pelos conselhos. É uma honra poder chamá-la não só de orientadora, mas de amiga, e como é bom ter a Sra. sonhando sempre cada sonho meu junto comigo. É uma alegria muito grande ao meu coração poder compartilhar com a Sra. o ato de concluir esta tese. Muito obrigada por tudo!

Meus agradecimentos se estendem:

À Dra. Maria da Penha Albuquerque Potiens, por autorizar sempre que eu precisei o uso do Laboratório de Calibração de Instrumentos (LCI) para a realização da parte experimental do trabalho, e pelos momentos de descontração.

Ao Dr. Vitor Vivolo, pela convivência tão prazerosa, pelas conversas, opiniões e disposição constante em me auxiliar com assuntos e dúvidas relacionados ao meu trabalho, por ser sempre tão atencioso e educado, e também pelas sugestões na avaliação do meu exame de Qualificação.

À Dra. Letícia Lucente Campos Rodrigues, pelo esclarecimento de dúvidas relacionadas à utilização e caracterização de dosímetros termoluminescentes.

À Dra. Helen Jamil Khoury, por ser sempre tão simpática e atenciosa comigo, e por dispensar tanto tempo me ensinando a trabalhar com o sistema leitor LOE, fabricado pelo Departamento de Energia Nuclear (DEN), da Universidade Federal de Pernambuco (UFPE), e também pelo fornecimento de filtros e outros acessórios para o trabalho com materiais luminescentes.

À Dra. Denise Yanikian Nersissian, pelas sugestões tão importantes no meu Exame de Qualificação.

À Dra. Teresa Cristina Nathan Outeiro Pinto, pelas conversas sempre tão agradáveis, por tantas risadas, pelos nossos trabalhos e por todo o auxílio com relação às técnicas luminescentes. Muito obrigada por estar sempre tão disposta em me ajudar.

À Dra. Claudia Carla Gronchi, pelos momentos sempre tão bons no Laboratório de Termoluminescência, de conversas e risadas, e por todo auxílio no trabalho com o sistema leitor da Landauer.

À Dra. Carmen Cecília Bueno, por ser sempre tão atenciosa e motivadora, e pela grande contrubuição por meio de sugestões no meu Seminário de Área.

À Dra. Divanizia do Nascimento Souza, por permitir o envio do sistema postal dosimétrico ao Laboratório de Física da Universidade Federal de Sergipe (UFS). Muito obrigada pelo seu apoio e sua atenção sempre constante.

Ao M.Sc. Rogério M. V. Silva, da Universidade Federal de Sergipe, pela disponibilidade e atenção em irradiar os dosímetros de $\mathrm{CaSO}_{4}$ :Dy e de $\mathrm{Al}_{2} \mathrm{O}_{3}: \mathrm{C}$ com os aplicadores clínicos de ${ }^{90} \mathrm{Sr}^{90} \mathrm{Y}$. 
Ao Dr. Goro Hiromoto, pela disponibilidade em me auxiliar no esclarecimento de dúvidas com relação a cálculos de incertezas.

Ao Dr. Orlando Rodrigues Jr., por todo auxílio na instalação e utilização de softwares dos sistemas medidores TL, e na manutenção de computadores.

Ao Dr. Larry DeWerd, do Departamento de Física Médica da Universidade de Wisconsin, por ser sempre tão simpático e atencioso, e por todo o auxílio com relação às minhas dúvidas sobre cálculos de incerteza e medições com aplicadores clínicos de ${ }^{90} \mathrm{Sr}+{ }^{90} \mathrm{Y}$.

Ao Dr. Graham Bass, do laboratório padrão primário da Inglaterra, National Physical Laboratory (NPL), pela câmara de extrapolação Böhm e pela disposição em nos fornecer janelas de entrada para a câmara.

Aos cinco hospitais da cidade de São Paulo, pela disponibilidade em aprender sobre a importância da calibração de aplicadores clínicos de ${ }^{90} \mathrm{Sr}+{ }^{90} \mathrm{Y}$, e por fazerem parte desta etapa do meu trabalho: Instituto de Assistência Médica ao Servidor Público Estadual (na pessoa da Dra. Maria José Alves), Sociedade Beneficente de Senhoras Hospital Sírio Libanês (Dra. Cecília Maria Kalil Haddad), Hospital Alemão Oswaldo Cruz (Física Mônica Lagatta), Hospital A.C. Camargo (Dr. Petrus Paulo C. E. da Silva), e Instituto de Radiologia do Hospital das Clínicas de São Paulo (Físico Médico Marco Antonio da Silva).

Aos técnicos do $\mathrm{LCl}$, pela ajuda no desenvolvimento deste trabalho, pelas instruções e pela manutenção de equipamentos, em especial ao Sr. Claudinei Cescon, e Sr. Marcos Xavier, a quem agradeço também por toda disposição em me auxiliar com a câmara de extrapolação, atenção, pelos ensinamentos de eletrônica, e pelas conversas nos momentos de descontração; ao Sr. Rafael Elias Diniz, por permitir a utilização do Laboratório de Calibração Beta e pelo auxílio nas irradiações feitas neste laboratório.

À Sra. Donata Celicea de Oliveira Zanin que, de forma atenciosa, sempre se dispôs a me atender, auxiliar em tudo o que eu precisasse, e fornecer materiais importantes para o desenvolvimento deste trabalho. Muito obrigada pelo carinho!

Aos meus queridos pais, Omar e Marisa, meus amores, meus amigos, pastores, conselheiros, companheiros de riso e lágrimas, meus incentivadores e motivadores. Muito obrigada por tanto amor, impagável e imensurável, por toda compreensão nos momentos em que eu me mostrei tão distante, mesmo estando presente, por me apoiarem tanto e a todo momento, por sempre me fazerem avançar, seguir em frente, por torcerem por mim, e por sonharem cada sonho meu junto comigo. Vocês são meus exemplos para tantas coisas que eu poderia escrever, escrever, escrever... e não caberia aqui. Eu os amo tanto!

Ao meu irmão, Thiago, por me fazer rir tantas vezes, por se preocupar comigo e me socorrer, pessoal e virtualmente, sempre quando encontrei problemas com relação a computador.

A todos os meus familiares, tios e primos, por todo amor e carinho.

Aos Apóstolos Jesher e Marycleide Cardoso, e Reinaldo Moraes, pelo amor, incentivo e pelos momentos de desabafo.

A todos os irmãos da Igreja Apostólica Plenitude da Graça, minha outra família, em especial à equipe do Ministério de Louvor, por compreender meus momentos de ausência, e por todo apoio e carinho. 
Ao Prof. MSc. Ricardo Coura Oliveira, pelo incentivo e torcida constantes, e por ser um amigo especial e sempre presente, mesmo estando longe.

À minha amiga Isis Sabrina S. Ximenes, pela amizade fiel, pelo carinho, apoio e incentivo constantes. Muito obrigada por sempre entender meus momentos de "sumiço".

Aos meus amigos companheiros de sala no IPEN: Maíra Tiemi Yoshizumi, Jonas Oliveira da Silva, Fernanda Beatrice Conceição Nonato, Cristiane Jordão de Carvalho Honda e Maria Inês Teixeira, pela amizade e convivência. Aos amigos Christianne Cobello Cavinato, Lizandra Pereira de Souza, Lucia Helena da Silva Santos, Claudio Antonio Federico, Eric Alexandre Brito da Silva, Gustavo Barreto Vila, Leonardo de Holanda Mencarini e Tallyson Sarmento Alvarenga, pela amizade, pelo companheirismo e pelas conversas sempre agradáveis. Aos amigos e colegas Daniela Piai Groppo, Felipe Belonsi de Cintra, Mateus Hilário de Lima, Ana Paula Perini e Lucio Pereira Neves, por todos os momentos que passamos juntos.

À Michelle G. de Carvalho, minha companheira de apartamento, pela amizade, carinho e pelos ótimos anos de convivência na moradia.

A todos os funcionários da Gerência de Ensino (GE) do IPEN, na pessoa do Presidente da Comissão de Pós-Graduação (CPG), Dr. Delvonei Alves de Andrade, por todos os serviços prestados.

Ao Instituto de Pesquisas Energéticas e Nucleares, Comissão Nacional de Energia Nuclear (IPEN-CNEN/SP), na pessoa do Superintendente Dr. José Carlos Bressiani, pela rica oportunidade de realizar e concluir este trabalho de doutorado em Tecnologia Nuclear.

À Fundação de Amparo à Pesquisa do Estado de São Paulo (FAPESP), por me conceder a bolsa de doutorado para a realização deste projeto (Projeto FAPESP no 2009/52724-7).

E a todos aqueles que, de uma forma ou de outra, contribuíram para que este trabalho fosse desenvolvido e concluído. Muito obrigada!

Ao Amado Senhor Jesus, Santo, Santo, Santo, o Todo-Poderoso, que era, que é e que há de vir, agradeço pelo cuidado diário, pela força que muitas vezes eu pude ver que era sobrenatural (quando eu já não acreditava mais), por me ajudar a fazer tantas coisas ao mesmo tempo (como tantas vezes foi preciso), por ser meu sustento e meu Amigo Fiel. Eu te amo! E agradeço por me dar a Dra. Linda como orientadora e amiga, por me dar pais e um irmão tão abençoados, familiares e amigos tão especiais. E por colocar em meu caminho tantas pessoas que participaram da elaboração deste projeto.

"Digno és de receber glória, e honra, e poder; porque Tu criaste todas as coisas, e por Tua vontade são e foram criadas." (Ap. 4:11) 


\section{EPÍGRAFE}

“...Spirit lead me where my trust is without borders Let me walk upon the waters Wherever you would call me Take me deeper than my feet could ever wander And my faith will be made stronger In the presence of my Saviour

I will call upon Your name Keep my eyes above the waves My soul will rest in your embrace I am Yours and You are mine"

Trecho de "Oceans", Hillsong United (Letra: Joel Houston, Matt Crocker e Salomon Lightelm) 


\title{
ESTABELECIMENTO DE PADRONIZAÇÃO PRIMÁRIA E DE MÉTODOS RELATIVOS COM O USO DE TÉCNICAS LUMINESCENTES EM DOSIMETRIA DA RADIAÇÃO BETA
}

\author{
Patrícia de Lara Antonio
}

\begin{abstract}
RESUMO
Devido à inexistência de um laboratório de padronização primária na América Latina, para calibração e dosimetria de fontes de radiação beta, neste trabalho uma câmara de extrapolação Böhm foi caracterizada e estabelecida como um sistema padrão primário no Laboratório de Calibração de Instrumentos (LCI) do IPEN. Como objetivo principal deste trabalho, a câmara de extrapolação Böhm foi caracterizada com relação à sua resposta em feixes padrões secundários de radiação beta de fontes de ${ }^{90} \mathrm{Sr}+{ }^{90} \mathrm{Y}$, com duas janelas de entrada diferentes: Mylar aluminizado e Hostaphan grafitado, e com dois métodos de determinação de taxa de dose absorvida, para verificação do seu desempenho com cada material. Embora se trate do instrumento mais adequado para a calibração de detectores e fontes de radiação beta, a câmara de extrapolação deve ser utilizada apenas em laboratórios de calibração e não em programas de controle de qualidade, pois ela tem $7 \mathrm{~kg}$ e é de alto custo. Assim, é importante ter sistemas considerados padrões de trabalho e métodos alternativos para substituir a câmara de extrapolação em medições realizadas em campo, como em hospitais ou clínicas. Por este motivo, foram caracterizadas três câmaras de ionização de placas paralelas, com o objetivo de se verificar a possibilidade de seu uso como sistemas padrões de trabalho em programas de controle de qualidade, e também foram estudados materiais dosimétricos diferentes, em campos de radiação beta de ${ }^{90} \mathrm{Sr}+{ }^{90} \mathrm{Y}$, utilizando-se os fenômenos da termoluminescência (TL) e da luminescência opticamente estimulada (LOE), como métodos alternativos na calibração de fontes de radiação beta. Inclui-se aqui o desenvolvimento de um sistema postal dosimétrico para a calibração de aplicadores clínicos de ${ }^{90} \mathrm{Sr}+{ }^{90} \mathrm{Y}$. Os resultados obtidos com a câmara de extrapolação Böhm permitiram o seu estabelecimento como sistema padrão primário na calibração de fontes de ${ }^{90} \mathrm{Sr}+{ }^{90} \mathrm{Y}$, pois a câmara com as duas janelas de entrada diferentes permitiram a determinação de taxas de dose absorvida no ar e no tecido, à profundidade nula e a 0,07 mm. A caracterização das três câmaras de ionização de placas paralelas mostraram que elas podem ser usadas em programas de controle de qualidade de fontes de radiação beta, pois suas respostas se apresentaram adequadas para esta finalidade. Os materiais dosimétricos testados com relação às suas respostas TL e LOE também se mostraram adequados para uso em campos de radiação beta, pois suas respostas foram satisfatórias. O sistema dosimétrico, utilizando dosímetros $\mathrm{TL}$, foi testado em hospitais e, posteriormente, foi enviado na forma postal a um laboratório, contendo detectores TL e LOE, e o resultado da calibração dos aplicadores clínicos foi adequado.
\end{abstract}




\title{
ESTABLISHMENT OF PRIMARY STANDARDIZATION AND RELATIVE METHODS WITH THE USE OF LUMINESCENT TECHNIQUES IN BETA RADIATION DOSIMETRY
}

\author{
Patrícia de Lara Antonio
}

\begin{abstract}
Due to the lack of a primary standard laboratory at the Latin America, for the calibration and dosimetry of beta radiation sources, it was decided to establish the Böhm extrapolation chamber at the Calibration Laboratory (LCI) at IPEN as a primary standard. As a main objective of this work, the Böhm extrapolation chamber was characterized in relation to its response in beta radiation secondary standard beams of ${ }^{90} \mathrm{Sr}+{ }^{90} \mathrm{Y}$ sources, using two different entrance windows: aluminized Mylar and graphited Hostaphan, and using two methods of determination of absorbed dose rates, to verify its performance in each material. Although it is the most adequate instrument for the calibration of beta radiation detectors and sources, the extrapolation chamber should only be used at calibration laboratories, and not in quality control programs, because it weights $7 \mathrm{~kg}$, and it is expensive. Thus, it is important to have systems considered work standards and alternative methods to replace the extrapolation chamber in measurements performed outside laboratories, such as in hospitals and clinics. For this reason, three parallel plate ionization chambers were characterized, with the objective to verify the possibility of their use as work standard systems, and different dosimetric materials were also studied, in beta radiation fields, using the thermoluminescence (TL) and optically stimulated luminescence (OSL) phenomena, as alternative methods for the calibration of beta radiation sources. The development of a dosimetric postal system for the calibration of ${ }^{90} \mathrm{Sr}+{ }^{90} \mathrm{Y}$ clinical applicators was included in this objective. The results obtained using the Böhm extrapolation chamber allowed its establishment as a primary standard system at the calibration of ${ }^{90} \mathrm{Sr}+{ }^{90} \mathrm{Y}$ sources, because it was possible to determine the absorbed dose rates in air and in the tissue, at null depth and $0.07 \mathrm{~mm}$ using the chamber with the two different entrance windows. The characterization of the three parallel plate ionization chambers showed that they can be used in quality control programs of beta radiation sources, because their responses were adequate to this purpose. The dosimetric materials were tested in relation to their TL and OSL response, and their use showed also to be adequate in beta radiation fields. The dosimetric postal system, using TL dosimeters, was tested in hospitals, and afterwards, it was sent to a laboratory, by conventional mail, with TL and OSL detectors, and the results of the calibration of the clinical applicators was adequate.
\end{abstract}




\section{SUMÁRIO}

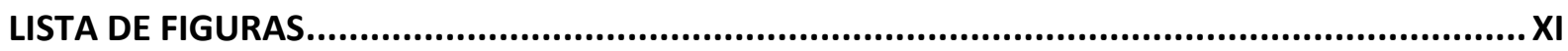

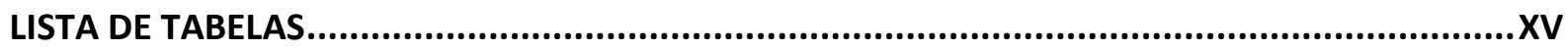

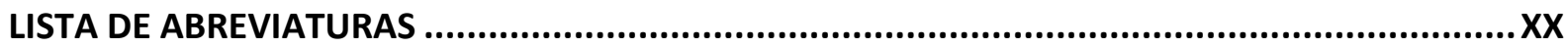

1. INTRODUÇÃO

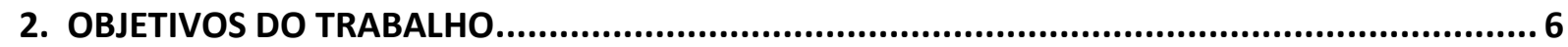

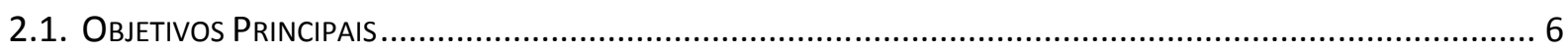

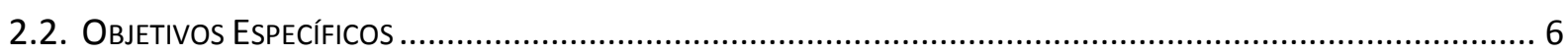

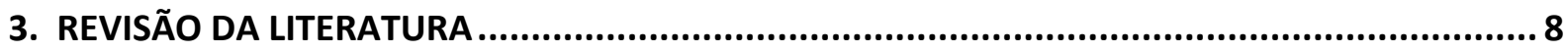

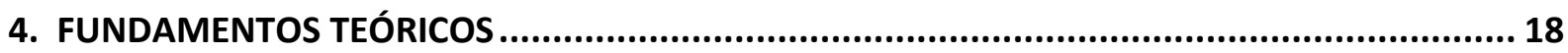

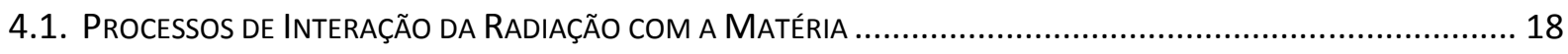

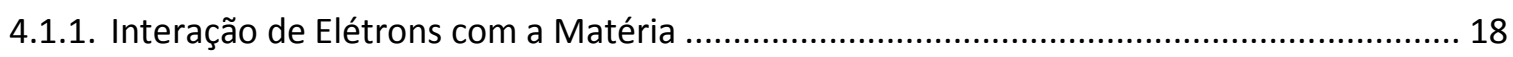

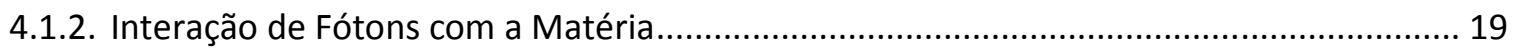

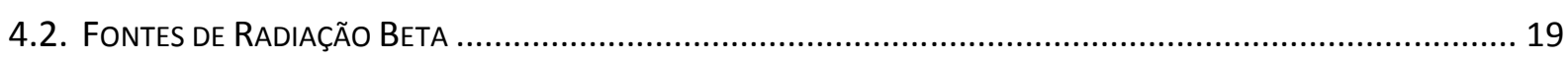

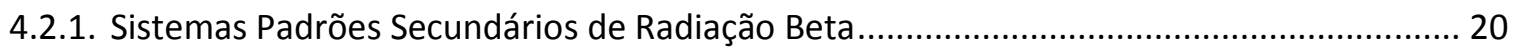

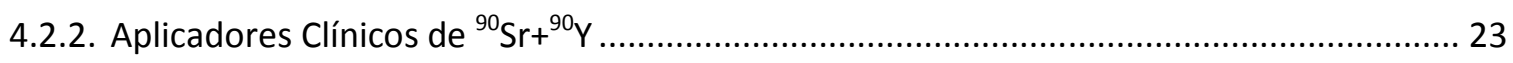

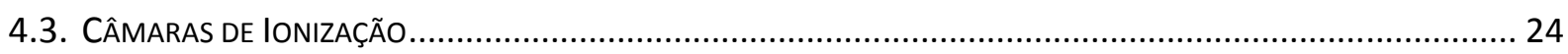

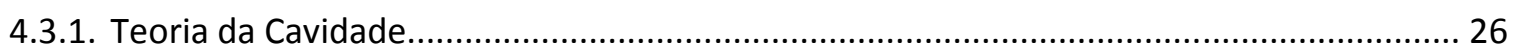

4.3.2. Caracterização da Resposta de Câmaras de Ionização ...................................................... 28

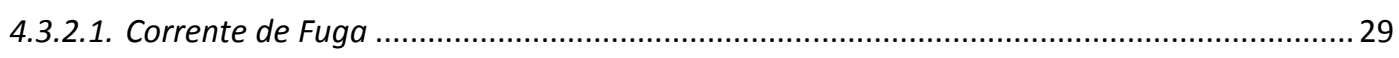

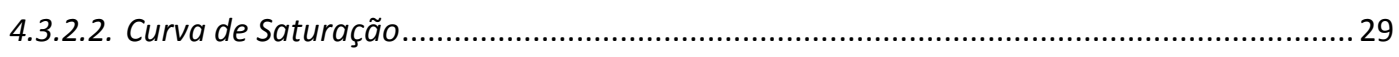

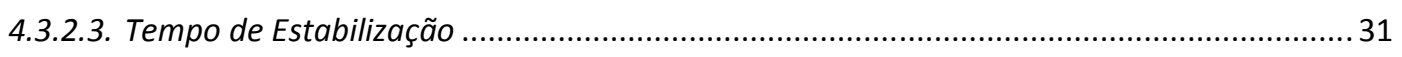

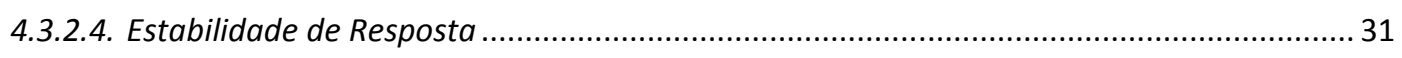

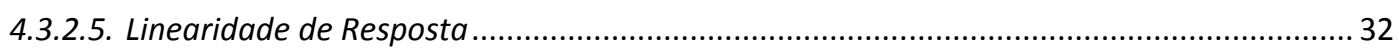

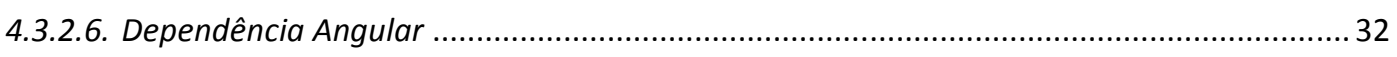

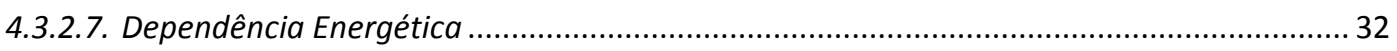

4.3.2.8. Variação da Resposta da Câmara com a Distância Fonte-Detector ..................................... 32

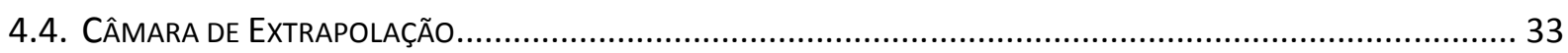

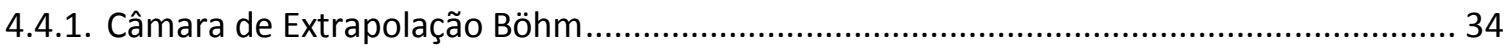

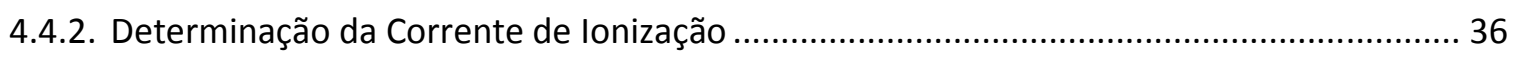

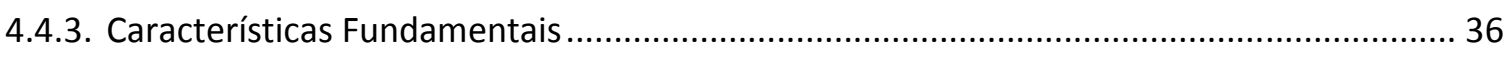

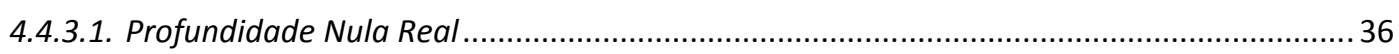

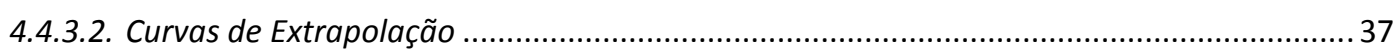

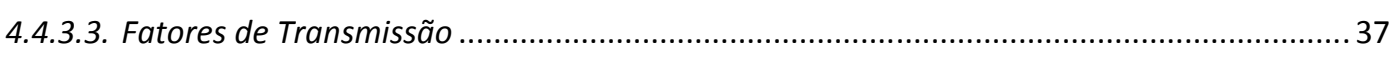

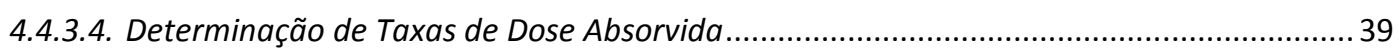

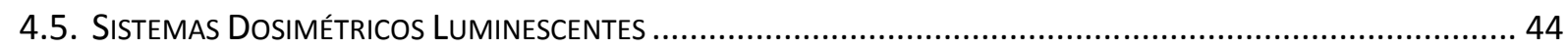

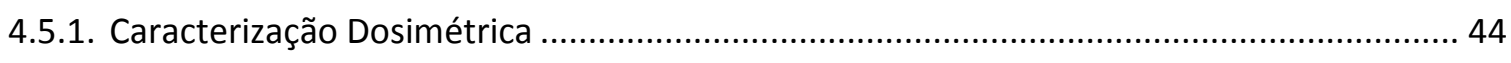

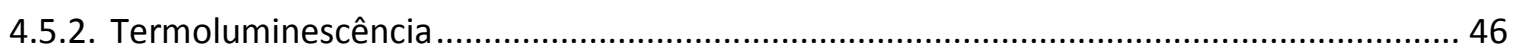




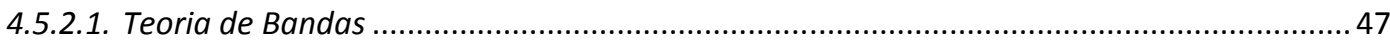

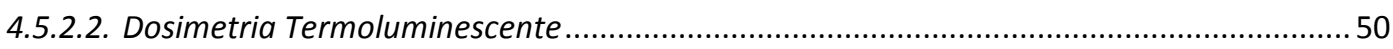

4.5.2.3. Sistema Medidor de Termoluminescência .......................................................................... 51

4.5.3. Luminescência Opticamente Estimulada ........................................................ 52

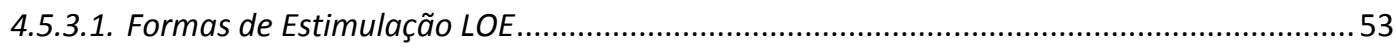

4.5.3.2. Dosimetria Luminescente Opticamente Estimulada ........................................................... 55

4.5.3.3. Sistema Medidor de Luminescência Opticamente Estimulada .......................................... 56

4.5.4. Vantagens e Desvantagens dos Sistemas TL e LOE.................................................. 57

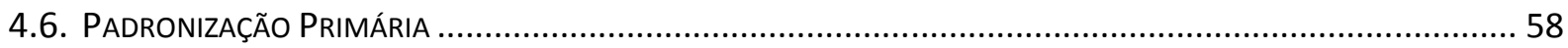

4.7. Calibração e Dosimetria de Fontes e Detectores de Radiação Beta ...........................................59

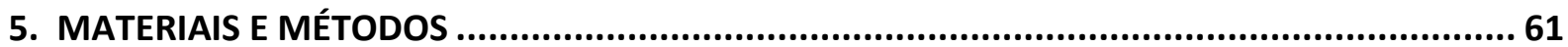

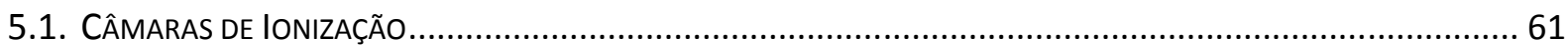

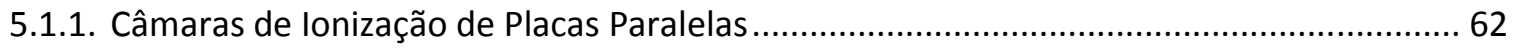

5.1.2. Câmara de Extrapolação Böhm............................................................................ 62

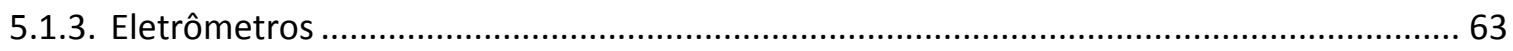

5.1.4. Determinação de Fatores de Correção ..................................................................... 63

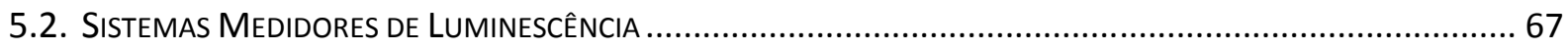

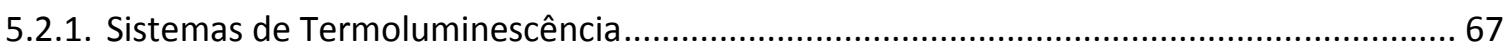

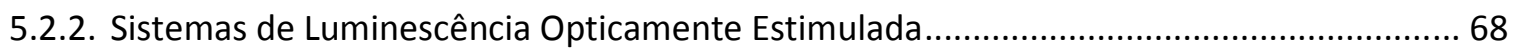

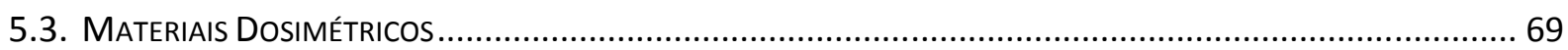

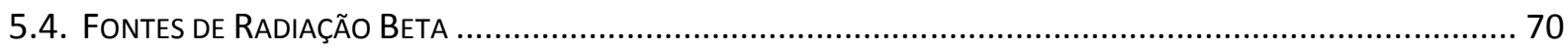

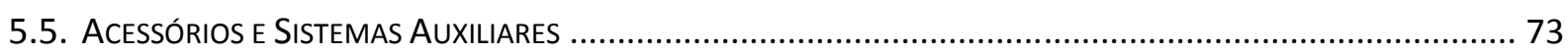

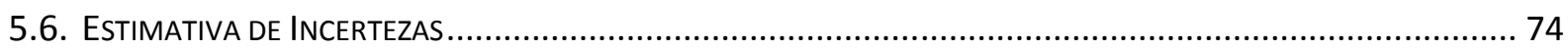

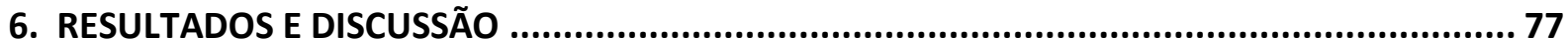

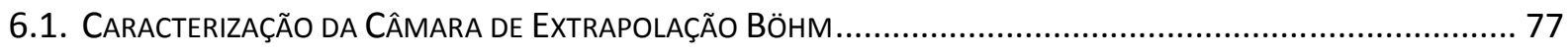

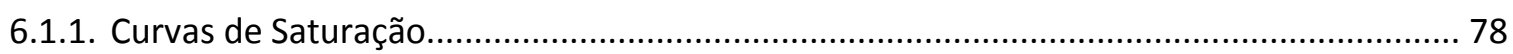

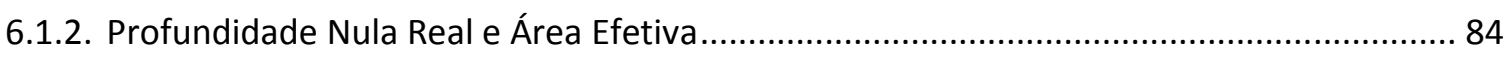

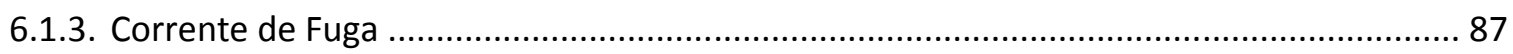

6.1.4. Estabilidade de Resposta .............................................................................. 88

6.1.5. Variação da Resposta em Função da Distância Fonte-Detector..................................... 89

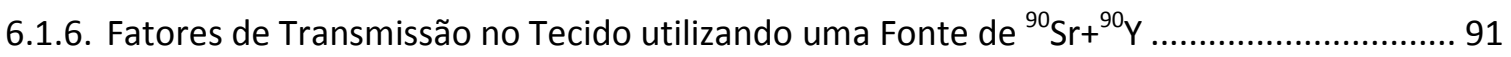

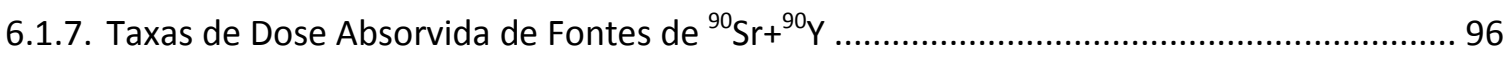

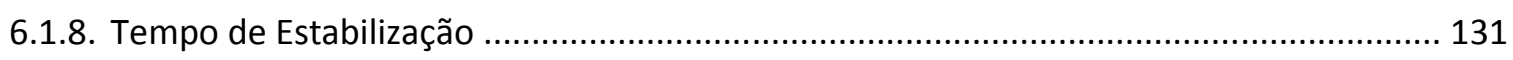

6.2. CaracterizaÇÃo de TrÊs CÂMaras de IonizaÇÃo em FeiXeS de RAdiaÇão Beta................................. 132

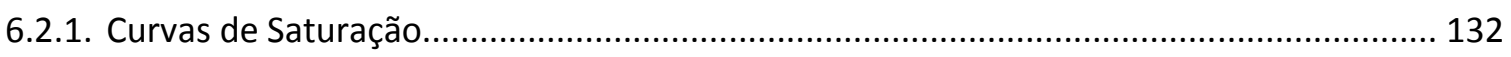

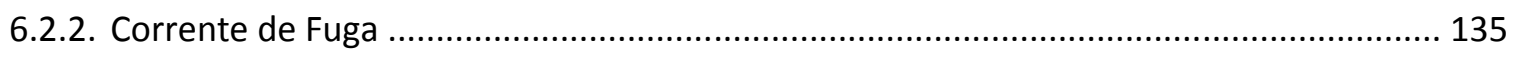

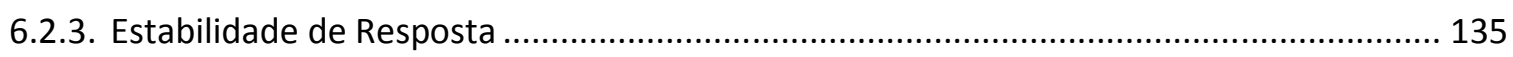

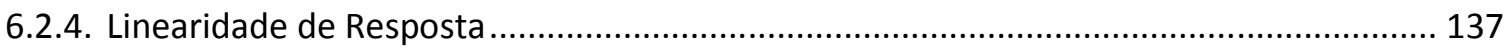

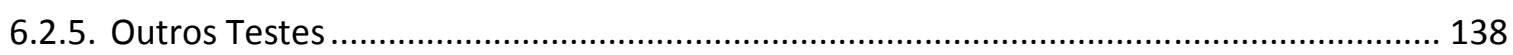

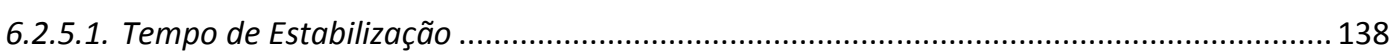

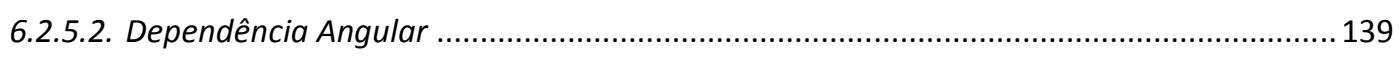

6.2.5.3. Calibração das Câmaras de lonização C2 e C3 ................................................................. 143 
6.2.5.4. Variação da Resposta em Função da Distância Fonte-Detector. 144

6.2.5.5. Determinação de Taxas de Dose Absorvida para Aplicadores Dermatológicos ................ 146

6.3. Dosimetria dA RADIAÇÃo BETA UTILIZANDO TÉCNICAS LUMINESCENTES.

6.3.1. Desenvolvimento de uma Metodologia na Forma Postal para Calibração de Aplicadores Clínicos

6.3.1.1. Calibração de Aplicadores Clínicos de ${ }^{90} \mathrm{Sr}^{90} \mathrm{Y}$............................................................ 147

6.3.1.2. Formação de um Sistema Dosimétrico TL Postal com CaSO $\mathrm{C}_{4}$ :Dy ...................................... 149

6.3.1.3. Formação de um Sistema Dosimétrico $T L / L O E$ Postal com $\mathrm{Al}_{2} \mathrm{O}_{3}: \mathrm{C} \ldots \ldots \ldots \ldots . . . . . . . . . . . . . . . . . . . . . . .152$

6.3.2. Caracterização e Comparação de Detectores de Radiação Beta em Campos Padrões .... 158

6.3.2.1. Reprodutibilidade de Resposta .................................................................................... 158

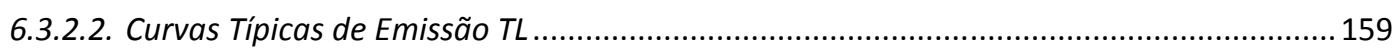

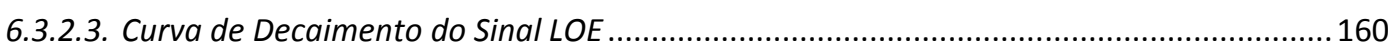

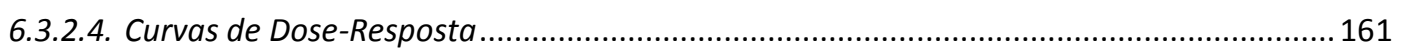

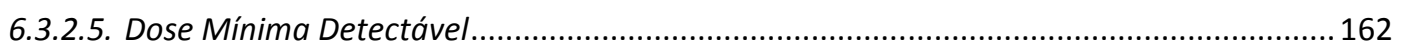

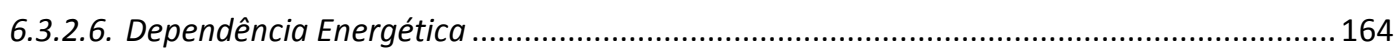

6.3.2.7. Variação da Resposta LOE em Função da Distância Fonte-Detector................................. 164

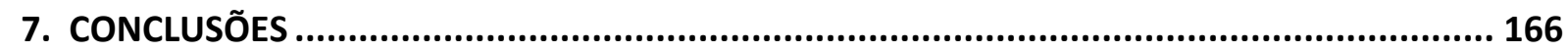

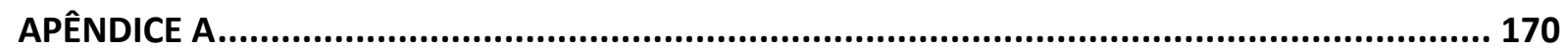

* Procedimento para utilização da Câmara de Extrapolação Böhm para Calibração de Fontes de ${ }^{90} \mathrm{Sr}+{ }^{90} \mathrm{Y}$

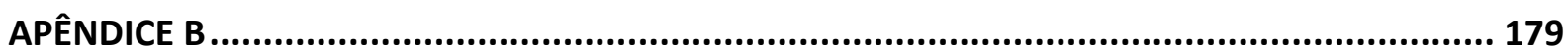

* Procedimento para utilização do Sistema Postal............................................................. 179

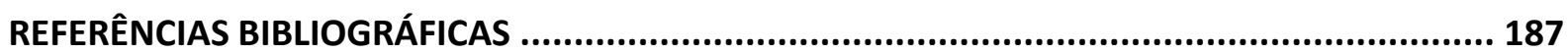

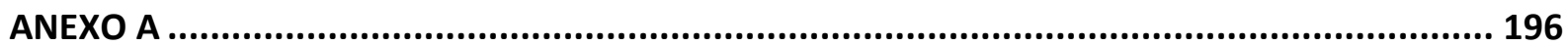

* Lista de Trabalhos desenvolvidos ao longo do Doutorado ...................................................... 196 


\section{LISTA DE FIgURAS}

FIGURA 4.1 - Sistema padrão secundário beta 1 (BSS1): (a) fontes de radiação beta e instrumentos para o seu posicionamento; (b) unidade de controle; e (c) sistema de suporte para a fonte (porta-fonte).

FIGURA 4.2 - Sistema padrão secundário beta 2 (BSS2): (a) unidade de controle; (b) maleta com os instrumentos para o posicionamento das fontes, filtros uniformizadores de campo e ferramentas para manutenção do sistema; e (c) sistema de suporte para a fonte (porta-fonte).

FIGURA 4.3 - Esquema de aplicadores clínicos convencionais: (a) dermatológico; e (b) oftálmico, mostrando a localização da fonte radioativa, a haste metálica e a proteção de acrílico.

FIGURA 4.4 - Outros modelos de aplicadores clínicos de ${ }^{90} \mathrm{Sr}+{ }^{90} \mathrm{Y}$ (baseado em Scaff (1979))................. 24

FIGURA 4.5 - Esquema de uma câmara de extrapolação (Adaptado de Dias (DIAS, 1996))....................... 33

FIgURA 4.6 - Esquema da câmara de extrapolação Böhm: (1) haste de fixação da câmara no sistema de irradiação, (2) conector para tensão de polarização, (3) anel de acrílico para a formação da cavidade (volume sensível) e posicionamento da janela de entrada, (4) anel de fixação da janela de entrada, (5) bloco de acrílico, (6) superfície grafitada do bloco de acrílico (formando o eletrodo coletor e o anel de guarda), (7) janela de entrada, (8) conector para medições de corrente de ionização (ligado ao eletrômetro), (9) êmbolo para sustentação do conjunto de eletrodo coletor e ajuste de distância entre os eletrodos, (10) estrutura central que sustenta o anel de acrílico (3) e o conjunto de ajuste de distância entre os eletrodos (por meio de abertura do parafuso micrométrico), (11) anel de acoplamento da estrutura central e haste de fixação, (12) porca de travamento do conjunto de ajuste de distância entre os eletrodos, (13) anel roscado para fixação da mola de recuo, (14) parafuso de acoplamento do êmbolo com o conjunto de ajuste de distância entre os eletrodos, (15) mola de recuo do conjunto do êmbolo, (16) cilindro externo do conjunto de ajuste de distância entre os eletrodos, (17) base de fixação do parafuso micrométrico ao cilindro externo (16), (18) parafuso micrométrico para ajuste de distância entre os eletrodos, (19) parafuso de travamento para transporte da câmara, (20) capa de proteção da janela de entrada (Adaptado de PTW (PTW, 2002))...

FIGURA 4.7 - Representação esquemática dos dois estágios da termoluminescência (McKEEVER e col., 1995)...

FIGURA 4.8 - Esquema dos níveis de energia e transições eletrônicas que ocorrem durante o processo de ionização e aquecimento da amostra TL: (1) processo de ionização; (2) e (6) armadilhamento de elétron e buraco, respectivamente; (3) e (7) desarmadilhamento (liberação) de elétron e buraco, respectivamente; (4) e (8) recombinações indiretas; e (5) recombinação direta (Adaptado de McKeever e col. (McKEEVER e col., 1995)).

FIgURA 4.9 - Curva de emissão TL típica de uma amostra de $\mathrm{CaSO}_{4}$ :Dy, irradiada com uma dose absorvida de $10 \mathrm{mGy}$, com uma fonte de ${ }^{90} \mathrm{Sr}+{ }^{90} \mathrm{Y}$.

FIGURA 4.10 - Esquema simplificado de um sistema medidor termoluminescente (baseado em Campos (1998))... 
Figura 4.11 - Curva típica que mostra o decaimento da intensidade LOE em função do tempo de iluminação, de um detector de $\mathrm{Al}_{2} \mathrm{O}_{3}: \mathrm{C}$, pré-irradiado $\left({ }^{90} \mathrm{Sr}+{ }^{90} \mathrm{Y}\right)$...

FIgURA 4.12 - Curvas de resposta LOE, demonstradas experimentalmente e representadas graficamente, para os três tipos principais de estimulação LOE: (a) CW-OSL; (b) LM-OSL; e (c) POSL (BØTTER-JENSEN e col., 2003)..

FIGURA 4.13 - Representação esquemática de um sistema medidor LOE (B $\varnothing$ TTER-JENSEN e col., 2003).

FiguRA 5.1 - Câmaras de ionização de placas paralelas: (a) câmara C1; (b) câmara C2; e (c) câmara C3.

FiguRA 5.2 - Câmara de extrapolação Böhm, PTW, modelo 23392.

FIgURA 5.3 - Eletrômetros utilizados nos experimentos com as câmaras de ionização: (a) eletrômetro PTW, modelo UNIDOS E; e (b) eletrômetro Keithley, modelo 6517B......

FIGURA 5.4 - Sistema medidor de termoluminescência da Harshaw, modelo 3500.

FIGURA 5.5 - Sistema medidor de termoluminescência e luminescência opticamente estimulada Risoe: (a) medidor luminescente; e (b) sistema de controle...

FIgURA 5.6 - Sistemas medidores de luminescência opticamente estimulada: (a) da Landauer, para medição de detectores $\mathrm{Al}_{2} \mathrm{O}_{3}: \mathrm{C}$, da Landauer; e (b) DOIN-L001, para medição de diferentes materiais LOE.

Figura 5.7 - Materiais dosimétricos utilizados neste trabalho: (a) TL; e (b) TL e $\operatorname{LOE}\left(\mathrm{Al}_{2} \mathrm{O}_{3}: \mathrm{C}\right)$, da Rexon.

FIGURA 5.8 - Detector LOE de $\mathrm{Al}_{2} \mathrm{O}_{3}: \mathrm{C}$, tipo nanoDot, da Landauer: (a) com o material dentro do adaptador; e (b) com o material puxado para fora do adaptador..

FIGURA 5.9 - Fontes padrões secundários de radiação beta dos sistemas: (a) BSS1; e (b) BSS2... 70

FIGURA 5.10 - Exemplos de aplicadores clínicos de ${ }^{90} \mathrm{Sr}+{ }^{90} \mathrm{Y}$ : (a) $\mathrm{A}_{\mathrm{NIST}}$ e (b) fonte 6 (dermatológicos); (c) fonte 3 e (d) fonte 8 (oftálmicos)...

FIGURA 5.11 - Fonte de controle de ${ }^{90} \mathrm{Sr}+{ }^{90} \mathrm{Y}$, utilizada em testes de caracterização da resposta de câmaras de ionização estudadas neste trabalho.

FIGURA 6.1 - Câmara de extrapolação Böhm, em duas vistas, mostrando alguns dos seus acessórios: (a) anel de acrílico; (b) anel de fixação da janela de entrada; (c) bloco de acrílico que forma o eletrodo coletor; (d) anel de acoplamento da estrutura central e haste de fixação; (e) corpo da câmara (cilindro externo); (f) base de fixação do parafuso micrométrico ao cilindro externo; e (g) parafuso micrométrico...

FIGURA 6.2 - Câmara de extrapolação Böhm, com janela de entrada de Mylar aluminizado, posicionada no sistema BSS1.

FIGURA 6.3 - Verificação da saturação da corrente de ionização medida em três profundidades diferentes, $d$, da câmara de extrapolação Böhm com janela de entrada de Mylar aluminizado: (a) curvas de saturação; e (b) correntes de saturação..

FIGURA 6.4 - Verificação da saturação da corrente de ionização medida em três profundidades diferentes, $d$, da câmara de extrapolação Böhm com janela de entrada de Hostaphan grafitado: (a) curvas de saturação; e (b) correntes de saturação... 
FIGURA 6.5 - Efeito de polaridade como uma função do volume ativo da câmara, obtido para duas câmaras de extrapolação Böhm: a estudada neste trabalho (utilizando as duas janelas de entrada), e a calibrada pelo NIST.

FIGURA 6.6 - Determinação da profundidade nula real da câmara de extrapolação Böhm, com janela de Mylar aluminizado, por meio de dois métodos: (a) medindo-se a carga em ambas as polaridades de tensão; e (b) medindo-se a capacitância .

FIGURA 6.7 - Profundidade nula real da câmara de extrapolação Böhm, com janela de Hostaphan grafitado, por meio de dois métodos: (a) medindo-se a carga em ambas as polaridades de tensão; e (b) medindo-se a capacitância

FIGURA 6.8 - Reprodutibilidade da resposta da câmara de extrapolação Böhm, utilizando-se uma fonte de ${ }^{90} \mathrm{Sr}+{ }^{90} \mathrm{Y}$, com as janelas de entrada: (a) Mylar aluminizado; e (b) Hostaphan grafitado. As linhas pontilhadas indicam o limite recomendado pela IEC (2011) de $0,5 \%$ para o teste de reprodutibilidade.

FIGURA 6.9 - Variação da resposta da câmara de extrapolação Böhm em função da distância fontedetector, utilizando uma fonte de ${ }^{90} \mathrm{Sr}+{ }^{90} \mathrm{Y}(1850 \mathrm{MBq}, 1981)$ e as janelas de entrada: (a) Mylar aluminizado; e (b) Hostaphan grafitado

FIGURA 6.10 - Câmara de extrapolação Böhm com janela de entrada de Hostaphan grafitado, coberta com uma folha de Hostaphan, para medições para a determinação de fatores de transmissão

FIGURA 6.11 - Determinação dos fatores de transmissão no tecido, com a câmara de extrapolação Böhm com a janela de entrada de Mylar aluminizado, e a fonte de ${ }^{90} \mathrm{Sr}+{ }^{90} \mathrm{Y}$ (1850 MBq, 1981): (a) obtenção da corrente de ionização $I(0)$; e (b) curva final dos fatores de transmissão.

FIGURA 6.12 - Determinação dos fatores de transmissão no tecido, com a câmara de extrapolação Böhm com a janela de entrada de Hostaphan grafitado, e a fonte de ${ }^{90} \mathrm{Sr}^{90} \mathrm{Y}$ (1850 MBq, 1981): (a) obtenção da corrente de ionização $I(0)$; e (b) curva final dos fatores de transmissão

FIGURA 6.13 - Curvas de extrapolação da câmara de extrapolação Böhm, com janela de entrada de Mylar aluminizado, utilizando três fontes de ${ }^{90} \mathrm{Sr}+{ }^{90} \mathrm{Y}$, à distância fonte-detector de $30 \mathrm{~cm}$, e em condições específicas de uso de filtro uniformizador de campo.

FIGURA 6.14 - Curvas de extrapolação para a câmara de extrapolação Böhm, com janela de entrada de Hostaphan, utilizando três fontes de ${ }^{90} \mathrm{Sr}^{90} \mathrm{Y}$ : (a) $74 \mathrm{MBq}$; (b) $1850 \mathrm{MBq}$; e (c) $460 \mathrm{MBq}$

FIGURA 6.15 - Câmara de extrapolação Böhm, com janela de entrada de Hostaphan grafitado (coberta com uma placa de Plexiglas), posicionado no sistema BSS2, durante procedimento para determinação do fator de correção $\boldsymbol{k}_{\boldsymbol{B} \boldsymbol{r}}$

FIGURA 6.16 - Curvas de saturação obtidas para as três câmaras de ionização estudadas neste trabalho: (a) C1; (b) C2; e (c) C3.

FIGURA 6.17 - Câmara de ionização C3 durante o experimento de estabilidade de resposta da câmara, com a fonte de controle de ${ }^{90} \mathrm{Sr}+{ }^{90} \mathrm{Y}$ posicionada sobre ela.

FIGURA 6.18 - Teste de estabilidade da resposta de três câmaras de ionização: (a) C1; (b) C2; e (c) $\mathrm{C} 3$, utilizando uma fonte de controle de ${ }^{90} \mathrm{Sr}+{ }^{90} \mathrm{Y}$. As linhas pontilhadas mostram os limites recomendados pela norma IEC 60731 (2011), de 0,5\% para o teste de reprodutibilidade. 
FIGURA 6.19 - Linearidade de resposta das três câmaras de ionização de placas paralelas, utilizando a fonte de controle de ${ }^{90} \mathrm{Sr}+{ }^{90} \mathrm{Y}$...

FIGURA 6.20 - Arranjos experimentais utilizados no teste de dependência angular da resposta das câmaras: (a) C1, irradiada com o aplicador NIST; e (b) C2, irradiada no sistema BSS1 ....

FIGURA 6.21 - Resultados obtidos no teste de dependência angular, realizados com as câmaras de ionização: (a) C1, irradiada com o aplicador NIST $\left({ }^{90} \mathrm{Sr}+{ }^{90} \mathrm{Y}\right)$; e (b) $\mathrm{C} 2$, irradiada com a fonte de ${ }^{90} \mathrm{Sr}+{ }^{90} \mathrm{Y}$ do sistema BSS1 (1850 MBq, 1981)...

FIGURA 6.22 - Comportamento da resposta das câmaras de ionização: (a) C2; e (b) C3, quando irradiadas em feixes padrões secundários de fontes de radiação beta de diferentes energias.

FIGURA 6.23 - Estudo de variação da resposta da câmara em função da distância fonte-detector, realizado para as câmaras: (a) C1, irradiada com o aplicador NIST $\left({ }^{90} \mathrm{Sr}+{ }^{90} \mathrm{Y}\right)$; e (b) C2, irradiada com a fonte de ${ }^{90} \mathrm{Sr}+{ }^{90} \mathrm{Y}$ do sistema BSS1 (1850 MBq, 1981).

FIGURA 6.24 - Curvas de dose-resposta obtidas para: (a) amostras TL; e (b) detectores LOE... 148

FIGURA 6.25 - Sistema dosimétrico postal TL com dosímetros de $\mathrm{CaSO}_{4}$ :Dy ..

FIGURA 6.26 - Curvas de dose-resposta dos detectores de $\mathrm{Al}_{2} \mathrm{O}_{3}: \mathrm{C}$, expostos à fonte de ${ }^{90} \mathrm{Sr}+{ }^{90} \mathrm{Y}$ (1850 MBq, 1981): (a) TL; e (b) LOE.

FIGURA 6.27 - Sistema dosimétrico postal TL/LOE, utilizando-se dosímetros de $\mathrm{Al}_{2} \mathrm{O}_{3}: \mathrm{C}$.

FIGURA 6.28 - Curvas de emissão TL para amostras irradiadas com fonte de ${ }^{90} \mathrm{Sr}+{ }^{90} \mathrm{Y}(1850 \mathrm{MBq}$, 1981, $1 \mathrm{~Gy}$ ): (a) $\mathrm{CaSO}_{4}: \mathrm{Dy}\left(20 \mathrm{mg}\right.$ ); e (b) $\mathrm{Al}_{2} \mathrm{O}_{3}: \mathrm{C}$, Rexon .

FIGURA 6.29 - Curva de decaimento LOE de detectores de $\mathrm{Al}_{2} \mathrm{O}_{3}: \mathrm{C}$, Rexon, irradiados com fonte de ${ }^{90} \mathrm{Sr}+{ }^{90} \mathrm{Y}(1850 \mathrm{MBq}, 1981,400 \mathrm{mGy})$.

FIGURA 6.30 - Curvas de dose-resposta obtidas para os detectores TL: (a) $\mathrm{CaSO}_{4}$ :Dy (20 mg); e (b) $\mathrm{Al}_{2} \mathrm{O}_{3}: \mathrm{C}$, Rexon.

FIGURA 6.31 - Curvas de dose-resposta obtidas para os detectores LOE de $\mathrm{Al}_{2} \mathrm{O}_{3}: \mathrm{C}$ : (a) Rexon; e (b) NanoDot, Landauer.

FIGURA 6.32 - Doses mínimas detectáveis obtidas para detectores de $\mathrm{Al}_{2} \mathrm{O}_{3}: \mathrm{C}$, Rexon: (a) resposta $\mathrm{TL}$; e (b) resposta LOE..

FIGURA 6.33 - Variação da resposta LOE em função da distância fonte-detector, utilizando-se os detectores de $\mathrm{Al}_{2} \mathrm{O}_{3}: \mathrm{C}$, NanoDot, Landauer, e a fonte de ${ }^{90} \mathrm{Sr}+{ }^{90} \mathrm{Y}$ do sistema BSS1 (1850 MBq, 1981)

FigURA B.1 - Protetor facial de acrílico e óculos protetores de acrílico, para utilização durante o manuseio das fontes de ${ }^{90} \mathrm{Sr}+{ }^{90} \mathrm{Y}$.

FIGURA B.2 - Esquema de aplicadores clínicos convencionais: (a) dermatológico; e (b) oftálmico ......

FIGURA B.3 - Exemplo de um arranjo experimental para o posicionamento do aplicador clínico sobre o dosímetro termoluminescente.

FIGURA B.4 - Suporte de acrílico contendo um dosímetro termoluminescente: (a) ao remover uma parte do filme plástico para posicionamento do dosímetro; e (b) com o filme plástico sobre o dosímetro, para o procedimento de irradiação

FIGURA B.5 - Exemplo de um procedimento de irradiação: um dosímetro termoluminescente está sendo irradiado por um aplicador oftálmico de ${ }^{90} \mathrm{Sr}+{ }^{90} \mathrm{Y}$ (com haste curva) 


\section{LISTA DE TABELAS}

TABELA 4.1 - Características das fontes de radiação beta dos sistemas BSS1 e BSS2 ................................. 20

TABELA 4.2 - Características da câmara de extrapolação Böhm (PTW, 2002) ……………………………….... 34

TABELA 4.3 - Definição dos fatores de correção (envolvidos em $k$ ) que dependem da variação da profundidade da câmara, e os parâmetros que podem influenciá-los (ISO, 2004).

TABELA 4.4 - Definição dos fatores de correção (envolvidos em $k^{\prime}$ ) que não dependem da variação da profundidade da câmara, e os parâmetros que podem influenciá-los (ISO, 2004).....

TABELA 4.5 - Comparação entre as vantagens dos dois tipos de dosimetria TL e LOE (OLKO, 2010).... 58

TABELA 5.1 - Características das câmaras de ionização (placas paralelas) utilizadas neste trabalho.... 62

TABELA 5.2 - Fatores de correção utilizados neste trabalho e seus respectivos valores (CALDAS, 1980)...

TABELA 5.3 - Outros fatores de correção utilizados neste trabalho, com seus valores e referências... 67

TABELA 5.4 - Características dos materiais luminescentes estudados neste trabalho. 69

TABELA 5.5 - Características das fontes de radiação beta dos sistemas padrões secundários BSS1 e BSS2, e suas condições de utilização.

TABELA 5.6 - Características dos aplicadores clínicos de ${ }^{90} \mathrm{Sr}+{ }^{90} \mathrm{Y}$ do $\mathrm{LCl} .$.

TABELA 5.7 - Características dos aplicadores clínicos de ${ }^{90} \mathrm{Sr}+{ }^{90} \mathrm{Y}$, de diferentes hospitais, utilizados em betaterapia, calibrados neste trabalho

TABELA 5.8 - Características dos aplicadores clínicos de ${ }^{90} \mathrm{Sr}^{90} \mathrm{Y}$, da Universidade Federal de Sergipe (UFS).

TABELA 5.9 - Valores de incerteza usados para se calcular a incerteza expandida associada à taxa de dose absorvida determinada para uma fonte padrão secundário de radiação beta de ${ }^{90} \mathrm{Sr}+{ }^{90} \mathrm{Y}$ (a taxa de dose absorvida, neste caso, foi obtida pelo método descrito por Caldas (1980)).

TABELA 6.1 - Correntes de ionização médias obtidas na região de saturação para as polaridades positiva e negativa de tensão com a câmara de extrapolação Böhm (em três profundidades da câmara), e janela de entrada de Mylar aluminizado.

TABELA 6.2 - Correntes de ionização médias obtidas na região de saturação para ambas as polaridades de tensão com a câmara de extrapolação Böhm (em três profundidades diferentes), e janela de entrada de Hostaphan grafitado.

TABELA 6.3 - Correntes de saturação obtidas com a câmara de extrapolação Böhm e as duas janelas de entrada: Mylar aluminizado e Hostaphan grafitado.

TABELA 6.4 - Eficiência de coleção de íons da câmara de extrapolação Böhm, com as duas janelas de entrada: Mylar aluminizado e Hostaphan grafitado, e para profundidades da câmara diferentes

TABELA 6.5 - Recombinação iônica da câmara de extrapolação Böhm, com as duas janelas de entrada: Mylar aluminizado e Hostaphan grafitado, e para profundidades da câmara diferentes. 
TABELA 6.6 - Efeitos de polaridade da câmara de extrapolação Böhm, com as duas janelas de entrada: Mylar aluminizado e Hostaphan grafitado (para três profundidades da câmara diferentes)..

TABELA 6.7 - Valores de profundidade nula real da câmara de extrapolação Böhm para as duas janelas de entrada: Mylar aluminizado e Hostaphan grafitado.

TABELA 6.8 - Teste de estabilidade da resposta da câmara de extrapolação Böhm para as duas janelas de entrada: Mylar aluminizado e Hostaphan.

TABELA 6.9 - Determinação dos fatores de transmissão obtidos com a câmara de extrapolação Böhm, utilizando uma fonte de ${ }^{90} \mathrm{Sr}+{ }^{90} \mathrm{Y}$ (1850 MBq, 1981), e janela de entrada de Mylar aluminizado..

TABELA 6.10 - Determinação dos fatores de transmissão obtidos com a câmara de extrapolação Böhm, utilizando uma fonte de ${ }^{90} \mathrm{Sr}+{ }^{90} \mathrm{Y}(1850 \mathrm{MBq}, 1981)$, e janela de entrada de Hostaphan grafitado.

TABELA 6.11 - Fatores de transmissão obtidos com a câmara de extrapolação Böhm com as janelas de entrada de Mylar aluminizado e Hostaphan grafitado, e a fonte de ${ }^{90} \mathrm{Sr}+{ }^{90} \mathrm{Y}$ (1850 MBq)

TABELA 6.12 - Condições utilizadas para a determinação de taxas de dose absorvida para fontes de ${ }^{90} \mathrm{Sr}+{ }^{90} \mathrm{Y}$.

TABELA 6.13 - Valores de coeficiente angular obtidos das curvas de extrapolação para cada uma das fontes de ${ }^{90} \mathrm{Sr}+{ }^{90} \mathrm{Y}$, em condições diferentes com relação ao uso de filtro e distância fonte-detector.

TABELA 6.14 - Fatores de correção $\boldsymbol{k}_{\boldsymbol{B} \boldsymbol{r}}$, obtidos neste trabalho para três fontes de ${ }^{90} \mathrm{Sr}+{ }^{90} \mathrm{Y}$, e com a câmara de extrapolação Böhm com janela de entrada de Mylar aluminizado.

TABELA 6.15 - Fatores de correção $\boldsymbol{k}_{\boldsymbol{i n h}}$, obtidos neste trabalho para três fontes de ${ }^{90} \mathrm{Sr}+{ }^{90} \mathrm{Y}$, à distância fonte-detector de $30 \mathrm{~cm}$, e com a câmara de extrapolação Böhm com janela de entrada de Mylar aluminizado.

TABELA 6.16 - Fatores de correção $\boldsymbol{k}_{a d}$, obtidos neste trabalho para três fontes de ${ }^{90} \mathrm{Sr}+{ }^{90} \mathrm{Y}$, a distâncias fonte-detector diferentes, e para as cinco profundidades da câmara, $d$, utilizadas na curva de extrapolação; estas medições foram feitas com a câmara de extrapolação Böhm com janela de entrada de Mylar aluminizado e de Hostaphan grafitado

TABELA 6.17 - Fatores de correção $\boldsymbol{k}_{\boldsymbol{\rho}}$, obtidos com a câmara de extrapolação Böhm com janela de entrada de Mylar aluminizado, para três fontes de ${ }^{90} \mathrm{Sr}+{ }^{90} \mathrm{Y}$, à distância fontedetector de $30 \mathrm{~cm}$, e para cinco profundidades da câmara, $d$.

TABELA 6.18 - Grandezas e seus valores utilizados na determinação das taxas de dose absorvida no ar, $\dot{D}_{a}$, e no tecido, $\dot{D}_{t}$, para três fontes de ${ }^{90} \mathrm{Sr}+{ }^{90} \mathrm{Y}$, utilizando a câmara de extrapolação Böhm com janela de entrada de Mylar aluminizado (CALDAS, 1980; ISO, 2004).

TABela 6.19 - Taxas de dose absorvida no ar, $\dot{D}_{a}$, e no tecido, $\dot{D}_{t}$, para as três fontes de ${ }^{90} \mathrm{Sr}+{ }^{90} \mathrm{Y}$, utilizando a câmara de extrapolação e janela de entrada de Mylar aluminizado, à distância fonte-detector de $30 \mathrm{~cm}$

TABELA 6.20 - Fatores de transmissão, $T$, obtidos para a janela de entrada de Mylar aluminizado. 
TABela 6.21 - Taxas de dose absorvida no tecido, $\dot{D}_{t}(0)$, e no ar, $\dot{D}_{c}$, para as três fontes de ${ }^{90} \mathrm{Sr}+{ }^{90} \mathrm{Y}$, utilizando a câmara de extrapolação e janela de entrada de Mylar aluminizado, à distância fonte-detector de $30 \mathrm{~cm}$.

TABELA 6.22 - Fatores de transmissão, $T$, utilizados para a determinação das taxas de dose absorvida a $0 \mathrm{~mm}$ ou $0,07 \mathrm{~mm}$ de profundidade no tecido, obtidos para as fontes de ${ }^{90} \mathrm{Sr}+{ }^{90} \mathrm{Y}$ e para a janela de entrada de Mylar aluminizado (PTB, 1981a; 1981b; 2005).

TABELA 6.23 - Taxas de dose absorvida para as fontes de ${ }^{90} \mathrm{Sr}^{90} \mathrm{Y}$ às profundidades de $0 \mathrm{~mm}$ e $0,07 \mathrm{~mm}$ no ar, utilizando a câmara de extrapolação e janela de entrada de Mylar aluminizado, à distância fonte-detector de $30 \mathrm{~cm}$.

TABela 6.24 - Taxas de dose absorvida para as fontes de ${ }^{90} \mathrm{Sr}+{ }^{90} \mathrm{Y}$ às profundidades de $0 \mathrm{~mm}$ e $0,07 \mathrm{~mm}$ no tecido, utilizando a câmara de extrapolação e janela de entrada de Mylar aluminizado, à distância fonte-detector de $30 \mathrm{~cm}$..

TABELA 6.25 - Fatores de correção $\boldsymbol{k}_{a d v}$, obtidos com a câmara de extrapolação Böhm com janela de entrada de Mylar aluminizado, para três fontes de ${ }^{90} \mathrm{Sr}+{ }^{90} \mathrm{Y}$, à distância fontedetector de $30 \mathrm{~cm}$, e para cinco profundidades da câmara, $d$.

TABELA 6.26 - Fatores de correção $\boldsymbol{k}_{d i}$, obtidos com a câmara de extrapolação Böhm com janela de entrada de Mylar aluminizado, para três fontes de ${ }^{90} \mathrm{Sr}+{ }^{90} \mathrm{Y}$, à distância fontedetector de $30 \mathrm{~cm}$, e para cinco profundidades da câmara, $d$.

TABELA 6.27 - Taxas de dose absorvida no tecido, $\dot{D}_{t}$, e no tecido à profundidade de $0 \mathrm{~mm} \dot{D}_{t}(0)$, para as três fontes de ${ }^{90} \mathrm{Sr}^{90} \mathrm{Y}$, utilizando a câmara de extrapolação e janela de entrada de Mylar aluminizado, à distância fonte-detector de $30 \mathrm{~cm}$

TABELA 6.28 - Taxas de dose absorvida para as fontes de ${ }^{90} \mathrm{Sr}+{ }^{90} \mathrm{Y}$ à profundidades de $0 \mathrm{~mm}$ e $0,07 \mathrm{~mm}$ no ar, utilizando a câmara de extrapolação e janela de entrada de Mylar aluminizado, à distância fonte-detector de $30 \mathrm{~cm}$.

TABELA 6.29 - Taxas de dose absorvida para as fontes de ${ }^{90} \mathrm{Sr}+{ }^{90} \mathrm{Y}$ à profundidades de $0 \mathrm{~mm}$ e $0,07 \mathrm{~mm}$ no tecido, utilizando a câmara de extrapolação e janela de entrada de Mylar aluminizado à distância fonte-detector de $30 \mathrm{~cm}$.

TABELA 6.30 - Fatores de correção $\boldsymbol{k}_{\boldsymbol{B} \boldsymbol{r}}$, obtidos neste trabalho para três fontes de ${ }^{90} \mathrm{Sr}+{ }^{90} \mathrm{Y}$, e com a câmara de extrapolação Böhm com janela de entrada de Hostaphan grafitado.

TABELA 6.31 - Fatores de correção $\boldsymbol{k}_{\text {inh }}$, obtidos neste trabalho para três fontes de ${ }^{90} \mathrm{Sr}+{ }^{90} \mathrm{Y}$, a distâncias fonte-detector diferentes, e com a câmara de extrapolação Böhm com janela de entrada de Hostaphan grafitado.

TABELA 6.32 - Fatores de correção $\boldsymbol{k}_{\boldsymbol{\rho}}$, obtidos com a câmara de extrapolação Böhm com janela de entrada de Hostaphan grafitado, para três fontes de ${ }^{90} \mathrm{Sr}+{ }^{90} \mathrm{Y}$, e para cinco profundidades da câmara, $d$.

TABela 6.33 - Taxas de dose absorvida no ar, $\dot{D}_{a}$, e no tecido, $\dot{D}_{t}$, para as três fontes de ${ }^{90} \mathrm{Sr}+{ }^{90} \mathrm{Y}$, utilizando a câmara de extrapolação e janela de entrada de Hostaphan grafitado

TABELA 6.34 - Fatores de transmissão, $T$, obtidos para a janela de entrada de Hostaphan grafitado.....

TABela 6.35 - Taxas de dose absorvida no tecido, $\dot{D}_{t}(0)$, e no ar, $\dot{D}_{c}$, para as três fontes de ${ }^{90} \mathrm{Sr}+{ }^{90} \mathrm{Y}$, utilizando a câmara de extrapolação e janela de entrada de Hostaphan grafitado 
TABELA 6.36 - Fatores de transmissão, $T$, utilizados para a determinação das taxas de dose absorvida a $0 \mathrm{~mm}$ ou $0,07 \mathrm{~mm}$ de profundidade no tecido, obtidos para fontes de ${ }^{90} \mathrm{Sr}+{ }^{90} \mathrm{Y}$ e para a janela de entrada de Hostaphan grafitado (PTB, 1981a; 1981b; 2005).

TABELA 6.37 - Taxas de dose absorvida para as fontes de ${ }^{90} \mathrm{Sr}+{ }^{90} \mathrm{Y}$ à profundidades de $0 \mathrm{~mm}$ e $0,07 \mathrm{~mm}$ no ar, utilizando a câmara de extrapolação e janela de entrada de Hostaphan grafitado

TABELA 6.38 - Taxas de dose absorvida para as fontes de ${ }^{90} \mathrm{Sr}+{ }^{90} \mathrm{Y}$ às profundidades de $0 \mathrm{~mm}$ e $0,07 \mathrm{~mm}$ no tecido, utilizando a câmara de extrapolação e janela de entrada de Hostaphan grafitado.

TABELA 6.39 - Fatores de correção $\boldsymbol{k}_{a d v}$, obtidos com a câmara de extrapolação Böhm com janela de entrada de Hostaphan grafitado, para as três fontes de ${ }^{90} \mathrm{Sr}^{90} \mathrm{Y}$, e para cinco profundidades da câmara, $d$..

TABELA 6.40 - Fatores de correção $\boldsymbol{k}_{d i}$, obtidos com a câmara de extrapolação Böhm com janela de entrada de Hostaphan grafitado, para três fontes de ${ }^{90} \mathrm{Sr}^{90} \mathrm{Y}$, e para cinco profundidades da câmara, $d$.

TABela 6.41 - Taxas de dose absorvida no tecido, $\dot{D}_{t}$, e no tecido à profundidade de $0 \mathrm{~mm} \dot{D}_{t}(0)$, para as três fontes de ${ }^{90} \mathrm{Sr}+{ }^{90} \mathrm{Y}$, utilizando a câmara de extrapolação e janela de entrada de Hostaphan grafitado.

TABELA 6.42 - Taxas de dose absorvida para as fontes de ${ }^{90} \mathrm{Sr}+{ }^{90} \mathrm{Y}$ às profundidades de $0 \mathrm{~mm} \mathrm{e}$ 0, $07 \mathrm{~mm}$ no ar, utilizando a câmara de extrapolação e janela de entrada de Hostaphan grafitado.

TABELA 6.43 - Taxas de dose absorvida para as fontes de ${ }^{90} \mathrm{Sr}+{ }^{90} \mathrm{Y}$ às profundidades de $0 \mathrm{~mm}$ e $0,07 \mathrm{~mm}$ no tecido, utilizando a câmara de extrapolação e janela de entrada de Hostaphan grafitado

TABELA 6.44 - Taxas de dose absorvida obtidas experimentalmente, neste trabalho, para as fontes de ${ }^{90} \mathrm{Sr}+{ }^{90} \mathrm{Y}$ às profundidades de $0,07 \mathrm{~mm}$ no tecido, utilizando-se a câmara de extrapolação e as janelas de entrada de Mylar aluminizado e de Hostaphan grafitado

TABELA 6.45 - Diferenças obtidas entre as taxas de dose absorvida utilizando dois materiais de janela de entrada: Mylar aluminizado e Hostaphan grafitado, por dois métodos diferentes.

TABELA 6.46 - Diferenças obtidas entre as taxas de dose absorvida utilizando dois métodos diferentes: Caldas (1980) e ISO 6980-2 (2004), com janelas de entrada de materiais diferentes.

TABELA 6.47 - Teste de tempo de estabilização realizado com a câmara de extrapolação Böhm com janela de entrada de Hostaphan grafitado, utilizando-se a fonte de ${ }^{90} \mathrm{Sr}^{90} \mathrm{Y}$ (1850 MBq, 1981).

TABELA 6.48 - Condições experimentais utilizadas na determinação das curvas de saturação, e correntes de ionização médias obtidas para ambas as polaridades de tensão.

TABELA 6.49 - Testes de repetibilidade e reprodutibilidade da resposta de três câmaras de ionização, realizados com uma fonte de controle de ${ }^{90} \mathrm{Sr}+{ }^{90} \mathrm{Y}$. 
TABELA 6.50 - Teste de tempo de estabilização realizado com as câmaras de ionização C1 e C2, utilizando-se a fonte de controle de ${ }^{90} \mathrm{Sr}+{ }^{90} \mathrm{Y}$ (33 MBq, 1988)...

TABELA 6.51 - Resposta relativa das câmaras de ionização C1 e C2 em função do ângulo de $0^{\circ}$.

TABELA 6.52 - Coeficientes de calibração obtidos as para duas câmaras de ionização de placas paralelas $\mathrm{C} 2$ e $\mathrm{C} 3$..

TABELA 6.53 - Taxas de dose absorvida obtidas para aplicadores clínicos dermatológicos de ${ }^{90} \mathrm{Sr}+{ }^{90} \mathrm{Y}$, utilizando o aplicador NIST como referência, e em comparação com resultados obtidos em um trabalho prévio (Antonio e col., 2009).

TABela 6.54 - Taxas de dose absorvida obtidas para aplicadores clínicos de cinco hospitais de São Paulo..

TABELA 6.55 - Características dos aplicadores clínicos da UFS e taxas de dose absorvida obtidas neste trabalho.

TABELA 6.56 - Condições de irradiação (sistema BSS2) e resultados obtidos no estudo de

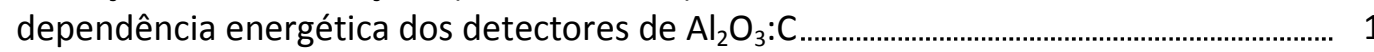

TABELA 6.57 - Taxas de dose absorvida obtidas para os aplicadores clínicos de ${ }^{90} \mathrm{Sr}+{ }^{90} \mathrm{Y}$, utilizando o sistema dosimétrico postal TL/LOE..

TABELA 6.58 - Taxas de dose absorvida finais obtidas para os aplicadores clínicos de ${ }^{90} \mathrm{Sr}+{ }^{90} \mathrm{Y}$, utilizando o sistema dosimétrico postal TL/LOE.

TABELA A.1 - Grandezas e seus valores utilizados na determinação das taxas de dose absorvida no ar, $\dot{D}_{a}$, e no tecido, $\dot{D}_{t}$, para três fontes de ${ }^{90} \mathrm{Sr}+{ }^{90} \mathrm{Y}$, utilizando a câmara de extrapolação Böhm com janela de entrada de Hostaphan grafitado (CALDAS, 1980; ISO, 2004).

TABELA A.2 - Fatores de transmissão, $T$, obtidos para a janela de entrada de Hostaphan grafitado.... 176

TABELA A.3 - Fatores de correção utilizados neste trabalho e seus respectivos valores (CALDAS, 1980). 


\section{LISTA DE ABREVIATURAS}

ABNT

$\mathrm{ADCL}$

BARC

BIPM

BSS1

BSS2

CASMIE

CDTN

CNEN

CW-OSL

DEN

ELETRONUCLEAR

IAEA

ICRU

IEC

INMETRO

IPEN

ISO

$\mathrm{LCl}$

LCR

LCMR

LM-OSL

LMRI

LMRI

LNMRI

LOE

METROBRAS

NBS

NIST
Associação Brasileira de Normas Técnicas

Accredited Dosimetry Calibration Laboratory

Bhabha Atomic Research Centre

Bureau International des Poids et Mesures

Beta Secondary Standard System 1

Beta Secondary Standard System 2

Comitê de Avaliação dos Serviços de Monitoração Individual Externa

Centro de Desenvolvimento da Tecnologia Nuclear

Comissão Nacional de Energia Nuclear

Continuous Wave OSL

Departamento de Energia Nuclear

Eletrobrás Termonuclear S.A.

International Atomic Energy Agency

International Commission on Radiation Units and Measurements

International Electrotechnical Commission

Instituto Nacional de Metrologia, Qualidade e Tecnologia

Instituto de Pesquisas Energéticas e Nucleares

International Organization for Standardization

Laboratório de Calibração de Instrumentos

Laboratório de Ciências Radiológicas

Laboratório de Calibração de Monitores de Radiação

Linear Modulation OSL

Laboratório de Metrologia das Radiações Ionizantes

Laboratoire de Métrologie dês Rayonnements lonisants

Laboratório Nacional de Metrologia das Radiações lonizantes

Luminescência Opticamente Estimulada

Centro de Ensaios e Pesquisa em Metrologia

National Bureau of Standards

National Institute of Standards and Technology 
NMi

NPL

OSL

POSL

PTB

$R P$ \& $A D$

TL

TSEE

UERJ

UFPE

UFS

UWADCL

VNIIM
Nederlands Meetinstitut

National Physical Laboratory

Optically Stimulated Luminescence

Pulsed OSL

Physikalisch-Technische Bundesanstalt

Radiological Physics \& Advisory Division

Termoluminescência

Thermally Stimulated Exoelectron Emission (Emissão Exoeletrônica Termicamente Estimulada)

Universidade Estadual do Rio de Janeiro

Universidade Federal de Pernambuco

Universidade Federal de Sergipe

University of Wisconsin Accredited Dosimetry Calibration Laboratory

D. I. Mendeleyev Institute for Metrology 


\section{INTRODUÇÃO}

A calibração de um instrumento metrológico ocorre quando é realizada uma comparação entre os valores obtidos pelo instrumento que está sendo calibrado e os valores determinados por um sistema padrão, por exemplo uma grandeza ou um instrumento de medição, ou um determinado material. Em metrologia das radiações, é necessária a utilização de um sistema padrão devido à importância do estabelecimento de condições específicas e bem definidas para os procedimentos de calibração e dosimetria de instrumentos metrológicos ou fontes radioativas. Este sistema padrão representa a garantia de que a resposta do detector ou a fonte de radiação é adequada e, neste caso, torna-se uma referência. Por este motivo, a rastreabilidade metrológica na calibração é fundamental, pois representa a garantia de que um resultado pode ser comparado ao de uma referência (ALBERTAZZI e SOUSA, 2008; INMETRO, 2012).

Os laboratórios de padronização primária trabalham com sistemas padrões primários, que foram escolhidos, por convenção, por apresentarem qualidades metrológicas maiores do que em outros laboratórios, e oferecem serviços de calibração de detectores e fontes de radiação que, por serem submetidos a processos primários, são classificados como sistemas padrões secundários.

A Agência Internacional de Energia Atômica (IAEA) recomenda a calibração periódica de instrumentos metrológicos e fontes de radiação, para que as suas respostas sejam avaliadas em relação a um sistema padrão adotado e, assim, que o seu desempenho adequado seja garantido; esta prática faz parte de programas de controle de qualidade que visam à utilização e à aplicação segura e eficiente destas fontes. No caso das fontes de radiação beta, a calibração é realizada em termos de taxa de dose absorvida no ar ou no tecido/água (IAEA, 2002; ICRU, 2004).

De acordo com recomendações internacionais (De ALMEIDA e col., 2000; IAEA, 2002; ICRU, 2004; ISO, 2004) e de especialistas (SOARES, 1995; KOLLAARD e col., 2006; SOARES e col., 2001; 2009), as fontes de radiação beta de ${ }^{90} \mathrm{Sr}^{90} \mathrm{Y}$ utilizadas em betaterapia, os aplicadores clínicos, devem ser calibradas, em programas de controle de qualidade a fim de 
se assegurar o uso correto e eficiente destas fontes. Como estas fontes ainda são utilizadas no Brasil, embora não sejam mais comercializadas pelos fabricantes, as que restaram devem ser submetidas aos procedimentos de calibração e dosimetria. Estas atividades são necessárias para, além de fornecerem taxas de dose absorvida atualizadas, serem utilizadas pelos operadores destas fontes e contribuírem para a decisão da continuidade do uso da fonte. Devido ao seu uso em tratamentos de pterígio ou queloide, estas fontes devem ser limpas com produtos específicos e que, se usados incorretamente, podem causar a remoção do material da fonte do instrumento.

Existem alguns laboratórios padrões primários que realizam a calibração de fontes de radiação beta em termos de taxa de dose absorvida no ar ou no tecido/água, são eles: o National Institute of Standards and Technology (NIST), nos Estados Unidos, o PhysikalischTechnische Bundesanstalt (PTB), na Alemanha, e o National Physical Laboratory (NPL), na Inglaterra. Um laboratório padrão secundário, Accredited Dosimetry Calibration Laboratory $(A D C L)$, da Universidade de Wisconsin, nos Estados Unidos, também oferece este tipo de serviço.

Não há nenhum laboratório padrão primário de dosimetria de radiações ionizantes no Brasil e na América Latina. No Brasil existe apenas um laboratório padrão secundário apoiado pela IAEA, denominado Laboratório Nacional de Metrologia das Radiações lonizantes (LNMRI), que também é o Laboratório de Metrologia das Radiações lonizantes do Instituto Nacional de Metrologia, Normalização e Qualidade Industrial (INMETRO). O LNMRI oferece uma série de serviços de calibração de detectores e de fontes de radiação $X$, gama e nêutrons, mas não de radiação beta em termos de taxa de dose absorvida no ar ou no tecido.

Além do LNMRI, existem outros laboratórios que oferecem calibração de detectores de radiação no Brasil, em modalidades diferentes: calibração de detectores portáteis com radiação $X$ e gama e de detectores de contaminação (nível radioproteção), calibração de detectores utilizados na área de radiodiagnóstico, e calibração de dosímetros clínicos (nível radioterapia). A calibração de detectores de nêutrons é um serviço exclusivo do IRD/CNEN. Os laboratórios são:

- Laboratório de Ciências Radiológicas (LCR), da Universidade Estadual do Rio de Janeiro (UERJ), no Rio de Janeiro; 
- Laboratório de Calibração de Monitores de Radiação (LCMR), da Eletrobrás Termonuclear S.A. (ELETRONUCLEAR), no Rio de Janeiro;

- Laboratório de Metrologia das Radiações Ionizantes (LMRI), do Departamento de Energia Nuclear da Universidade Federal de Pernambuco (DEN/UFPE), em Recife;

- Laboratório de Metrologia das Radiações Ionizantes (LMRI), do Centro de Desenvolvimento da Tecnologia Nuclear, Comissão Nacional de Energia Nuclear (CDTN/CNEN), em Belo Horizonte;

- Laboratório de Calibração de Monitores de Radiação, do Centro de Ensaios e Pesquisas em Metrologia, (LCMR/METROBRAS), em Ribeirão Preto;

- Laboratório de Calibração de Instrumentos (LCI), do Instituto de Pesquisas Energéticas e Nucleares, Comissão Nacional de Energia Nuclear (IPEN/CNEN), em São Paulo.

O LCI do IPEN oferece diversos serviços de calibração: detectores portáteis com radiação $\mathrm{X}$, gama e beta, detectores de contaminação alfa e beta, dosímetros clínicos com radiação gama, detectores utilizados em radiodiagnóstico (convencional, tomografia e mamografia), activímetros utilizados na área de Medicina Nuclear, e aplicadores clínicos para betaterapia. Este laboratório possui arranjos adequados e sistemas padrões rastreáveis ao laboratório nacional LNMRI/CNEN-RJ, e aos laboratórios padrões primários da Alemanha (PTB), Estados Unidos (NIST) e Inglaterra (NPL).

No $\mathrm{LCl}$ são calibrados diversos detectores de radiação beta anualmente e este serviço vem sendo oferecido desde a década de 80 , possibilitando arranjos adequados aos dois sistemas padrões secundários de radiação beta que possui (obedecendo assim às condições definidas nos certificados de calibração): BSS1, Buchler $\mathrm{GmbH} \&$ Co., Alemanha (com fontes de ${ }^{90} \mathrm{Sr}+{ }^{90} \mathrm{Y},{ }^{204} \mathrm{Tl}$ e ${ }^{147} \mathrm{Pm}$ ) e BSS2, Isotrak, Alemanha (com fontes de ${ }^{90} \mathrm{Sr}+{ }^{90} \mathrm{Y},{ }^{85} \mathrm{Kr}$ e ${ }^{147} \mathrm{Pm}$ ).

Os sistemas padrões primários e secundários de radiação beta são utilizados não apenas na calibração de detectores de radiação, mas também para irradiações de diferentes dosímetros, como os termoluminescentes, filmes radiocrômicos, detectores luminescentes opticamente estimulados, em pesquisa e em diversas outras aplicações (PRUITT e col., 1988; BÖHM e col., 1999; NIST, 2004; AMBROSI e col., 2007; SOARES e col., 2009). No IPEN já foram calibrados, de forma rotineira, centenas de detectores beta-gama, e irradiados vários tipos de dosímetros e amostras de várias procedências. 
De maneira geral, a calibração de detectores beta-gama é realizada apenas para radiação gama, embora a calibração para radiação beta seja extremamente importante. Esta importância deve-se ao fato dos fatores de correção para radiação beta superarem, muitas vezes, fatores de 3 a 5, levando a erros enormes de interpretação das medições, subestimando-se os riscos a que os usuários estão expostos. No LCI/IPEN, os detectores beta-gama são inicialmente calibrados em feixes de radiação gama $\left({ }^{137} \mathrm{Cs}\right.$ e $\left.{ }^{60} \mathrm{Co}\right)$, e a seguir com radiação beta. Sendo assim, é recomendável a implantação de arranjos de calibração com radiação beta em todos os laboratórios de calibração de monitores portáteis.

O instrumento metrológico adequado e utilizado como sistema padrão primário em diferentes laboratórios de metrologia de radiação beta é a câmara de extrapolação (BÖHM, 1986; CALDAS, 1986; NIST, 2010; BEHRENS e col., 2011; ANTONIO e col., 2012a; BRUNZENDORF, 2012a). Este tipo de câmara de ionização difere dos outros modelos por possibilitar um aumento ou uma diminuição no espaçamento entre os eletrodos coletores da câmara (eletrodo central e janela de entrada) e, assim, ela permite a realização de medições em várias profundidades diferentes da câmara. Analisando-se os resultados, a taxa de dose absorvida pode ser determinada por meio da técnica de extrapolação.

O LCl possui uma câmara de ionização de extrapolação doada pelo NPL, a câmara de extrapolação Böhm (PTW, 2002), que foi desenvolvida para ser utilizada como sistema padrão primário ou secundário na calibração de detectores e fontes de radiação beta, pois pode fornecer medidas absolutas de dose absorvida de radiação beta e raios $X$ de baixas energias com altíssima precisão e em meio equivalente ao tecido. Os laboratórios de dosimetria padrões primários (PSDL) e padrões secundários (SSDL) utilizam este tipo de câmara na calibração de fontes de radiação (PRUITT e col., 1988; NIST, 2004; AMBROSI e col., 2007; BEHRENS e col., 2007).

Embora a câmara de extrapolação seja, por excelência, o detector de radiação beta (recomendado e utilizado), ela não é adequada para uso em programas de controle de qualidade, pois apresenta um custo alto e requer muito tempo para a obtenção da taxa de dose absorvida de uma fonte (as medições experimentais são demoradas). Além disso, a sua utilização necessita de um controle rigoroso das condições ambientais e, por este motivo, elas são utilizadas apenas em laboratórios de metrologia. 


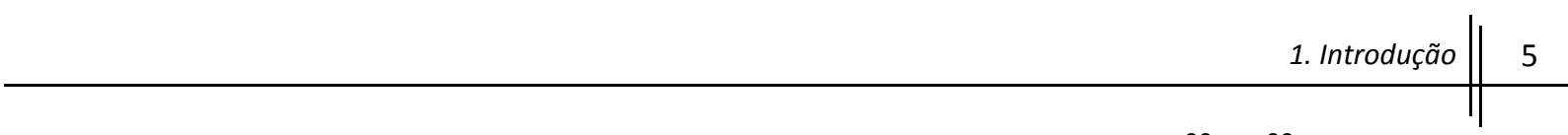

Alguns tipos de fontes de radiação beta (aplicadores clínicos de ${ }^{90} \mathrm{Sr}+{ }^{90} \mathrm{Y}$ ) são utilizadas em hospitais ou clínicas e, sendo assim, elas devem ser enviadas ao LCI para sua calibração. Entretanto, nem sempre estas fontes podem sair do seu local de uso, devido ao fato, por exemplo, deste transporte e a falta deles causar um atraso nas clínicas nos tratamentos médicos dos pacientes. Assim, é necessário o estabelecimento de métodos alternativos para calibração destas fontes e, nesse caso, padrões de trabalho devem ser implementados para este propósito. Quando medições com uma câmara de extrapolação não se tornam possíveis, uma alternativa é a aplicação de outras técnicas, como por exemplo, as que envolvem fenômenos luminescentes.

A técnica de termoluminescência (TL) tem sido utilizada em diferentes aplicações envolvendo a radiação beta, incluindo a calibração e dosimetria destas fontes, bem como de aplicadores clínicos (IAEA, 2002; ICRU, 2004; OLIVEIRA e CALDAS, 2007; SOARES e col., 2009; MANCOSU e col., 2010; ANTONIO e col., 2012b). A escolha do melhor material termoluminescente a ser utilizado em uma determinada aplicação é importante para que o dosímetro possa oferecer um desempenho adequado. No caso da radiação beta, que possui poder de penetração baixo, os dosímetros finos são os mais empregados, como, por exemplo, o sulfato de cálcio, $\mathrm{CaSO}_{4}: \mathrm{Dy}_{\text {e }} \mathrm{CaSO}_{4}: \mathrm{Dy}+10 \%$ de grafite (CAMPOS e LIMA, 1987).

A luminescência opticamente estimulada (LOE), do inglês optically stimulated luminescence (OSL) consiste numa outra técnica que vem sendo estudada e aplicada em feixes de radiação beta, e apresentando respostas satisfatórias a este tipo de feixe. A alumina $\left(\mathrm{Al}_{2} \mathrm{O}_{3}: \mathrm{C}\right)$ é um material que exemplifica muito bem este tipo de aplicação, pois vem sendo estudado e utilizado em campos de radiação beta, embora existam, como no caso da dosimetria TL, diversos materiais que podem ser utilizados como detectores LOE. Este material, inicialmente desenvolvido como material TL, apresenta alta sensibilidade à luz e, por este motivo, passou a ser atualmente mais utilizado como detector LOE, fornecendo características dosimétricas excelentes, inclusive em campos de radiação beta (McKEEVER e col., 1995; AKSELROD e col., 1999; PINTO e col., 2008; YUKIHARA e McKEEVER, 2008; DING e MALCOLM, 2013; NASCIMENTO e col., 2013). 


\section{Objetivos do Trabalho}

Levando-se em conta a inexistência de um laboratório de padronização primária em radiação beta no Brasil, bem como na América Central e na América do Sul, surgiu a necessidade de formação de um laboratório que esteja totalmente apto para atender às solicitações referentes à calibração e à dosimetria de fontes de radiação beta. Para tal, tornou-se necessário o cumprimento dos objetivos principais e específicos, inicialmente propostos para a realização deste trabalho.

\subsection{Objetivos Principais}

O primeiro objetivo principal deste trabalho consistiu na implantação de uma metodologia de padronização primária em feixes de radiação beta no LCl. Para esta finalidade, foi utilizada a câmara de extrapolação Böhm, que foi inicialmente estudada e caracterizada em feixes de radiação beta. Ela será estabelecida como sistema padrão primário para a determinação da taxa de dose absorvida no ar ou no tecido, de fontes de radiação beta de ${ }^{90} \mathrm{Sr}+{ }^{90} \mathrm{Y}$.

Ao longo do desenvolvimento do trabalho, a resposta de diferentes tipos de detectores de radiação (câmaras de ionização de placas paralelas, dosímetros termoluminescentes e luminescentes opticamente estimulados) foi estudada em feixes padrões de radiação beta, a fim de se verificar seu comportamento e possibilidade de uso na determinação de taxas de dose absorvida e em programas de controle de qualidade de aplicadores clínicos de ${ }^{90} \mathrm{Sr}+{ }^{90} \mathrm{Y}$. A partir destes estudos, pode-se citar o segundo objetivo do trabalho, que consistiu no desenvolvimento de uma metodologia para calibração de aplicadores clínicos.

\subsection{ObJetivos EspecífICOS}

Este trabalho também apresenta objetivos específicos, que complementam o estudo para o estabelecimento da câmara de extrapolação Böhm como sistema padrão primário no $\mathrm{LCl}$ e a calibração e dosimetria de fontes de radiação beta: 
1) Estudo e caracterização da resposta da câmara de extrapolação Böhm com dois materiais diferentes de janela de entrada: Mylar aluminizado e Hostaphan grafitado;

2) Determinação de taxas de dose absorvida no ar e no tecido (profundidade de 0,07 mm) das fontes de ${ }^{90} \mathrm{Sr}+{ }^{90} \mathrm{Y}$ dos sistemas padrões secundários do LCl (BSS1 e BSS2), utilizando a câmara de extrapolação Böhm;

3) Estudo e caracterização de câmaras de ionização de placas paralelas de volumes sensíveis fixos diferentes, para verificação do seu desempenho em campos de radiação beta (para a calibração de fontes e aplicadores clínicos de $\left.{ }^{90} \mathrm{Sr}+{ }^{90} \mathrm{Y}\right)$;

4) Estudo das técnicas de termoluminescência e de luminescência opticamente estimulada, e caracterização de materiais, em campos padrões de radiação beta, como métodos alternativos para dosimetria da radiação beta;

5) Utilização e testes de detectores luminescentes opticamente estimulados na calibração de aplicadores clínicos;

6) Desenvolvimento e estabelecimento de um sistema dosimétrico para a calibração de aplicadores clínicos nos hospitais que utilizam o procedimento terapêutico de betaterapia, da cidade de São Paulo, como uma forma de demonstração de sua utilização com segurança e eficácia durante a calibração destas fontes;

7) Envio do sistema dosimétrico, de maneira postal, para calibração periódica de aplicadores clínicos de ${ }^{90} \mathrm{Sr}+{ }^{90} \mathrm{Y}$;

8) Elaboração de procedimentos de utilização da câmara de extrapolação Böhm e da calibração de aplicadores clínicos de ${ }^{90} \mathrm{Sr}+{ }^{90} \mathrm{Y}$. 


\section{REVISÃO DA LITERATURA}

Embora em muitos materiais radioativos ocorra a presença simultânea de radiação beta e gama, a dosimetria gama sempre foi estudada e aplicada com maior segurança do que se pode observar com relação à dosimetria beta. Devido a fatores como o baixo poder de penetração no tecido e dos seus altos gradientes de dose (a partícula beta ioniza o meio com o qual interage e, por este motivo, sua trajetória torna-se complexa, pois ela deposita energia na matéria), a radiação beta apresenta certa dificuldade em sua dosimetria (SOARES e PRUITT, 1993; ICRU, 2004; ISO, 2004).

Como uma forma de se resolver esta questão, é necessária a utilização de campos padrões rigorosamente definidos para calibração e dosimetria beta; os sistemas padrões (uma fonte de radiação ou um instrumento de referência) minimizam os erros durante a determinação da dose absorvida, e também as incertezas, fazendo com que a resposta do detector à exposição da fonte seja muito reprodutível (BÖHM, 1991; SOARES e PRUITT, 1993; IAEA, 2002; ISO, 2004; 2006; NIST, 2004; SOARES e col., 2009).

A IAEA apresentou recomendações que tratam da calibração de feixes de radiação utilizados em radioterapia (IAEA, 1994; 2000a; 2002). Além disso, outras organizações e instituições publicaram recomendações que não apenas discutem assuntos referentes à calibração e dosimetria de detectores e fontes de radiação, como também mostram como a operação de calibração deve ser realizada (ICRU, 2004; ISO, 2004; 2006; NIST, 2004).

No caso dos detectores de radiação, a calibração também apresenta grande importância, uma vez que estes instrumentos são utilizados, em geral, em proteção radiológica. A IAEA apresentou uma publicação (IAEA, 2002) que discute exclusivamente este assunto: a calibração de monitores utilizados em proteção radiológica. A grande contribuição deste relatório implica em auxiliar laboratórios na calibração de instrumentos que medem fótons, radiação beta e nêutrons, além de monitores de contaminação de superfície.

Em se tratando da aplicação da radiação beta na área da saúde, a calibração e a dosimetria deste tipo de radiação devem ser realizadas com programas e métodos bem 
estabelecidos. Este fato torna-se imprescindível para o caso de fontes de radiação beta, em forma de placas contendo o material radioativo, utilizadas em betaterapia (aplicadores clínicos). Devido ao fato desta radiação apresentar certo limite de penetração no tecido humano, sua utilização foi incorporada em tratamentos dermatológicos e oftálmicos.

Os primeiros aplicadores clínicos de ${ }^{90} \mathrm{Sr}+{ }^{90} \mathrm{Y}$ (posteriores ao uso de placas de ${ }^{226} \mathrm{Ra}$, ${ }^{106} \mathrm{Ru}$ e ${ }^{144} \mathrm{Ce}$ ) foram desenvolvidos e utilizados por Friedell e colaboradores (1950). Sinclair e Trott (1956) apresentaram a construção e a aplicação de novos aplicadores de radiação beta para oftalmologia. Lederman (1956) discutiu as diferentes aplicações da radiação em oftalmologia. Era o início do que viria a ser bem estudado num futuro próximo.

Os estudos com aplicadores clínicos intensificou-se, conforme os tratamentos de braquiterapia foram aumentando e, ao longo dos anos, laboratórios padrões, como o NIST, começaram a oferecer a calibração destas fontes que, devido a sua geometria, é um procedimento complexo. Assim, estas fontes passaram a apresentar certificados de calibração de laboratórios padrões ou das próprias empresas fabricantes, como é o caso da Amersham. Soares (1991) realizou uma comparação entre as calibrações feitas no NIST e as realizadas pela Amersham. Ele observou uma discrepância entre as taxas de dose absorvidas obtidas nas duas calibrações e, com isso, sugeriu algumas correções no sistema de calibração adotado pelo NIST.

Mais tarde, Soares (1995) realizou um estudo no qual ele fez comparações entre a calibração de aplicadores de ${ }^{90} \mathrm{Sr}+{ }^{90} \mathrm{Y}$ realizada no NIST e por diversos fabricantes das fontes, como Amersham, Tracerlab e Atlantic Research, que mostrou uma discrepância entre as calibrações de até 61\%. Mais recentemente, Holmes e colaboradores (2009) também publicaram os resultados de um estudo de comparação entre calibrações realizadas na University of Wisconsin Accredited Dosimetry Calibration Laboratory (UWADCL) e nas empresas que fabricavam as fontes. Ambos os trabalhos de comparação mostraram que esta diferença indica a necessidade de padrões primários para a calibração destas fontes, por possuírem métodos e sistemas bem definidos de calibração e sistemas de referência.

No decorrer dos estudos sobre calibração de aplicadores clínicos de ${ }^{90} \mathrm{Sr}+{ }^{90} \mathrm{Y}$, outras fontes foram estudadas para utilização em braquiterapia, como, por exemplo, ${ }^{125} \mid$ e ${ }^{192} \mid r$, e os fatores, como por exemplo a necessidade de sistemas padrões, foram verificados por diversos autores. Todos estes estudos citam a calibração de fontes utilizadas em 
braquiterapia, onde as taxas de dose absorvida no tecido podem ser obtidas utilizando-se, por exemplo, câmaras de extrapolação, dosímetros termoluminescentes ou filmes radiocrômicos (SOARES, 1995; BAMBYNEK, 2002; IAEA, 2002; QUAST e col., 2002; SELBACH e SOARES, 2003; VAN DER MAREL e VAN DIJK, 2003; ICRU, 2004; HOLMES e col., 2009; SOARES e col., 2009).

A primeira câmara de extrapolação foi desenvolvida e utilizada por Failla (1937), que era uma câmara de ionização de placas paralelas, com a finalidade de medir a dose superficial (no tecido) em um material irradiado por meio de medições de corrente de ionização, variando-se o espaçamento entre o eletrodo coletor e a janela de entrada da câmara. Neste trabalho, a medição da grandeza dose absorvida foi testada para as radiações beta, gama e X.

Desde então, várias câmaras de extrapolação foram desenvolvidas ao longo dos anos e para vários propósitos diferentes, como por exemplo para medições de: fontes de radiação beta (LOEVINGER, 1953), feixes de radioterapia (GENNA e LAUGHLIN, 1955), feixes de radiação X de ortovoltagem (GENNA e col., 1956), radiação alfa, radiação beta e raios X de energias baixas (LOEVINGER e TROTT, 1966), feixes de radiação $X$ de megavoltagem (MANSON e col., 1975), radiação beta e raios X de energias baixas (BÖHM e SCHNEIDER, 1986), e ainda utilização como sistema padrão primário para fontes de braquiterapia (BAMBYNEK, 2002). Câmaras de extrapolação também foram utilizadas para outras finalidades, como: dosimetria de fontes de radiação beta planas e puntiformes (DARLEY e col., 1991), medições de dose absorvida absoluta em uma câmara de extrapolação com janela de entrada de material equivalente ao osso (DeBLOIS e col., 2002), e calibração de feixes de fótons de energias altas e elétrons de um acelerador clínico linear (RAVICHANDRAN e col., 2009).

No LCl, Dias (1996) desenvolveu uma câmara de extrapolação como instrumento de referência para dosimetria de radiação beta. Esta câmara também foi testada e apresentou bom desempenho em feixes de raios $\mathrm{X}$ e na calibração de aplicadores clínicos. Silva e Caldas (2012) verificaram o comportamento desta câmara em feixes de raios $X$ de energias baixas, e observaram o seu bom desempenho como sistema de referência. Os resultados obtidos com a câmara desenvolvida por Dias (1996) foram comparados aos obtidos com uma câmara de extrapolação comercial, PTW, modelo 23391, e ambos os instrumentos mostraram-se aptos 
para utilização como sistemas padrões absolutos em feixes de raios $\mathrm{X}$, nível radioterapia (SILVA e CALDAS, 2012).

Oliveira (2005) projetou e construiu duas câmaras de extrapolação, uma com janela de entrada plana e outra com janela curva, para calibração de aplicadores dermatológicos e oftálmicos, respectivamente. Com o desempenho obtido destas câmaras, foi possível utilizálas como sistemas de referência para calibração de aplicadores clínicos de ${ }^{90} \mathrm{Sr}+{ }^{90} \mathrm{Y}$. As câmaras de extrapolação desenvolvidas no LCI por Dias (1996) e Oliveira (2005) permitem a determinação da taxa de dose absorvida na superfície das fontes pelo método absoluto, ou seja, sem a necessidade de calibrações prévias com uma fonte ou instrumento padrão.

Böhm e colaboradores (1976) apresentaram, em uma intercomparação dos padrões nacionais utilizados para dosimetria beta no PTB, Alemanha, e no Laboratoire de Métrologie dês Rayonnements lonisants (LMRI), na França, os procedimentos adotados para a obtenção da taxa de dose absorvida no tecido para radiação de ${ }^{90} \mathrm{Sr}+{ }^{90} \mathrm{Y}$, utilizando-se câmaras de extrapolação. A determinação da grandeza pôde ser realizada com a mesma acurácia em ambos os laboratórios.

Caldas (1980), por meio de diversos experimentos e análises, apresentou métodos eficientes de calibração da radiação beta utilizando sistemas padrões primário e secundário, além das técnicas de termoluminescência ( $T L)$ e emissão exoeletrônica termicamente estimulada (TSEE). Os resultados obtidos neste trabalho demonstraram que os instrumentos de referência utilizados puderam ser adotados como padronização com eficiência para a calibração e dosimetria da radiação beta. Também foi verificado que as técnicas TL e TSEE podem ser utilizadas em dosimetria beta.

Böhm (1986) relatou a implantação de um laboratório padrão primário nacional no PTB para dosimetria da radiação beta, a fim de se obter a taxa de dose absorvida no tecido. Neste relatório, Böhm descreveu detalhadamente este sistema padrão com câmaras de extrapolação, apresentando procedimentos minuciosos para as medições que devem ser realizadas e a obtenção de fatores de correção necessários para os resultados. Ainda neste relatório, Böhm forneceu os resultados obtidos durante uma intercomparação realizada entre o PTB e o NPL, incluindo a comparação entre as incertezas dos valores obtidos.

Caldas (1986) estudou o desempenho da resposta de uma câmara de extrapolação comercial para detecção de radiação beta no LCI (IPEN), expondo o instrumento a feixes 
padrões de radiação beta do sistema padrão secundário de radiação beta, BSS1, da Buchler $\mathrm{GmbH} \&$ Co., Alemanha (fontes padrões de ${ }^{90} \mathrm{Sr}+{ }^{90} \mathrm{Y},{ }^{147} \mathrm{Pm}$ e ${ }^{204} \mathrm{TI}$ ). As principais características de uma câmara de extrapolação foram estudadas, bem como a influência do material do eletrodo coletor na determinação dos fatores de calibração.

Pruitt e colaboradores (1988) descreveram o trabalho de calibração de instrumentos e fontes de radiação beta desenvolvidos no National Bureau of Standards (NBS), nos Estados Unidos. Este relatório detalha todos os procedimentos necessários para a execução de calibrações com radiação beta, proporcionando os mais altos níveis de exatidão e qualidade nas medições. Tanto neste trabalho, como no desenvolvido por Böhm (1986), a câmara de extrapolação Böhm, PTW, foi utilizada como sistema padrão, e também foi utilizado o sistema padrão secundário de radiação beta BSS1.

Visando à continuidade das calibrações com sistemas padrões, o NBS, que hoje se chama National Institute of Standards and Technology (NIST), realizou um estudo sobre os procedimentos de controle de qualidade para calibração de radiação beta. Neste trabalho, Soares e Pruitt (1993) também discutiram os métodos utilizados para laboratórios padrões secundários serem rastreáveis ao NIST (padrão primário).

Em 2002, a IAEA publicou um documento sobre métodos de calibração de fótons e fontes de radiação beta utilizados em braquiterapia. Este relatório é um guia com os procedimentos necessários para a padronização secundária de um laboratório de calibração e de hospitais. Neste documento, fontes de braquiterapia são caracterizadas e o método de sua calibração é definido, utilizando câmaras de ionização ou outros detectores de radiação (dosímetros termoluminescentes, detectores de diodo e de diamante, entre outros), além dos programas de controle de qualidade (IAEA, 2002).

Levando-se em conta que a distribuição de dose é um fator que deve ser muito bem estudado e avaliado para as fontes de radiação beta utilizadas em braquiterapia, a ICRU (2004) apresentou um relatório no qual demonstrou como devem ser realizadas as calibrações destas fontes, bem como os cálculos aplicados aos resultados das medições, e como deve ser determinada a distribuição de dose destas fontes. Todas estas recomendações são apresentadas para fontes em forma de aplicadores clínicos planos e curvos, e em forma de sementes ou fios (ICRU, 2004). 
Ainda em 2004, a ISO (International Organization for Standardization) estabeleceu métodos e referências para a dosimetria de partículas beta, por meio de especificações para a determinação da grandeza taxa de dose absorvida em um meio equivalente ao tecido. Para isso, os métodos descritos nesta recomendação fazem uso de uma câmara de extrapolação como instrumento de referência para dosimetria beta. São fornecidos também a descrição de todos os fatores de correção aplicados na determinação da taxa de dose absorvida e os métodos de obtenção das incertezas de medições (ISO, 2004).

Em 2006, a ISO descreveu os procedimentos para a calibração e a determinação da resposta de dosímetros e detectores, cuja resposta é dada em termos de taxa de dose absorvida, em termos das grandezas definidas para medições com radiação ionizante pela International Commission on Radiation Units and Measurements (ICRU) no relatório ICRU Report no 85 (2011). O documento da ISO (2006) fornece também informações sobre como devem ser elaborados os certificados de calibração destes dosímetros e detectores (ISO, 2006).

Soares e colaboradores (2009) apresentaram um trabalho de revisão sobre os padrões primários existentes para a calibração de partículas beta e fótons de diferentes energias utilizados em braquiterapia, em diferentes laboratórios de padronização (PTB, NPL, NIST, e Nederlands Meetinstitut (NMi)) e utilizando-se diferentes instrumentos (câmaras de extrapolação, câmaras de ionização de ar livre, dosímetros TL, filmes radiocrômicos e outros). Também foram discutidos os métodos utilizados para o controle de qualidade destas fontes e para a transferência destes padrões para laboratórios secundários. Além disso, foram também descritos os protocolos de dosimetria de fontes beta em aplicações clínicas.

Em 2012, Brunzendorf apresentou dois trabalhos sobre curvas de dose absorvida em função da profundidade no tecido, ou curvas de fatores de transmissão; este estudo é de importância fundamental para dosimetria beta, uma vez que a taxa de dose absorvida apresenta grande dependência com a profundidade do meio. Em um destes trabalhos (BRUNZENDORF, 2012a), são descritos os métodos para se determinar os fatores de transmissão utilizando-se câmaras de ionização (não sendo necessariamente as câmaras de extrapolação) e fontes de radiação beta; os procedimentos apresentados foram realizados de acordo com a recomendação da ISO 6980-2 (2004). No segundo trabalho 
(BRUNZENDORF, 2012b), o autor aplicou os métodos descritos no trabalho anterior (BRUNZENDORF, 2012a), demonstrando agora os fatores de transmissão obtidos no PTB para as fontes do sistema padrão secundário de radiação beta BSS2 $\left({ }^{147} \mathrm{Pm},{ }^{85} \mathrm{Kr}\right.$ e $\left.{ }^{90} \mathrm{Sr}+{ }^{90} \mathrm{Y}\right)$, utilizando a câmara de extrapolação Böhm. Estes resultados foram comparados aos fatores de transmissão demonstrados na ISO 6980-2 (2004), variando de 0,31\% $\left({ }^{90} \mathrm{Sr}+{ }^{90} \mathrm{Y}\right)$ a $3,90 \%$ ( $\left.{ }^{147} \mathrm{Pm}\right)$.

Além das câmaras de extrapolação, a termoluminescência ( $T L$ ) é outra técnica muito utilizada na dosimetria da radiação beta. Os autores Marshall e Docherty (1971) já utilizavam pastilhas termoluminescentes em campos de radiação beta. Neste trabalho, eles determinaram a dose absorvida na pele expondo dosímetros de LiF + Teflon em campos de radiação beta e gama de diferentes energias. Assim, o desempenho deste material foi comprovado, em especial em casos de medições de dose em extremidades.

Caldas e colaboradores (1985) testaram dosímetros de extremidade utilizando a técnica da termoluminescência. As principais características, como sensibilidade, linearidade e dependência energética foram estudadas em feixes de radiação beta, gama e $X$, demonstrando a eficiência destes dosímetros nos campos de radiação utilizados.

Uchrin (1986) expôs diferentes materiais TL a fontes de radiação ${ }^{90} \mathrm{Sr}+{ }^{90} \mathrm{Y},{ }^{204} \mathrm{Tl}$ e ${ }^{147} \mathrm{Pm}$. Estes materiais (LiF em pastilha e em pó, com e sem grafite, e $\mathrm{MgB}_{4} \mathrm{O}_{7}: \mathrm{Dy}+$ grafite) apresentaram bom desempenho em campos de radiação beta. Ainda em 1986, Rosa e colaboradores (ROSA e col., 1986) estudaram o comportamento de pastilhas ultra-finas de $\mathrm{CaSO}_{4}: \mathrm{Dy}+$ Teflon em feixes de radiação beta das mesmas fontes utilizadas por Uchrin. Para isso, os testes de caracterização das amostras foram realizados e os resultados apresentaram a viabilidade deste material para dosimetria beta.

Um ano mais tarde, Campos e Lima (1987) mostraram a utilização e o bom desempenho de pastilhas de $\mathrm{CaSO}_{4}: \mathrm{Dy}+$ Teflon na detecção de radiação beta. A estas pastilhas, fabricadas no IPEN, foi adicionado grafite que, apesar de ocasionar uma redução na sensibilidade do material à exposição da radiação beta, fez com que houvesse uma redução na dependência energética das amostras, conforme estudo realizado por Campos (1993).

González e Azorín (2001) estudaram e compararam o comportamento de dois materiais TL, LiF:Mg,Cu,P + Teflon, e LiF (comercialmente denominado de TLD-100, da 
Harshaw), expostos à radiação de ${ }^{90} \mathrm{Sr}+{ }^{90} \mathrm{Y}$, para se verificar a possibilidade de realização da dosimetria deste tipo de fonte. Os dois materiais apresentaram boa resposta a esta fonte e utilidade em sua dosimetria, observando-se que o primeiro material apresentou picos de emissão mais intensos e picos mais definidos em temperaturas mais altas, comparado ao LiF.

Em um outro estudo, Oliveira e Caldas (2004) estudaram o desempenho de diversos materiais TL: LiF (TLD-100, Harshaw), $\mathrm{CaF}_{2}$ :Dy (TLD-200, Harshaw), $\mathrm{CaF}_{2}: \mathrm{Mn}$ (TLD-400, Harshaw), $\mathrm{CaF}_{2}: \mathrm{Mn}$ fino (TLD-400 fino, Harshaw), $\mathrm{CaSO}_{4}:$ Dy fino (IPEN), $\mathrm{CaSO}_{4}: \mathrm{Dy}+10 \%$ de grafite (IPEN), e $\mathrm{CaSO}_{4}$ :Dy convencional (IPEN). Os testes diferentes de caracterização realizados demonstraram que todos os materiais apresentam boa aplicação em dosimetria beta, em especial os dosímetros finos, como o $\mathrm{CaF}_{2}: \mathrm{Mn}$ fino, $\mathrm{CaSO}_{4}$ :Dy fino (IPEN), e o $\mathrm{CaSO}_{4}: \mathrm{Dy}+10 \%$ de grafite (IPEN), que apresentaram os melhores resultados devido ao baixo poder de penetração das partículas beta na matéria.

Aplicando-se a conclusão dos resultados obtidos nos estudo de 2004, Oliveira e Caldas (2004; 2007) utilizaram pastilhas finas de $\mathrm{CaSO}_{4}$ :Dy na calibração de aplicadores clínicos de radiação beta de ${ }^{90} \mathrm{~S} r+{ }^{90} \mathrm{Y}$. A reprodutibilidade da resposta do material do dosímetro, as curvas de calibração obtidas e as taxas de dose absorvida comprovaram a eficiência do $\mathrm{CaSO}_{4}$ :Dy fino na calibração deste tipo de fonte.

Sendo assim, e levando-se em conta o grande número de aplicadores clínicos de ${ }^{90} \mathrm{Sr}+{ }^{90} \mathrm{Y}$ ainda em uso em São Paulo e em todo o Brasil, foi desenvolvido no LCl, por Antonio e Caldas (2009), um sistema dosimétrico de calibração de aplicadores contendo pastilhas finas de $\mathrm{CaSO}_{4}$ :Dy. Para a elaboração deste sistema, foram comparadas as taxas de dose absorvida obtidas com estes dosímetros TL e com uma mini-câmara de extrapolação, que foi utilizada como sistema absoluto na calibração das fontes. Concluiu-se que as pastilhas finas de $\mathrm{CaSO}_{4}$ :Dy poderiam ser utilizadas como um método alternativo e eficiente de calibração de aplicadores clínicos, evitando-se, assim, a necessidade do transporte das fontes ao $\mathrm{LCl}$ e validando, desta forma, o uso do sistema dosimétrico.

Outra técnica que vem sendo utilizada com eficiência em campos de radiação beta é a luminescência opticamente estimulada (LOE). Göksu e colaboradores (1995) realizaram um estudo de intercomparação entre diferentes laboratórios de calibração expondo quartzo à radiação beta de ${ }^{90} \mathrm{Sr}+{ }^{90} \mathrm{Y}$; este estudo foi realizado com as técnicas de TL e LOE. Os resultados obtidos apresentaram, além das propriedades TL e LOE do quartzo, uma 
diferença de até $\pm 3 \%$ entre as calibrações realizadas nos laboratórios e os valores de taxa de dose absorvida fornecidos nos certificados de calibração das fontes.

Anos depois, Akselrod e colaboradores (1999) estudaram as propriedades LOE de detectores de $\mathrm{Al}_{2} \mathrm{O}_{3}: \mathrm{C}$, em forma de pastilha e em pó, em campos de radiação beta de ${ }^{90} \mathrm{Sr}+{ }^{90} \mathrm{Y},{ }^{204} \mathrm{Tl}$ e ${ }^{147} \mathrm{Pm}$. Estes resultados foram comparados com resultados obtidos pela técnica TL. Os resultados demonstraram que o $\mathrm{Al}_{2} \mathrm{O}_{3}: \mathrm{C}$ em forma de pastilhas apresentou maior dependência energética.

Durham e colaboradores (2002) estudaram uma aplicação diferente para o uso de detectores LOE; neste caso, eles empregaram o $\alpha-\mathrm{Al}_{2} \mathrm{O}_{3}: \mathrm{C}$ como um dosímetro de extremidade em forma de anel. Este material é composto por três componentes $\left(\mathrm{Al}_{2} \mathrm{O}_{3}: \mathrm{C}\right.$ em pó, um substrato de alumínio que fornece a estrutura do anel, e uma cobertura de Mylar aluminizado que previne a exposição do $\mathrm{Al}_{2} \mathrm{O}_{3}: \mathrm{C}$ à luz). $\mathrm{O}$ desempenho verificado deste material como um dosímetro de extremidade comprovou a sua utilidade para a devida finalidade, mostrando que o anel, quando posicionado na direção da irradiação, mostra resultados satisfatórios.

Os detectores LOE também podem ser empregados em dosimetria pessoal, em feixes de radiação beta; é o que foi observado por Pinto e colaboradores (2008). Neste estudo, os autores caracterizaram amostras de $\mathrm{Al}_{2} \mathrm{O}_{3}: \mathrm{C}$ (Dot, Landauer), com a finalidade de verificar o desempenho deste material para a monitoração de trabalhadores expostos à radiação beta. Os resultados obtidos mostraram a grande possibilidade de aplicação deste material na dosimetria de extremidades de trabalhadores expostos a este tipo de radiação.

Yukihara e McKeever (2008), em um trabalho amplo, descreveram as diversas aplicações da dosimetria LOE na Medicina, fazendo distinção, inclusive, entre os principais modos de estimulação óptica: LOE contínua (continuous-wave OSL - CW-OSL), LOE de modulação linear (linear modulation OSL - LM-OSL) e LOE pulsada (pulsed OSL - POSL). Os resultados apresentados neste estudo mostram a possibilidade de aplicação do fenômeno de LOE em feixes de radioterapia e radiodiagnóstico (com diferentes fontes de radiação, incluindo radiação beta) e na dosimetria de partículas carregadas pesadas.

McKeever (2011) realizou um estudo com diferentes materiais dosimétricos, já conhecidos, para comprovar sua utilidade em dosimetria médica ( $\mathrm{KBr}$ :Eu) e espacial 
$\left(\mathrm{Al}_{2} \mathrm{O}_{3}: \mathrm{C}\right)$, e demonstrou que o estudo de processos básicos, como o conhecimento dos defeitos do cristal, determina em que situação o material pode ser aplicado.

Aydin e colaboradores (2013) utilizaram os fenômenos de TL e LOE para se verificar a viabilidade de $\mathrm{Li}_{2} \mathrm{~B}_{4} \mathrm{O}_{7}: \mathrm{Cu}$ como um detector para se medir doses de radiação beta em dosimetria pessoal. Para tal, os autores realizaram testes de caracterização da resposta do material, utilizando uma fonte de ${ }^{90} \mathrm{Sr}+{ }^{90} \mathrm{Y}$, como reprodutibilidade, linearidade, limite inferior de detecção e curvas de dose-resposta; todos os resultados obtidos comprovaram a eficiência do material em campos de radiação beta. 


\section{FundAMENTOS TEÓRICOS}

Neste capítulo, serão abordados os principais conceitos de fundamentação teórica relevante ao desenvolvimento deste trabalho.

\subsection{Processos de INTERAÇão da Radiação COM a Matéria}

A seguir, serão apresentadas as definições necessárias para se compreender os processos de interação da radiação de elétrons e fótons com a matéria.

\subsubsection{Interação de Elétrons com a Matéria}

No momento em que um elétron incidente atravessa um material, ocorre o processo de interação desta partícula carregada com o meio; nesta interação, o elétron pode transmitir toda a sua energia, ou parte dela, para um elétron orbital ou para o núcleo atômico, e pode também mudar de direção.

A perda de energia por parte do elétron ocorre por processos de colisão, que podem ser do tipo elástico ou inelástico. Numa colisão elástica, o elétron é deslocado de seu caminho sem sofrer perda de energia; na colisão inelástica, o elétron muda de direção e perde parte de sua energia cinética, que pode ser transferida para um elétron orbital ou ser emitida sob a forma de fótons, chamados de radiação de freamento (Bremsstrahlung) (KNOLL, 2000; PODGORSĂK, 2005). Quando um elétron se aproxima de um núcleo atômico, ocorre uma interação entre este elétron e o campo eletromagnético gerado pelo núcleo, acarretando então uma mudança na direção da trajetória do elétron, o qual é desacelerado e emite fótons de raios $X$ (Bremsstrahlung).

Quando ocorre a interação do elétron incidente com o elétron orbital, processos de ionização e excitação são observados. No processo de ionização, as partículas carregadas (alfa e beta) perdem sua energia para um elétron orbital, para que ele seja expulso do átomo e ocorra a sua ionização. No processo de excitação, as partículas também transferem sua energia a um elétron orbital, mas para que ele se desloque de um estado de energia baixa para um outro excitado (KNOLL, 2000; PODGORSǍK, 2005). 


\subsubsection{Interação de Fótons com a Matéria}

Os fótons, que podem ser Bremsstrahlung (raios $X$ de freamento), raios $X$ característicos, radiação gama ou radiação de aniquilação, interagem com os átomos de um material, quando o atravessam, e esta interação de fótons com a matéria depende da energia do fóton incidente, e do número atômico, densidade e espessura do absorvedor. Os principais processos de interação são: efeito fotoelétrico, espalhamento coerente, espalhamento Compton e produção de pares (PODGORSǍK, 2005; MAYLES, 2007).

O efeito fotoelétrico ocorre quando um fóton interage com um elétron orbital transferindo toda a sua energia para ele. O fóton deve fornecer energia suficiente ao elétron para afastá-lo do núcleo e, assim, este elétron deixa o átomo na forma de um fotoelétron. Nesta interação, o fóton desaparece e o átomo é ionizado, e este processo tem maior probabilidade de ocorrer quando a energia do fóton é menor que $100 \mathrm{keV}$.

O espalhamento coerente é um processo no qual o fóton interage com um elétron orbital ligado ao átomo, porém sem removê-lo da eletrosfera. Esta interação é considerada elástica, porque o fóton não tem uma perda significativa de energia e, por este motivo, este espalhamento não contribui para a deposição de energia no material absorvedor, mas apenas para um aumento da atenuação do fluxo de fótons incidente.

No espalhamento Compton, o fóton interage com um elétron livre, o qual é fracamente ligado ao átomo do material. Assim, uma parte da energia do fóton é cedida ao elétron, enquanto a outra parte permanece como raios gama ou $\mathrm{X}$ de energias baixas. Este efeito ocorre com maior frequência quando a energia do fóton é maior que $100 \mathrm{keV}$.

O processo de produção de pares ocorre quando um fóton de energia alta se aproxima de um núcleo atômico e é absorvido, dando origem a um par elétron-pósitron. Para que este efeito ocorra, a energia do fóton incidente deve corresponder no mínimo a duas vezes a energia de repouso do elétron (1,02 MeV).

\subsection{Fontes de RADIAÇÃo Beta}

As fontes de radiação beta são utilizadas, principalmente, para duas finalidades: 
a. Aplicação em Proteção Radiológica - na calibração de detectores de radiação, como é o caso das fontes que compõem os sistemas padrões secundários de radiação beta $\left({ }^{90} \mathrm{Sr}+{ }^{90} \mathrm{Y},{ }^{204} \mathrm{TI},{ }^{147} \mathrm{Pm} \mathrm{e}{ }^{85} \mathrm{Kr}\right)$;

b. Aplicação na Medicina - em tratamentos de lesões superficiais (procedimentos de betaterapia), como os aplicadores clínicos dermatológicos e oftálmicos de ${ }^{90} \mathrm{Sr}+{ }^{90} \mathrm{Y}$.

\subsubsection{Sistemas Padrões Secundários de Radiação Beta}

O sistema padrão secundário beta tipo 1 (BSS1) foi projetado há aproximadamente 35 anos no laboratório padrão primário do PTB, e comercializado pela empresa Buchler GmbH \& Co., na Alemanha. Ele foi desenvolvido para ser utilizado em proteção radiológica na calibração e na determinação da resposta de medidores de taxa de dose absorvida, em feixes de radiação beta de referência produzidos pelas fontes de ${ }^{90} \mathrm{Sr}+{ }^{90} \mathrm{Y},{ }^{204} \mathrm{Tl}$ e ${ }^{147} \mathrm{Pm}$, constituintes do BSS1 (AMBROSI e col., 2007). As fontes que constituem o BSS1 são calibradas e rastreáveis ao sistema padrão primário de radiação beta do PTB. As características, como a meia-vida e a energia, destas fontes podem ser observadas na Tabela 4.1.

Tabela 4.1 - Características das fontes de radiação beta dos sistemas BSS1 e BSS2.

\begin{tabular}{ccc}
\hline $\begin{array}{c}\text { Fonte de Radiação } \\
\text { Beta }\end{array}$ & $\begin{array}{c}\text { Energia Beta Média } \\
\text { (MeV) }\end{array}$ & $\begin{array}{c}\text { Meia-Vida } \\
\text { (Anos) }\end{array}$ \\
\hline${ }^{90} \mathrm{Sr}^{90} \mathrm{Y}$ & 0,80 & 28,50 \\
\hline${ }^{204} \mathrm{Tl}$ & 0,24 & 3,780 \\
\hline${ }^{85} \mathrm{Kr}$ & 0,14 & 10,76 \\
\hline${ }^{147} \mathrm{Pm}$ & 0,06 & 2,620 \\
\hline
\end{tabular}

A importância de se calibrar instrumentos de proteção radiológica em feixes de radiação beta padrões tem relação direta com o fato da necessidade da taxa de dose absorvida apresentar rastreabilidade a um padrão primário, conforme é descrito nas recomendações da ISO 6980-2 (2004) e como será citado no item 4.7 deste capítulo.

O sistema BSS1 do LCI/IPEN é composto por quatro fontes de radiação: duas fontes de ${ }^{90} \mathrm{Sr}+{ }^{90} \mathrm{Y}(74 \mathrm{MBq}$ e $1850 \mathrm{MBq}, 1981)$, uma fonte de ${ }^{147} \mathrm{Pm}$ (518 MBq, 1990) e uma fonte de ${ }^{204} \mathrm{TI}$ (18,5 MBq, 1990), e instrumentos para o posicionamento delas (Fig. 4.1.a). Além disso, este sistema apresenta um filtro uniformizador de campo para cada uma das fontes de 
${ }^{90} \mathrm{Sr}+{ }^{90} \mathrm{Y}(74 \mathrm{MBq}),{ }^{147} \mathrm{Pm}$ e ${ }^{204} \mathrm{Tl}$. Uma unidade de controle é responsável pelo processo de abertura e fechamento da fonte, que determina que ela fique ou não exposta (Fig. 4.1.b). Para tal, a fonte deve ser posicionada no seu suporte, localizado num sistema constituído pela fonte, um suporte de acrílico onde são posicionados os detectores ou dosímetros, e um trilho, que permite a variação da distância fonte-detector (Fig. 4.1.c).

Devido ao fato da fonte de ${ }^{204} \mathrm{Tl}$ apresentar meia-vida relativamente curta $(3,78$ anos) e atividade nominal baixa (18,5 MBq), o seu decaimento radioativo pode ser considerado rápido quando se refere à necessidade do uso desta fonte. Além disso, em 1994 a empresa Buchler encontrou problemas no fornecimento destas fontes. Estes motivos fizeram com que a ideia de um novo sistema padrão secundário de radiação beta, de tipo 2 , fosse colocada em prática; então, em 1998 o sistema BSS2, desta vez comercializado pela Isotrak (QSA Global GmbH \& Co.), entrou em operação, com um novo modelo e algumas diferenças com relação ao sistema BSS1, como por exemplo a substituição da fonte de ${ }^{204} \mathrm{TI}$ por uma de ${ }^{85} \mathrm{Kr}$, e o acompanhamento de um software, necessário para a configuração do programa que possibilita o uso do sistema BSS2.

O sistema BSS2 do LCI/IPEN é constituído por três fontes de radiação: uma fonte de ${ }^{90} \mathrm{Sr}+{ }^{90} \mathrm{Y}(460 \mathrm{MBq}, 2005)$, uma fonte de ${ }^{147} \mathrm{Pm}(3,7 \mathrm{GBq}, 2005)$, e uma fonte de ${ }^{85} \mathrm{Kr}(3,7 \mathrm{GBq}$, 2005); estas fontes também possuem certificado de calibração do PTB. Uma unidade de controle envia as informações para o sistema, e permite a constatação da abertura ou não da fonte (no BSS2, as próprias fontes possuem um obturador que permite sua exposição) (Fig. 4.2.a). Uma maleta acompanha o sistema BSS2, e é composta por ferramentas para a manutenção e um eventual ajuste das peças do sistema, um filtro uniformizador de campo para cada uma das fontes (usado de acordo com a distância adotada na calibração da fonte pelo PTB), e um instrumento para o posicionamento das fontes (Fig. 4.2.b). Além disso, o sistema no qual a fonte é posicionada (Fig. 4.2.C) apresenta sensores medidores de temperatura, pressão e umidade, e um goniômetro acoplado ao trilho (para o estudo de dependência angular dos detectores ou dosímetros), o que não havia no sistema anterior. A energia média e a meia-vida das fontes que constituem os sistemas BSS1 e BSS2 podem ser observadas na Tabela 4.1. 

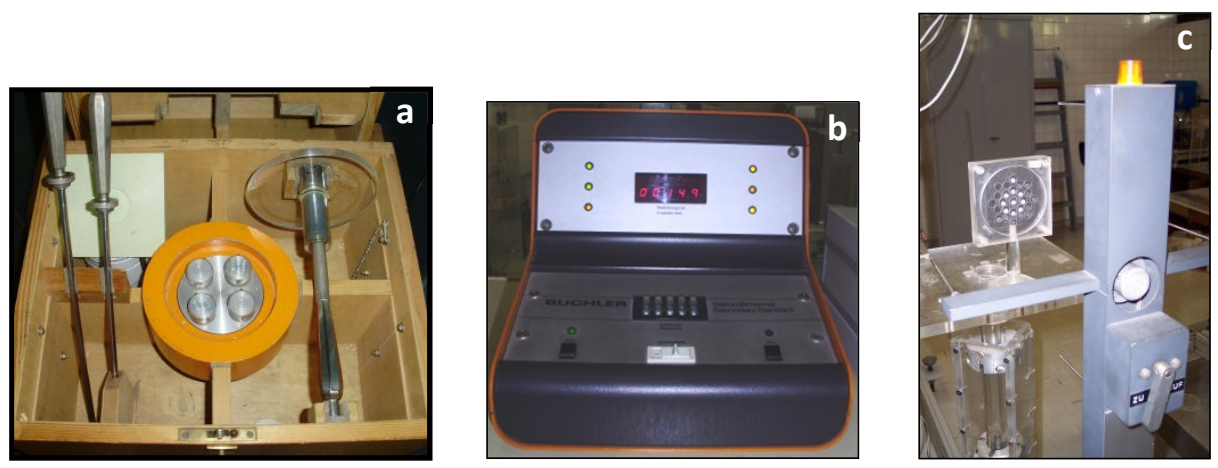

Figura 4.1 - Sistema padrão secundário beta 1 (BSS1): (a) fontes de radiação beta e instrumentos para o seu posicionamento; (b) unidade de controle; e (c) sistema de suporte para a fonte (porta-fonte).
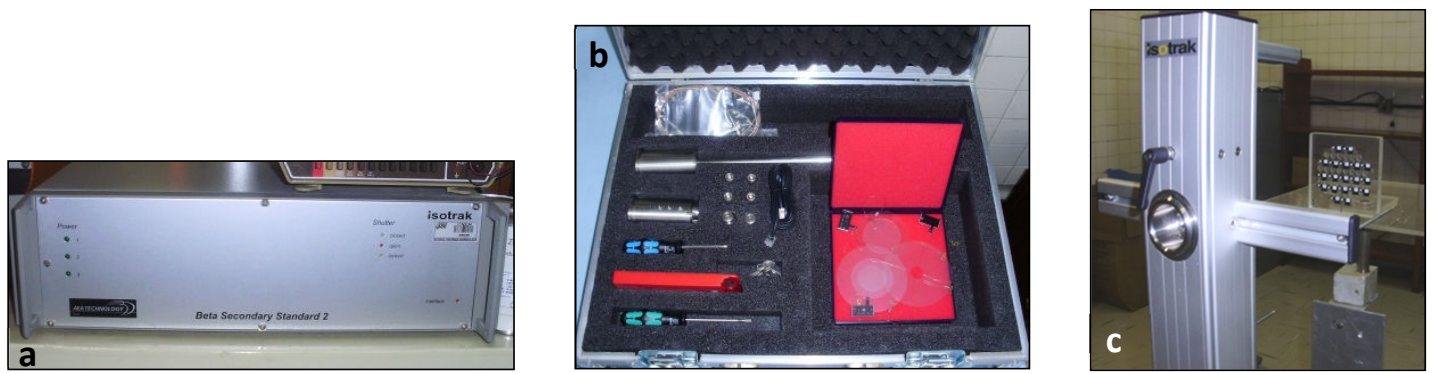

Figura 4.2 - Sistema padrão secundário beta 2 (BSS2): (a) unidade de controle; (b) maleta com os instrumentos para o posicionamento das fontes, filtros uniformizadores de campo e ferramentas para manutenção do sistema; e (c) sistema de suporte para a fonte (portafonte).

As fontes de radiação beta dos sistemas BSS1 e BSS2 devem obedecer a todas as condições adotadas e especificadas nos seus certificados de calibração, como utilização ou não de filtro uniformizador de campo e distância fonte-detector. O uso correto destas especificações implica na garantia de que os campos padrões de referência produzidos pelas fontes tenham as mesmas características dos campos padrões a que são rastreáveis (BÖHM, 1986).

Desde os seus desenvolvimentos, os sistemas BSS1 e BSS2 vêm sendo utilizados e estudados em diversos trabalhos e para diversas aplicações, tanto para a calibração de detectores de radiação ou até mesmo de dosímetros, para fins de proteção radiológica, como na caracterização de diferentes câmaras de ionização e dosímetros, com propósitos de diversos estudos (CALDAS, 1980; HELMSTÄDTER e col., 2004; AMBROSI e col., 2007; BEHRENS e col., 2007). 


\subsubsection{Aplicadores Clínicos de ${ }^{90} \mathrm{Sr}+{ }^{90} \mathrm{Y}$}

A utilização dos aplicadores clínicos teve início no século $X X$, em operações de braquiterapia denominadas betaterapia (procedimento no qual uma fonte de radiação beta é colocada em contato com a lesão, ocasionando a irradiação do tecido). Devido ao grande poder de ionização de suas partículas e do seu pequeno alcance no tecido, a radiação beta começou a ser empregada em tratamentos superficiais (SCAFF, 1979).

Estas fontes de radiação apresentam muitas aplicações, como para tratamento de úlceras oftálmicas, melanomas cancerígenos, e pterígios, em casos de problemas oftálmicos, e câncer de pele, queloides, correções pós-operatórias, ou diminuição de cicatrizes hipertróficas (fins estéticos), em casos de tratamentos dermatológicos (LEDERMAN, 1956).

Anteriormente aos aplicadores clínicos (comumente chamados também de placas) de ${ }^{90} \mathrm{Sr}+{ }^{90} \mathrm{Y}$, as fontes de ${ }^{226} \mathrm{Ra}$ foram utilizadas por muitos anos. Este elemento era depositado em um bulbo de vidro com paredes finas o suficiente para permitir a emissão de partículas beta. Entretanto, era difícil de conseguir bulbos de vidro com paredes de espessuras idênticas, o que dificultava a determinação da dose de radiação beta desejada. Devido a este fator, e também à presença de raios gama indesejáveis nos feixes de radiação beta do ${ }^{226} \mathrm{Ra}$, estes aplicadores foram substituídos (JOHNS e CUNNINGHAM, 1974).

Assim, os aplicadores clínicos de ${ }^{90} \mathrm{Sr}+{ }^{90} \mathrm{Y}$ foram apresentados em 1950, quando Friedell e colaboradores (1950) descreveram um modelo e colocaram em prática o uso destas fontes, que passaram a ser utilizadas por apresentaram certas vantagens em relação às fontes de ${ }^{226}$ Ra: ausência dos produtos de decaimento gasosos, curto alcance das partículas beta e baixa contaminação gama (SINCLAIR e TROTT, 1956).

Os aplicadores clínicos de ${ }^{90} \mathrm{Sr}+{ }^{90} \mathrm{Y}$ apresentam uma cobertura de prata, uma camada fina que serve de proteção para o aplicador, e também para absorver as partículas de energias mais baixas do ${ }^{90} \mathrm{Sr}$, enquanto as partículas emitidas pelo ${ }^{90} \mathrm{Y}$ são usadas terapeuticamente. Embora os aplicadores de ${ }^{90} \mathrm{Sr}+{ }^{90} \mathrm{Y}$ consistam de fontes seladas, o seu uso rotineiro pode danificar as fontes. Este fato, juntamente com a limpeza inadequada das fontes após a sua utilização (o uso destas fontes se dá pelo seu contato direto com o paciente), pode acarretar perda do material (fonte radioativa) depositado no aplicador, pois a camada de prata fica desgastada. Por este motivo também, a calibração deste tipo de fonte torna-se indispensável, pois resulta na determinação da taxa de dose absorvida da 
fonte, a ser utilizada pelos usuários. Este fato garante o êxito do tratamento do paciente, além de outros parâmetros físicos como a distância fonte-lesão, o tamanho do campo de radiação, a dose total a ser administrada e o seu fracionamento.

De maneira geral, os aplicadores clínicos de ${ }^{90} \mathrm{Sr}+{ }^{90} \mathrm{Y}$ apresentam uma haste metálica (que serve para o operador manusear o aplicador), um protetor de acrílico próximo à fonte (para proteção das mãos do operador) e a fonte radioativa, depositada em uma das extremidades do aplicador. O formato do local onde é depositado o material radioativo pode ser plano ou côncavo, dependendo da finalidade do aplicador: dermatológico ou oftálmico. Existem aplicadores clínicos que não possuem a proteção de acrílico, e outros ainda que possuem a fonte móvel, para facilitar o manuseio da fonte durante o tratamento. Diferentes esquemas de aplicadores clínicos podem ser observados nas Fig. 4.3 e 4.4.
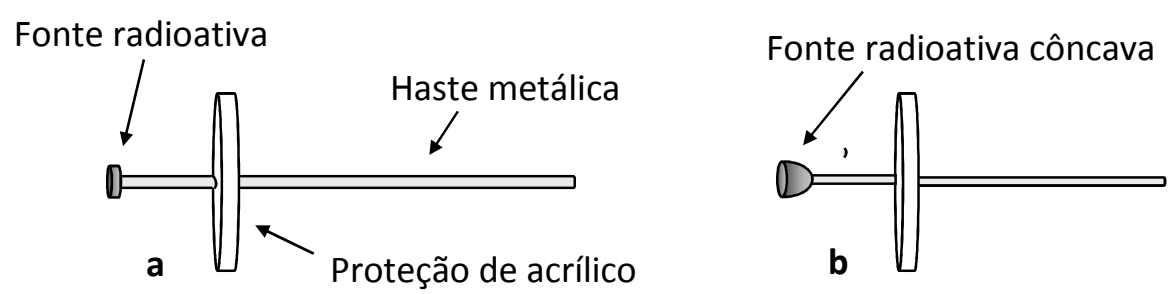

Figura 4.3 - Esquema de aplicadores clínicos convencionais: (a) dermatológico; e (b) oftálmico, mostrando a localização da fonte radioativa, a haste metálica e a proteção de acrílico.
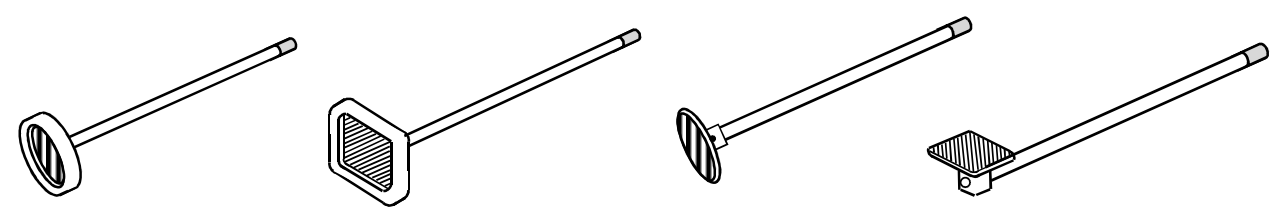

Figura 4.4 - Outros modelos de aplicadores clínicos de ${ }^{90} \mathrm{Sr}+{ }^{90} \mathrm{Y}$ (baseado em Scaff (1979)).

\subsection{CÂMARAS de IONIZAÇÃo}

A dose absorvida presente em um meio ou material que foi submetido à radiação ionizante deve ser medida; nisso se baseia a dosimetria das radiações, pois a grandeza dose absorvida representa a energia absorvida depositada em uma determinada massa. Os instrumentos apropriados para esta medição são os detectores de radiação, também denominados dosímetros (ATTIX, 2004; STABIN, 2008; PODGORSǍK, 2010). 
As câmaras de ionização consistem nos detectores de radiação mais antigos e mais utilizados. Estes instrumentos, que são fabricados e comercializados de diferentes formas e para diversas aplicações, e que apresentam manuseio simples, precisão e fácil compreensão de seu processo físico, baseiam-se nos efeitos que são produzidos quando uma partícula carregada passa através de certo volume de gás; por este motivo, recebem o nome de detectores a gás (KNOLL, 2000; ATTIX, 2004; AHMED; 2007).

As câmaras de ionização podem ser de dois tipos: câmaras de ar livre e câmaras cavitárias. As câmaras de ar livre são detectores padrões, também chamados de absolutos. Elas permitem a medição da dose absorvida no meio sem a necessidade de que ela esteja calibrada em feixes padrões de radiação. Este tipo de câmara de ionização tem grande utilidade na calibração de outros tipos de detectores, e é adotada como padrão primário na determinação da grandeza kerma no ar para raios $\mathrm{X}$ superficiais (de energias baixas) e de ortovoltagem (acima de $400 \mathrm{kV}$ ). Também pode ser considerada padrão primário para feixes de ${ }^{60} \mathrm{Co}$, mas desde que a condição de equilíbrio eletrônico seja estabelecida (ATTIX, 2004; PODGORSǍK, 2005).

O equilíbrio eletrônico é um fator de grande importância para as câmaras de ionização, pois é alcançado quando o número de elétrons que saem do volume sensível da câmara, e não depositam toda a sua energia nela, compensa o número de elétrons que entram com as mesmas características dos que saíram (BOAG, 1987).

As câmaras cavitárias são as mais comuns. Ao contrário das câmaras de ar livre, que devem ser grandes para que haja uma espessura grande de ar anteriormente ao volume sensível da câmara (garantia do equilíbrio eletrônico), as câmaras cavitárias podem variar na sua forma, dimensão e até mesmo volume sensível (de acordo com as finalidades à quais se destinam), não sendo necessário serem tão grandes, pois o equilíbrio eletrônico é facilmente alcançado quando o feixe atravessa a parede da câmara, que pode também ser coberta com uma capa extra, dependendo da energia da radiação incidente (BOAG, 1987).

Estas câmaras consistem basicamente de paredes, que as delimitam e podem variar de material, e de uma determinada massa de gás que preenche este volume, e podem ser empregadas na detecção de radiações alfa, beta, $X$, gama e fragmentos de fissão, e em diferentes aplicações, como na dosimetria das radiações, calibração de detectores, controle de qualidade em mamografia e tomografia, entre outras. As formas mais comuns das 
câmaras cavitárias são as esféricas, as cilíndricas (dedais) e as de placas paralelas. (ATTIX, 2004; AHMED; 2007; PODGORSǍK, 2010).

O princípio físico das câmaras de ionização é simples. Estas câmaras possuem dois eletrodos coletores que devem ser condutores (eletrodo central e janela de entrada), que são envoltos por uma parede que delimita uma cavidade de gás (volume ativo, ou sensível, da câmara). Uma estrutura denominada anel de guarda auxilia na definição do volume sensível da câmara. Quando as partículas carregadas atravessam o primeiro eletrodo (janela de entrada) e o gás do volume, ionizações e excitações são produzidas no interior do volume. Com a ionização das moléculas neutras do gás, dois elementos são formados: elétrons livres e íons positivos. Aplicando-se uma tensão entre a janela de entrada e a parede da câmara, o campo elétrico produzido faz com que os elétrons migrem em direção ao eletrodo central, sendo coletados, e os íons migrem em direção à parede, produzindo pulsos elétricos (KNOLL, 2000; ATTIX, 2004; AHMED, 2007).

A medição da câmara de ionização (intensidade do sinal de saída), obtida a partir da interação da radiação com o gás da cavidade, é diretamente proporcional à quantidade de íons coletados e, desta forma, ela dependerá do número de pares de íons produzidos no gás.

\subsubsection{Teoria da Cavidade}

Para se medir a dose absorvida em um meio, é necessária a introdução de um detector ou dosímetro sensível à radiação. É a relação entre a dose absorvida no detector sensível à radiação (cavidade) e a dose absorvida no meio que circunda o detector (meio no qual o dosímetro é introduzido), que solidifica o uso das câmaras de ionização em dosimetria das radiações. A este princípio dá-se o nome de "Teoria da Cavidade" (PODGORSǍK, 2005; AHMED, 2007).

Entretanto, quando se introduz um dosímetro, pode haver um desequilíbrio no meio no qual ele foi introduzido, devido a certas diferenças, como tamanho, composição e número atômico. Este problema é resolvido por meio da teoria da cavidade. Deste modo, é necessário se conhecer a teoria apropriada para cada caso, que será determinada pelo tamanho da cavidade quando comparado ao alcance dos elétrons em um determinado meio (AHMED, 2007). 
O primeiro modelo de teoria cavitária foi estabelecido por W. H. Bragg e L. H. Gray. Após diversos estudos realizados por Bragg em 1910, e por Gray em 1929, foi apresentada, em 1936, a "Teoria de Bragg-Gray" (ATTIX, 2004; AHMED, 2007). Esta teoria é adotada em cavidades pequenas, e é baseada em duas condições: 1) a cavidade deve ser pequena em relação ao alcance das partículas geradas pela radiação ionizante (para que a sua introdução no meio não desequilibre o campo das partículas carregadas; 2) a energia depositada na cavidade deve ser proveniente apenas das partículas que a atravessam. Partindo-se do princípio destas condições, Bragg e Gray estabeleceram a Equação 4.1 (ATTIX, 2004):

$$
D_{\text {meio }}=\frac{m S_{\text {meio }}}{m S_{c a v}} D_{c a v}
$$

onde: $D_{\text {meio }}$ é a dose absorvida no meio que circunda a cavidade (Gray, (Gy)), $D_{\text {cav }}$ é a dose absorvida no detector (cavidade), $m S_{\text {meio }}$ é o poder de freamento de massa no meio, e $m S_{c a v}$ é o poder de freamento de massa na cavidade.

Entretanto, nem sempre é possível aplicar as condições estabelecidas por Bragg e Gray, pois em alguns casos um detector pode não apresentar uma cavidade muito pequena. Por este motivo, outras teorias foram propostas.

Como a teoria de Bragg-Gray não considerou o fato de que as colisões de elétrons primários produzem elétrons de altas energias, os chamados raios delta $(\delta)$, que ocorrem quando partículas carregadas atravessam a cavidade e depositam energia fora do volume de interesse e colidem entre si, uma nova teoria foi estudada e aplicada por L. V. Spencer e F. H. Attix, em 1955 (ATTIX, 2004; AHMED, 2007).

A teoria de Spencer-Attix, aplicada em detectores de cavidades pequenas, considera uma energia de corte (energia $\Delta$ ), a qual representa a energia cinética necessária para que elétrons possuam alcance igual ao tamanho médio da cavidade, e tenham energia suficiente para atravessarem esta cavidade (ATTIX, 2004; AHMED, 2007). A relação que demonstra a dose absorvida, por meio da teoria de Spencer e Attix, pode ser observada na Equação 4.2 (PODGORSǍK, 2005):

$$
\frac{D_{\text {meio }}}{D_{c a v}}=S_{\text {meio,cav }}
$$


onde: $s_{\text {meio ,av }}$ é a relação entre os poderes de freamento de massa do meio e da cavidade.

Conforme as teorias apresentavam limitações para algumas situações, outras teorias foram sendo criadas, buscando-se suprir as deficiências encontradas nas anteriores. T. E. Burlin, em 1966, formulou a teoria que atualmente é a mais utilizada: a "Teoria da Cavidade de Burlin" ou "Teoria da Cavidade Geral" (ATTIX, 2004).

A teoria de Burlin, proposta para todos os tamanhos de cavidades, trata-se, na realidade, de uma extensão das teorias de Bragg-Gray e de Spencer-Attix para cavidades maiores, para as quais a influência da parede é insignificante. Esta teoria leva em conta a atenuação dos elétrons gerados no meio e o aumento dos elétrons gerados na cavidade (ATTIX, 2004). Para que esta teoria seja aplicada, algumas condições devem ser estabelecidas, como: o material do detector e o meio que o circunda têm que ser homogêneos; um equilíbrio entre as partículas carregadas deve existir em todos os pontos no detector e no meio; e o equilíbrio dos espectros dos elétrons secundários no meio e no detector deve ser o mesmo (PODGORSǍK, 2005). A teoria de Burlin é dada pela Equação 4.3:

$$
\frac{D_{\text {meio }}}{D_{c a v}}=\left[d_{m} \frac{m S_{\text {meio }}}{m S_{c a v}}+(1-d) \frac{\left(\mu_{e n} / \rho\right)_{\text {meio }}}{\left(\mu_{e n} / \rho\right)_{c a v}}\right] D_{c a v}
$$

onde: $\left(\mu_{e n} / \rho\right)$ é o coeficiente de absorção de energia de massa do meio ou da cavidade, e $d$ é um fator que depende do tamanho da cavidade e é dado pela Equação 4.4 (ATTIX, 2004; PODGORSǍK, 2005):

$$
d=\frac{1-e^{-\beta g}}{\beta g}
$$

onde: $\beta$ é o coeficiente de atenuação de massa efetivo para elétrons, e $g$ é o caminho médio livre para os elétrons que atravessam a cavidade.

\subsubsection{Caracterização da Resposta de Câmaras de Ionização}

Quando uma câmara de ionização é exposta à radiação, é necessário que ela esteja em boas condições de operação, para que possa corresponder à finalidade para a qual é aplicada. Assim, a resposta de uma câmara deve ser adequada o suficiente para possibilitar o 
seu uso em campos diferentes de radiação. A garantia da boa funcionalidade de uma câmara de ionização pode ser determinada por meio de testes de caracterização de sua resposta.

Não há na literatura uma norma específica que indique os limites aceitáveis para a maioria dos testes de caracterização de câmaras de ionização expostas à radiação beta. Por este motivo, serão considerados, neste trabalho, os limites recomendados pela IEC, de acordo com a IEC 60731 (2011), que trata de equipamentos médico-eletrônicos, como as câmaras de ionização, para uso em radioterapia. Decidiu-se seguir os limites estabelecidos nesta recomendação, pois eles são considerados os mais rigorosos, por se tratar de uso em radioterapia.

Os diversos testes de caracterização da resposta de uma câmara estão descritos a seguir.

\subsubsection{Corrente de Fuga}

O teste de corrente de fuga tem o propósito de verificar a presença da corrente de ionização que representa algum sinal que não seja proveniente dos processos de ionização que ocorrem no volume sensível da câmara. Desta forma, é possível verificar se há fuga da corrente na câmara, nos cabos que ligam a câmara ao eletrômetro, ou no eletrômetro. Este teste deve ser realizado fazendo-se medições com a câmara sem que ela esteja exposta à radiação.

No caso do teste de corrente de fuga, a International Electrotechnical Commission (IEC), de acordo com a IEC 60731 (2011), recomenda que esta corrente não deve exceder 0,5\% do maior valor de corrente de ionização produzida durante uma irradiação.

\subsubsection{Curva de Saturação}

O teste de saturação é muito importante porque representa a determinação da melhor tensão de operação da câmara de ionização. Esta tensão de polarização deve ser suficiente para coletar todos os íons primários produzidos pela interação da radiação incidente com o gás contido no volume ativo da câmara.

Com o teste de saturação, é possível determinar-se a corrente de saturação. Com o aumento da diferença de potencial que é aplicada aos eletrodos de uma câmara de ionização, a corrente de ionização coletada aumenta logo nos primeiros valores de tensão de 
polarização, geralmente de forma linear, e este aumento vai diminuindo até a corrente atingir um valor praticamente constante com o aumento da tensão. Esta corrente de ionização representa a corrente de saturação, que seria medida se todos os íons formados na câmara fossem coletados pelos eletrodos (CALDAS, 1980).

A partir da curva de saturação, é possível verificar o efeito de polaridade da tensão, e determinar a eficiência de coleção de íons, e a recombinação iônica.

O efeito de polaridade na resposta da câmara quantifica a variação da corrente de ionização medida com a mudança da polaridade da tensão aplicada à câmara, que ocorre devido à presença de forças eletromotrizes térmicas, eletrolíticas ou de contato, no circuito de medição (CALDAS, 1980). O valor recomendado pela IEC 60731 (IEC, 2011) para este efeito é de até $1,0 \%$.

A eficiência de coleção de íons representa a razão entre a corrente medida com uma câmara de ionização, operando em certas condições, e a corrente de saturação ideal, conforme pode ser observado na Equação 4.5 (IAEA, 2000a):

$$
f=\frac{\left(V_{1} / V_{2}\right)^{2}-1}{\left(V_{1} / V_{2}\right)^{2}-\left(M_{1} / M_{2}\right)}
$$

onde: $f$ é a eficiência de coleção de íons, $M_{1}$ e $M_{2}$ são os valores das medições de carga, e $V_{1}$ e $V_{2}$ são os valores positivo e negativo de tensão.

No caso da câmara de extrapolação, a eficiência de coleção de íons foi obtida por meio da razão entre a corrente de ionização média para cada tensão de polarização aplicada e a corrente de saturação, conforme pode ser observado na Equação 4.6 (CALDAS, 1980; BÖHM, 1986):

$$
f=\frac{I}{I_{S}}
$$

onde: $I$ é a corrente de ionização média obtida em cada tensão de polarização aplicada (para ambas as polaridades positiva e negativa de tensão), e $I_{S}$ é a corrente de saturação.

O limite estabelecido pela IEC 60731 (IEC, 2011) para o teste de eficiência de coleção de íons é de 99,0\%, que possui relação direta com a recombinação iônica, que não deve ultrapassar 1,0\% (IEC, 2011). A recombinação iônica indica as condições ideais de operação 
de uma câmara de ionização, pois ocorre quando íons positivos e negativos, formados na interação da radiação com o meio, encontram-se e recombinam. Existem dois tipos de recombinação iônica, a colunar e a volumétrica. Quando íons de sinais opostos se encontram ao longo da trajetória na qual foram criados, ocorre a recombinação colunar; caso os íons se encontrem em trajetórias diferentes, ocorre a recombinação volumétrica. $\mathrm{O}$ resultado obtido neste teste de caracterização revela a perda por recombinação iônica que ocorre quando há saturação da corrente de ionização.

\subsubsection{Tempo de Estabilização}

O teste do tempo de estabilização da câmara é necessário para se verificar a estabilidade da resposta da câmara quando ela é exposta a um feixe de radiação. De acordo com a IEC 60731 (IEC, 2011), a variação da resposta neste teste, que deve ser realizado durante intervalos de tempo compreendidos entre 15 min e 2 horas, não deve exceder 0,5\%.

\subsubsection{Estabilidade de Resposta}

O teste de estabilidade da resposta da câmara permite avaliar o modo como as respostas são obtidas após a exposição da câmara a uma fonte de radiação (geralmente uma fonte de controle). Para que este teste seja desempenhado com eficiência e se possa atingir o resultado esperado, é necessário que ele ocorra em condições que cooperem para a reprodutibilidade das medições, como o uso de um sistema de posicionamento para a fonte de controle e a obediência ao arranjo experimental. Este teste pode ser de dois tipos: estabilidade a curto e a longo prazo.

A estabilidade a curto prazo (teste de repetibilidade) é obtida realizando-se 10 medições consecutivas com a câmara e a fonte. O teste de estabilidade a longo prazo (teste de reprodutibilidade) consiste em se avaliar a estabilidade da resposta da câmara ao longo de um determinado tempo, por meio de vários testes de repetibilidade periódicos. De acordo com a IEC 60731 (IEC, 2011), o limite aceitável para o primeiro teste é de 0,3\%, e para o segundo é de $0,5 \%$. 


\subsubsection{Linearidade de Resposta}

O teste de linearidade da resposta de uma câmara tem o objetivo de verificar o comportamento e o desempenho do detector quando ele é submetido a uma irradiação; neste caso, a resposta da câmara (dada em carga elétrica) deve ser linear em função do tempo de irradiação. Por este motivo, é importante que o resultado deste teste apresente fator de correlação $\left(R^{2}\right)$ o mais próximo possível de 1,0.

\subsubsection{Dependência Angular}

Com o teste de dependência angular é possível verificar-se o comportamento da câmara de ionização em função do ângulo de incidência da radiação. Este teste também é importante para se observar o efeito que pequenos erros de posicionamento da câmara em frente à fonte de radiação acarretam na resposta do detector (MAIA, 2005; OLIVEIRA, 2005).

\subsubsection{Dependência Energética}

O teste de dependência energética possibilita a avaliação do desempenho da câmara de ionização em campos de radiação com energias diferentes, e a verificação de uma possível variação na resposta da câmara nestes feixes diferentes. Como o resultado deste teste se dá na forma de coeficientes de calibração, pois a câmara é calibrada durante este procedimento, o valor da dependência energética pode ser determinado pela razão entre o maior e o menor coeficiente de calibração (em porcentagem), obtidos entre todas as fontes (MAIA, 2005; OLIVEIRA, 2005).

\subsubsection{Variação da Resposta da Câmara com a Distância Fonte-Detector}

Este estudo tem a finalidade de se observar a ocorrência da variação na resposta da câmara de ionização de acordo com a distância entre ela e a fonte de radiação. Este teste contribui, além disso, para se verificar o intervalo da validade da lei do inverso do quadrado da distância da resposta da câmara para o feixe de radiação beta (CALDAS, 1980). 


\subsection{CÂmARA DE Extrapolação}

As câmaras de ionização do tipo placas paralelas, em geral, possuem volume sensível fixo. Entretanto, há um modelo deste tipo que apresenta volume variável: é a câmara de extrapolação.

O volume sensível de uma câmara de placas paralelas é localizado entre a janela de entrada da câmara, que é um dos eletrodos, e o outro eletrodo que é coletor e é circundado por um anel de guarda, de maneira que os eletrodos fiquem em posição paralela. No caso da câmara de extrapolação, que pode ser observada na Fig. 4.5, a estrutura física do instrumento é a mesma, porém, a distância intereletródica (também denominada profundidade da câmara), e portanto o volume sensível, pode variar por meio de um parafuso micrométrico, presente neste tipo de câmara.

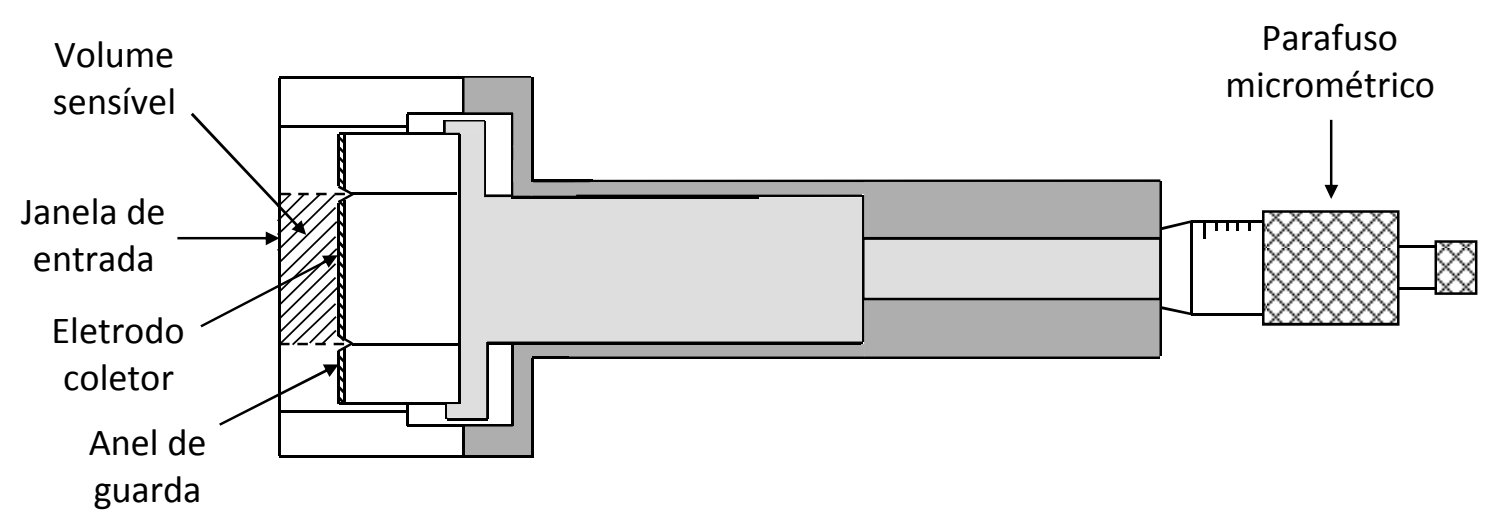

Figura 4.5 - Esquema de uma câmara de extrapolação (Adaptado de Dias (DIAS, 1996)).

A janela de entrada da câmara de extrapolação, também denominada eletrodo de alta tensão, deve ser constituída por uma folha fina de um material que colabore para a minimização da atenuação da radiação ou do espalhamento, e deve apresentar boa resistência mecânica; ela é presa por um anel enrijecido (ATTIX, 2004).

O anel de guarda da câmara de ionização tem duas finalidades: 1) impedir a fuga da corrente de ionização, e 2) definir o volume dentro da câmara suficiente para que os íons gerados alcancem o eletrodo coletor.

A câmara de extrapolação é útil para a detecção de radiação beta e $X$ de energias baixas, e é empregada na determinação de taxas de dose absorvida. Além disso, esta câmara 
pode ser utilizada como um sistema padrão primário ou secundário em dosimetria de feixes de radiação beta e $X$.

A dose superficial no centro da janela de entrada da câmara pode ser estimada medindo-se a corrente de ionização em função da variação da distância intereletródica, e extrapolando-se a curva obtida para a distância nula.

\subsubsection{Câmara de Extrapolação Böhm}

A câmara de extrapolação Böhm, fabricada e comercializada pela PTW (PTW, 2002), foi inicialmente proposta por Jürgen Böhm, que demonstrou o seu uso como sistema padrão primário para a determinação de taxas de dose absorvida para fontes de radiação beta (BÖHM, 1986). Desde então, esta câmara de extrapolação comercial tem sido usada como sistema padrão primário na calibração e dosimetria de fontes beta por diferentes laboratórios padrões primários, como o NIST, nos Estados Unidos, o PTB, na Alemanha, o NPL, na Inglaterra, e o D. I. Mendeleyev Institute for Metrology (VNIIM), na Rússia. A Tabela 4.2 apresenta as principais características da câmara de extrapolação Böhm. Na Fig. 4.6 pode ser observado o esquema da câmara de extrapolação Böhm, com todos os seus componentes.

Tabela 4.2 - Características da câmara de extrapolação Böhm (PTW, 2002).

\begin{tabular}{ccc}
\hline Câmara de Extrapolação & \multicolumn{2}{c}{ Características } \\
\hline Corpo & Material & Alumínio \\
\hline \multirow{2}{*}{ Janela de Entrada } & Material & $\begin{array}{c}\text { Hostaphan, } \\
\text { coberto com grafite }\end{array}$ \\
\cline { 2 - 3 } & Densidade Superficial $\left(\mathrm{mg} / \mathrm{cm}^{2}\right)$ & 0,71 \\
\cline { 2 - 3 } & Diâmetro $(\mathrm{mm})$ & 60,5 \\
\hline \multirow{2}{*}{ Eletrodo Coletor } & Material & $\begin{array}{c}\text { Polimetilmetacrilato } \\
\text { (PMMA) grafitado }\end{array}$ \\
\cline { 2 - 3 } & Diâmetro $(\mathrm{mm})$ & 30 \\
\cline { 2 - 3 } Anel de Guarda & Área $\left(\mathrm{cm}^{2}\right)$ & 0,35 \\
\cline { 2 - 3 } & Espessura $(\mathrm{mm})$ & 0,2 \\
\hline Parafuso Micrométrico & Intervalo da Profundidade da Câmara $(\mathrm{mm})$ & $0,5-10,5$ \\
\hline
\end{tabular}




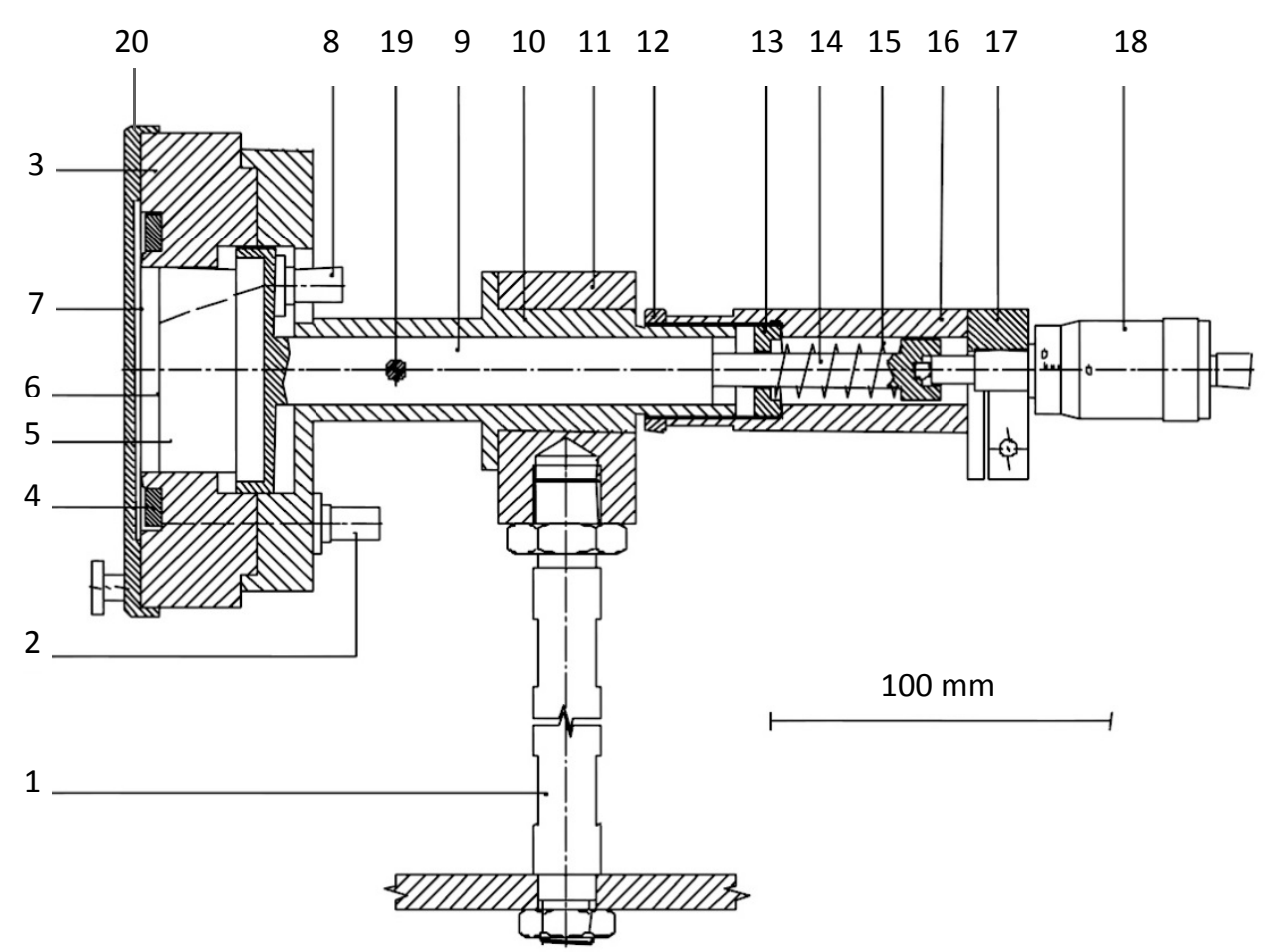

Figura 4.6 - Esquema da câmara de extrapolação Böhm: (1) haste de fixação da câmara no sistema de irradiação, (2) conector para tensão de polarização, (3) anel de acrílico para a formação da cavidade (volume sensível) e posicionamento da janela de entrada, (4) anel de fixação da janela de entrada, (5) bloco de acrílico, (6) superfície grafitada do bloco de acrílico (formando o eletrodo coletor e o anel de guarda), (7) janela de entrada, (8) conector para medições de corrente de ionização (ligado ao eletrômetro), (9) êmbolo para sustentação do conjunto de eletrodo coletor e ajuste de distância entre os eletrodos, (10) estrutura central que sustenta o anel de acrílico (3) e o conjunto de ajuste de distância entre os eletrodos (por meio de abertura do parafuso micrométrico), (11) anel de acoplamento da estrutura central e haste de fixação, (12) porca de travamento do conjunto de ajuste de distância entre os eletrodos, (13) anel roscado para fixação da mola de recuo, (14) parafuso de acoplamento do êmbolo com o conjunto de ajuste de distância entre os eletrodos, (15) mola de recuo do conjunto do êmbolo, (16) cilindro externo do conjunto de ajuste de distância entre os eletrodos, (17) base de fixação do parafuso micrométrico ao cilindro externo (16), (18) parafuso micrométrico para ajuste de distância entre os eletrodos, (19) parafuso de travamento para transporte da câmara, (20) capa de proteção da janela de entrada (Adaptado de PTW (PTW, 2002)). 


\subsubsection{Determinação da Corrente de Ionização}

Em cada profundidade, ou volume sensível, da câmara de extrapolação, devem ser tomados valores de corrente de ionização em ambas as polaridades positiva e negativa de tensão. Este procedimento deve ocorrer devido à presença de uma corrente negativa, produzida a partir da interação das partículas beta com o eletrodo coletor, denominada corrente $I_{\beta}$. Além disso, a corrente negativa contribui para o efeito de polaridade que ocorre em cada valor de volume da câmara de extrapolação. Assim, a corrente de ionização no volume da câmara é dada pela Equação 4.7 (CALDAS, 1980; BÖHM, 1986; ISO, 2004):

$$
I=\left(I_{+}-I_{-}\right) / 2
$$

onde: I é a corrente de ionização média obtida em cada tensão de polarização aplicada (para ambas as polaridades de tensão), $I_{+}$é a corrente obtida na polaridade positiva, e $I_{-}$é a corrente obtida na polaridade negativa.

\subsubsection{Características Fundamentais}

Uma câmara de extrapolação também deve ter sua resposta caracterizada em relação ao seu desempenho quando exposta a feixes de radiação. Esta caracterização compreende os testes descritos no item 4.3.2. Entretanto, há outros estudos e testes que podem ser realizados com a câmara de extrapolação e que contribuem para a determinação de outras características importantes, como a profundidade nula real, as curvas de extrapolação (que permitem observar a linearidade de resposta da câmara), e os fatores de transmissão e no tecido.

\subsubsection{Profundidade Nula Real}

A determinação da profundidade nula real, ou ponto zero, $d_{0}$, é um teste inicial necessário de ser realizado com toda câmara de extrapolação. Esta profundidade, ou este ponto, consiste na distância mínima necessária que deve haver entre os dois eletrodos para que eles não encostem um no outro, o que acarretaria um dano na janela de entrada, pelo fato dela ser fina. A determinação deste valor (que idealmente deveria ser igual a zero) é necessária, pois ele é aplicado em todos os valores de profundidades da câmara (para sua 
representação exata) a serem utilizados nos estudos, de maneira a corrigi-los para a profundidade real (ISO, 2004).

\subsubsection{Curvas de Extrapolação}

A curva de extrapolação permite avaliar a variação da corrente de ionização medida quando o espaçamento entre os eletrodos é alterado, ou seja, a profundidade da câmara de extrapolação é alterada. Os coeficientes angulares obtidos a partir destas curvas são utilizados na calibração das câmaras de extrapolação e para a determinação da taxa de dose absorvida da câmara ou de uma fonte de radiação beta. Para a obtenção das curvas de extrapolação, assim como para outros estudos de caracterização, é necessário se utilizar o valor da profundidade nula real obtida para a câmara. Esta profundidade deve ser somada à profundidade ideal da câmara na qual se deseja medir a corrente de ionização (por exemplo: tem-se uma profundidade nula real igual a 0,08 $\mathrm{mm}$, e deseja-se medir a corrente de ionização numa profundidade ideal de $0,50 \mathrm{~mm}$; portanto, o valor a ser ajustado no parafuso micrométrico será a profundidade real de $0,58 \mathrm{~mm}$ ).

\subsubsection{Fatores de Transmissão}

Os fatores de transmissão de uma fonte de radiação beta são características importantes a serem determinadas, principalmente em casos nos quais a fonte tem aplicação médica, para a obtenção da taxa de dose absorvida em certa espessura do tecido. Utilizando-se a câmara de extrapolação, esta determinação pode ocorrer quando a corrente de ionização medida é obtida para espessuras diferentes de absorvedores, e então ela é extrapolada para uma espessura de absorvedor nula (a qual representa a superfície da pele).

Para a determinação dos fatores de transmissão, é necessário usar uma relação de equivalência entre o material do absorvedor e o tecido. A relação entre Hostaphan (material original da janela de entrada da câmara) e o tecido é (OWEN, 1973):

$$
10,8 \mathrm{mg} / \mathrm{cm}^{2} \text { de Hostaphan }=10,0 \mathrm{mg} / \mathrm{cm}^{2} \text { de tecido }
$$

e a relação entre Plexiglas (acrílico), outro material comumente utilizado na determinação de fatores de transmissão, além de Hostaphan, é (CALDAS, 1980):

$$
10,4 \mathrm{mg} / \mathrm{cm}^{2} \text { de Plexiglas }=10,0 \mathrm{mg} / \mathrm{cm}^{2} \text { de tecido }
$$


Além destas relações, é necessário também converter a densidade superficial do material da janela de entrada da câmara para o tecido. Para casos nos quais a janela de entrada não é de Hostaphan, mas de Mylar, que é um tipo de material frequentemente utilizado como janela de entrada de uma câmara de ionização, pode-se utilizar a mesma relação entre a estabelecida entre Hostaphan e tecido (PINTO, 2010).

Para a obtenção dos fatores de transmissão, deve-se, inicialmente, determinar a espessura equivalente ao tecido, ou densidade superficial, para cada absorvedor utilizado, por meio da Equação 4.8 (CALDAS, 2012):

$$
t_{T}=\left(d_{J} \cdot c_{J}\right)+\left(e_{H} \cdot \rho_{H} \cdot c_{H}\right)
$$

onde: $t_{T}$ é a espessura, do absorvedor, de valor equivalente ao tecido, $d_{J}$ é a densidade superficial da janela de entrada, $c_{J}$ é o coeficiente de conversão do material da janela de entrada para equivalente ao tecido, $e_{H}$ é a espessura do absorvedor, $\rho_{H}$ é a densidade volumétrica do material do absorvedor $\left(1,40 \mathrm{~g} / \mathrm{cm}^{3}\right.$, para Hostaphan, e $1,18 \mathrm{~g} / \mathrm{cm}^{3}$, para Plexiglas), e $c_{H}$ é o coeficiente de conversão do material do absorvedor para equivalente ao tecido.

Medindo-se a corrente de ionização, $I\left(d_{0}\right)$, obtida para cada absorvedor de espessura diferente, é possível a determinação da corrente de ionização para densidade superficial nula, $I(0)$, por meio de extrapolação, a partir de um gráfico que forneça a corrente de ionização, $I\left(d_{0}\right)$, em função da densidade superficial no tecido, $t_{T}$, de cada absorvedor. A razão entre a corrente de ionização medida utilizando-se cada absorvedor, e a corrente de ionização para densidade superficial nula, fornece o fator de transmissão obtido com cada absorvedor, $T^{\prime}$, como mostra a Equação. 4.9:

$$
T^{\prime}=I\left(d_{0}\right) / I(0)
$$

Aos fatores de transmissão, $T^{\prime}$, um fator de correção, $k_{d}$, deve ser incorporado, relacionando a distância fonte-detector utilizada nas medições, $a$, e a espessura do absorvedor, $a_{1}$; este fator de correção pode ser obtido pela Equação. 4.10:

$$
k_{d}=\left(a-a_{1}\right)^{2} / a^{2}
$$


Assim, os fatores de transmissão finais, $T$, são determinados pela Equação. 4.11:

$$
T=T^{\prime} \cdot k_{d}
$$

Com os valores dos fatores de transmissão, $T$, e a densidade superficial no tecido para cada absorvedor, $t_{T}$, pode-se obter um gráfico, a partir do qual é possível se determinar os fatores de transmissão para as respectivas densidades superficiais equivalentes ao tecido que são fornecidas nos certificados de calibração das fontes. Desta maneira, pode-se comparar os valores de fatores de transmissão do certificado com os obtidos experimentalmente (CALDAS, 1980).

\subsubsection{Determinação de Taxas de Dose Absorvida}

A taxa de dose absorvida no tecido (ou na água) é a grandeza dosimétrica recomendada para a especificação de fontes de radiação beta, e o detector deve estar a uma distância de referência da fonte, que pode variar; por exemplo, para fontes planas esta distância é de 1,0 mm do centro da fonte, e para fontes do tipo sementes, a distância de referência é de 2,0 mm (BÖHM, 1986; IAEA, 2002; ICRU; 2004).

A taxa de dose absorvida pode ser determinada de maneira absoluta, ou seja, utilizando-se um instrumento, como uma câmara de extrapolação, como sistema absoluto (padrão). De acordo com a teoria de Bragg-Gray, a taxa de dose absorvida no tecido está relacionada com a taxa de dose absorvida no ar e o valor médio da razão entre os poderes de freamento da água e do ar; esta relação é representada pela Equação 4.12 (DIAS, 1996; OLIVEIRA, 2005):

$$
\dot{D}_{t}=\dot{D}_{a} \cdot s_{t, a}
$$

onde: $\dot{D}_{t}$ e $\dot{D}_{a}$ são as taxas de dose absorvida no tecido e no ar, respectivamente, e $s_{t, a}$ é a razão entre os poderes de freamento médios do tecido e do ar.

Caldas, em 1980, descreve os procedimentos necessários para se determinar taxas de dose absorvida no ar e no tecido, a $0 \mathrm{~mm}$ (na superfície) utilizando uma câmara de extrapolação como sistema padrão primário. De acordo com Caldas (1980), a taxa de dose absorvida no tecido pode ser obtida de acordo com a relação Bragg-Gray (já demonstrada na 
Equação 4.12), multiplicando-se a taxa de dose e os poderes de fretamento para tecido e ar, mas, também, associando-se a esta relação dois fatores de correção, devidos a:

- $\boldsymbol{k}_{\boldsymbol{b} \boldsymbol{a}}$ - diferença no retroespalhamento entre o material do tecido e do eletrodo coletor;

- $\boldsymbol{k}_{\boldsymbol{f}}$ - espessura e material da folha de entrada, e para normalização para uma folha de espessura equivalente a $2 \mathrm{mg} / \mathrm{cm}^{2}$ de tecido.

A relação descrita acima pode ser observada na Equação 4.13 (CALDAS, 1980):

$$
\dot{D}_{t}=\dot{D}_{a} \cdot s_{t, a} \cdot k_{b a} \cdot k_{f}
$$

Há quatro etapas para a determinação das taxas de dose absorvida no tecido e no ar. A primeira delas permite a obtenção da taxa de dose absorvida no ar dentro do volume sensível da câmara, $\dot{D}_{a}$. Para tal, utiliza-se a Equação 4.14:

$$
\dot{D}_{a}=\frac{\bar{W}}{e} \cdot \frac{k^{\prime}}{a_{e f} \cdot \rho} \cdot \frac{d}{d l}(I \cdot k(\ell))
$$

onde: $\bar{W}$ é a energia média dispendida pelas partículas ionizantes na formação de um par de íons no ar, $e$ é a carga elementar, $a_{e f}$ é a área efetiva do eletrodo coletor, $\rho$ é a densidade do ar, $\frac{d}{d l}(I . k(\ell))$ é a derivada da função corrente de ionização corrigida para $k(\ell)$ (representa o coeficiente angular, $B$, da curva de extrapolação), onde $\ell$ é a profundidade da câmara (no caso da Equação 4.15), e $k$ e $k$ ' são produtos entre fatores de correção diferentes, de acordo com as Equações 4.15 e 4.16:

$$
\begin{gathered}
k=k_{B r} \cdot k_{d e} \cdot k_{h u} \cdot k_{\text {gap }} \cdot k_{\text {esp }} \cdot k_{\text {inh }} \\
k^{\prime}=k_{\text {sat }} \cdot k_{\text {ad }} \cdot k_{\rho}
\end{gathered}
$$

Os fatores de correção envolvidos nas relações 4.15 e 4.16 ocorrem para:

- $\boldsymbol{k}_{\boldsymbol{B} \boldsymbol{r}}$ - emissão de Bremsstrahlung da fonte de radiação beta (este fator pode ser obtido experimentalmente);

- $\boldsymbol{k}_{\boldsymbol{d e}}$ - decaimento radioativo da fonte;

- $\boldsymbol{k}_{\boldsymbol{h u}}$ - umidade relativa do ar;

- $\boldsymbol{k}_{\text {gap }}$ - ranhura entre o eletrodo coletor e o anel de guarda (falta do retroespalhador, deformação do volume coletor); 
- $\boldsymbol{k}_{\text {esp }}$ - partículas beta espalhadas pelo material na vizinhança da fonte e da câmara;

- $\boldsymbol{k}_{\boldsymbol{i n h}}$ - inhomogeneidade do campo da radiação primária dentro do volume coletor, e depende da distância entre a fonte e a câmara, e das dimensões dos raios da fonte e do eletrodo coletor da câmara;

- $\boldsymbol{k}_{\text {sat }}$ - falta de saturação, ou perda de ionização, devido à recombinação colunar e volumétrica;

- $\boldsymbol{k}_{\boldsymbol{a d}}$ - partículas beta espalhadas pelas paredes laterais;

- $\boldsymbol{k}_{\boldsymbol{\rho}}$ - densidade do ar.

A segunda etapa consiste na determinação da taxa de dose absorvida no tecido dentro do volume sensível da câmara, e esta grandeza é determinada pela Equação 4.13, já descrita.

Na terceira etapa, pode-se calcular a taxa de dose absorvida no tecido na superfície externa da janela da câmara, $\dot{D}_{t}(0)$, por meio da razão entre a taxa de dose no tecido no volume da câmara, $\dot{D}_{t}$, e o fator de transmissão equivalente à densidade superficial da janela de entrada da câmara, $T$ (o qual é determinado pelo gráfico dos fatores de transmissão finais em função da densidade superficial, equivalente ao tecido, de absorvedores de espessuras diferentes), como pode ser observado na Equação 4.17:

$$
\dot{D}_{t}(0)=\frac{\dot{D}_{t}}{T}
$$

Concluindo, por meio da quarta etapa é possível se determinar a taxa de dose absorvida no ar na superfície externa da janela da câmara, $\dot{D}_{c}$, que consiste na razão entre a taxa de dose no tecido na superfície externa da câmara, $\dot{D}_{t}(0)$, e a razão entre os poderes de freamento médios do tecido e do ar, $s_{t, a}$, como mostra a Equação 4.18:

$$
\dot{D}_{c}=\frac{\dot{D}_{t}(0)}{S_{t, a}}
$$

Em 1986, Böhm descreveu um novo método para a obtenção de taxas de dose absorvida no tecido, a $0 \mathrm{~mm}$ (superficial), mas agora também a 0,07 $\mathrm{mm}$ de profundidade no tecido, que é a profundidade de referência no tecido estabelecida pela ICRU (ICRU, 1985). Para este novo método, Böhm utilizou novos fatores de correção que ainda não haviam sido 
incorporados em 1980 por Caldas (BÖHM, 1986). Em 2004, este mesmo método estabelecido por Böhm foi recomendado pela ISO, para a determinação de taxas de dose absorvida de fontes de radiação beta de referência (ISO, 2004).

De acordo com a ISO 6980-2 (2004), a taxa de dose absorvida no tecido, para fontes de radiação beta, pode ser determinada pela Equação 4.19:

$$
\dot{D}_{t}=\frac{\left(\bar{W}_{0} / e\right) \cdot s_{t, a}}{\rho_{0} \cdot a_{e f}} \cdot\left[\frac{d}{d l}\left\{k \cdot k^{\prime} \cdot I(\ell)\right\}\right]_{l=0}
$$

onde: $\left(\bar{W}_{0} / e\right)$ é o quociente de energia médio necessário para produzir um par de íons no ar sob condições de referência e a carga elementar $e, \rho_{0}$ é a densidade do ar em condições de referência de temperatura, pressão e umidade, $\left[\frac{d}{d l}\left\{k \cdot k^{\prime} . I(\ell)\right\}\right]_{l=0}$ é o valor limite da inclinação da corrente de ionização corrigida e a profundidade da câmara, $k$ é o produto dos fatores de correção que podem variar com a profundidade da câmara, e $k^{\prime}$ é o produto dos fatores de correção que não variam com a profundidade da câmara. As condições de referência, especificadas na ISO 6980-2 (2004) encontram-se dentro dos intervalos de temperatura (de $19^{\circ} \mathrm{C}$ a $23^{\circ} \mathrm{C}$ ), de pressão (de 86 a $106 \mathrm{kPa}$ ), e de umidade relativa (de $30 \%$ a $75 \%$ ).

As Tabelas 4.3 e 4.4, adaptadas da recomendação da ISO 6980-2 (2004), definem os fatores de correção envolvidos em $k$ e $k^{\prime}$, respectivamente, bem como os parâmetros que os influenciam. 
Tabela 4.3 - Definição dos fatores de correção (envolvidos em $k$ ) que dependem da variação da profundidade da câmara, e os parâmetros que podem influenciá-los (ISO, 2004).

\begin{tabular}{|c|c|c|c|c|c|}
\hline \multirow{2}{*}{$\begin{array}{c}\text { Fator } \\
\text { de } \\
\text { Correção }\end{array}$} & \multirow{2}{*}{ Definição } & \multicolumn{4}{|c|}{ Parâmetros } \\
\hline & & $\begin{array}{c}\text { Câmara de } \\
\text { Extrapolação }\end{array}$ & $\begin{array}{c}\text { Condições } \\
\text { de Uso }\end{array}$ & $\begin{array}{l}\text { Fonte de } \\
\text { Radiação }\end{array}$ & $\begin{array}{c}\text { Condições de } \\
\text { Irradiação }\end{array}$ \\
\hline $\boldsymbol{k}_{a b s}$ & $\begin{array}{l}\text { Variações na atenuação de } \\
\text { partículas beta entre a fonte e o } \\
\text { volume sensível }\end{array}$ & $x$ & & $x$ & $x$ \\
\hline $\boldsymbol{k}_{a c}$ & $\begin{array}{c}\text { Atenuação de partículas beta } \\
\text { no volume sensível }\end{array}$ & $x$ & $x$ & $x$ & \\
\hline $\boldsymbol{k}_{a d v}$ & Variações na densidade do ar & & $x$ & & \\
\hline $\boldsymbol{k}_{d e}$ & Decaimento radioativo da fonte & & & $x$ & \\
\hline $\boldsymbol{k}_{d i}$ & $\begin{array}{l}\text { Falta de uniformidade axial do } \\
\text { campo de radiação beta }\end{array}$ & $x$ & & $x$ & $x$ \\
\hline $\boldsymbol{k}_{p e}$ & $\begin{array}{l}\text { Perturbação da densidade do } \\
\text { fluxo de partículas beta pelas } \\
\text { paredes laterais da câmara }\end{array}$ & $x$ & & $x$ & $x$ \\
\hline $\boldsymbol{k}_{\text {sat }}$ & $\begin{array}{l}\text { Perdas de ionização devido à } \\
\text { recombinação iônica }\end{array}$ & $x$ & $x$ & & $x$ \\
\hline
\end{tabular}

Tabela 4.4 - Definição dos fatores de correção (envolvidos em $k^{\prime}$ ) que não dependem da variação da profundidade da câmara, e os parâmetros que podem influenciá-los (ISO, 2004).

\begin{tabular}{|c|c|c|c|c|c|}
\hline \multirow{2}{*}{$\begin{array}{l}\text { Fator } \\
\text { de } \\
\text { Correção }\end{array}$} & \multirow{2}{*}{ Definição } & \multicolumn{4}{|c|}{ Parâmetros } \\
\hline & & $\begin{array}{c}\text { Câmara de } \\
\text { Extrapolação }\end{array}$ & $\begin{array}{l}\text { Condições } \\
\text { de Uso }\end{array}$ & $\begin{array}{l}\text { Fonte de } \\
\text { Radiação }\end{array}$ & $\begin{array}{l}\text { Condições de } \\
\text { Irradiação }\end{array}$ \\
\hline $\boldsymbol{k}_{b a}$ & $\begin{array}{c}\text { Diferença no } \\
\text { retroespalhamento entre o } \\
\text { tecido e o material do eletrodo } \\
\text { coletor } \\
\end{array}$ & $x$ & & $x$ & $x$ \\
\hline$k_{b r}$ & $\begin{array}{l}\text { Efeito de Bremsstrahlung da } \\
\text { fonte de radiação beta }\end{array}$ & & & $x$ & \\
\hline $\boldsymbol{k}_{e l}$ & $\begin{array}{l}\text { Atração eletrostática da janela } \\
\text { de entrada devido à tensão de } \\
\text { polarização }\end{array}$ & $x$ & $x$ & & \\
\hline $\boldsymbol{k}_{h u}$ & $\begin{array}{l}\text { Efeito da umidade do ar no } \\
\text { volume sensível }\end{array}$ & & $x$ & & \\
\hline $\boldsymbol{k}_{\text {in }}$ & $\begin{array}{c}\text { Efeitos de interface entre o ar } \\
\text { no volume sensível e a janela } \\
\text { de entrada adjacente e o } \\
\text { eletrodo coletor }\end{array}$ & $x$ & & & \\
\hline $\boldsymbol{k}_{r a}$ & $\begin{array}{l}\text { Falta de uniformidade radial do } \\
\text { campo de radiação beta }\end{array}$ & $x$ & & & $x$ \\
\hline
\end{tabular}




\subsection{Sistemas DosimÉtRICOS LUMINESCENTES}

Além das câmaras de extrapolação, existem outros tipos de detectores, ou dosímetros, empregados na calibração e dosimetria de instrumentos ou fontes de radiação. Exemplos deles são os sistemas dosimétricos luminescentes, como os termoluminescentes (TL) e os luminescentes opticamente estimulados (LOE), que são de materiais geralmente em forma de pastilha ou pó. O processo físico que engloba estes dois tipos de fenômenos é semelhante.

Quando um material isolante ou semicondutor absorve a energia oriunda de um feixe de radiação ionizante, os elétrons e os buracos livres são excitados e, consequentemente, ocorre o armadilhamento destes elétrons e buracos em locais denominados defeitos (estados armadilhados), na estrutura interior do material dosimétrico. Após o fim do processo de excitação, a amostra deve ser estimulada de tal forma que a energia absorvida cause a liberação de cargas de mesmo sinal, as quais se recombinarão com cargas de sinais opostos (BØTTER-JENSEN e col., 2003).

Os processos de absorção da radiação e de excitação das cargas (por efeito Compton ou efeito fotoelétrico, dependendo do tipo de radiação e de sua energia) causam uma perturbação no sistema do equilíbrio termodinâmico para o metaestável. A absorção subsequente de energia externa pelas cargas armadilhadas metaestáveis resulta num relaxamento do sistema de volta à sua condição de equilíbrio (estado fundamental). Durante o processo de relaxação, ocorre a recombinação das cargas eletrônicas e, se a recombinação for radioativa, a luminescência é emitida (BØTTER-JENSEN e col., 2003).

No caso dos dosímetros $T L$, a fonte de estimulação é o calor. Nos detectores LOE, a fonte de estimulação é a luz (ultravioleta, visível ou infravermelha).

\subsubsection{Caracterização Dosimétrica}

Assim como para o caso das câmaras de ionização, os detectores TL e LOE devem ser caracterizados em relação à sua resposta após uma irradiação, para a verificação de suas condições dosimétricas. Alguns dos testes de caracterização são realizados com o mesmo objetivo e o mesmo procedimento que no caso das câmaras de ionização: linearidade da 
resposta, estabilidade da resposta, dependência energética, dependência angular, e variação da resposta dos dosímetros em função da distância fonte-detector.

Os materiais TL e LOE, independentemente do tipo, devem apresentar preferencialmente linearidade entre a indicação que fornecem e a dose absorvida, e serem independentes da taxa de dose. Para o caso dos materiais que não apresentem esta linearidade, eles devem ser calibrados previamente, e um fator de correção deve ser obtido a fim de se corrigir a condição da falta de linearidade de resposta (McKEEVER, 1985).

A estabilidade de um dosímetro é influenciada pelo decaimento do sinal armazenado na amostra, entre o momento da irradiação e o instante da medição (McKEEVER, 1985).

No caso dos detectores TL e LOE, há alguns testes de caracterização que não são realizados para as câmaras de ionização, e que, por este motivo, definem as características dosimétricas do material com especificidade: são os testes de limite mínimo detectável, curva de dose-resposta, decaimento do sinal, extinção térmica (thermal quenching), e estabilidade térmica do sinal LOE (conhecido como step-annealing, e somente para as amostras da LOE).

O limite mínimo detectável (também denominado limite inferior de detecção, ou dose mínima detectável) apresenta relação dependente da sensibilidade das amostras TL e LOE, com o tamanho dos dosímetros ou detectores, e com a sensibilidade dos sistemas medidores de TL e LOE. Além disso, este limite também apresenta importância considerável, pois depende das características do material, e quanto menor for este limite, maior será a utilidade da amostra para fins dosimétricos (McKEEVER, 1985).

A determinação da curva da resposta do material TL ou LOE em função da dose absorvida (curva dose-resposta ou curva de calibração) permite a calibração dos dosímetros e a verificação do seu comportamento, como, por exemplo, o intervalo de linearidade da resposta do material, e a ocorrência de supralinearidade ou saturação no intervalo de dose testado.

O estudo do decaimento térmico do sinal de TL ou de LOE (também denominado fading) mostra a porcentagem de perda de sinal após a sua irradiação; sendo assim, quanto menor for este valor, melhor é a utilidade do material em dosimetria.

O estudo da extinção térmica está relacionado com a eficiência do processo da luminescência, que é um fator dependente da temperatura, e pode ser estudado em 
amostras TL e LOE. Assim, a extinção térmica representa uma redução na eficiência da luminescência conforme a temperatura da amostra aumenta devido à abertura do processo de competição entre transições radiativas e não-radiativas. Este efeito pode ser estudado aplicando-se duas taxas de aquecimento diferentes ao processo de luminescência, e medindo-se a intensidade total de luz emitida em cada caso (B $\emptyset$ TTER-JENSEN e col., 2003; FURETTA, 2008).

O fenômeno da estabilidade térmica mostra o efeito da temperatura no sinal LOE de uma amostra. Neste estudo, a sensibilidade LOE pode ser monitorada, para se verificar se há esvaziamento térmico das armadilhas que dão origem ao sinal LOE. Além disso, estas medições permitem observar se há mudança na sensibilidade das amostras LOE quando elas são submetidas a variações de temperatura (BØTTER-JENSEN e col., 2003).

O tratamento das amostras TL e LOE antes ou após a sua irradiação e medição é necessário para que elas voltem às suas condições físicas iniciais e, desta forma, possam ser reutilizadas. Em termos físicos, o tratamento tem por objetivo o esvaziamento das armadilhas correspondentes aos picos de emissão do sinal cujas temperaturas são iguais ou inferiores à temperatura de tratamento. Quando a profundidade de uma armadilha é pequena, a energia fornecida por lâmpadas fluorescentes (tratamento no caso das amostras de LOE) ou altas temperaturas (tratamento no caso das amostras de TL) é suficiente para desarmadilhar os elétrons (McKEEVER, 1985).

Quando um tratamento é realizado antes de uma irradiação, ele recebe o nome tratamento pré-irradiação; caso uma amostra seja tratada depois de uma irradiação, este tratamento recebe o nome de tratamento pós-irradiação.

\subsubsection{Termoluminescência}

A termoluminescência (TL) é a emissão da energia armazenada em alguns materiais isolantes ou semicondutores na forma de luz, após serem expostos a feixes de radiação ionizante, e estimulados por meio de aquecimento. Esta descrição ocorre do ponto de vista macroscópico (McKEEVER e col., 1995; FURETTA, 2003).

O fenômeno da TL é caracterizado por dois estágios. O estágio 1 consiste numa perturbação do sistema eletrônico de materiais isolantes ou semicondutores, de um estado de equilíbrio para o estado metaestável, por meio da absorção de energia externa (quando o material é 
irradiado). O estágio 2 é a relaxação, ou retorno, do sistema termicamente estimulado à condição de equilíbrio, emitindo energia. Esta descrição é observada do ponto de vista microscópico, e está representada na Fig. 4.7 (McKEEVER e col., 1995; FURETTA, 2003).

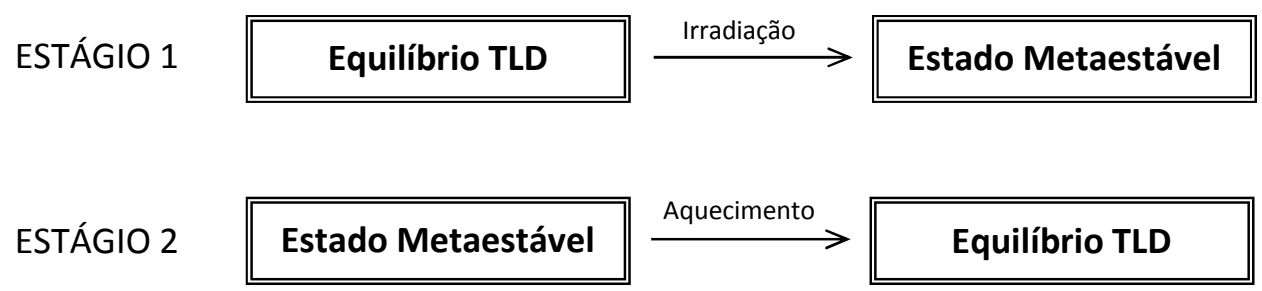

Figura 4.7 - Representação esquemática dos dois estágios da termoluminescência (McKEEVER e col., 1995).

\subsubsection{Teoria de Bandas}

O fenômeno da termoluminescência pode ser explicado pelo modelo de bandas de energia, também denominado "teoria de bandas", que trata dos níveis de energia dos elétrons para sólidos.

Os materiais TL são, em geral, constituídos por cristais iônicos, e apresentam três bandas: banda de valência, banda proibida e banda de condução. A primeira banda, de valência, encontra-se preenchida por elétrons presos a sítios na estrutura cristalina; a segunda, proibida, localiza-se entre as bandas de valência e de condução, e sua largura determina se o cristal é um isolante ou um semicondutor; e a terceira, de condução, é aquela na qual os elétrons ficam livres para se moverem no cristal (SCHARMANN e BÖHM, 1993; McKEEVER e col., 1995).

$\mathrm{Na}$ banda proibida estão os níveis metaestáveis, na qual ocorre a presença de impurezas ou a formação de defeitos, denominados armadilhas. Os defeitos mais comuns são a vacância de um átomo ou íon (defeito Schottky), a existência de um átomo numa posição intersticial (defeito Frenkel), ou aqueles que conferem coloração ao cristal (centros de cor) (McKEEVER e col., 1995, FURETTA, 2003).

A exposição do cristal a um feixe de radiação ionizante faz com que pares de elétrons e buracos (ou elétrons-lacunas) sejam produzidos no seu interior. Desta forma, estes pares migram pelo cristal até se recombinarem ou serem capturados nas armadilhas (estados 
metaestáveis de energia) (McKEEVER e col., 1995). A Fig. 4.8 mostra um esquema do modelo de bandas para a emissão TL.

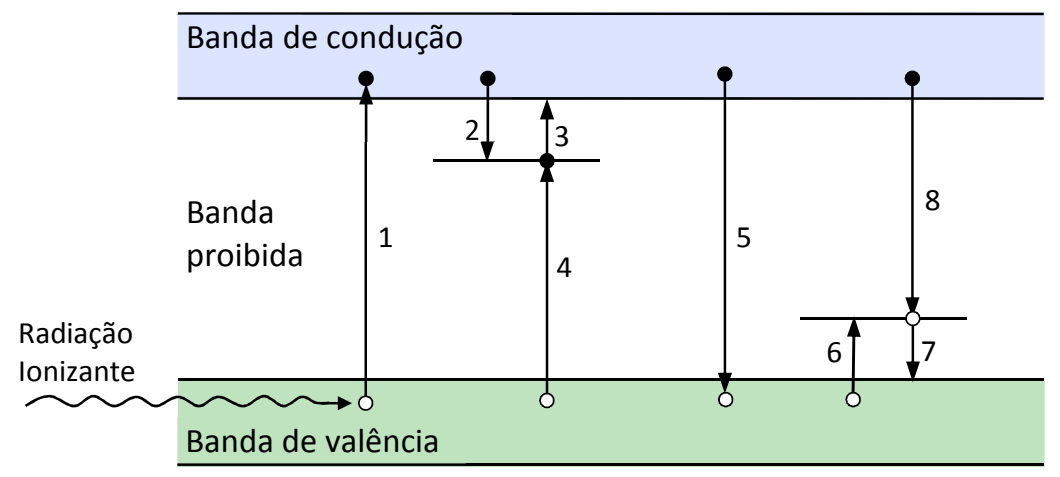

Figura 4.8 - Esquema dos níveis de energia e transições eletrônicas que ocorrem durante o processo de ionização e aquecimento da amostra TL: (1) processo de ionização; (2) e (6) armadilhamento de elétron e buraco, respectivamente; (3) e (7) desarmadilhamento (liberação) de elétron e buraco, respectivamente; (4) e (8) recombinações indiretas; e (5) recombinação direta (Adaptado de McKeever e col. (McKEEVER e col., 1995)).

Quando ocorre o processo de interação da radiação com a matéria, muitos elétrons são excitados e se movem da banda de valência para a banda de condução; o mesmo pode ocorrer quando o cristal é aquecido, após absorver energia térmica. Entretanto, alguns elétrons podem ficar presos em armadilhas existentes na banda proibida. Cada elétron armadilhado deixa um buraco na banda de valência que pode se recombinar com outro elétron de sinal de carga oposta ou ser preso em uma armadilha de buraco. Após a excitação, o elétron pode retornar ao estado fundamental em um intervalo de tempo muito curto (McKEEVER, 1985; FURETTA, 2003).

O fenômeno da termoluminescência representa a luminescência que pode ser representada em função do tempo ou da temperatura de aquecimento. $O$ gráfico obtido é denominado curva de emissão TL. Um exemplo típico de uma curva de emissão TL pode ser observado na Fig. 4.9. Neste caso, dois picos de emissão podem ser vistos para o material $\mathrm{CaSO}_{4}:$ Dy: o pico principal (dosimétrico), que ocorre a uma temperatura de aproximadamente $220^{\circ} \mathrm{C}$, e um outro pico, em torno de $120^{\circ} \mathrm{C}$ (McKEEVER e col., 1995; ROSA, 2000; FURETTA, 2003). 


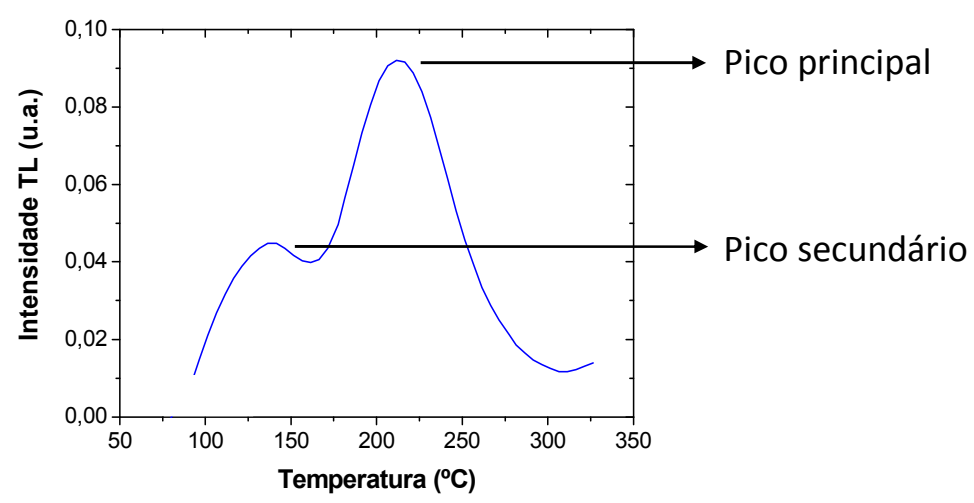

Figura 4.9 - Curva de emissão TL típica de uma amostra de $\mathrm{CaSO}_{4}$ :Dy, irradiada com uma dose absorvida de $10 \mathrm{mGy}$, com uma fonte de ${ }^{90} \mathrm{Sr}+{ }^{90} \mathrm{Y}$.

A curva de emissão TL pode apresentar mais de um pico de emissão que, do ponto de vista físico, ocorre quando se atinge uma temperatura de aquecimento que libera o máximo de elétrons que se encontram armadilhados a uma certa profundidade. Logo após a liberação destes elétrons, a intensidade de emissão decresce, justamente devido a uma redução do número de elétrons. Sendo assim, a presença de mais de um pico em uma curva de emissão indica que no cristal existem armadilhas com mais de uma profundidade. A forma da curva de emissão depende do material e de fatores como a taxa de aquecimento, a dose de radiação fornecida ao material e o número de armadilhas presentes no cristal (ROSA, 2000).

Além do $\mathrm{CaSO}_{4}: \mathrm{Dy}$, outros materiais são comumente estudados com relação à sua resposta termoluminescente, como, por exemplo, $\mathrm{LiF}: \mathrm{Mg}, \mathrm{Ti}, \mathrm{CaF}_{2}: \mathrm{Dy}, \mathrm{CaF}_{2}: \mathrm{Mn} \mathrm{e} \mathrm{Al}_{2} \mathrm{O}_{3}: \mathrm{C}$.

O LiF:Mg,Ti apresenta vários picos, mas o pico principal situa-se em aproximadamente $235^{\circ} \mathrm{C}$. O $\mathrm{CaF}_{2}$ :Dy apresenta ao menos quatro picos em aproximadamente $160^{\circ} \mathrm{C}, 185^{\circ} \mathrm{C}$, $245^{\circ} \mathrm{C}$ e $290^{\circ} \mathrm{C}$, além de picos em temperaturas mais altas, como $350^{\circ} \mathrm{C}$ e $400^{\circ} \mathrm{C}$. No caso do $\mathrm{CaF}_{2}: \mathrm{Mn}$, um único pico dosimétrico principal pode ser observado, em aproximadamente $313^{\circ} \mathrm{C}$. Para as amostras de $\mathrm{Al}_{2} \mathrm{O}_{3}: \mathrm{C}$, geralmente pode ser observado também um único pico, em aproximadamente $209^{\circ} \mathrm{C}$. Estes picos TL são obtidos em análises da resposta TL numa condição de taxa de aquecimento de $10^{\circ} \mathrm{C} / \mathrm{s}$ (McKEEVER e col., 1995). 


\subsubsection{Dosimetria Termoluminescente}

A dosimetria TL consiste na determinação da quantidade de energia absorvida por unidade de massa da amostra TL em questão. São vários os materiais que apresentam propriedades termoluminescentes, e é importante que eles tenham certas características de acordo com a aplicação; só assim os materiais TL poderão ser considerados dosímetros (McKEEVER e col., 1995; ROSA, 2000).

Para que um material TL possa ser utilizado em dosimetria das radiações, ele deve possuir algumas características, como as já apresentadas no item "4.5.1. Caracterização Dosimétrica", do presente trabalho. Além delas, deve-se considerar (McKEEVER, 1985; ROSA, 2000):

- Resposta TL pouco dependente com a energia da radiação incidente;

- Sensibilidade da resposta adequada mesmo para doses muito baixas;

- Resposta TL estável, mesmo em condições ambientais desfavoráveis (a estabilidade pode ser afetada pelo decaimento do sinal armazenado, seja por mecanismos ópticos ou térmicos, entre o momento da irradiação e a medição);

- Boa reprodutibilidade da resposta, mesmo para doses muito pequenas (ou seja, próximas ao limite inferior de detecção);

- Curva de emissão TL simples, e de preferência com um único pico de emissão ou com picos bem definidos e distintos.

Além disso, é importante que seja estabelecida uma condição na qual o sinal de ruído provocado durante a medição da resposta do dosímetro e também a radiação de fundo não interfiram na resposta TL final. Para que isso ocorra, o detector deve ser caracterizado por uma curva de emissão que apresente preferencialmente um pico de emissão no intervalo entre $200^{\circ} \mathrm{C}$ e $250^{\circ} \mathrm{C}$. Além disso, este intervalo de temperatura também assegura que a profundidade da armadilha seja suficiente para garantir que nenhuma armadilha seja esvaziada sem estímulo externo (McKEEVER, 1985).

Com relação à dosimetria de partículas beta, ela é dificultada pela dependência da resposta TL com certas características do dosímetro, como sua espessura e o tamanho dos grãos que compõem o material TL (no caso de amostras que sejam utilizadas na forma de pó). 
Como não há um material TL que apresente todas estas características, faz-se necessário que sua caracterização seja feita e que uma análise do maior número de condições seja realizada, para se verificar a viabilidade do uso de cada material em dosimetria das radiações. Uma vantagem que pode colaborar com o uso de materiais TL para dosimetria é que eles podem ser manufaturados em diferentes formas e dimensões, além da possibilidade de reutilização destes materiais após o seu uso, por meio de tratamentos térmicos bem definidos com relação à temperatura e ao tempo de tratamento.

\subsubsection{Sistema Medidor de Termoluminescência}

Além do fato que os dosímetros TL devem obedecer a certas condições para utilização, o desempenho também depende do sistema medidor $\mathrm{TL}$, que é o equipamento com que se faz as medições da resposta TL do material em questão.

O instrumento medidor TL constitui-se basicamente de três partes: o sistema de aquecimento da amostra, a unidade de controle da temperatura, e o sistema fotomultiplicador (composto por um detector cintilador, uma válvula fotomultiplicadora e circuitos de amplificação e polarização), responsável pela deteç̧ão da luz emitida pelo dosímetro. Além disso, podem ser utilizados filtros, que permitem a discriminação da influência de sinais que não provêm da amostra e da emissão de luz infravermelha, a qual é emitida quando os materiais são submetidos a altas temperaturas (McKEEVER, 1985).

Para o aquecimento da amostra $\mathrm{TL}$, dois processos devem ser realizados. No primeiro, a amostra é colocada em uma prancheta, constituída por uma placa metálica fina (geralmente de platina), onde ela é aquecida por meio da passagem de uma corrente elétrica. No segundo método, a temperatura da amostra é aumentada submetendo-a a um fluxo de gás inerte aquecido (nitrogênio). O sistema de aquecimento da amostra fica no interior de uma câmara resistente a vácuo moderado e ao fluxo de gás. (McKEEVER, 1985).

Para as medições TL, é necessária uma taxa de aquecimento com crescimento linear em função do tempo. É um termopar que desempenha a função de controle, associando o aumento da temperatura com o aumento da tensão. Entretanto, o termopar mede a temperatura da prancheta, que não é necessariamente igual à da amostra. Como as amostras mantêm contato direto com a prancheta por apenas um dos seus lados, haverá um certo gradiente de temperatura através da amostra, e a magnitude deste gradiente 
dependerá de alguns fatores, como a espessura da amostra, sua condutividade térmica e a taxa de aquecimento. Para controlar este problema, é necessário um ambiente constituído por uma atmosfera de gás inerte no interior da câmara, que se constitui de um condutor térmico, e permite o aquecimento da amostra por todos os lados (McKEEVER, 1985).

O tubo fotomultiplicador realiza a captação da luz produzida e detecta a luz emitida pela amostra originando um sinal proporcional à $T L$, que é convertido em corrente elétrica e amplificado pelo eletrômetro. Os sinais produzidos são enviados para um microcomputador, e assim a curva de emissão é gerada. O sinal da fotomultiplicadora é enviado para um integrador de carga, que determina o valor da área integrada sob a parte estável da curva de emissão, digitaliza os dados, e os apresenta num mostrador digital. A Fig. 4.10 mostra um esquema de um sistema medidor $\mathrm{TL}$, com as suas partes fundamentais especificadas (CAMPOS, 1998).

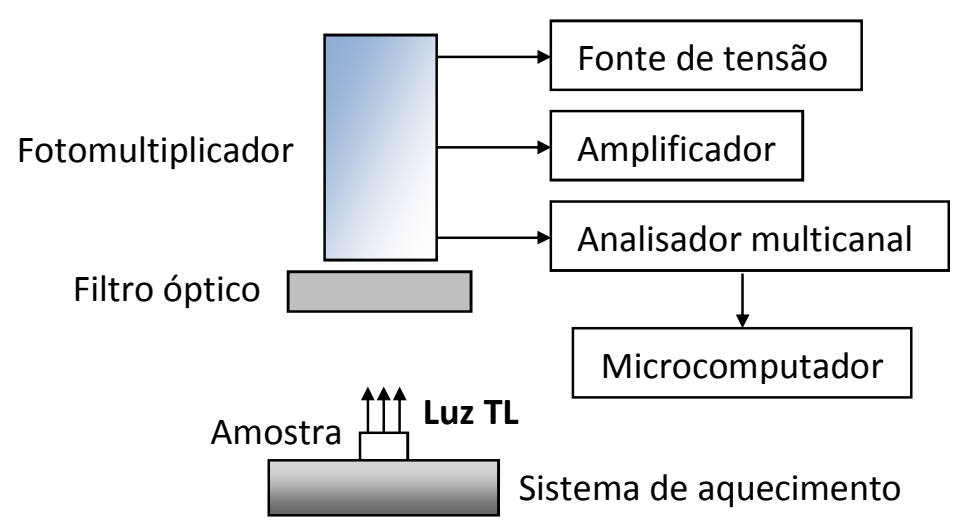

Figura 4.10-Esquema simplificado de um sistema medidor termoluminescente (baseado em Campos (1998)).

\subsubsection{Luminescência Opticamente Estimulada}

A luminescência opticamente estimulada (LOE) é o efeito da luminescência emitida por um material isolante ou semicondutor durante sua exposição à luz. Para que isso ocorra, é necessário que um material LOE seja exposto a uma fonte de luz de comprimento de onda e intensidade adequados e capazes de estimular a luminescência do material. A intensidade LOE é proporcional à dose absorvida de radiação pela amostra e, desta maneira, detectores LOE podem ser usados em dosimetria das radiações (BØTTER-JENSEN e col., 2003; FURETTA, 2008). 
O princípio físico da LOE assemelha-se ao da TL. Ele inicia-se quando uma amostra é irradiada, com excitação dos elétrons livres e dos buracos (criação de pares elétrons e buracos). Então, os elétrons livres e os buracos são armadilhados nos defeitos existentes no interior do material. Após este processo, a amostra pode ser estimulada por meio da exposição do material à luz, levando à absorção de energia pelos elétrons armadilhados, e a indução da liberação de cargas de mesmo sinal e sua recombinação com cargas de sinais opostos. Assim, após esta recombinação ocorre uma perturbação no sistema, que passa do estado de equilíbrio para o estado metaestável. Quando o sistema volta ao equilíbrio, ocorre a emissão de luz, ou seja, a luminescência (McKEEVER, 2001; BØTTER-JENSEN e col., 2003).

$\mathrm{Na} L \mathrm{LOE}$, a intensidade do sinal é proporcional à dose absorvida de radiação no material. Para esta técnica especificamente, a intensidade da luminescência emitida relaciona-se com o tempo no qual o sistema retorna ao estado de equilíbrio. Este tempo é uma função da concentração de cargas armadilhadas (que deve ser proporcional à dose absorvida inicial), e esta relação deve ser, preferencialmente, linear. Para a análise do sinal LOE pode-se obter também uma curva, como no caso da TL, e esta curva deve relacionar a intensidade da luminescência com o tempo, por meio de sua área integrada. Na Fig. 4.11 pode ser observada uma curva de resposta LOE (McKEEVER, 2001; BØTTER-JENSEN e col., 2003; FURETTA, 2008).

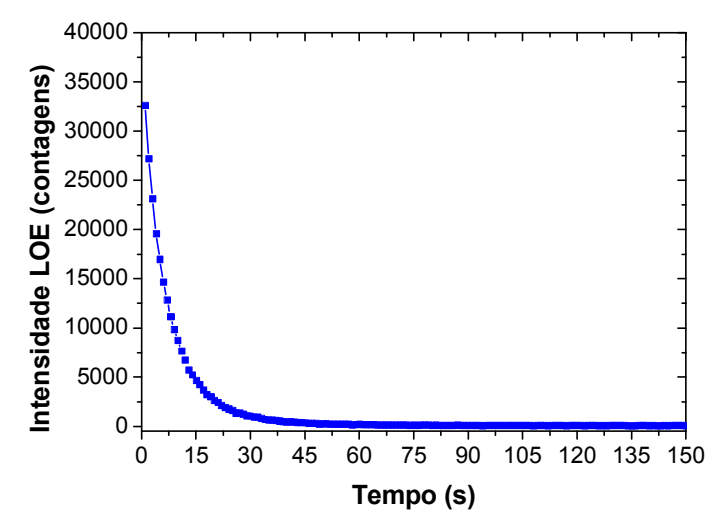

Figura 4.11 - Curva típica que mostra o decaimento da intensidade LOE em função do tempo de iluminação, de um detector de $\mathrm{Al}_{2} \mathrm{O}_{3}: \mathrm{C}$, pré-irradiado $\left({ }^{90} \mathrm{Sr}+{ }^{90} \mathrm{Y}\right)$.

\subsubsection{Formas de Estimulação LOE}

As curvas de decaimento da intensidade LOE em função do tempo dependem do modo de estimulação luminosa aplicada às amostras. Fisicamente, esta característica tem relação 
com o esvaziamento das armadilhas. As formas de estimulação das amostras LOE podem ocorrer de diversas formas, mas as principais são: onda contínua, modulação linear, ou pulsada (BØTTER-JENSEN e col., 2003). Na Fig. 4.12 podem ser observadas algumas ilustrações de curvas de resposta LOE, obtidas experimentalmente, e as respectivas representações gráficas dos principais modos de estimulação LOE.

Nas medições de LOE de onda contínua (continuous-wave OSL, CW-OSL) as armadilhas são esvaziadas usando-se um comprimento de onda fixo e uma intensidade de iluminação estável, que são independentes do tempo. Nesta forma de estimulação, a luminescência é monitorada durante a estimulação óptica até todas as armadilhas serem esvaziadas. Além disso, filtros são utilizados para discriminar a luz de estímulo e a luz emitida. Esta é a forma de estimulação mais simples, embora seja dependente de filtros (BØTTER-JENSEN e col., 2003).

A LOE de modulação linear (linear modulation OSL, LM-OSL) pode ser medida mantendo-se um comprimento de onda fixo, porém aumentando-se linearmente a intensidade de estimulação óptica; assim, ocorre uma dependência do sinal LOE com o tempo. Nesta forma de estimulação, a intensidade LOE também pode ser modulada de maneira não-linear, por meio do aumento exponencial da intensidade de estimulação (BØTTER-JENSEN e col., 2003).

Outra forma de estimulação é a LOE pulsada (pulsed OSL, POSL), estudada aplicando-se intervalos de intensidade zero entre os pulsos de intensidade constante. Nesta forma de estimulação, a luminescência é detectada somente entre os pulsos (após o fim da luz de estimulação da luz), mas não durante os pulsos. Por este motivo, esta forma de estímulo requer uma condição menor de filtração, uma vez que os sinais de estimulação e emissão luminescente não ocorrem no mesmo instante (BØTTER-JENSEN e col., 2003). 

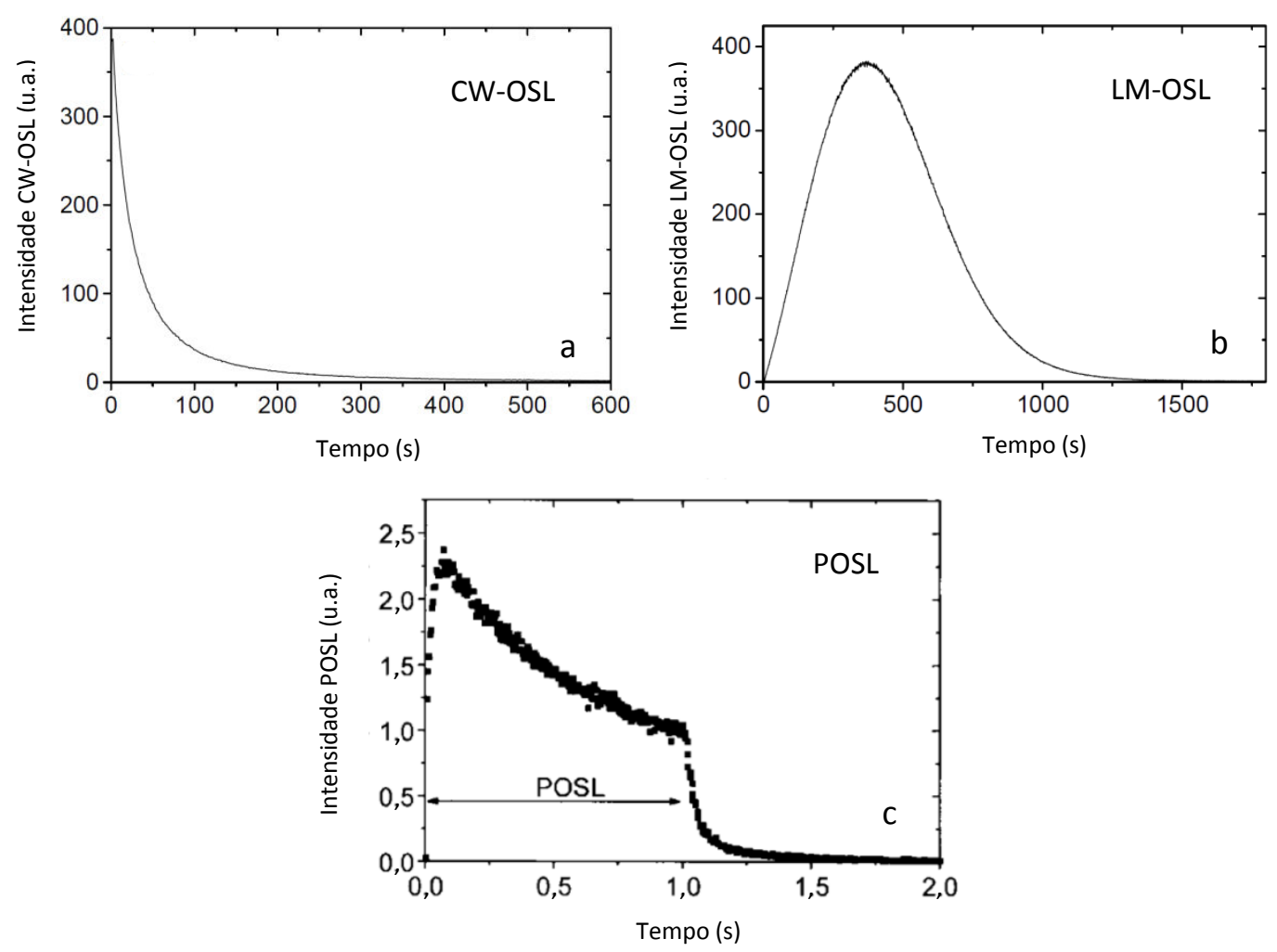

Figura 4.12-Curvas de resposta LOE, demonstradas experimentalmente e representadas graficamente, para os três tipos principais de estimulação LOE: (a) CW-OSL; (b) LM-OSL; e (c) POSL (BØTTER-JENSEN e col., 2003).

\subsubsection{Dosimetria Luminescente Opticamente Estimulada}

O fenônemo da LOE vem sendo empregado para a determinação da dose absorvida em diversas áreas da dosimetria das radiações, como na dosimetria retrospectiva, médica, pessoal, ambiental e espacial (McKEEVER, 2001; BØTTER-JENSEN e col., 2003; YUKIHARA e col., 2010).

Para que um material apresente uma boa resposta LOE e, por este motivo seja considerado um bom detector LOE, é necessário que ele apresente algumas características, assim como no caso da TL, como (McKEEVER, 2001; BØTTER-JENSEN e col., 2003):

- Ser altamente sensível à radiação (isso indica que a medição da luminescência pode ser realizada a temperaturas menores do que aquelas para a qual a extinção térmica ocorre);

- Apresentar número atômico efetivo baixo;

- Ter eficiência de estimulação óptica alta;

- Ter sinal luminescente estável à temperatura ambiente. 
O quartzo é um exemplo de material LOE que apresenta todas estas características, e é usado principalmente para dosimetria retrospectiva (BØTTER-JENSEN e col., 2003). Entretanto, é o óxido de alumínio dopado com carbono, $\mathrm{Al}_{2} \mathrm{O}_{3}: \mathrm{C}$, que vem sendo mais utilizado na maioria das áreas de dosimetria, inclusive para radiação beta, por apresentar características adequadas como detector LOE (AKSELROD e col., 1999; PINTO e col., 2008).

\subsubsection{Sistema Medidor de Luminescência Opticamente Estimulada}

Um sistema leitor LOE é composto basicamente por três sistemas: um detector de luz, uma fonte de estimulação óptica e um filtro óptico (BØTTER-JENSEN e col., 2003).

A fonte de estimulação óptica (que se mantém fixa) estimula a amostra por meio da emissão de luz com um determinado comprimento de onda e uma determinada intensidade. O sistema de detecção de luz avalia a luminescência emitida, e seu sinal é amplificado por uma fotomultiplicadora (em função do tempo de estimulação). A integral da emissão durante o período de estimulação, portanto, pode ser obtida, e representa a medição da dose de radiação inicialmente absorvida pelo material que constitui o detector (B $\varnothing$ TTERJENSEN e col., 2003). Na Fig. 4.13 pode ser observado um esquema de um sistema medidor LOE, com seus componentes básicos.

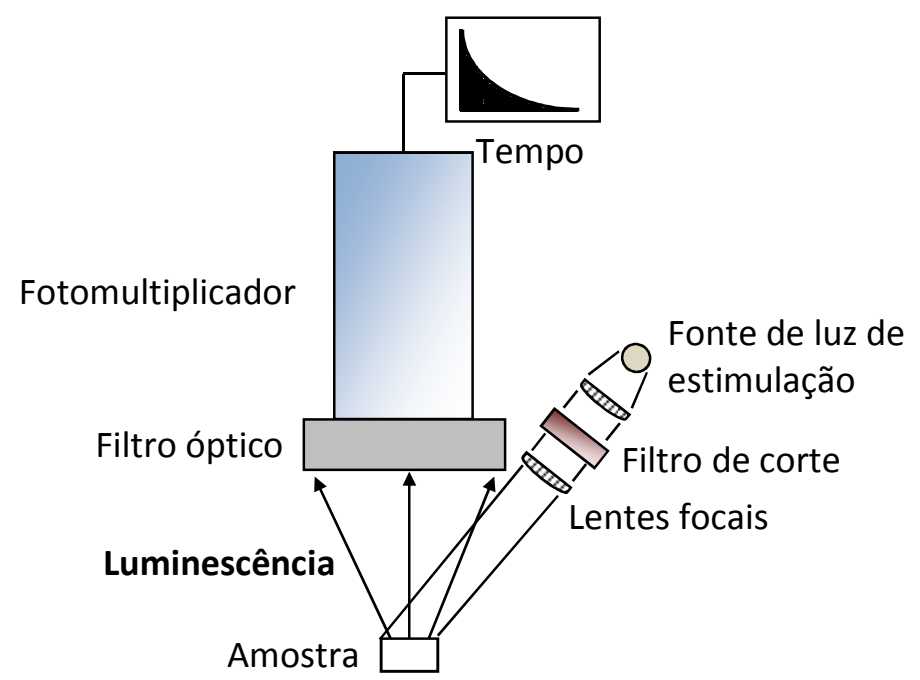

Figura 4.13 - Representação esquemática de um sistema medidor LOE (BØTTER-JENSEN e col., 2003).

As formas de estimulação da resposta LOE (CW-OSL, LM-OSL ou POSL) podem variar de um detector para outro, bem como as fontes de estimulação óptica, que podem ser: LED 
vermelho, LED verde, LED azul, diodo de laser e infravermelho, e banda larga (BØTTERJENSEN e col., 2003).

Quando a resposta de um detector for avaliada após sua irradiação a doses baixas, o sistema medidor LOE utiliza vários LEDs; assim, o sinal LOE passa a ser mais alto devido à máxima estimulação, apesar de apresentar uma depleção alta no sinal. Quando um detector LOE é irradiado com doses altas, o sistema medidor pode utilizar um menor número de LEDs para estimular a luminescência, resultando em um sinal LOE mais baixo e um grau de depleção mais baixo também (JURSINIC, 2007).

Neste sistema medidor, assim como no caso da TL, a luminescência é detectada e medida pelo tubo fotomultiplicador, e deve ser proporcional à dose absorvida.

\subsubsection{Vantagens e Desvantagens dos Sistemas TL e LOE}

A diferença principal entre as técnicas TL e LOE é a forma de estimulação do processo da luminescência (calor e luz, respectivamente), uma vez que os processos físicos que ocorrem nestes fenômenos são bem semelhantes.

Levando-se em conta que o princípio da aplicação da luminescência implica numa relação entre a dose absorvida e a intensidade de luz emitida, é possível se analisar as duas técnicas sob este ponto de vista. Desta forma, pode-se perceber que a técnica da LOE apresenta algumas vantagens em relação à TL (MCKEEVER, 2001; BØTTER-JENSEN e col., 2003; OLKO, 2010):

- A TL é um método destrutivo, enquanto a LOE é não destrutiva (OLKO, 2010);

- O sinal LOE pode ser medido várias vezes após uma irradiação, enquanto que na TL o sinal pode ser medido uma única vez (perda total do sinal);

- É possível obter-se, em uma mesma amostra, um sinal TL após medições LOE;

- Na maioria dos casos, a LOE apresenta a mesma curva de dose-resposta da TL;

- A maioria das amostras LOE apresenta maior sensibilidade à radiação do que os materiais utilizados como TL.

Sabe-se que as maiores vantagens das técnicas luminescentes são, por exemplo, a possibilidade de reutilização, alta sensibilidade à radiação e sua boa resistência à umidade (OLKO, 2010). Na Tabela 4.5 podem ser observadas algumas vantagens dos dois tipos de dosimetria TL e LOE (OLKO, 2010). 
Tabela 4.5 - Comparação entre as vantagens dos dois tipos de dosimetria TL e LOE (OLKO, 2010).

\begin{tabular}{ll}
\hline \multicolumn{1}{c}{ Dosimetria TL } & \multicolumn{1}{c}{ Dosimetria LOE } \\
\hline $\begin{array}{l}\text { - Não possui sensibilidade à luz, dependendo do } \\
\text { material }\end{array}$ & - Sensibilidade estável \\
\hline - Calibração individual dos dosímetros & - Alta precisão e acurácia \\
\hline $\begin{array}{l}\text { - Curva de emissão TL usada em controle de } \\
\text { qualidade }\end{array}$ & - Controle da luminescência emitida \\
\hline - Fácil manuseio & - Rapidez na medição da resposta \\
\hline - Simples medição & - Baixo consumo elétrico dos sistemas leitores \\
\hline - Alta sensibilidade à radiação & - Alta eficiência de luminescência \\
\hline
\end{tabular}

Desta maneira, pode-se concluir que a escolha do dosímetro e da melhor técnica de luminescência a ser utilizada deve ser feita com base no propósito a que o material se destina.

\subsection{PadRonização Primária}

Um padrão consiste num sistema de medição capaz de definir, realizar, quantificar ou reproduzir um ou mais valores de uma determinada grandeza, atuando desta maneira como referência. Um sistema padrão pode ser classificado como primário, secundário e terciário, ou ainda como nacional ou internacional.

O padrão primário, por definição, consiste em um sistema adotado e reconhecido por apresentar ótimas qualidades metrológicas e excelentes valores de incerteza. Os valores de medição fornecidos em seus certificados de calibração (taxas de dose absorvida, para radiação beta) não fazem referência a nenhum outro padrão. Estes sistemas são utilizados por laboratórios de padronização primária, que oferecem serviços de calibração de detectores e fontes de radiação que passam a ser classificados como sistemas padrões secundários.

Um padrão secundário também é estabelecido por meio de uma calibração, porém difere no fato de que os seus valores fazem referência a um padrão primário de uma grandeza do mesmo tipo. Eles são utilizados por laboratórios de padronização secundária, que, para alcançarem esta denominação devem possuir ao menos um padrão secundário calibrado em relação a um padrão primário por tipo de radiação. O sistema padrão terciário tem a sua calibração comparada com um sistema padrão secundário; são utilizados por laboratórios de padronização terciária (ALBERTAZZI e SOUZA, 2008; VIM, 2012). 
Um laboratório considerado padrão nacional é aquele reconhecido e constituído por uma autoridade nacional, dentro de um país, para servir como base ou referência, atribuindo valores a outros padrões de grandezas do mesmo tipo, que servem de rastreabilidade para outros padrões do mesmo país. Estes laboratórios são mantidos pelos Laboratórios Nacionais de Metrologia (LNM) de cada país. Os laboratórios padrões nacionais possuem rastreabilidade aos laboratórios de nível padrão internacional, reconhecidos por meio de um acordo internacional, e que têm, como propósito, serem utilizados não apenas dentro de um país, mas de maneira mundial. Os laboratórios padrões internacionais são mantidos pelo Bureau International des Poids et Mesures (BIPM), laboratório padrão international de metrologia, com sede em Paris, França (ALBERTAZZI e SOUZA, 2008; VIM, 2012).

Os campos de referência de radiação beta são importantes na calibração de instrumentos metrológicos. De acordo com a ISO (ISO, 2006), as fontes de radiação de referência são divididas em duas séries: 1 e 2 . As fontes da série 1 devem utilizar filtros uniformizadores de campo para produzir uma taxa de dose absorvida uniforme em uma área de aproximadamente $15 \mathrm{~cm}$ de diâmetro, para a calibração de detectores de área ou dosímetros individuais. Para tal, deve-se usar distâncias de calibração e filtros adequados para cada fonte. Alguns exemplos destas fontes são ${ }^{90} \mathrm{Sr}+{ }^{90} \mathrm{Y},{ }^{204} \mathrm{TI},{ }^{147} \mathrm{Pm} \mathrm{e}{ }^{85} \mathrm{Kr}$ (ISO, 2006).

As fontes de radiação da série 2 são utilizadas sem filtros uniformizadores de campo, e apresentam a vantagem de terem energia e taxa de dose maiores do que as das fontes da série 1 , além de poderem ser utilizadas em um intervalo maior de distâncias fonte-detector. Exemplos destas fontes são as da série $1,{ }^{14} \mathrm{C} \mathrm{e}{ }^{106} \mathrm{Ru}+{ }^{106} \mathrm{Rh}$ (ISO, 2006).

\subsection{Calibração e Dosimetria de Fontes e Detectores de Radiação Beta}

A definição do termo calibração é discutida por vários autores e em recomendações internacionais, o que torna clara e evidente a importância deste procedimento para um instrumento metrológico ou uma fonte radioativa.

A calibração consiste na maneira mais comum de se caracterizar e avaliar o desempenho de um instrumento. Desta maneira, faz-se necessária a realização de um conjunto de operações ou procedimentos, sob determinadas condições, que estabeleçam uma relação entre os valores indicados pelo instrumento ou representados por uma 
medição (com as suas incertezas associadas) e os valores estabelecidos como grandezas padrões (ALBERTAZZI e SOUZA, 2008; VIM, 2012). A calibração também pode ser definida, em termos práticos, de acordo com uma recomendação da ISO (ISO, 2006), como a determinação quantitativa de um fator de calibração e um fator de correção a partir de condições específicas e testes padrões.

Para a calibração é necessário conhecer-se a rastreabilidade do sistema padrão. A taxa de dose absorvida (no caso da radiação beta) de referência, produto de uma calibração, obtida a partir de um campo de radiação conhecido, deve ser rastreável a um padrão reconhecido. A rastreabilidade é a condição do resultado de uma medição que garante sua relação com uma referência (padrão nacional ou internacional), por meio de uma série de comparações, fornecendo incertezas bem estabelecidas. Esta relação garante uniformidade nas medições efetuadas em qualquer momento ou lugar. A rastreabilidade pode ser comprovada quando um laboratório de calibração obtém um fator de calibração semelhante ao do laboratório padrão, com diferenças consideradas aceitáveis dentro de suas incertezas (ISO, 2006; ALBERTAZZI e SOUZA, 2008).

A dosimetria, também conhecida como avaliação de dose, consiste na medição da grandeza física dose absorvida ou taxa de dose absorvida resultante do processo de interação da radiação ionizante com a matéria (ATTIX, 2004; STABIN, 2008).

A calibração de instrumentos metrológicos em feixes de radiação beta, bem como a dosimetria, é um procedimento consideravelmente complexo, pois é necessário um campo de radiação rigorosamente definido para que haja reprodutibilidade nos experimentos nos laboratórios. Este fato é devido ao baixo poder de penetração das partículas beta e aos altos gradientes de dose relacionados a elas, o que contribui para que a dosimetria destas fontes também se torne complicada.

A calibração de fontes de radiação beta, ou a determinação de sua taxa de dose absorvida, também deve ser realizada por meio de uma série de medições (IAEA, 1994; 2000b). A grandeza recomendada no caso de fontes de radiação beta é a taxa de dose absorvida no tecido/água a uma distância de referência da fonte, que pode variar de uma fonte a outra (IAEA, 2002; ICRU, 2004). 


\section{MAteriais e MÉtodos}

Neste capítulo, serão descritos as diferentes câmaras de ionização de placas paralelas e a câmara de extrapolação Böhm, os sistemas medidores de luminescência, as diversas fontes de radiação beta, os materiais dosimétricos e os sistemas auxiliares utilizados durante todo o desenvolvimento deste trabalho. Toda a infraestrutura necessária para a realização dos experimentos encontra-se disponível no $\mathrm{LCl}$, com exceção dos sistemas de radiação dos hospitais que realizam procedimentos de betaterapia, com aplicadores clínicos de ${ }^{90} \mathrm{Sr}+{ }^{90} \mathrm{Y}$, e dos sistemas de radiação da UFS, para onde foi enviado o sistema postal dosimétrico.

\subsection{CÂmaras de IONIZAÇÃo}

As câmaras de ionização diferentes utilizadas neste trabalho tiveram suas medições tomadas em termos de carga para, então, serem convertidas para corrente de ionização e corrigidas para as condições de referência de temperatura e pressão. Como os valores de corrente de ionização podem ser muito baixos (dependendo, por exemplo, da atividade da fonte), optou-se pelo procedimento de coleta de carga elétrica.

Neste item, serão descritas as quatro câmaras de ionização utilizadas neste trabalho: três câmaras de ionização de placas paralelas convencionais, e uma câmara de extrapolação. Informações também serão fornecidas a respeito dos eletrômetros utilizados com estas câmaras de ionização, e a metodologia para a determinação de fatores de correção envolvidos na obtenção de taxas de dose absorvida.

Nos procedimentos de caracterização da resposta das câmaras de ionização, elas foram posicionadas de maneira que o feixe de radiação incidisse no centro de cada janela de entrada, e a câmara de ionização foi sempre posicionada sobre um suporte de acrílico que faz parte do conjunto dos sistemas padrões secundários de radiação beta do $\mathrm{LCl}$. Quando as fontes de radiação destes sistemas foram utilizadas, as câmaras de ionização foram irradiadas sob as condições estabelecidas em seus certificados de calibração, com relação à distância fonte-detector e uso de filtro uniformizador de campo. 


\subsubsection{Câmaras de Ionização de Placas Paralelas}

Três câmaras de ionização de placas paralelas foram estudadas neste trabalho com a finalidade de sua aplicação em dosimetria beta: câmaras C1, C2 e C3. As duas primeiras (C1 e C2) foram desenvolvidas no IPEN (SOUZA e col., 1996; GUERRA, 2001), e a terceira câmara estudada (C3) foi fabricada e comercializada pela Physikalisch-Technische Werkstätten (PTW), Alemanha, modelo 23344 (PTW, 2003). Na Tabela 5.1 estão detalhadas as principais características destas câmaras, que podem ser observadas nas Fig. 5.1.a-c.

Tabela 5.1 - Características das câmaras de ionização (placas paralelas) utilizadas neste trabalho.

\begin{tabular}{|c|c|c|c|c|c|c|}
\hline \multirow{3}{*}{$\begin{array}{c}\text { Câmara } \\
\text { de } \\
\text { lonização }\end{array}$} & \multirow{3}{*}{$\begin{array}{c}\text { Utilização } \\
\text { Recomendada }\end{array}$} & \multicolumn{5}{|c|}{ Dados Técnicos } \\
\hline & & \multicolumn{2}{|c|}{ Corpo da câmara } & \multirow{2}{*}{ Janela } & \multirow{2}{*}{$\begin{array}{c}\text { Eletrodo } \\
\text { Coletor }\end{array}$} & \multirow{2}{*}{$\begin{array}{l}\text { Volume } \\
\left(\mathrm{cm}^{3}\right)\end{array}$} \\
\hline & & Material & Dimensões $(\mathrm{mm})$ & & & \\
\hline$C 1$ & $\begin{array}{l}\text { Feixes de } \\
\text { elétrons de } \\
\text { alta energia }\end{array}$ & Lucite & $\begin{aligned} \text { Diâmetro } & =25,40 \\
\text { Espessura } & =17,25\end{aligned}$ & $\begin{array}{c}\text { Mylar } \\
\text { aluminizado }\end{array}$ & Grafite & 0,06 \\
\hline$C 2$ & $\begin{array}{l}\text { Feixes de } \\
\text { mamografia }\end{array}$ & Lucite & $\begin{array}{l}\text { Diâmetro }=90,00 \\
\text { Espessura }=30,00\end{array}$ & $\begin{array}{l}\text { Mylar } \\
\text { aluminizado }\end{array}$ & Grafite & 6,00 \\
\hline C3 & $\begin{array}{l}\text { Padrão } \\
\text { secundário, } \\
\text { nível } \\
\text { radioterapia }\end{array}$ & Polietileno & $\begin{array}{c}\text { Largura interna }=13,00 \\
\text { Largura externa }=16,00 \\
\text { Altura }=61,00\end{array}$ & Poletileno & Alumínio & 0,20 \\
\hline
\end{tabular}
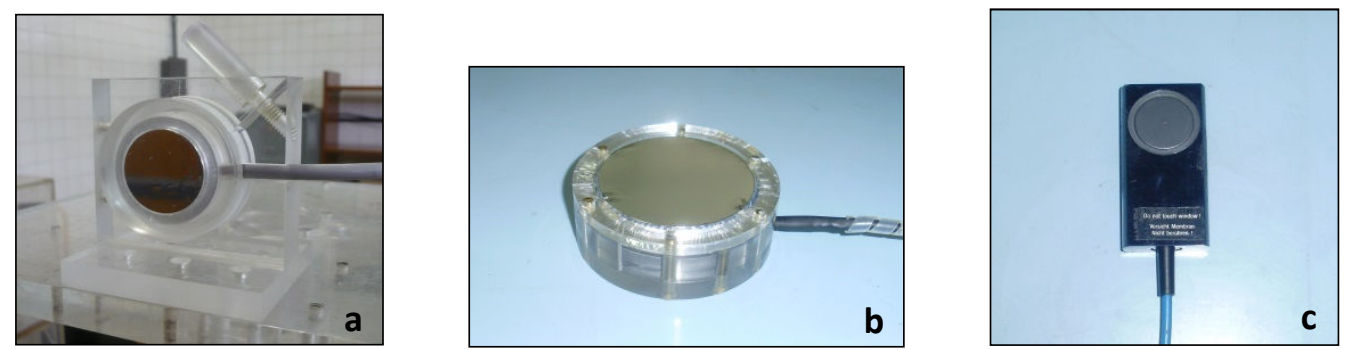

Figura 5.1 - Câmaras de ionização de placas paralelas: (a) câmara C1; (b) câmara C2; e (c) câmara C3.

\subsubsection{Câmara de Extrapolação Böhm}

A câmara de ionização que consistiu no principal objeto de estudo deste trabalho é a câmara de extrapolação Böhm (Fig. 5.2). Esta câmara, fabricada pela PTW, Alemanha, modelo 23392, e comercializada para ser utilizada como sistema padrão primário ou secundário para calibração de detectores e fontes de radiação beta, apresenta paredes de alumínio, eletrodo coletor de grafite de $30 \mathrm{~mm}$ de diâmetro, e profundidade com variação 
de $0 \mathrm{~mm}$ a $10 \mathrm{~mm}$ (PTW, 2002). Esta câmara já foi descrita com maiores detalhes no item “4.4.1. Câmara de Extrapolação Böhm”, deste trabalho.

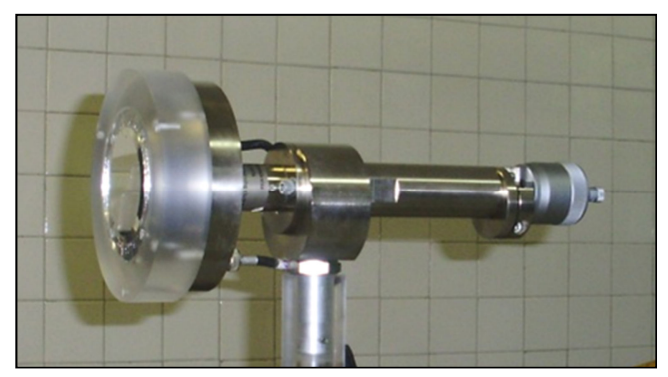

Figura 5.2 - Câmara de extrapolação Böhm, PTW, modelo 23392.

\subsubsection{Eletrômetros}

Durante os experimentos com as três câmaras de ionização de placas paralelas, foi utilizado um eletrômetro PTW, modelo UNIDOS E (Fig. 5.3.a), com uma variação de $\pm 50 \mathrm{~V}$ na tensão, para as medições de corrente de ionização.

Para as medições de carga com a câmara de extrapolação, os valores foram tomados com a câmara acoplada a um eletrômetro Keithley, modelo 6517B (Fig. 5.3.b). Decidiu-se utilizar este eletrômetro por ele permitir uma variação inferior a $1 \mathrm{~V}$ na tensão aplicada à câmara e, assim, possibilitar o uso de um campo elétrico constante de $10 \mathrm{~V} / \mathrm{mm}$ durante as medições, conforme recomendado para utilização de câmaras de extrapolação (ISO, 2004).
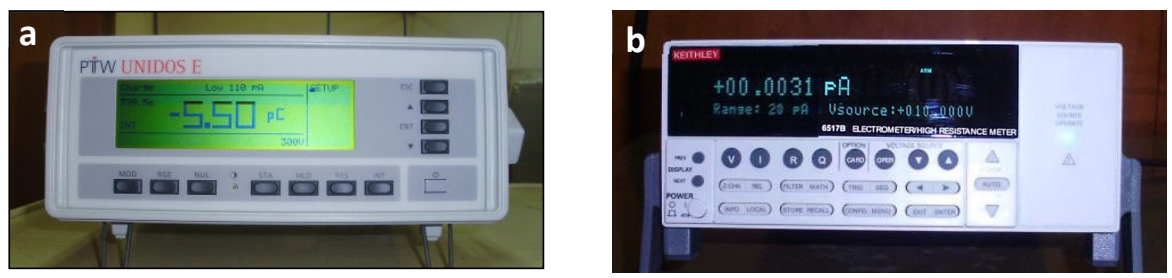

Figura 5.3 - Eletrômetros utilizados nos experimentos com as câmaras de ionização: (a) eletrômetro PTW, modelo UNIDOS E; e (b) eletrômetro Keithley, modelo 6517B.

\subsubsection{Determinação de Fatores de Correção}

Para a determinação das taxas de dose absorvida, tanto pelo método descrito por Caldas (1980), como pelo método descrito pela ISO (2004), diversos fatores de correção devem ser levados em conta (descritos no item "4.4.4. Determinação de Taxas de Dose Absorvida"). Alguns destes fatores foram obtidos, neste trabalho, por meio de cálculos ou 
experimentos, enquanto outros foram adotados como sendo os valores demonstrados por Caldas (1980), Böhm (1986) e ISO (2004).

Com relação ao método de obtenção de taxas de dose absorvida demonstrado por Caldas (1980), os fatores de correção determinados neste trabalho foram: $\boldsymbol{k}_{\boldsymbol{B} \boldsymbol{r}}, \boldsymbol{k}_{\boldsymbol{i n h}}, \boldsymbol{k}_{\boldsymbol{s a t}}, \boldsymbol{k}_{\boldsymbol{a d}}$, e $\boldsymbol{k}_{\boldsymbol{\rho}}$.

Durante todo o desenvolvimento deste trabalho, as medições foram feitas sob as seguintes condições ambientais médias: temperatura, $T=\left[(21,50 \pm 0,05)^{\circ} \mathrm{C}\right]$; pressão, $p=[(93,500 \pm 0,001) \mathrm{kPa}] ;$ e umidade relativa, $H=[(60,0 \pm 0,1) \%]$.

O fator de correção devido à emissão de Bremsstrahlung da fonte de radiação beta, $\boldsymbol{k}_{\boldsymbol{B} \boldsymbol{r}}$, pode ser determinado experimentalmente cobrindo-se a janela de entrada da câmara de extrapolação com uma placa de Plexiglas de $1 \mathrm{~cm}$ de espessura, para toda a radiação beta ser absorvida. Assim, o valor da corrente de ionização medida corresponde à radiação Bremsstrahlung. De acordo com Caldas (1980), este fator pode ser determinado por meio da Equação 5.1:

$$
k_{B r}=1-\frac{I_{B r}}{I}
$$

onde: $I$ é a corrente de ionização medida sem o absorvedor de acrílico, e $I_{B r}$ é a corrente de ionização medida com o absorvedor de acrílico.

O fator que corrige a corrente de ionização para a inhomogeneidade do campo da radiação primária dentro do volume coletor, $\boldsymbol{k}_{\boldsymbol{i n h}}$, pode ser obtido utilizando-se a Equação 5.2 (CALDAS, 1980):

$$
k_{i n h}=\frac{1-\frac{r_{3}^{2}}{2}}{1-\frac{r_{3}^{2}}{2}-\frac{r_{2}^{2}}{2}}, \quad \text { com } \quad r_{2}=\frac{a_{2}}{a} \quad \text { e } \quad r_{3}=\frac{a_{3}}{a}
$$

onde: $a$ é a distância entre a fonte e a câmara, durante as medições, $a_{2}$ é o raio do eletrodo coletor da câmara, e $a_{3}$ é o raio da fonte.

O fator de correção aplicado à corrente de ionização devido à falta de saturação da resposta da câmara, no seu volume sensível, $\boldsymbol{k}_{\text {sat }}$, é determinado pela Equação 5.3 (CALDAS, 1980): 


$$
k_{\text {sat }}=\frac{1}{f}
$$

onde: $f$ é a eficiência de coleção de íons da câmara.

A correção para os efeitos da parede da câmara é representada pelo fator, $\boldsymbol{k}_{\boldsymbol{a d}}$, que depende da distância entre a fonte e a câmara de extrapolação, e da profundidade, como é observado na Equação 5.4 (CALDAS, 1980):

$$
k_{a d}=\frac{a+d}{a} \cdot\left(1-3,5 \cdot 10^{-2} d\right)
$$

onde: $a$ é a distância fonte-detector, e $d$ é a profundidade da câmara.

O fator de correção para a variação na densidade do ar no volume sensível da câmara de extrapolação, $\boldsymbol{k}_{\boldsymbol{\rho}}$, é dado pela Equação 5.5 (CALDAS, 1980):

$$
k_{\rho}=\frac{p_{0} \cdot T}{p \cdot T_{0}}
$$

onde: $p_{0}$ é a pressão do ar $(101,3 \mathrm{kPa})$ e $T_{0}$ é a temperatura $\left(20^{\circ} \mathrm{C}\right)$, em condições de referência, $p$ é a pressão e $T$ é a temperatura durante a medição.

Os fatores de correção que não foram obtidos neste trabalho experimentalmente ou por meio de Equações (já definidos no item "4.4.4. Determinação de Taxas de Dose Absorvida"), são aqueles cujos valores foram especificados por Caldas (1980), e que estão mostrados na Tabela 5.2. Com relação ao fator de correção para a umidade do ar, o valor adotado neste trabalho foi o mesmo demonstrado por Rogers e Ross (1988).

No caso do fator de correção para o decaimento da fonte, $\boldsymbol{k}_{d e}$, ele foi adotado como sendo igual a 1, porque ele não foi obtido por meio de cálculo. A taxa de dose absorvida presente no certificado original de cada fonte teve o seu valor calculado para a data da medição por meio da própria fórmula do decaimento radioativo e, desta forma, não foi necessário se calcular o fator de correção específico para isso.

Para a determinação de taxas de dose absorvida utilizando o método descrito pela ISO (2004), diferentes fatores de correção também foram associados às correntes de ionização. Destes fatores, alguns puderam ser obtidos neste trabalho: $\boldsymbol{k}_{a d v}, \boldsymbol{k}_{d i}, \boldsymbol{k}_{\mathbf{s a t}}, \boldsymbol{k}_{\boldsymbol{b r}}$. 
Tabela 5.2 - Fatores de correção utilizados neste trabalho e seus respectivos valores (CALDAS, 1980).

\begin{tabular}{cc}
\hline Fator de Correção & Valor \\
\hline $\boldsymbol{k}_{\boldsymbol{b} \boldsymbol{a}}$ & $1,0100 \pm 0,0003$ \\
\hline $\boldsymbol{k}_{f}$ & 1 \\
\hline $\boldsymbol{k}_{d e}$ & 1 \\
\hline $\boldsymbol{k}_{h u}$ & $0,9970 \pm 0,0005$ \\
\hline $\boldsymbol{k}_{g a p}$ & 1 \\
\hline $\boldsymbol{k}_{\text {esp }}$ & 1 \\
\hline
\end{tabular}

O fator de correção $\boldsymbol{k}_{\boldsymbol{a d v}}$, devido à variações na densidade do ar, embora tenha a mesma função que o fator $\boldsymbol{k}_{\boldsymbol{\rho}}$, utilizado no método definido por Caldas (1980), é obtido de maneira diferente, pois faz uso não apenas dos valores de temperatura e pressão, mas também da umidade durante as medições. O fator $\boldsymbol{k}_{\boldsymbol{a d v}}$ pode ser obtido por meio da Equação 5.6 (ISO, 2004):

$$
k_{a d v}=\frac{\rho_{a 0}}{\rho_{a}}, \quad \text { com } \quad \rho_{a}=\rho_{a 0}\left[\frac{p}{100,726}-\frac{r}{114,2}\left(\frac{T}{T_{0}}\right)^{17,97}\right] \frac{T_{0}}{T}
$$

onde: $\rho_{a 0}$ é a densidade do ar nas condições de referência $\left[(1,1974 \pm 0,0005) \mathrm{kg} / \mathrm{m}^{3}\right], p$ é a pressão do $a r, r$ é a umidade relativa do ar, $T$ é a temperatura absoluta do ar no volume sensível, e $T_{0}$ é a temperatura em condições de referência $\left(20^{\circ} \mathrm{C}\right)$.

As condições ambientais de referência, neste caso, são descritas pela ISO (ISO, 2004) como: $T_{0}=\left[(21 \pm 0,1)^{\circ} \mathrm{C}\right] ; p_{0}=[(101,325 \pm 0,05) \mathrm{kPa}] ; \mathrm{e} r_{0}=[(0,65 \pm 0,02)]$.

A falta de uniformidade axial do campo de radiação beta pode ser corrigida, e o fator de correção, $\boldsymbol{k}_{\boldsymbol{d} i}$, pode ser calculado pela Equação 5.7 (ISO, 2004):

$$
k_{d i}=1+\frac{d}{y_{0}}
$$

onde: $d$ é a profundidade da câmara, e $y_{0}$ é a distância fonte-detector utilizada durante o experimento.

Tanto o fator de correção para as perdas de ionização (falta de saturação) da resposta da câmara de extrapolação, $\boldsymbol{k}_{\text {sat }}$, como o fator devido à presença de Bremsstrahlung, $\boldsymbol{k}_{\boldsymbol{B} \boldsymbol{r}}$, também essenciais para a correção da corrente de ionização pelo método da ISO (2004), 
foram obtidos da mesma forma que o procedimento adotado por Caldas (1980), ou seja, de acordo com as Equações 5.1 e 5 3, respectivamente.

Com exceção do fator de correção para o decaimento radioativo, $\boldsymbol{k}_{\boldsymbol{d e}}$, os demais fatores de correção envolvidos na determinação da taxa de dose absorvida pelo método da ISO (2004), que não foram calculados neste trabalho, foram adotados como sendo os valores já descritos na literatura. Estes fatores, com seus valores e referências, podem ser observados na Tabela 5.3.

Tabela 5.3 - Outros fatores de correção utilizados neste trabalho, com seus valores e referências.

\begin{tabular}{ccc}
\hline Fator de Correção & Valor & Referências \\
\hline $\boldsymbol{k}_{a b s}$ & $1,000 \pm 0,003$ & Böhm (1986); ISO (2004) \\
\hline $\boldsymbol{k}_{a c}$ & $1,0000 \pm 0,0005$ & Böhm (1986); ISO (2004) \\
\hline $\boldsymbol{k}_{d e}$ & 1 & - \\
\hline $\boldsymbol{k}_{p e}$ & $1,002 \pm 0,001$ & ISO (2004) \\
\hline $\boldsymbol{k}_{b a}$ & $1,010 \pm 0,003$ & Böhm (1986); ISO (2004) \\
\hline $\boldsymbol{k}_{\boldsymbol{l} l}$ & $1,000 \pm 0,001$ & Böhm (1986); ISO (2004) \\
\hline $\boldsymbol{k}_{h u}$ & $1,0000 \pm 0,0005$ & ISO (2004) \\
\hline $\boldsymbol{k}_{\boldsymbol{i n}}$ & $1,0000 \pm 0,0001$ & Böhm (1986); ISO (2004) \\
\hline $\boldsymbol{k}_{r a}$ & $1,000 \pm 0,005$ & Böhm (1986); ISO (2004) \\
\hline
\end{tabular}

\subsection{SISTEMAS MEDIDORES DE LUMINESCÊNCIA}

Dois sistemas medidores de luminescência: termoluminescência (TL) e luminescência opticamente estimulada (LOE), foram utilizados para a análise dos materiais dosimétricos, estudados neste trabalho, para dosimetria da radiação beta.

\subsubsection{Sistemas de Termoluminescência}

Para a avaliação do sinal TL presente em dosímetros irradiados com diferentes fontes de radiação beta e sob diferentes condições, foram utilizados dois sistemas: o sistema TL Harshaw TLD Reader, modelo 3500 (Fig. 5.4), e o sistema medidor de TL e LOE Risoe (Fig. 5.5.a), acoplado a um sistema de controle, modelo Risoe TL/OSL-DA-200 (Fig. 5.5.b).

Durante as medições no sistema da Harshaw, foi utilizada uma taxa de aquecimento de $10^{\circ} \mathrm{C} / \mathrm{s}$ e uma temperatura final de $255^{\circ} \mathrm{C}$, com um fluxo constante de $\mathrm{N}_{2}$ de $5 \mathrm{~L} / \mathrm{min}$. Para a análise da resposta TL dos dosímetros estudados com o sistema TL da Risoe, foi utilizada 
uma taxa de aquecimento de $10^{\circ} \mathrm{C} / \mathrm{s}$ e uma temperatura final de $400^{\circ} \mathrm{C}$, com um fluxo de $\mathrm{N}_{2}$ de $1 \mathrm{~L} / \mathrm{min}$. Neste sistema, uma máscara preta com um orifício central de $5 \mathrm{~mm}$ de diâmetro foi utilizada entre a fotomultiplicadora e o filtro Hoya U-340 (usado nas medições), para evitar a saturação da fotomultiplicadora (em casos de doses acima de $1 \mathrm{~Gy}$, dependendo do material).

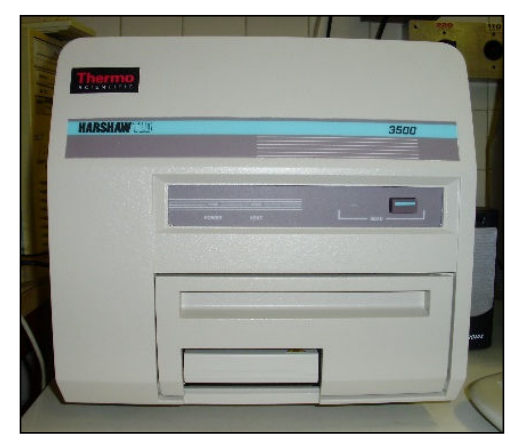

Figura 5.4 - Sistema medidor de termoluminescência da Harshaw, modelo 3500.
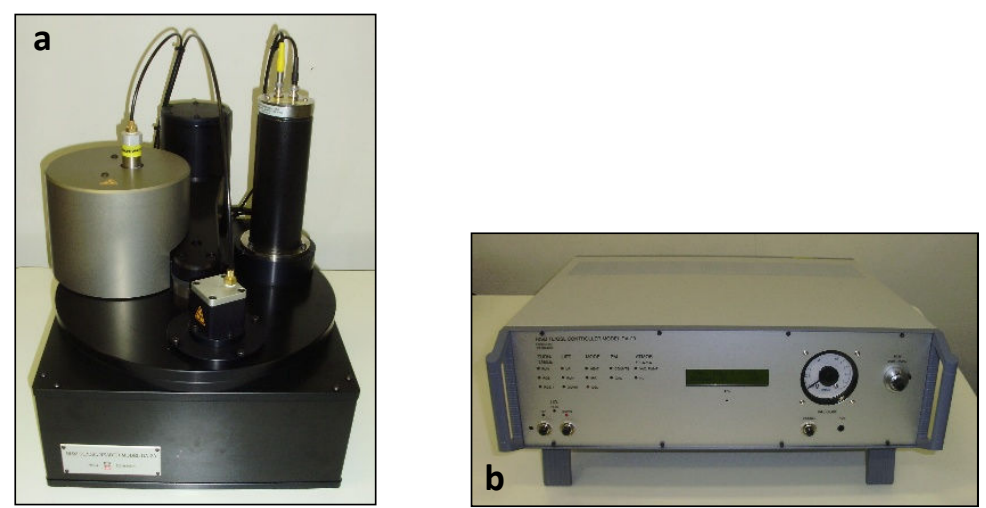

Figura 5.5 - Sistema medidor de termoluminescência e luminescência opticamente estimulada Risoe: (a) medidor luminescente; e (b) sistema de controle.

\subsubsection{Sistemas de Luminescência Opticamente Estimulada}

O sinal LOE presente em dosímetros estudados com relação à sua resposta em diferentes campos de radiação beta foi avaliado utilizando-se três sistemas: o sistema da Landauer, modelo microStar (Fig. 5.6.a), o sistema medidor de LOE modelo DOIN-L001, fabricado na Universidade Federal de Pernambuco, acoplado ao sistema de aquisição de dados Logan, modelo SAD-2000 (Fig. 5.6.b), e o sistema da Risoe (Fig. 5.5.a-b), já descrito no item 5.2.1.

O sistema da Landauer utiliza LEDs verdes para estimular o sinal LOE das amostras, enquanto o sistema DOIN-L001 utiliza dois tipos de LEDs: verde e azul. No caso do sistema 
medidor da Risoe, foram utilizados LEDs azuis com potência óptica de $90 \%$ e um tempo de estimulação de $50 \mathrm{~s}$.
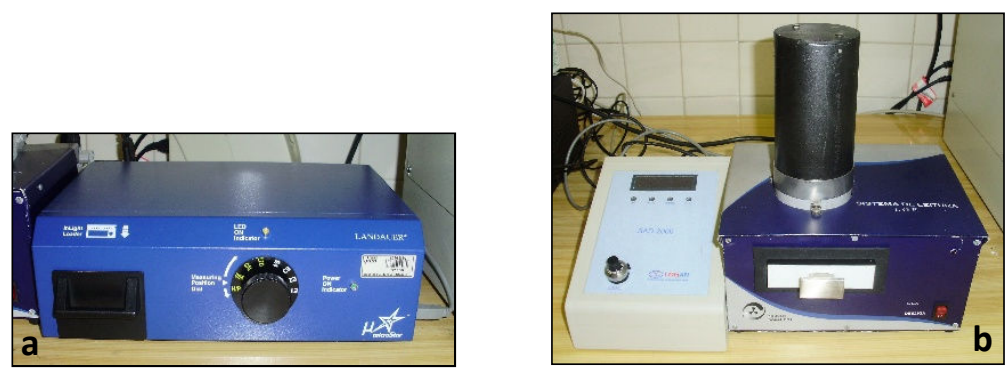

Figura 5.6 - Sistemas medidores de luminescência opticamente estimulada: (a) da Landauer, para medição de detectores $\mathrm{Al}_{2} \mathrm{O}_{3}: \mathrm{C}$, da Landauer; e (b) DOIN-L001, para medição de diferentes materiais LOE.

\subsection{MATERIAIS DosimÉtricos}

Durante o desenvolvimento deste trabalho, diferentes materiais dosimétricos foram estudados e caracterizados com relação à sua resposta TL e LOE. Os materiais TL foram os seguintes: $\mathrm{CaSO}_{4}: \mathrm{Dy}$ + Teflon (de $20 \mathrm{mg}$ e de $50 \mathrm{mg}$ ), produzido no IPEN; LiF:Mg,Ti (TLD-100), $\mathrm{CaF}_{2}: \mathrm{Dy}(\mathrm{TLD}-200)$ e $\mathrm{CaF}_{2}: \mathrm{Mn}$ (TLD-400), da Harshaw; e $\mathrm{Al}_{2} \mathrm{O}_{3}: \mathrm{C}$, da Rexon. As amostras LOE foram: $\mathrm{Al}_{2} \mathrm{O}_{3}: \mathrm{C}$, tipo NanoDot, da Landauer, e $\mathrm{Al}_{2} \mathrm{O}_{3}: \mathrm{C}$, da Rexon. A Tabela 5.4 apresenta as características mais importantes destes materiais, bem como as condições de tratamento para sua reutilização. Nas Fig. 5.7.a-b e 5.8.a-b são mostrados todos os detectores utilizados.

Tabela 5.4 - Características dos materiais luminescentes estudados neste trabalho.

\begin{tabular}{|c|c|c|c|c|c|}
\hline \multirow{2}{*}{ Material } & \multirow{2}{*}{ Dimensões } & \multicolumn{2}{|c|}{ Luminescência } & \multicolumn{2}{|c|}{ Tratamento } \\
\hline & & TL & LOE & Térmico & Óptico \\
\hline $\begin{array}{c}\mathrm{CaSO}_{4}: \mathrm{Dy}+\text { Teflon } \\
(20 \mathrm{mg})\end{array}$ & $\begin{array}{l}\text { Diâmetro: } 6,0 \mathrm{~mm} \\
\text { Espessura: } 0,2 \mathrm{~mm}\end{array}$ & $x$ & - & $300^{\circ} \mathrm{C} / 3 \mathrm{~h}$ & - \\
\hline $\begin{array}{c}\mathrm{CaSO}_{4}: \mathrm{Dy}+\text { Teflon } \\
(50 \mathrm{mg})\end{array}$ & $\begin{array}{l}\text { Diâmetro: } 6,0 \mathrm{~mm} \\
\text { Espessura: } 0,8 \mathrm{~mm}\end{array}$ & $x$ & - & $300^{\circ} \mathrm{C} / 3 \mathrm{~h}$ & - \\
\hline LiF:Mg,Ti & $3 \times 3 \times 0,9 \mathrm{~mm}^{3}$ & $x$ & - & $400^{\circ} \mathrm{C} / 1 \mathrm{~h}$ & - \\
\hline $\mathrm{CaF}_{2}: \mathrm{Dy}$ & $3 \times 3 \times 0,9 \mathrm{~mm}^{3}$ & $x$ & - & $500^{\circ} \mathrm{C} / 1 \mathrm{~h}$ & - \\
\hline $\mathrm{CaF}_{2}: \mathrm{Mn}$ & $3 \times 3 \times 0,9 \mathrm{~mm}^{3}$ & $x$ & - & $500^{\circ} \mathrm{C} / 1 \mathrm{~h}$ & - \\
\hline $\begin{array}{l}\mathrm{Al}_{2} \mathrm{O}_{3}: \mathrm{C} \\
\text { Rexon }\end{array}$ & $\begin{array}{l}\text { Diâmetro: } 5,0 \mathrm{~mm} \\
\text { Espessura: } 1,0 \mathrm{~mm}\end{array}$ & $x$ & $x$ & $400^{\circ} \mathrm{C} / 1 \mathrm{~h}$ & - \\
\hline $\begin{array}{l}\mathrm{Al}_{2} \mathrm{O}_{3}: \mathrm{C} \\
\text { NanoDot }\end{array}$ & $\begin{array}{l}\text { Diâmetro: 7,0 mm } \\
\text { Espessura: 0,3 mm }\end{array}$ & - & $x$ & - & $\begin{array}{l}21.000 \text { lux } / 24 \mathrm{~h} \\
\text { (luz fluorescente) }\end{array}$ \\
\hline
\end{tabular}




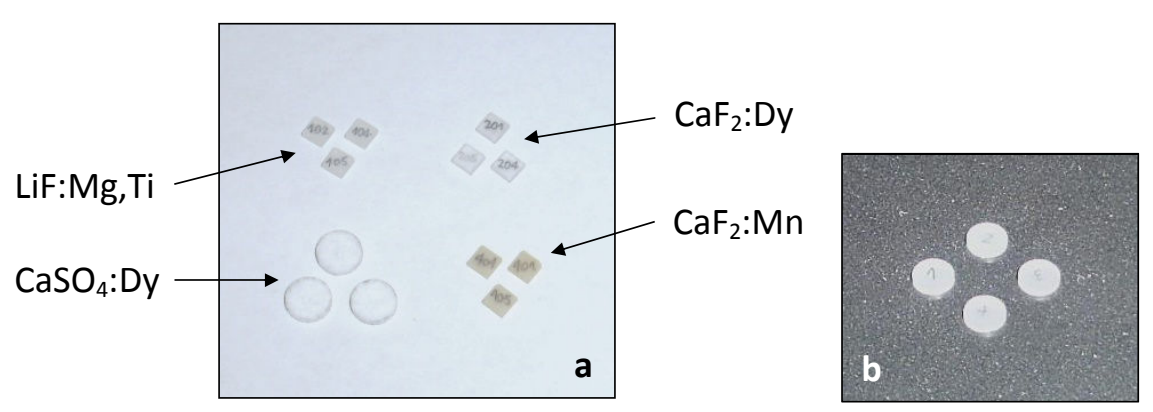

Figura 5.7 - Materiais dosimétricos utilizados neste trabalho: (a) TL; e (b) TL e $\operatorname{LOE}\left(\mathrm{Al}_{2} \mathrm{O}_{3}: \mathrm{C}\right)$, da Rexon.

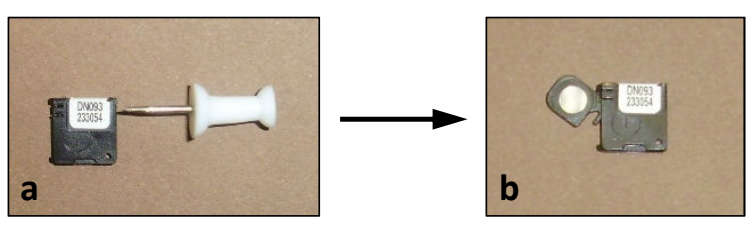

Figura 5.8 - Detector LOE de $\mathrm{Al}_{2} \mathrm{O}_{3}: \mathrm{C}$, tipo nanoDot, da Landauer: (a) com o material dentro do adaptador; e (b) com o material puxado para fora do adaptador.

\subsection{FONTES de RADIAÇÃo BETA}

Para o desenvolvimento deste trabalho, diferentes fontes de radiação beta foram utilizadas: fontes padrões secundários e aplicadores clínicos de ${ }^{90} \mathrm{Sr}+{ }^{90} \mathrm{Y}$.

O LCl possui dois sistemas padrões secundários de radiação beta, cujas fontes (Fig. 5.9.a-b) foram calibradas no laboratório padrão primário da Alemanha, PTB: o BSS1, Buchler GmbH \& Co., Alemanha (Fig. 4.1), e o BSS2, Isotrak, Alemanha (Fig. 4.2). Estes dois sistemas apresentam diversos componentes, como os filtros uniformizadores de campo, que foram ou não utilizados durante as irradiações, de acordo com as condições especificadas em cada certificado de calibração. A Tabela 5.5 especifica as fontes que compõem os sistemas e mostra as suas características.
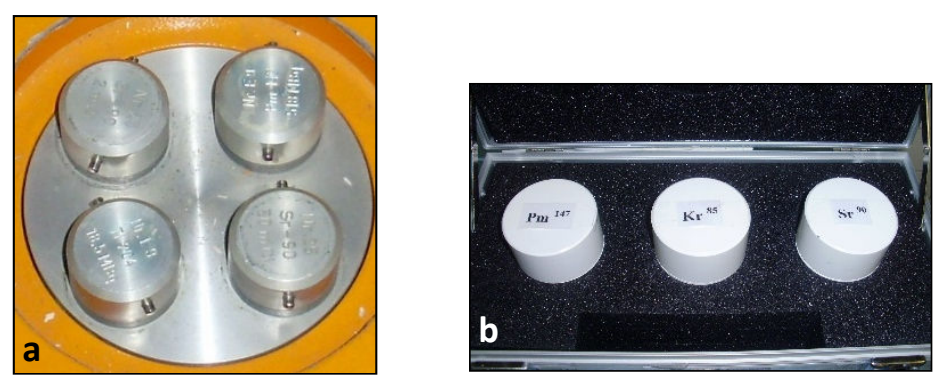

Figura 5.9 - Fontes padrões secundários de radiação beta dos sistemas: (a) BSS1; e (b) BSS2. 
Tabela 5.5 - Características das fontes de radiação beta dos sistemas padrões secundários BSS1 e BSS2, e suas condições de utilização.

\begin{tabular}{|c|c|c|c|c|c|c|}
\hline $\begin{array}{c}\text { Sistema Padrão } \\
\text { Secundário } \\
\text { de Radiação Beta }\end{array}$ & $\begin{array}{l}\text { Fonte de } \\
\text { Radiação }\end{array}$ & Filtro & $\begin{array}{c}\text { Taxa de Dose } \\
\text { Absorvida } \\
(\mu \mathrm{Gy} / \mathrm{s})\end{array}$ & $\begin{array}{c}\text { Atividade } \\
\text { Nominal } \\
(\mathrm{MBq})\end{array}$ & $\begin{array}{c}\text { Distância } \\
\text { de Calibração } \\
(\mathrm{cm})\end{array}$ & $\begin{array}{l}\text { Data de } \\
\text { Referência }\end{array}$ \\
\hline \multirow{6}{*}{ BSS1 } & ${ }^{90} \mathrm{Sr}+{ }^{90} \mathrm{Y}$ & Sim & $1,707 \pm 0,017$ & 74 & 30 & 12.01 .1981 \\
\hline & \multirow{3}{*}{${ }^{90} \mathrm{Sr}+{ }^{90} \mathrm{Y}$} & \multirow{3}{*}{ Não } & $518,4 \pm 5,180$ & \multirow{3}{*}{1850} & 11 & 04.02 .1981 \\
\hline & & & $70,60 \pm 0,710$ & & 30 & 04.02 .1981 \\
\hline & & & $25,23 \pm 0,252$ & & 50 & 04.02 .1981 \\
\hline & ${ }^{204} \mathrm{TI}$ & Sim & $0,412 \pm 0,002$ & 18,5 & 30 & 09.06 .1990 \\
\hline & ${ }^{147} \mathrm{Pm}$ & Sim & $0,366 \pm 0,004$ & 518 & 20 & 25.05 .1990 \\
\hline \multirow{7}{*}{ BSS2 } & \multirow{5}{*}{${ }^{90} \mathrm{Sr}+{ }^{90} \mathrm{Y}$} & \multirow{2}{*}{ Não } & $119,5 \pm 1,500$ & \multirow{5}{*}{460} & 11 & 10.02 .2005 \\
\hline & & & $37,10 \pm 0,500$ & & 20 & 21.01.2005 \\
\hline & & Sim & $10,56 \pm 0,140$ & & 30 & 08.12 .2004 \\
\hline & & Não & $16,46 \pm 0,220$ & & 30 & 12.01 .2005 \\
\hline & & Não & $5,820 \pm 0,080$ & & 50 & 21.12.2004 \\
\hline & ${ }^{85} \mathrm{Kr}$ & Sim & $39,70 \pm 0,500$ & 3700 & 30 & 30.11 .2004 \\
\hline & ${ }^{147} \mathrm{Pm}$ & Sim & $2,350 \pm 0,050$ & 3700 & 20 & 19.11.2004 \\
\hline
\end{tabular}

O LCl também possui aplicadores clínicos de ${ }^{90} \mathrm{Sr}+{ }^{90} \mathrm{Y}$, todos planos e para uso dermatológico: um calibrado no laboratório padrão primário do NIST, Estados Unidos, Atlantic Research Corporation, modelo B-1 S/N 233 (utilizado como aplicador de referência neste trabalho), dois aplicadores com certificados de calibração do fabricante Amersham, Inglaterra, e um que não possui certificado. Na Tabela 5.6 podem ser observadas outras características destas fontes.

Tabela 5.6 - Características dos aplicadores clínicos de ${ }^{90} \mathrm{Sr}+{ }^{90} \mathrm{Y}$ do $\mathrm{LCl}$.

\begin{tabular}{cccccc}
\hline Aplicador & Tipo & $\begin{array}{c}\text { Marca } \\
\text { e Modelo }\end{array}$ & $\begin{array}{c}\text { Atividade } \\
\text { Nominal } \\
\text { (MBq) }\end{array}$ & $\begin{array}{c}\text { Taxa de Dose } \\
\text { Absorvida } \\
(\mathbf{G y} / \mathbf{s})\end{array}$ & $\begin{array}{c}\text { Data } \\
\text { de } \\
\text { Calibração }\end{array}$ \\
\hline A $_{\text {NIST }}$ & Dermatológico & $\begin{array}{c}\text { Atlantic Research } \\
\text { Corporation/B-1 S/N 233 }\end{array}$ & $\begin{array}{c}\text { Não } \\
\text { informado }\end{array}$ & 0,40 & 28.01 .2003 \\
\hline A1 & Dermatológico & Amersham/SIQ 18 & 1480 & 0,056 & 08.11 .1968 \\
\hline A2 & Dermatológico & & Não possui certificado & \\
\hline A3 & Dermatológico & Amersham/SIQ 21 & 740 & 0,053 & 17.09 .1986 \\
\hline
\end{tabular}


Foram utilizados ainda diversos aplicadores clínicos de ${ }^{90} \mathrm{Sr}+{ }^{90} \mathrm{Y}$, oftálmicos e dermatológicos, de diferentes hospitais e serviços de radioterapia de São Paulo, e também da UFS. As Tabelas 5.7 e 5.8 mostram as especificações destas fontes, e nas Fig. 5.10.a-d, podem ser observados alguns exemplos de aplicadores clínicos.

Tabela 5.7 - Características dos aplicadores clínicos de ${ }^{90} \mathrm{Sr}+{ }^{90} \mathrm{Y}$, de diferentes hospitais, utilizados em betaterapia, calibrados neste trabalho.

\begin{tabular}{|c|c|c|c|c|c|c|}
\hline Hospital & Fonte & $\begin{array}{l}\text { Número } \\
\text { da Fonte }\end{array}$ & Modelo & $\begin{array}{c}\text { Atividade } \\
\text { Nominal } \\
(\mathrm{MBq}) \\
\end{array}$ & $\begin{array}{c}\text { Taxa de Dose } \\
\text { Absorvida } \\
\text { (Gy/s) }\end{array}$ & $\begin{array}{l}\text { Data de } \\
\text { Calibração }\end{array}$ \\
\hline \multirow{2}{*}{1} & Dermatológico & 1 & 0103MP - SIQ18 & 1480 & $0,060 \pm 0,012$ & 25.10 .78 \\
\hline & Oftálmico & 2 & 0071ML - SIA6 & 370 & $0,055 \pm 0,016$ & 02.10 .78 \\
\hline \multirow{3}{*}{2} & Dermatológico & $3^{*}$ & - & - & $0,033 \pm 0,007$ & 01.03 .91 \\
\hline & Dermatológico & $4^{*}$ & - & - & $0,033 \pm 0,007$ & 01.03 .91 \\
\hline & Oftálmico & $5^{*}$ & - & - & $0,033 \pm 0,010$ & 01.03 .91 \\
\hline \multirow{4}{*}{3} & Dermatológico & 6 & $0371 \mathrm{MP}$ - SIQ18 & 1480 & $0,062 \pm 0,012$ & 18.08 .93 \\
\hline & Dermatológico & 7 & 0360MP - SIQ21 & 740 & $0,070 \pm 0,014$ & 21.06 .93 \\
\hline & Oftálmico & 8 & $1003 \mathrm{ML}-\mathrm{SIA6}$ & 370 & $0,064 \pm 0,019$ & 21.06 .93 \\
\hline & Oftálmico & 9 & SIAS/1116 - SIA5 & 74 & $0,042 \pm 0,013$ & 01.02 .69 \\
\hline \multirow{2}{*}{4} & Dermatológico & 10 & SR 1073 - SIQ20 & 370 & $0,029 \pm 0,006$ & 15.08 .73 \\
\hline & Oftálmico & 11 & SIA6/1447 & 370 & $0,075 \pm 0,022$ & 05.06 .73 \\
\hline \multirow{3}{*}{5} & Dermatológico & 12 & 0333MP - SIQ21 & 740 & $0,051 \pm 0,010$ & 11.02 .92 \\
\hline & Oftálmico & 13 & SIA5/1298 & 74 & $0,036 \pm 0,011$ & 10.08 .71 \\
\hline & Oftálmico & 14 & 0931ML - SIA6 & 370 & $0,049 \pm 0,015$ & 24.01 .92 \\
\hline
\end{tabular}

* Não apresentam certificados originais

Tabela 5.8 - Características dos aplicadores clínicos de ${ }^{90} \mathrm{Sr}+{ }^{90} \mathrm{Y}$, da Universidade Federal de Sergipe (UFS).

\begin{tabular}{cccccc}
\hline Fonte & $\begin{array}{c}\text { Número } \\
\text { da Fonte }\end{array}$ & Modelo & $\begin{array}{c}\text { Atividade } \\
\text { Nominal } \\
\text { (MBq) }\end{array}$ & $\begin{array}{c}\text { Taxa de Dose } \\
\text { Absorvida } \\
(\text { Gy/s) }\end{array}$ & $\begin{array}{c}\text { Data de } \\
\text { Calibração }\end{array}$ \\
\hline Dermatológico & $1 \mathrm{~A}$ & $2167-\mathrm{SIQ7}$ & 370 & $14,6 \pm 2,9$ & 27.11 .1973 \\
\hline Dermatológico & $2 \mathrm{~A}$ & $1520-\mathrm{SIA5}$ & 74 & $44,0 \pm 8,8$ & 27.11 .1973 \\
\hline Oftálmico & $3 \mathrm{~A}$ & $9737-\mathrm{SIQ6}$ & 740 & $15,0 \pm 4,5$ & 14.01 .1992 \\
\hline Oftálmico & 4A & $1522-\mathrm{SIA6}$ & 370 & $55,0 \pm 16,5$ & 27.11 .1973 \\
\hline Oftálmico & 5A & $928-\mathrm{SIA6}$ & 370 & $43,8 \pm 13,1$ & 07.01 .1992 \\
\hline
\end{tabular}



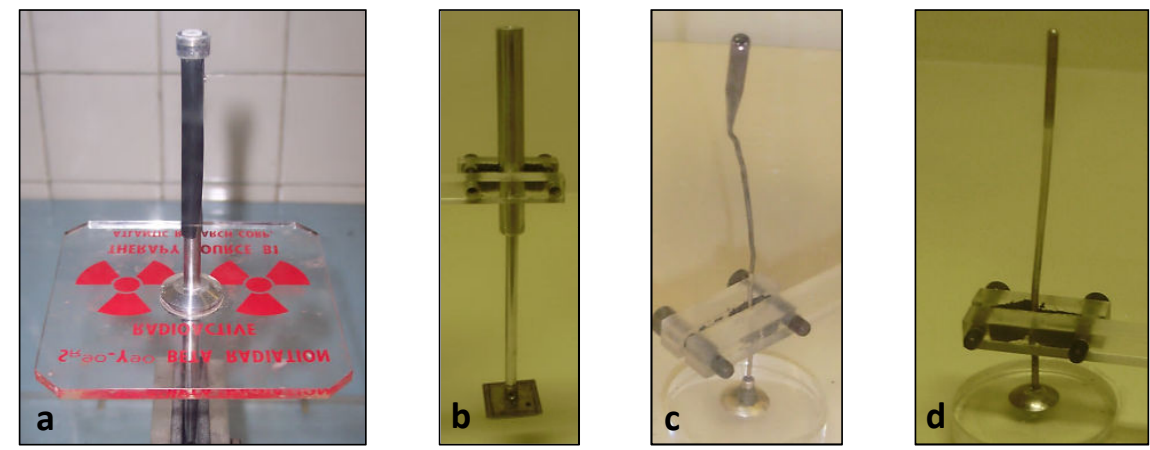

Figura 5.10 - Exemplos de aplicadores clínicos de ${ }^{90} \mathrm{Sr}+{ }^{90} \mathrm{Y}$ : (a) $\mathrm{A}_{\mathrm{NIST}}$ e (b) fonte 6 (dermatológicos); (c) fonte 3 e (d) fonte 8 (oftálmicos).

Uma fonte de controle de ${ }^{90} \mathrm{Sr}^{9}{ }^{90} \mathrm{Y}$ (atividade nominal de $33 \mathrm{MBq}, 1988$ ), PTW, tipo 8921, foi também utilizada neste trabalho, em testes de caracterização das câmaras de ionização. Na Fig. 5.11 pode-se observar esta fonte e sua blindagem.

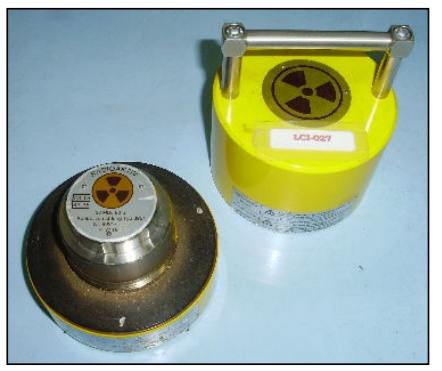

Figura 5.11 - Fonte de controle de ${ }^{90} \mathrm{Sr}+{ }^{90} \mathrm{Y}$, utilizada em testes de caracterização da resposta de câmaras de ionização estudadas neste trabalho.

\subsection{ACESSÓRIOS e Sistemas AuXILIARES}

Para o cumprimento da fase experimental deste trabalho, foram ainda utilizados diferentes acessórios e sistemas auxiliares:

¿ Termômetro de mercúrio, higrômetro Haenni e barômetro composto por um transdutor Setra, modelo 270, e um multímetro Keithley, modelo 177, para a monitoração das condições ambientais (temperatura, umidade e pressão atmosférica) dos laboratórios onde foram realizadas as medições com as câmaras de extrapolação;

¿ Cronômetro Herweg, modelo 8906;

¿ Dessecadores para armazenamento das câmaras de ionização e dos cabos, quando não em uso; 
¿ Dessecador para armazenamento da câmara de extrapolação Böhm, do eletrômetro Keithley, modelo 6517B, e dos cabos;

¿ Caixa de madeira com dimensões de $66 \times 21 \times 17 \mathrm{~cm}^{3}$, contendo duas lâmpadas fluorescentes de $20 \mathrm{~W}$, marca Sylvania, modelo F16 W/78, para tratamento de reutilização dos detectores LOE;

¿ Radiômetro da Delta OHM, modelo DO (série LP9021) e sensor de nível de iluminamento LP 9021 PHOT, calibrados pelo fabricante Delta OHM;

\& Forno fabricado pelo Instituto de Radioproteção e Dosimetria (IRD), CNEN, Rio de Janeiro, para tratamento térmico de reutilização dos dosímetros TL e LOE;

¿ Forno mufla por microondas Provecto Analítica, modelo MFL-1000;

Q Placas circulares de alumínio, de $7 \mathrm{~cm}$ de diâmetro, para o tratamento térmico das pastilhas;

¿. Suporte circular de acrílico com dimensões de $5 \mathrm{~cm}$ de diâmetro e $1 \mathrm{~cm}$ de espessura, e um orifício em seu centro para posicionamento das amostras luminescentes e posterior irradiação com aplicador clínico;

¿. Goniômetro para estudo da dependência angular das câmaras de ionização.

\subsection{ESTIMATIVA DE INCERTEZAS}

Em relação à análise e à expressão das incertezas relacionadas a todas as medições realizadas neste trabalho, elas foram obtidas de acordo com as recomendações da Associação Brasileira de Normas Técnicas (ABNT, 2003). As formas de avaliação das incertezas padrões envolveram as dos Tipos A e B, e então, as incertezas combinadas e posteriormente as expandidas foram determinadas.

A incerteza padrão envolve as formas de avaliação dos Tipos A e B. A avaliação da incerteza do Tipo A deve ser realizada por meio de uma análise estatística de uma série de observações, como por exemplo, as medições das correntes de ionização coletadas pelo eletrômetro (das medições destas correntes de ionização, são obtidos a média aritmética e o desvio-padrão); assim, a incerteza do tipo A consiste no desvio-padrão da média destas medições. A avaliação do Tipo B é aquela relacionada aos erros sistemáticos, e não depende de uma análise estatística, mas de outros parâmetros, como por exemplo: a resolução de instrumentos de medições (termômetro, barômetro, higrômetro, eletrômetro e parafuso 
micrométrico (no caso de uma câmara de extrapolação)), as incertezas dos fatores de correção, e a incerteza associada à fonte de radiação, fornecida em seu certificado de calibração.

Considerando, por exemplo, a análise para o cálculo da incerteza de um valor de taxa de dose absorvida, as incertezas associadas ao termômetro, barômetro, higrômetro, eletrômetro, parafuso micrométrico, fatores de correção e fonte de radiação foram usadas na determinação da incerteza do coeficiente angular, $B$, da curva de extrapolação.

A incerteza padrão combinada de uma medição é aquela na qual o resultado é obtido por meio de outras grandezas, e também envolve as avaliações de Tipos A e B; ela é obtida pela raiz quadrada da soma dos termos cada um ao quadrado. No caso da incerteza de uma taxa de dose absorvida, a incerteza combinada é obtida levando-se em conta as incertezas do coeficiente angular, da energia média de formação de um par de íons, da razão entre os poderes de freamento médios do tecido e do ar, da densidade do ar nas condições ambientais de referência de temperatura e pressão, e dos fatores de correção.

A incerteza expandida consiste no produto da incerteza padrão combinada e o fator de abrangência, $k$, maior ou igual a 1 . Os valores de incerteza finais obtidos neste trabalho correspondem à incerteza expandida usando o fator de abrangência de 2, o qual se refere ao nível de confiança de $95 \%$.

A Tabela 5.9 mostra um exemplo, resumidamente, da análise para a determinação de uma incerteza associada a um valor de taxa de dose absorvida (no caso, de um aplicador clínico de ${ }^{90} \mathrm{Sr}+{ }^{90} \mathrm{Y}$ ), podendo ser observadas as incertezas envolvidas, de acordo com as explicações dadas anteriormente. 
Tabela 5.9 - Valores de incerteza usados para se calcular a incerteza expandida associada à taxa de dose absorvida determinada para uma fonte padrão secundário de radiação beta de ${ }^{90} \mathrm{Sr}+{ }^{90} \mathrm{Y}$ (a taxa de dose absorvida, neste caso, foi obtida pelo método descrito por Caldas (1980)).

\begin{tabular}{|c|c|c|c|}
\hline Incerteza & & Componentes & Valor da Incerteza (\%) \\
\hline \multirow{15}{*}{ Padrão } & Tipo A & Desvio padrão das medições & 0,75 \\
\hline & \multirow{14}{*}{ Tipo B } & Termômetro & 0,23 \\
\hline & & Barômetro & 0,001 \\
\hline & & Higrômetro & 0,25 \\
\hline & & Eletrômetro & 0,03 \\
\hline & & Parafuso micrométrico & 0,05 \\
\hline & & Fonte de radiação & 1,32 \\
\hline & & $k_{b a}$ & 0,03 \\
\hline & & $\boldsymbol{k}_{f}$ & - \\
\hline & & $\boldsymbol{k}_{B r}$ & 0,96 \\
\hline & & $\boldsymbol{k}_{d e}$ & - \\
\hline & & $\boldsymbol{k}_{h u}$ & 0,05 \\
\hline & & $\boldsymbol{k}_{\text {gap }}$ & - \\
\hline & & $\boldsymbol{k}_{\text {esp }}$ & 一 \\
\hline & & $\boldsymbol{k}_{\text {inh }}$ & 0,44 \\
\hline \multirow{9}{*}{ Combinada } & & ficiente angular, $B$ & 0,36 \\
\hline & & ergia média, $\bar{W}$ & 0,44 \\
\hline & & rga elementar, e & - \\
\hline & $\begin{array}{r}\text { Razão } \\
\text { méc }\end{array}$ & $\begin{array}{l}\text { os poderes de freamento } \\
\text { o tecido e do ar, } S_{\text {air }}^{\text {water }}\end{array}$ & 0,62 \\
\hline & & nsidade do ar, $\rho_{0}$ & 0,08 \\
\hline & Área & va do eletrodo coletor, $a$ & 0,03 \\
\hline & & $\boldsymbol{k}_{\text {sat }}$ & 2,64 \\
\hline & & $\boldsymbol{k}_{a d}$ & 0,23 \\
\hline & & $\boldsymbol{k}_{\rho}$ & 0,23 \\
\hline Expandida & Incert & ombinada $(3,06 \%)$ x k (2) & 6,18 \\
\hline
\end{tabular}




\section{Resultados e Discussão}

Os resultados obtidos neste trabalho com a câmara de extrapolação Böhm e as outras câmaras de ionização de placas paralelas convencionais, e com os dosímetros TL e LOE, serão apresentados e discutidos neste capítulo. O uso de câmaras de ionização convencionais e de dosímetros TL e LOE são estabelecidos no presente trabalho como métodos alternativos para dosimetria de feixes de radiação beta quando não é possível se utilizar a câmara de extrapolação Böhm.

\subsection{Caracterização da Câmara de Extrapolação Böhm}

Como a câmara de extrapolação Böhm foi recebida no IPEN com sua janela de entrada rasgada (de Hostaphan grafitado), a primeira etapa realizada antes do início do estudo da resposta da câmara foi a aplicação de uma nova janela de entrada. Para tal, foi necessário se retirar o suporte para o posicionamento da janela, a fim de remover a janela de entrada rasgada e colocar uma nova, de Mylar aluminizado. Como esta etapa teve que ser realizada obrigatoriamente, aproveitou-se para desmontar completamente a câmara de extrapolação (Fig. 6.1), a fim de se verificar todas as suas peças e o estado delas.
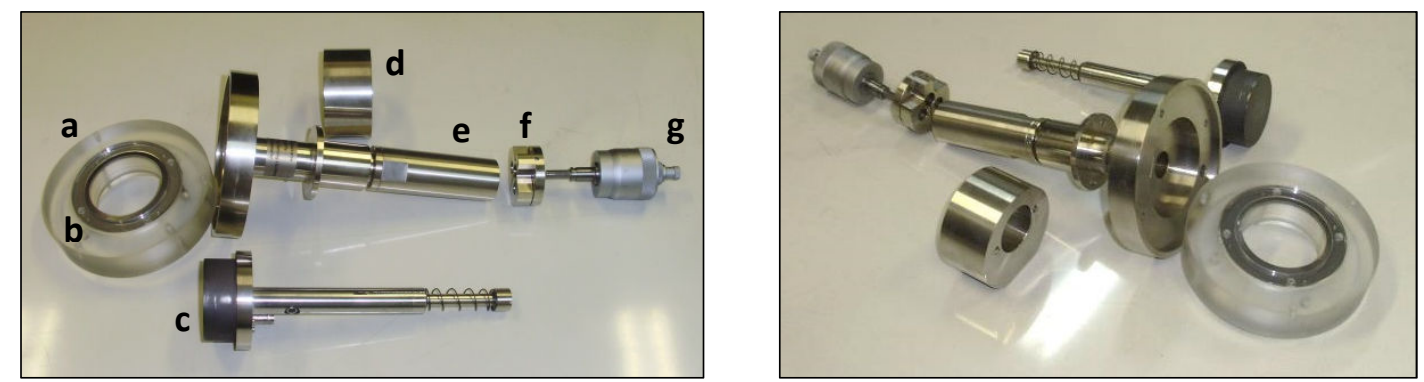

Figura 6.1 - Câmara de extrapolação Böhm, em duas vistas, mostrando alguns dos seus acessórios: (a) anel de acrílico; (b) anel de fixação da janela de entrada; (c) bloco de acrílico que forma o eletrodo coletor; (d) anel de acoplamento da estrutura central e haste de fixação; (e) corpo da câmara (cilindro externo); (f) base de fixação do parafuso micrométrico ao cilindro externo; e (g) parafuso micrométrico.

A câmara de extrapolação Böhm foi estudada inicialmente utilizando-se uma janela de entrada de Mylar aluminizado com densidade superficial de $0,71 \mathrm{mg} / \mathrm{cm}^{2}$. Logo após a janela 
de entrada original do fabricante ser adquirida (material de Hostaphan grafitado, com densidade superficial de $0,72 \mathrm{mg} / \mathrm{cm}^{2}$ ), a antiga foi substituída e a câmara de extrapolação teve, então, a sua resposta estudada com a segunda janela de entrada.

\subsubsection{Curvas de Saturação}

Com o propósito de se verificar o desempenho da câmara de extrapolação Böhm na presença de diferentes tensões aplicadas a ela, e para a determinação do efeito de polaridade em cada caso, foram determinadas, como teste de caracterização inicial, as curvas de saturação para três profundidades diferentes da câmara $(0,7 \mathrm{~mm}, 1,5 \mathrm{~mm}$ e 2,5 mm), expondo-se a câmara à fonte de ${ }^{90} \mathrm{Sr}+{ }^{90} \mathrm{Y}(1850 \mathrm{MBq}, 1981)$, como mostra a Fig. 6.2; neste item sobre a câmara de extrapolação Böhm, a profundidade da câmara será sempre simbolizada pela letra $d$. Com os resultados das curvas de saturação, podem ser determinadas outras características da câmara: eficiência de coleção de íons, recombinação iônica e efeito de polaridade.

Neste estudo, as condições adotadas para as medições foram: tensão aplicada entre os eletrodos da câmara de $\pm 2 \mathrm{~V}$ a $\pm 300 \mathrm{~V}$, distância fonte-detector de $11 \mathrm{~cm}$, e tempo de coleta de carga de $60 \mathrm{~s}$. As curvas de saturação foram obtidas sob as mesmas condições para ambas as janelas de entrada da câmara. Na Tabela 6.1 podem ser observados os valores de corrente de ionização obtidos para ambas as polaridades de tensão para cada uma das curvas de saturação, no caso da janela de entrada de Mylar aluminizado, enquanto que os resultados obtidos com a janela de Hostaphan podem ser observados na Tabela 6.2.

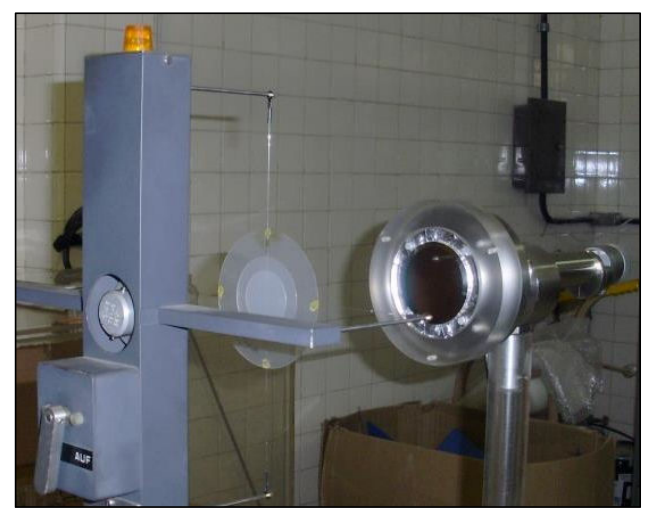

Figura 6.2 - Câmara de extrapolação Böhm, com janela de entrada de Mylar aluminizado, posicionada no sistema BSS1. 
Tabela 6.1 - Correntes de ionização médias obtidas na região de saturação para as polaridades positiva e negativa de tensão com a câmara de extrapolação Böhm (em três profundidades da câmara), e janela de entrada de Mylar aluminizado.

\begin{tabular}{|c|c|c|c|}
\hline \multirow{2}{*}{$\begin{array}{c}\text { Profundidade } \\
\text { da Câmara } \\
\text { (mm) }\end{array}$} & \multicolumn{2}{|c|}{$\begin{array}{l}\text { Corrente de lonização Média } \\
\text { (pA) }\end{array}$} & \multirow{2}{*}{$\begin{array}{c}\text { Coeficiente } \\
\text { de Variação Máximo } \\
(\%)\end{array}$} \\
\hline & Polaridade Positiva & Polaridade Negativa & \\
\hline 0,7 & $+3,562 \pm 0,016$ & $-5,188 \pm 0,024$ & $-2,33$ \\
\hline 1,5 & $+8,592 \pm 0,020$ & $-10,162 \pm 0,023$ & $-1,97$ \\
\hline 2,5 & $+14,596 \pm 0,029$ & $-16,097 \pm 0,032$ & $-2,35$ \\
\hline
\end{tabular}

Tabela 6.2-Correntes de ionização médias obtidas na região de saturação para ambas as polaridades de tensão com a câmara de extrapolação Böhm (em três profundidades diferentes), e janela de entrada de Hostaphan grafitado.

\begin{tabular}{|c|c|c|c|}
\hline \multirow{2}{*}{$\begin{array}{l}\text { Profundidade } \\
\text { da Câmara } \\
\text { (mm) }\end{array}$} & \multicolumn{2}{|c|}{$\begin{array}{l}\text { Corrente de lonização Média } \\
\text { (pA) }\end{array}$} & \multirow{2}{*}{$\begin{array}{c}\text { Coeficiente } \\
\text { de Variação Máximo } \\
(\%)\end{array}$} \\
\hline & Polaridade Positiva & Polaridade Negativa & \\
\hline 0,7 & $+3,385 \pm 0,015$ & $-4,995 \pm 0,017$ & $-1,08$ \\
\hline 1,5 & $+8,169 \pm 0,019$ & $-9,601 \pm 0,012$ & $-2,19$ \\
\hline 2,5 & $+14,120 \pm 0,018$ & $-15,613 \pm 0,026$ & $-0,83$ \\
\hline
\end{tabular}

Comparando-se os resultados de corrente de ionização obtidos para as polaridades positiva e negativa de tensão, e para ambas as janelas de entrada de Mylar aluminizado e Hostaphan grafitado, foi possível observar uma diferença que variou de 3,10\% (profundidade de 2,5 $\mathrm{mm}$ e polaridade negativa) a 5,84\% (profundidade de $1,5 \mathrm{~mm}$ e polaridade negativa). Esta comparação permite observar que não há uma diferença significativa entre o uso de Mylar aluminizado ou Hostaphan grafitado como materiais de janela de entrada, no caso da determinação de curvas de saturação.

A Figura 6.3.a foi elaborada nas mesmas condições de outros trabalhos (BÖHM, 1986; SILVA e CALDAS, 2012), na qual podem ser observadas as três curvas de saturação nas três profundidades da câmara, a fim de se verificar a similaridade de seu comportamento, para o caso da câmara Böhm com janela de entrada de Mylar aluminizado. Das curvas de saturação, foi possível determinar a corrente de ionização, $I_{S}$, presente em cada caso de profundidade da câmara. Esta corrente pode ser obtida dos valores de corrente de ionização em relação ao inverso do quadrado dos valores de tensão aplicados ao eletrodo coletor durante as medições para as curvas de saturação, e extrapolando-se os valores obtidos para tensão infinita. As correntes de saturação obtidas (Fig. 6.3.b) são fundamentais para o 
cálculo da eficiência de coleção de íons. No caso da janela de entrada de Hostaphan, as curvas de saturação e as correntes de saturação podem ser observadas nas Fig. 6.4.a e 6.4.b, respectivamente.
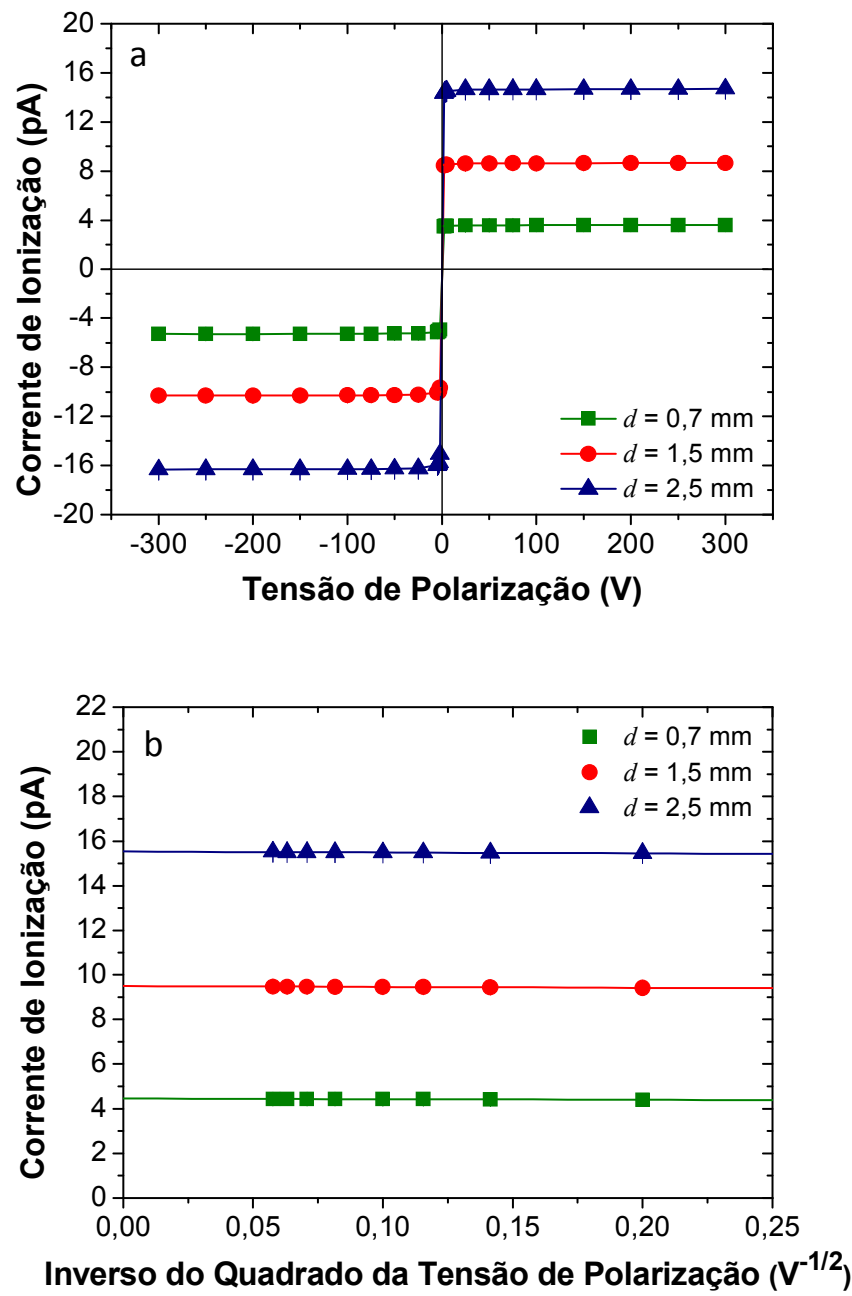

Figura 6.3 - Verificação da saturação da corrente de ionização medida em três profundidades diferentes, $d$, da câmara de extrapolação Böhm com janela de entrada de Mylar aluminizado: (a) curvas de saturação; e (b) correntes de saturação. 

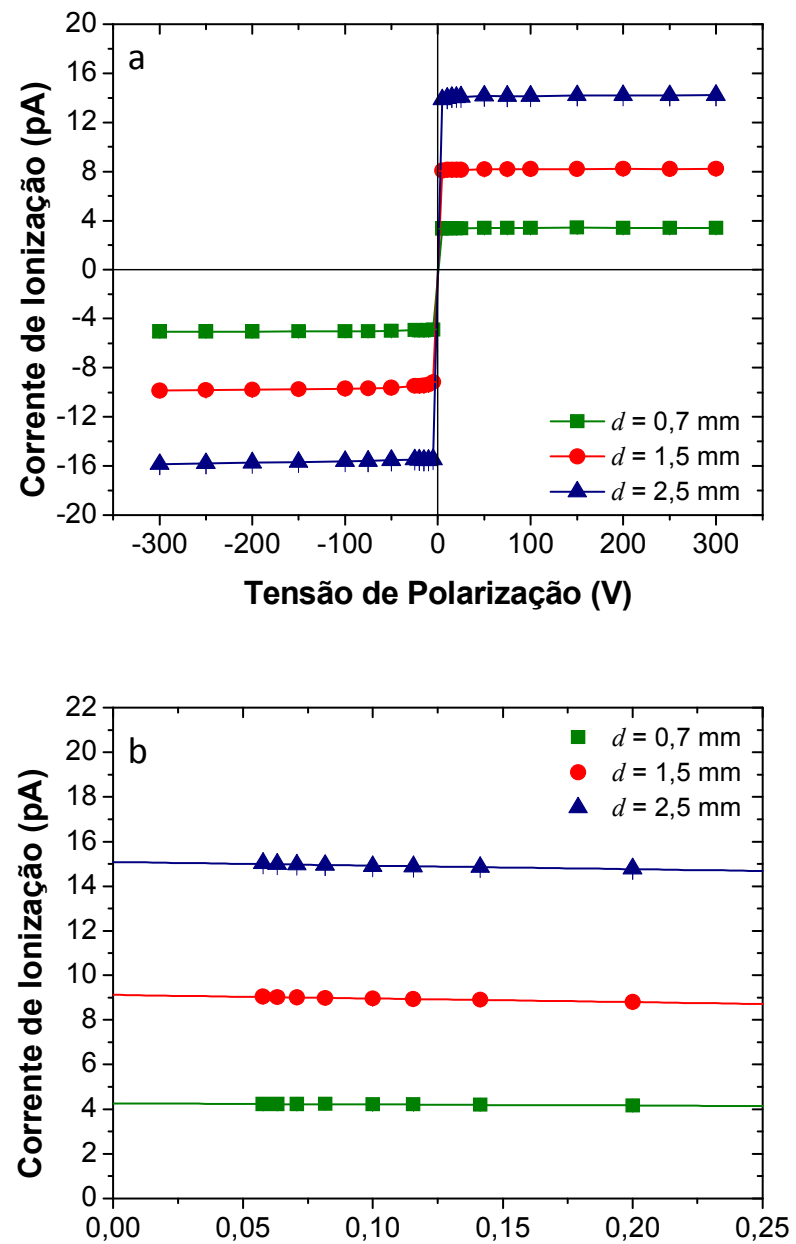

Inverso do Quadrado da Tensão de Polarização ( $\left.\mathbf{V}^{\mathbf{- 1 / 2}}\right)$

Figura 6.4 - Verificação da saturação da corrente de ionização medida em três profundidades diferentes, $d$, da câmara de extrapolação Böhm com janela de entrada de Hostaphan grafitado: (a) curvas de saturação; e (b) correntes de saturação.

Na Tabela 6.3 estão especificados os valores de corrente de saturação obtidos para a câmara de extrapolação Böhm com as duas janelas de entrada. É possível observar que a diferença máxima entre as duas janelas foi de 5,00\% para a profundidade de 0,7 $\mathrm{mm}$.

Tabela 6.3 - Correntes de saturação obtidas com a câmara de extrapolação Böhm e as duas janelas de entrada: Mylar aluminizado e Hostaphan grafitado.

\begin{tabular}{cccc}
\hline $\begin{array}{c}\text { Profundidade } \\
\text { da Câmara }\end{array}$ & \multicolumn{2}{c}{$\begin{array}{c}\text { Corrente de Saturação } \\
\text { ( } \mathbf{m m})\end{array}$} & $\begin{array}{c}\text { Diferença } \\
\text { (\%) }\end{array}$ \\
\cline { 2 - 3 } & Mylar Aluminizado & Hostaphan Grafitado & (\%) \\
\hline 0,7 & $+4,452 \pm 0,021$ & $-4,240 \pm 0,009$ & 5,00 \\
\hline 1,5 & $+9,481 \pm 0,022$ & $-9,057 \pm 0,008$ & 4,68 \\
\hline 2,5 & $+15,511 \pm 0,031$ & $-15,016 \pm 0,022$ & 3,30 \\
\hline
\end{tabular}


A eficiência de coleção de íons, $f$, foi calculada utilizando a Equação 4.6, já demonstrada no item "4.3.2. Caracterização da Resposta de Câmaras de Ionização". Os resultados obtidos mostraram que a câmara de extrapolação alcançou saturação no caso da profundidade igual a 2,5 mm (tensão de $\pm 300 \mathrm{~V}$ ), utilizando-se a janela de entrada de Mylar aluminizado. Com a janela de entrada de Hostaphan, a câmara alcançou saturação na sua resposta também à profundidade de $2,5 \mathrm{~mm}$, porém, na tensão de $\pm 50 \mathrm{~V}$. A Tabela 6.4 mostra os resultado de eficiência de coleção de íons para as duas janelas de entrada, e em cada profundidade da câmara.

Tabela 6.4 - Eficiência de coleção de íons da câmara de extrapolação Böhm, com as duas janelas de entrada: Mylar aluminizado e Hostaphan grafitado, e para profundidades da câmara diferentes.

\begin{tabular}{cccc}
\hline $\begin{array}{c}\text { Profundidade } \\
\text { da Câmara }\end{array}$ & \multicolumn{2}{c}{$\begin{array}{c}\text { Eficiência de Coleção de Íons Máxima } \\
\text { (mm) }\end{array}$} & \multicolumn{2}{c}{ (\%) } & Diferença \\
\cline { 2 - 3 } & Mylar Aluminizado & Hostaphan Grafitado & (\%) \\
\hline 0,7 & 99,49 & 99,56 & 0,07 \\
\hline 1,5 & 99,98 & 99,83 & 0,15 \\
\hline 2,5 & 100,00 & 100,00 & 0,00 \\
\hline
\end{tabular}

No caso dos resultados da câmara com janela de entrada de Mylar aluminizado, a eficiência de coleção de íons máxima foi obtida para a tensão de $\pm 300 \mathrm{~V}$, para as três profundidades, enquanto que para a janela de Hostaphan a eficiência foi máxima para a tensão de $\pm 50 \mathrm{~V}$.

Os resultados obtidos para as duas janelas de entrada foram considerados satisfatórios, pois a resposta da câmara apresentou eficiência de coleção de íons acima de 99\% na tensão de $25 \mathrm{~V}$, que se trata do limite recomendado pela norma IEC 60731 (2011). Estes resultados apresentam-se de acordo com os obtidos por Caldas (1980).

Embora tenha sido determinada a tensão de polarização adequada para ser aplicada à câmara de extrapolação, ainda assim decidiu-se adotar o campo elétrico constante, em todas as medições, de $10 \mathrm{~V} / \mathrm{mm}$, pois se trata do campo recomendado pela ISO 6980-2 (2004), para o uso de câmaras de extrapolação.

Com a obtenção da eficiência de coleção de íons, as perdas por recombinação iônica que podem ocorrer dentro do volume ativo da câmara de extrapolação puderam ser determinadas. A Tabela 6.5 mostra estes resultados. Como a IEC 60731 (2011) estabelece 
que este valor deve ser inferior a $1,00 \%$, os resultados obtidos neste estudo, para as duas janelas de entrada, foram considerados adequados.

Tabela 6.5 - Recombinação iônica da câmara de extrapolação Böhm, com as duas janelas de entrada: Mylar aluminizado e Hostaphan grafitado, e para profundidades da câmara diferentes.

\begin{tabular}{ccc}
\hline $\begin{array}{c}\text { Profundidade } \\
\text { da Câmara }\end{array}$ & \multicolumn{2}{c}{$\begin{array}{c}\text { Recombinação lônica } \\
\text { (\%) }\end{array}$} \\
\cline { 2 - 3 }$(\mathbf{m m})$ & Mylar Aluminizado & Hostaphan Grafitado \\
\hline 0,7 & 0,51 & 0,44 \\
\hline 1,5 & 0,02 & 0,17 \\
\hline 2,5 & 0,00 & 0,00 \\
\hline
\end{tabular}

O efeito de polaridade, $k_{p o l}$, também foi estudado para as três profundidades da câmara, demonstrando a variação que pode ocorrer em valores de corrente de ionização obtidos nas duas polaridades de tensão. Este efeito foi calculado por meio da Equação 6.1 (BÖHM, 1986):

$$
k_{p o l}=\frac{\left(I_{-}+I_{+}\right)}{\left(I_{-}-I_{+}\right)}
$$

onde: $I_{+}$e $I_{-}$são as correntes de ionização medidas nas polaridades positiva e negativa de tensão, respectivamente.

Os resultados obtidos neste teste demonstraram que o efeito de polaridade decresce com o aumento da profundidade da câmara, conforme pode ser observado na Tabela 6.6.

Tabela 6.6 - Efeitos de polaridade da câmara de extrapolação Böhm, com as duas janelas de entrada: Mylar aluminizado e Hostaphan grafitado (para três profundidades diferentes da câmara).

\begin{tabular}{ccc}
\hline $\begin{array}{c}\text { Profundidade } \\
\text { da Câmara }\end{array}$ & \multicolumn{2}{c}{$\begin{array}{c}\text { Efeito de Polaridade } \\
\text { (\%) }\end{array}$} \\
\cline { 2 - 3 }$(\mathbf{m m})$ & Mylar Aluminizado & Hostaphan Grafitado \\
\hline 0,7 & 19,00 & 19,61 \\
\hline 1,5 & 8,79 & 9,06 \\
\hline 2,5 & 5,33 & 5,49 \\
\hline
\end{tabular}

Embora a norma IEC 60731 (2011) recomende o valor de 1,00\% para o efeito de polaridade, os resultados obtidos podem ser aceitáveis em se tratando de radiação beta, devido à presença de uma corrente de ionização originada no momento em que as partículas beta interagem com o material da janela de entrada na câmara de extrapolação. 
Para este mesmo tipo de câmara, Böhm (1986) também obteve efeitos de polaridade acima de $1 \%$. Além disso, o mesmo comportamento foi observado em um relatório do NIST durante o procedimento de calibração de uma câmara de extrapolação Böhm em feixes padrões secundários de radiação beta (NIST, 2010). Embora Böhm (1986) tenha obtido um efeito de polaridade máximo de 2,4\% (profundidade de $0,5 \mathrm{~mm}$ ), o relatório do NIST apresentou um valor máximo de $16 \%$ (profundidade de $0,7 \mathrm{~mm}$ ). Portanto, os resultados obtidos neste trabalho podem ser considerados aceitáveis, pois se apresentam comportamento semelhante aos obtidos pelo NIST (2010). A Fig. 6.5 mostra uma comparação feita entre o resultado do efeito de polaridade num determinado volume ativo da câmara neste trabalho (utilizando as duas janelas de entrada) e no do NIST (2010).

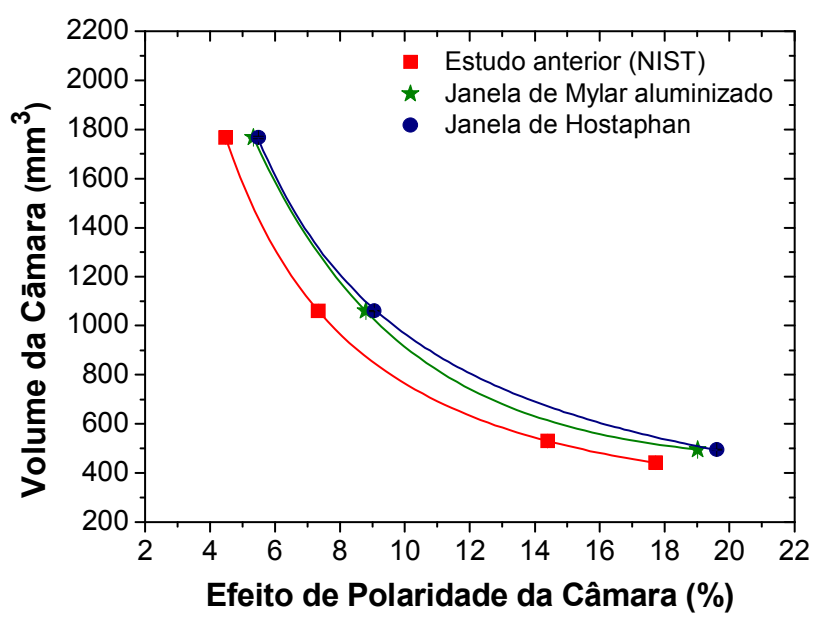

Figura 6.5 - Efeito de polaridade como uma função do volume ativo da câmara, obtido para duas câmaras de extrapolação Böhm: a estudada neste trabalho (utilizando as duas janelas de entrada), e a calibrada pelo NIST.

\subsubsection{Profundidade Nula Real e Área Efetiva}

Neste trabalho, a profundidade nula real, $d_{0}$, foi obtida por dois métodos, tanto para a câmara de extrapolação com a janela de Mylar aluminizado, como para a janela de Hostaphan grafitado (sob as mesmas condições): a) por medições de carga em ambas as polaridades de tensão, alterando-se a profundidade e a tensão aplicada; b) por medições de capacitância.

O primeiro método (das duas polaridades), utilizado por Caldas (1986), foi realizado expondo-se a câmara à fonte de ${ }^{90} \mathrm{Sr}+{ }^{90} \mathrm{Y}(1850 \mathrm{MBq}, 1981)$ a uma distância fonte-detector 
de $11 \mathrm{~cm}$. A profundidade da câmara foi variada de $0,5 \mathrm{~mm}$ a $3,0 \mathrm{~mm}$, em intervalos de $0,5 \mathrm{~mm}$, o tempo de coleta de carga foi de $60 \mathrm{~s}$, e a tensão aplicada foi de $5 \mathrm{~V}$ a $30 \mathrm{~V}$, em ambas as polaridades. No segundo método (CALDAS, 1980), por medições de capacitância, as medições de carga foram tomadas sem exposição da câmara a feixes de radiação; neste caso, os valores de carga foram coletados variando-se a profundidade da câmara também no intervalo de $0,5 \mathrm{~mm}$ a 3,0 $\mathrm{mm}$ (agora em passos de $0,25 \mathrm{~mm}$ ), e aplicando-se tensão de polarização de $\pm 5 \vee$ a \pm 30 V. As Fig. 6.6.a-b e Fig. 6.7.a-b mostram os resultados de profundidade nula real, obtidos graficamente, com a câmara de extrapolação com a janela de Mylar aluminizado e de Hostaphan grafitado, respectivamente. Os valores obtidos estão apresentados na Tabela 6.7.
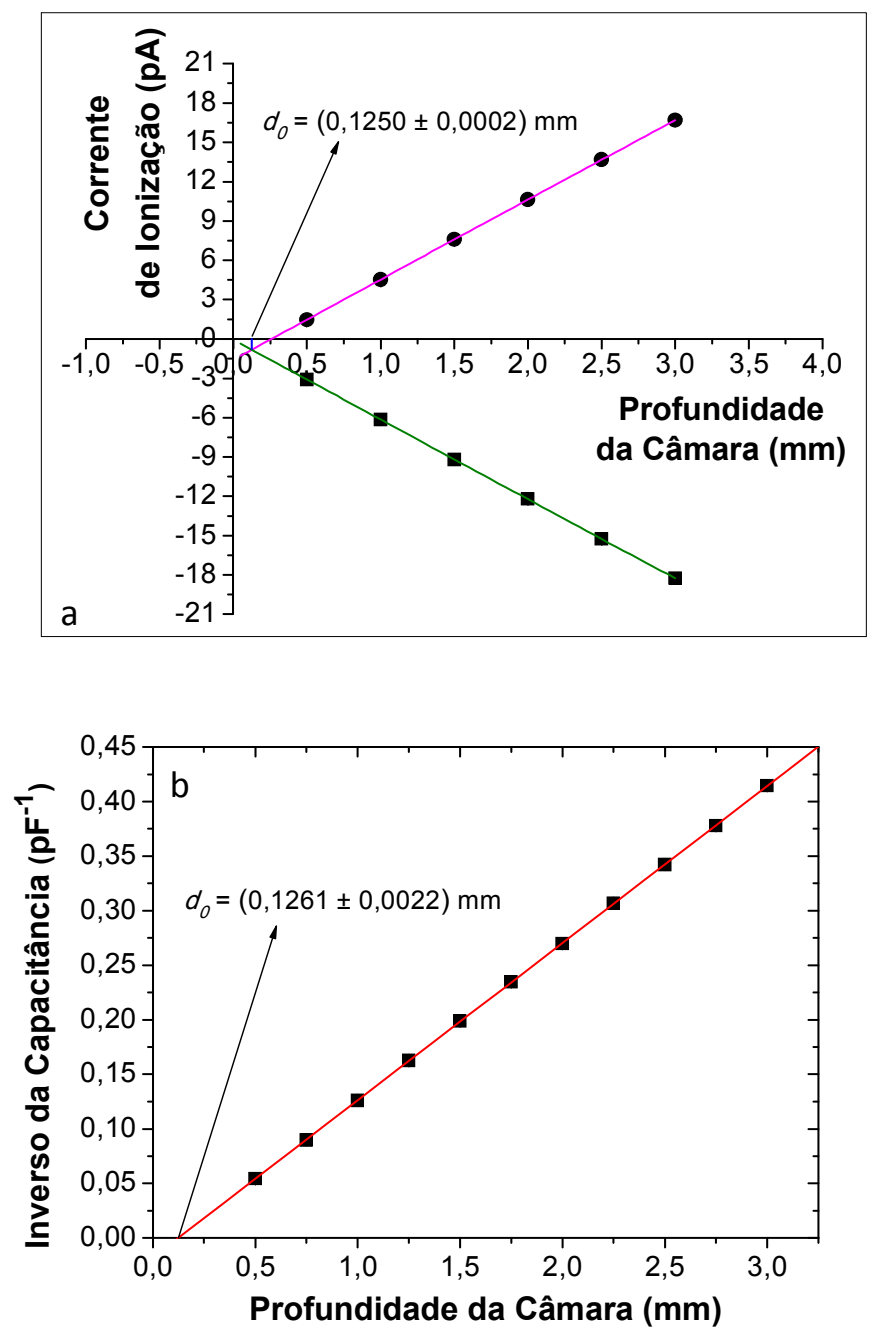

Figura 6.6 - Determinação da profundidade nula real da câmara de extrapolação Böhm, com janela de Mylar aluminizado, por meio de dois métodos: (a) medindo-se a carga em ambas as polaridades de tensão; e (b) medindo-se a capacitância. 

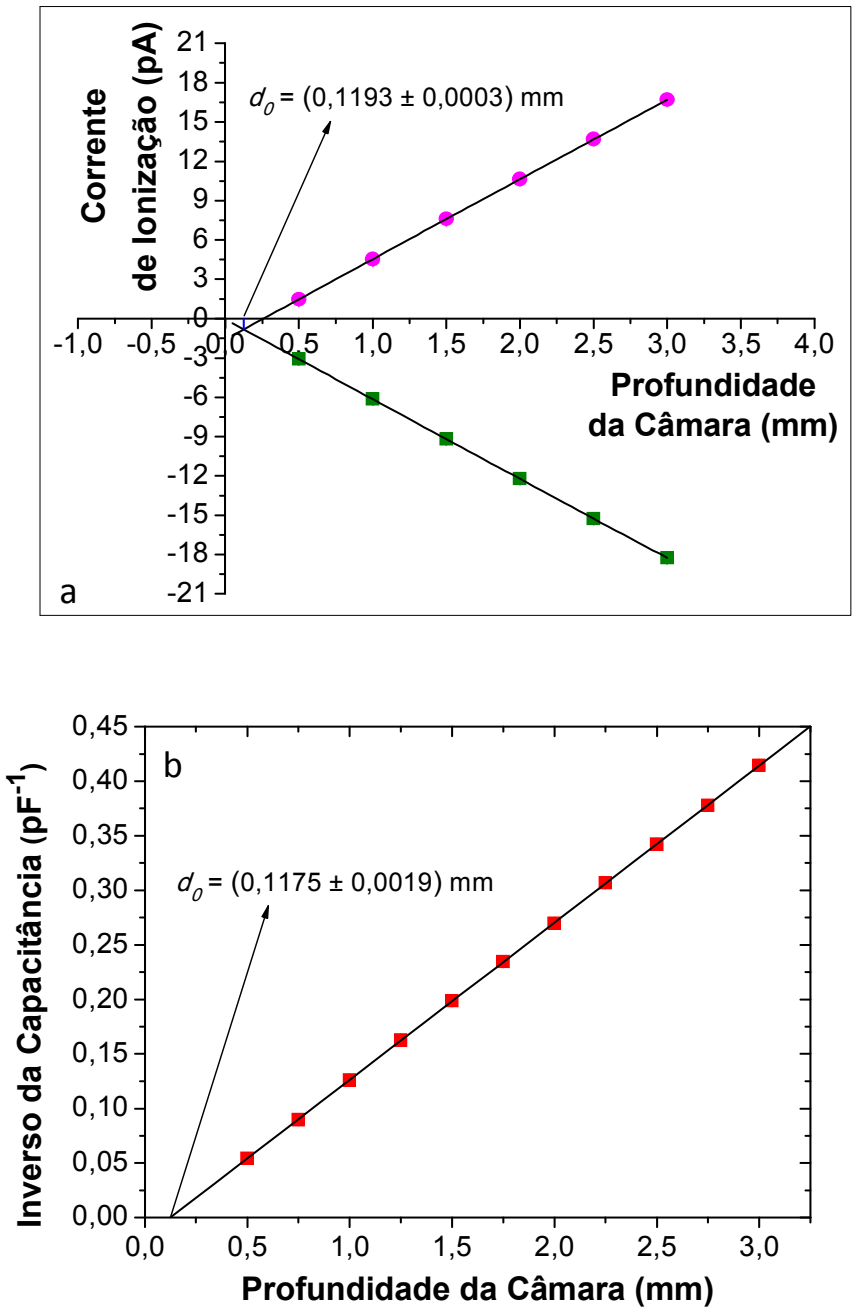

Figura 6.7 - Profundidade nula real da câmara de extrapolação Böhm, com janela de Hostaphan grafitado, por meio de dois métodos: (a) medindo-se a carga em ambas as polaridades de tensão; e (b) medindo-se a capacitância.

Tabela 6.7 - Valores de profundidade nula real da câmara de extrapolação Böhm para as duas janelas de entrada: Mylar aluminizado e Hostaphan grafitado.

\begin{tabular}{cccc}
\hline \multirow{2}{*}{$\begin{array}{c}\text { Janela } \\
\text { de Entrada }\end{array}$} & \multicolumn{3}{c}{$\begin{array}{c}\text { Profundidade Nula Real } \\
(\mathbf{m m})\end{array}$} \\
\cline { 2 - 4 } & $\begin{array}{c}\text { Método das Duas } \\
\text { Polaridades }\end{array}$ & Método da Capacitância & Valor Médio \\
\hline $\begin{array}{c}\text { Mylar } \\
\text { Aluminizado }\end{array}$ & $\begin{array}{c}0,1250 \pm 0,0002 \\
\text { (coeficiente de variação } \\
\text { máximo }=0,6 \%)\end{array}$ & $\begin{array}{c}0,1261 \pm 0,0022 \\
\text { (coeficiente de variação } \\
\text { máximo }=5,8 \%)\end{array}$ & $0,1255 \pm 0,0023$ \\
\hline $\begin{array}{c}\text { Hostaphan } \\
\text { Grafitado }\end{array}$ & $\begin{array}{c}0,1193 \pm 0,0003 \\
\text { (coeficiente de variação } \\
\text { máximo }=0,4 \%)\end{array}$ & $\begin{array}{c}0,1175 \pm 0,0019 \\
\text { (coeficiente de variação } \\
\text { máximo }=0,6 \%)\end{array}$ & $0,1184 \pm 0,0019$ \\
\hline
\end{tabular}


Os resultados obtidos foram similares com relação aos dois métodos para determinação da profundidade nula real, permitindo a decisão de se aplicar um valor de $d_{0}$ igual a $(0,1255 \pm 0,0023) \mathrm{mm}$ em todos os valores de profundidade utilizados nos experimentos, no caso da janela de entrada de Mylar aluminizado, e um $d_{0}$ igual a $(0,1184 \pm 0,0019) \mathrm{mm}$, no caso da janela de Hostaphan.

A determinação da área efetiva do eletrodo coletor, cujo valor é importante por fazer parte do cálculo da taxa de dose absorvida, foi realizada neste trabalho por meio de medições mecânicas, ou seja, utilizando um paquímetro. Foram realizadas 10 medições em torno do eletrodo coletor e no anel de guarda, quando a câmara foi desmontada. O diâmetro médio obtido somente do eletrodo coletor foi de $(30,4 \pm 0,01) \mathrm{mm}$, e a espessura média do anel de guarda foi de $(0,200 \pm 0,001) \mathrm{mm}$. Como o diâmetro total do eletrodo leva em conta o seu próprio valor somado à metade da espessura do anel de guarda de cada lado $[(30,4+0,1+0,1) \mathrm{mm}]$, então, o raio do eletrodo coletor passa a ser 15,3 mm. Assim, a área do eletrodo coletor da câmara de extrapolação Böhm obtida foi $(735,41 \pm 0,24) \mathrm{mm}^{2}$.

\subsubsection{Corrente de Fuga}

O teste de corrente de fuga pré-irradiação foi realizado diversas vezes tomando-se medições de carga elétrica sem expor a câmara a feixes de radiação, durante um intervalo de tempo de $20 \mathrm{~min}$. A tensão aplicada foi de $+10 \mathrm{~V}$ e a profundidade da câmara foi mantida fixa em $1 \mathrm{~mm}$. As mesmas condições experimentais foram utilizadas nos casos das janelas de entrada de Mylar aluminizado e Hostaphan grafitado.

De acordo com a norma IEC 60731 (2011), o limite recomendado para este teste é de 0,5\% do maior valor medido durante uma irradiação. Para a câmara com janela de entrada de Mylar aluminizado, o maior valor de corrente de fuga obtido foi de 0,03\%, e para a câmara com janela de Hostaphan grafitado, o maior valor foi de $0,06 \%$.

Os resultados obtidos neste teste confirmaram o bom desempenho do sistema composto pelo eletrômetro, cabos e a câmara de extrapolação, porque não houve a presença de corrente de fuga significativa o suficiente para influenciar as medições. 


\subsubsection{Estabilidade de Resposta}

A estabilidade da resposta da câmara de extrapolação Böhm foi verificada, quando exposta a uma fonte de ${ }^{90} \mathrm{Sr}+{ }^{90} \mathrm{Y}(1850 \mathrm{MBq}, 1981)$, por meio de dois testes: repetibilidade (estabilidade a curto prazo) e reprodutibilidade (estabilidade a médio prazo).

Para o teste de repetibilidade, a câmara foi posicionada a uma distância fonte-detector de $11 \mathrm{~cm}$, e sua profundidade foi mantida em $1 \mathrm{~mm}$. Foram tomadas dez medições de carga elétrica durante um intervalo de tempo de $60 \mathrm{~s}$ cada, aplicando-se uma tensão de $\pm 10 \mathrm{~V}$ à câmara. Estes parâmetros experimentais foram utilizados nas medições da câmara com janela de entrada de Mylar aluminizado e Hostaphan grafitado.

A norma IEC 60731 (2011) recomenda, para o teste de repetibilidade, um limite de $0,3 \%$, e para o teste de reprodutibilidade, um limite de 0,5\%. A Tabela 6.8 mostra os resultados obtidos neste trabalho para o teste de estabilidade de resposta da câmara de extrapolação Böhm, e nas Fig. 6.8.a-b pode ser observado, graficamente, o teste de reprodutibilidade para a janela de Mylar aluminizado e Hostaphan grafitado.

Todos os resultados obtidos no teste de estabilidade da resposta da câmara de extrapolação Böhm, para as duas janelas de entrada, apresentaram-se dentro do limite estabelecido pela norma IEC 60731 (2011), de 0,5\%, com exceção do ponto de número de medida 7, para o caso da janela de Hostaphan, cujo valor de reprodutibilidade foi $0,52 \%$.

Tabela 6.8 - Teste de estabilidade da resposta da câmara de extrapolação Böhm para as duas janelas de entrada: Mylar aluminizado e Hostaphan.

\begin{tabular}{ccc}
\hline \multirow{2}{*}{ Janela de Entrada } & \multicolumn{2}{c}{ Estabilidade de Resposta da Câmara } \\
\cline { 2 - 3 } & $\begin{array}{c}\text { Repetibilidade } \\
\text { (\%) }\end{array}$ & $\begin{array}{c}\text { Reprodutibilidade } \\
\text { (\%) }\end{array}$ \\
\hline Mylar Aluminizado & 0,2 & 0,4 \\
\hline Hostaphan Grafitado & 0,1 & 0,5 \\
\hline
\end{tabular}



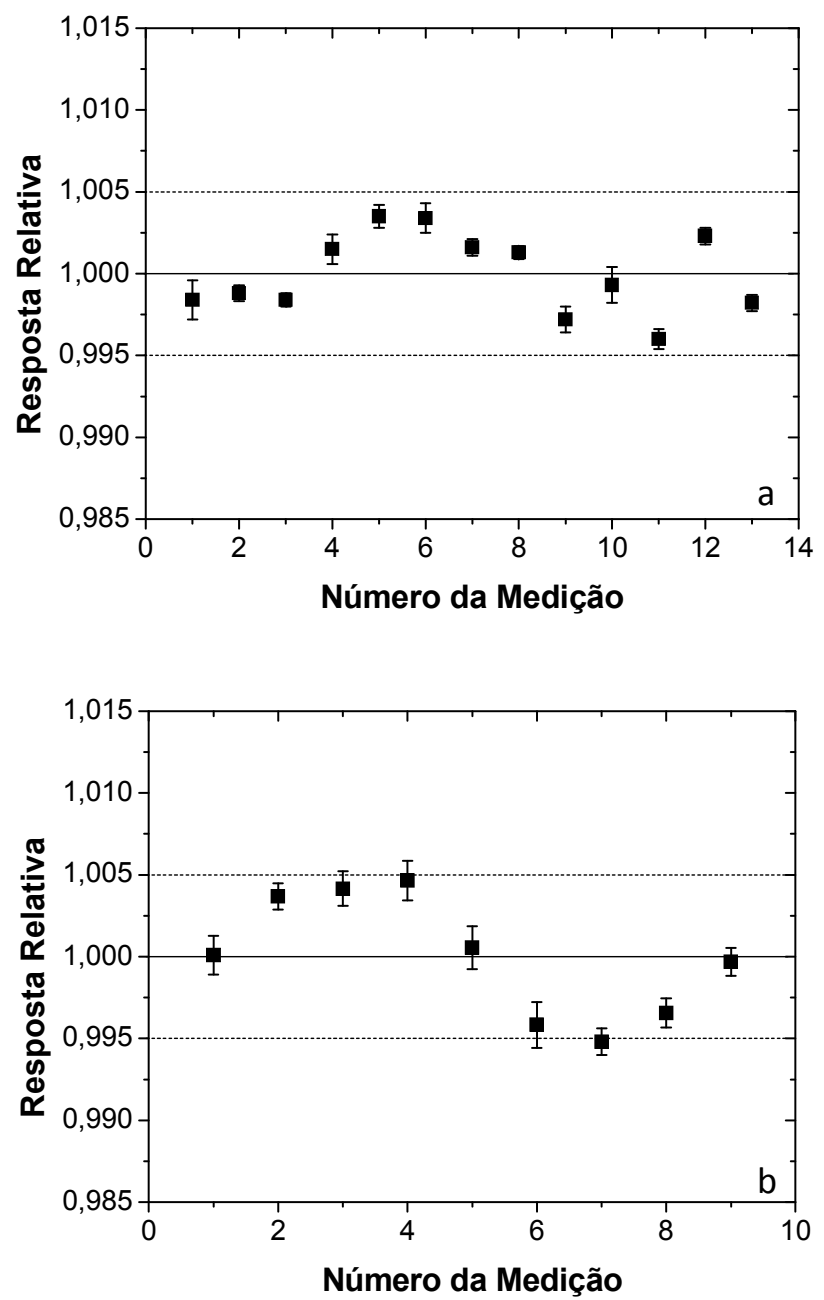

Figura 6.8 - Reprodutibilidade da resposta da câmara de extrapolação Böhm, utilizando-se uma fonte de ${ }^{90} \mathrm{Sr}+{ }^{90} \mathrm{Y}$, com as janelas de entrada: (a) Mylar aluminizado; e (b) Hostaphan grafitado. As linhas pontilhadas indicam o limite recomendado pela IEC (2011) de 0,5\% para o teste de reprodutibilidade.

\subsubsection{Variação da Resposta em Função da Distância Fonte-Detector}

A fim de se verificar a validade da lei do inverso do quadrado da distância neste arranjo experimental, e a possibilidade de se calibrar detectores de radiação beta em distâncias diferentes das especificadas nos certificados de calibração das fontes, foi realizado um estudo da variação da resposta da câmara de extrapolação, em função da distância fonte-detector. Neste teste, a profundidade da câmara foi mantida fixa em $1 \mathrm{~mm}$ e a tensão de polarização aplicada foi de $\pm 10 \mathrm{~V}$. Foi utilizado um intervalo de tempo de coleta de carga de $60 \mathrm{~s}$, e as medições foram tomadas em um intervalo de distância fonte-detector de $10 \mathrm{~cm}$ a $55 \mathrm{~cm}$, enquanto a câmara foi exposta à fonte de ${ }^{90} \mathrm{Sr}+{ }^{90} \mathrm{Y}(1850 \mathrm{MBq}, 1981)$. Todas estas 
condições experimentais foram utilizadas no caso da câmara de extrapolação com a janela de entrada tanto de Mylar aluminizado como de Hostaphan grafitado.

No caso das medições com a janela de entrada de Mylar aluminizado, a corrente de ionização variou de $(7,341 \pm 0,152) \mathrm{pA}$ a $(0,242 \pm 0,012) \mathrm{pA}$, e o coeficiente de variação máximo obtido foi 3,9\% (para a profundidade de $55 \mathrm{~cm}$ ). Nas medições com a janela de Hostaphan, a variação da corrente de ionização foi de $(7,245 \pm 0,150)$ pA a $(0,245 \pm 0,007)$ pA, e o coeficiente de variação máximo foi 2,18\%. A Fig. 6.9 apresenta o comportamento da corrente de ionização em função da distância fonte-detector.
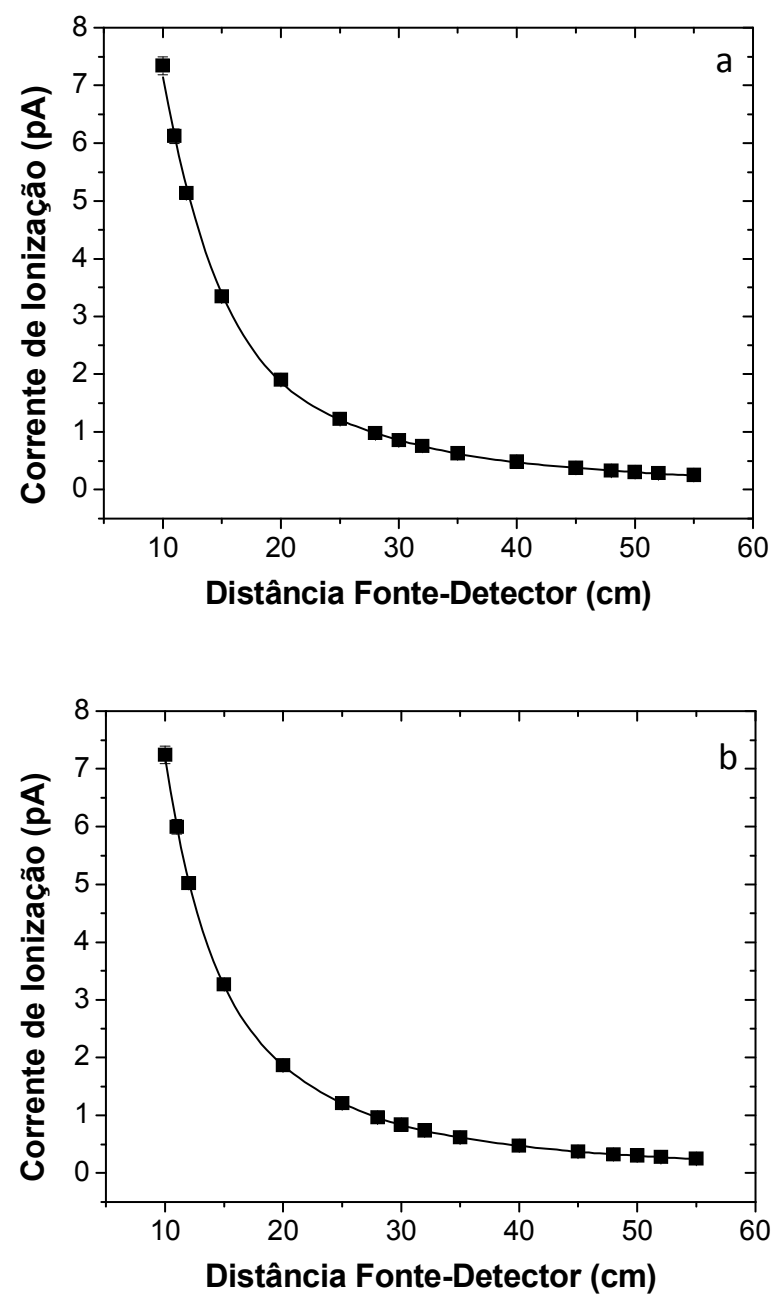

Figura 6.9 - Variação da resposta da câmara de extrapolação Böhm em função da distância fontedetector, utilizando uma fonte de ${ }^{90} \mathrm{Sr}+{ }^{90} \mathrm{Y}(1850 \mathrm{MBq}, 1981)$ e as janelas de entrada: (a) Mylar aluminizado; e (b) Hostaphan grafitado. 
Dos resultados obtidos neste estudo, pode-se concluir que a resposta da câmara de extrapolação Böhm segue a lei do inverso do quadrado da distância fonte-detector. Esta conclusão possibilita ao LCl fazer calibrações de detectores de radiação beta em distâncias fonte-detector além das fornecidas nos certificados de calibração das fontes.

\subsubsection{Fatores de Transmissão no Tecido utilizando uma Fonte de ${ }^{90} \mathrm{Sr}+{ }^{90} \mathrm{Y}$}

Para a determinação dos fatores de transmissão, as medições foram tomadas com a câmara de extrapolação Böhm com janela de entrada de Mylar aluminizado e Hostaphan grafitado. Para tal, foi utilizada uma fonte de ${ }^{90} \mathrm{Sr}+{ }^{90} \mathrm{Y}$ do sistema BSS1 (1850 MBq, 1981), com a câmara de extrapolação localizada a uma distância fonte-detector de $30 \mathrm{~cm}$; neste teste, a profundidade da câmara foi mantida fixa em $1 \mathrm{~mm}$, e a tensão aplicada foi de $\pm 10 \mathrm{~V}$. Para este estudo, dez absorvedores foram utilizados (posicionados o mais próximo possível da janela de entrada da câmara): oito de Hostaphan, RN 8 a RN 300 (correspondendo a espessuras de $8 \mu \mathrm{m}$ a $300 \mu \mathrm{m}$ ) (KALLE FOLIEN, s/ data), e dois de Plexiglas de $1 \mathrm{~mm}$ cada: foi utilizada uma placa (espessura de $1 \mathrm{~mm}$ ), e depois as duas juntas (espessura de $2 \mathrm{~mm}$ ). Além das medições com estes absorvedores, foram também tomados os valores de carga sem absorvedor. A Fig. 6.10 mostra a janela de entrada da câmara de extrapolação coberta com uma folha de Hostaphan.

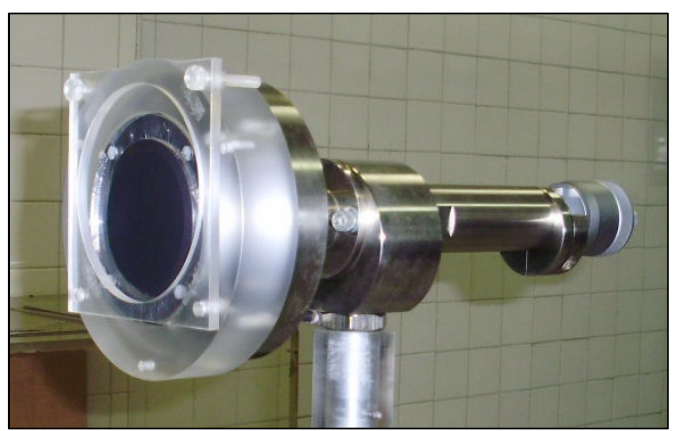

Figura 6.10 - Câmara de extrapolação Böhm com janela de entrada de Hostaphan grafitado, coberta com uma folha de Hostaphan, para medições para a determinação de fatores de transmissão.

Para se determinar o fator de transmissão no tecido, foram utilizadas as relações de equivalência entre o material do absorvedor e o tecido (já definidas no item "4.4.3.2. Fatores de Transmissão":

$10,8 \mathrm{mg} / \mathrm{cm}^{2}$ Hostaphan para $10,0 \mathrm{mg} / \mathrm{cm}^{2}$ tecido (OWEN, 1973) 
$10,4 \mathrm{mg} / \mathrm{cm}^{2}$ Plexiglas para $10,0 \mathrm{mg} / \mathrm{cm}^{2}$ tecido (CALDAS, 1980)

Aplicando-se estas duas relações à Equação 4.8, pôde-se determinar a espessura, ou a densidade superficial, das folhas de Hostaphan e das placas de Plexiglas no tecido. Também foi necessário converter a densidade superficial do material das duas janelas de entrada para o tecido. No caso da janela de Mylar aluminizado, foi utilizada a mesma relação entre Hostaphan e tecido (PINTO, 2010).

Com os valores de corrente de ionização medidos, $I\left(d_{0}\right)$, e as densidades superficiais obtidas no tecido (Fig. 6.11.a e 6.12.a), foi possível obter a corrente de ionização para densidade superficial nula, $I(0)$, e, assim, os fatores de transmissão $T^{\prime \prime}$, por meio da Equação 4.9. A estes fatores de transmissão, foi aplicado o fator de correção para a distância fonte-detector $(30 \mathrm{~cm}), k_{d}$, utilizando-se a Equação 4.10. Desta maneira, os fatores de transmissão finais puderam ser obtidos por meio da Equação 4.11, e podem ser observados na Tabela 6.9, para a janela de entrada de Mylar aluminizado, e na Tabela 6.10, para a janela de Hostaphan (CALDAS, 1980; 2012). As Fig. 6.11.a e 6.12.a apresentam o processo de determinação da corrente de ionização $I(0)$, e os fatores de transmissão finais obtidos pela Equação 4.11 podem ser observados nas Fig. 6.11.b e 6.12.b.

Das Fig. 6.11.b e 6.12.b foram determinados os fatores de transmissão para as mesmas densidades superficiais equivalentes ao tecido apresentadas no certificado de calibração da fonte de ${ }^{90} \mathrm{Sr}+{ }^{90} \mathrm{Y}$. A Tabela 6.11 mostra uma comparação entre os fatores de transmissão deste trabalho, com a câmara com janela de entrada de Mylar aluminizado, e aqueles do certificado de calibração (PTB, 1981a). O coeficiente de variação máximo obtido em todas as medições deste experimento com esta janela de entrada foi 2,45\%. Os mesmos valores, obtidos neste experimento, porém com a janela de entrada de Hostaphan, podem também ser observados na mesma Tabela 6.11; neste caso, o coeficiente de variação máximo obtido foi $0,33 \%$. 
Tabela 6.9 - Determinação dos fatores de transmissão obtidos com a câmara de extrapolação Böhm, utilizando uma fonte de ${ }^{90} \mathrm{Sr}+{ }^{90} \mathrm{Y}(1850 \mathrm{MBq}, 1981)$, e janela de entrada de Mylar aluminizado.

\begin{tabular}{|c|c|c|c|c|c|c|c|}
\hline Material & Absorvedor & $\begin{array}{c}\text { Espessura } \\
\text { do Absorvedor } \\
(\mathrm{cm}) \\
\end{array}$ & $\begin{array}{c}\text { Densidade } \\
\text { Superficial de } \\
\text { Tecido }\left(\mathrm{mg} / \mathrm{cm}^{2}\right)\end{array}$ & $\begin{array}{l}\text { Corrente de } \\
\text { Ionização } \\
(\mathrm{pA}), I\left(d_{0}\right) \\
\end{array}$ & $\begin{array}{c}\text { Fator de } \\
\text { Transmissão } T^{\prime}, \\
I\left(d_{0}\right) / I(0) \\
\end{array}$ & $\begin{array}{c}\text { Fator de Correção } \\
\text { para Distância } \boldsymbol{k}_{d}\end{array}$ & $\begin{array}{c}\text { Fator de } \\
\text { Transmissão } T\end{array}$ \\
\hline \multicolumn{2}{|c|}{ Sem absorvedor } & 0 & $0,660 \pm 0,009$ & $0,856 \pm 0,018$ & $1,009 \pm 0,021$ & $1,000 \pm 0,002$ & $1,009 \pm 0,021$ \\
\hline \multirow{8}{*}{ Hostaphan } & RN 8 & 0,0008 & $1,697 \pm 0,022$ & $0,869 \pm 0,011$ & $1,024 \pm 0,013$ & $0,999 \pm 0,002$ & $1,024 \pm 0,013$ \\
\hline & RN 15 & 0,0015 & $2,604 \pm 0,034$ & $0,877 \pm 0,010$ & $1,034 \pm 0,012$ & $0,999 \pm 0,002$ & $1,034 \pm 0,011$ \\
\hline & RN 25 & 0,0025 & $3,901 \pm 0,051$ & $0,888 \pm 0,006$ & $1,046 \pm 0,007$ & $0,999 \pm 0,002$ & $1,046 \pm 0,007$ \\
\hline & RN 50 & 0,0050 & $7,141 \pm 0,093$ & $0,906 \pm 0,013$ & $1,068 \pm 0,015$ & $0,999 \pm 0,002$ & $1,068 \pm 0,014$ \\
\hline & RN 75 & 0,0075 & $10,38 \pm 0,14$ & $0,922 \pm 0,008$ & $1,087 \pm 0,009$ & $0,999 \pm 0,002$ & $1,086 \pm 0,009$ \\
\hline & RN 100 & 0,0100 & $13,62 \pm 0,18$ & $0,942 \pm 0,011$ & $1,110 \pm 0,012$ & $0,999 \pm 0,002$ & $1,109 \pm 0,011$ \\
\hline & RN 250 & 0,0250 & $33,07 \pm 0,43$ & $0,991 \pm 0,012$ & $1,167 \pm 0,012$ & $0,998 \pm 0,002$ & $1,166 \pm 0,011$ \\
\hline & RN 300 & 0,0300 & $39,55 \pm 0,52$ & $0,999 \pm 0,006$ & $1,177 \pm 0,006$ & $0,998 \pm 0,002$ & $1,175 \pm 0,006$ \\
\hline \multirow{2}{*}{ Plexiglas } & 1 placa $(1 \mathrm{~mm})$ & 0,1 & $114,12 \pm 1,49$ & $0,945 \pm 0,006$ & $1,113 \pm 0,007$ & $0,993 \pm 0,002$ & $1,106 \pm 0,006$ \\
\hline & 2 placas $(2 \mathrm{~mm})$ & 0,2 & $227,59 \pm 2,97$ & $0,659 \pm 0,003$ & $0,777 \pm 0,006$ & $0,987 \pm 0,002$ & $0,766 \pm 0,007$ \\
\hline
\end{tabular}

Tabela 6.10 - Determinação dos fatores de transmissão obtidos com a câmara de extrapolação Böhm, utilizando uma fonte de ${ }^{90} \mathrm{Sr}+{ }^{90} \mathrm{Y}(1850 \mathrm{MBq}$ 1981), e janela de entrada de Hostaphan grafitado.

\begin{tabular}{|c|c|c|c|c|c|c|c|}
\hline Material & Absorvedor & $\begin{array}{c}\text { Espessura do } \\
\text { Absorvedor } \\
\text { (cm) } \\
\end{array}$ & $\begin{array}{c}\text { Densidade } \\
\text { Superficial de } \\
\text { Tecido }\left(\mathrm{mg} / \mathrm{cm}^{2}\right) \\
\end{array}$ & $\begin{array}{l}\text { Corrente de } \\
\text { lonização } \\
(\mathrm{pA}), I\left(d_{0}\right) \\
\end{array}$ & $\begin{array}{c}\text { Fator de } \\
\text { Transmissão } T, \\
I\left(d_{0}\right) / I(0) \\
\end{array}$ & $\begin{array}{l}\text { Fator de Correção } \\
\text { para Distância } \boldsymbol{k}_{\boldsymbol{d}}\end{array}$ & $\begin{array}{c}\text { Fator de } \\
\text { Transmissão } T\end{array}$ \\
\hline Sem & bsorvedor & 0 & $0,667 \pm 0,009$ & $0,818 \pm 0,002$ & $0,981 \pm 0,003$ & $1,000 \pm 0,002$ & $0,981 \pm 0,004$ \\
\hline \multirow{8}{*}{ Hostaphan } & RN 8 & 0,0008 & $1,704 \pm 0,022$ & $0,844 \pm 0,002$ & $1,013 \pm 0,003$ & $0,999 \pm 0,002$ & $1,013 \pm 0,003$ \\
\hline & RN 15 & 0,0015 & $2,611 \pm 0,034$ & $0,857 \pm 0,002$ & $1,028 \pm 0,003$ & $0,999 \pm 0,002$ & $1,028 \pm 0,003$ \\
\hline & RN 25 & 0,0025 & $3,907 \pm 0,051$ & $0,862 \pm 0,001$ & $1,034 \pm 0,002$ & $0,999 \pm 0,002$ & $1,034 \pm 0,003$ \\
\hline & RN 50 & 0,0050 & $7,148 \pm 0,092$ & $0,885 \pm 0,001$ & $1,062 \pm 0,002$ & $0,999 \pm 0,002$ & $1,061 \pm 0,003$ \\
\hline & RN 75 & 0,0075 & $10,39 \pm 0,13$ & $0,899 \pm 0,002$ & $1,079 \pm 0,003$ & $0,999 \pm 0,002$ & $1,078 \pm 0,003$ \\
\hline & RN 100 & 0,0100 & $13,63 \pm 0,18$ & $0,916 \pm 0,001$ & $1,099 \pm 0,003$ & $0,999 \pm 0,002$ & $1,099 \pm 0,003$ \\
\hline & RN 250 & 0,0250 & $33,07 \pm 0,43$ & $0,967 \pm 0,001$ & $1,160 \pm 0,002$ & $0,998 \pm 0,002$ & $1,158 \pm 0,003$ \\
\hline & RN 300 & 0,0300 & $39,56 \pm 0,51$ & $0,974 \pm 0,002$ & $1,168 \pm 0,003$ & $0,998 \pm 0,002$ & $1,166 \pm 0,003$ \\
\hline \multirow{2}{*}{ Plexiglas } & 1 placa $(1 \mathrm{~mm})$ & 0,1 & $114,12 \pm 1,48$ & $0,905 \pm 0,001$ & $1,086 \pm 0,002$ & $0,993 \pm 0,002$ & $1,079 \pm 0,003$ \\
\hline & 2 placas $(2 \mathrm{~mm})$ & 0,2 & $227,59 \pm 2,94$ & $0,633 \pm 0,001$ & $0,760 \pm 0,002$ & $0,987 \pm 0,002$ & $0,750 \pm 0,004$ \\
\hline
\end{tabular}



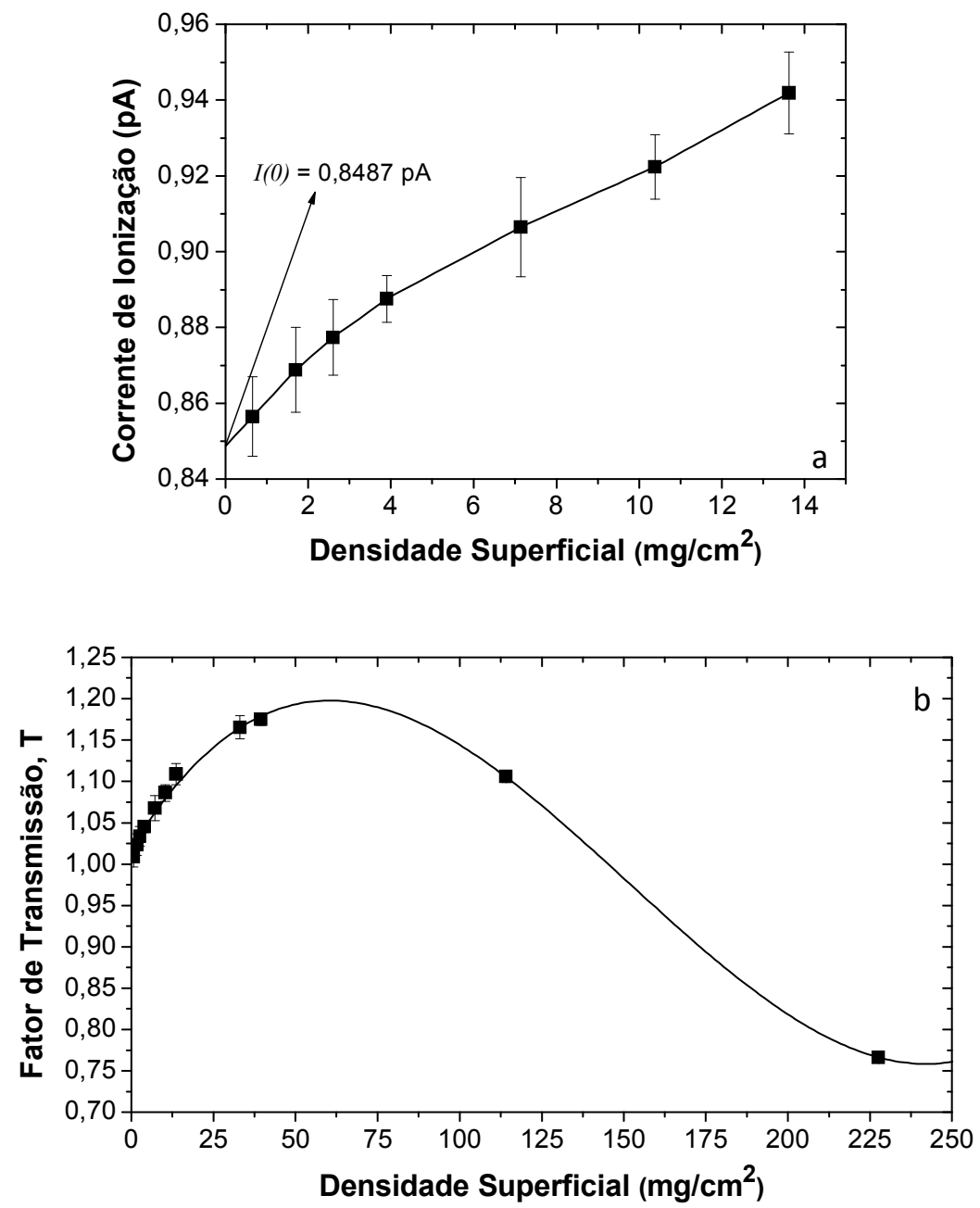

Figura 6.11 - Determinação dos fatores de transmissão no tecido, com a câmara de extrapolação Böhm com a janela de entrada de Mylar aluminizado, e a fonte de ${ }^{90} \mathrm{Sr}+{ }^{90} \mathrm{Y}(1850 \mathrm{MBq}$, 1981): (a) obtenção da corrente de ionização $I(0)$; e (b) curva final dos fatores de transmissão; neste caso, foi utilizado o ajuste polinomial de 3 a ordem. 

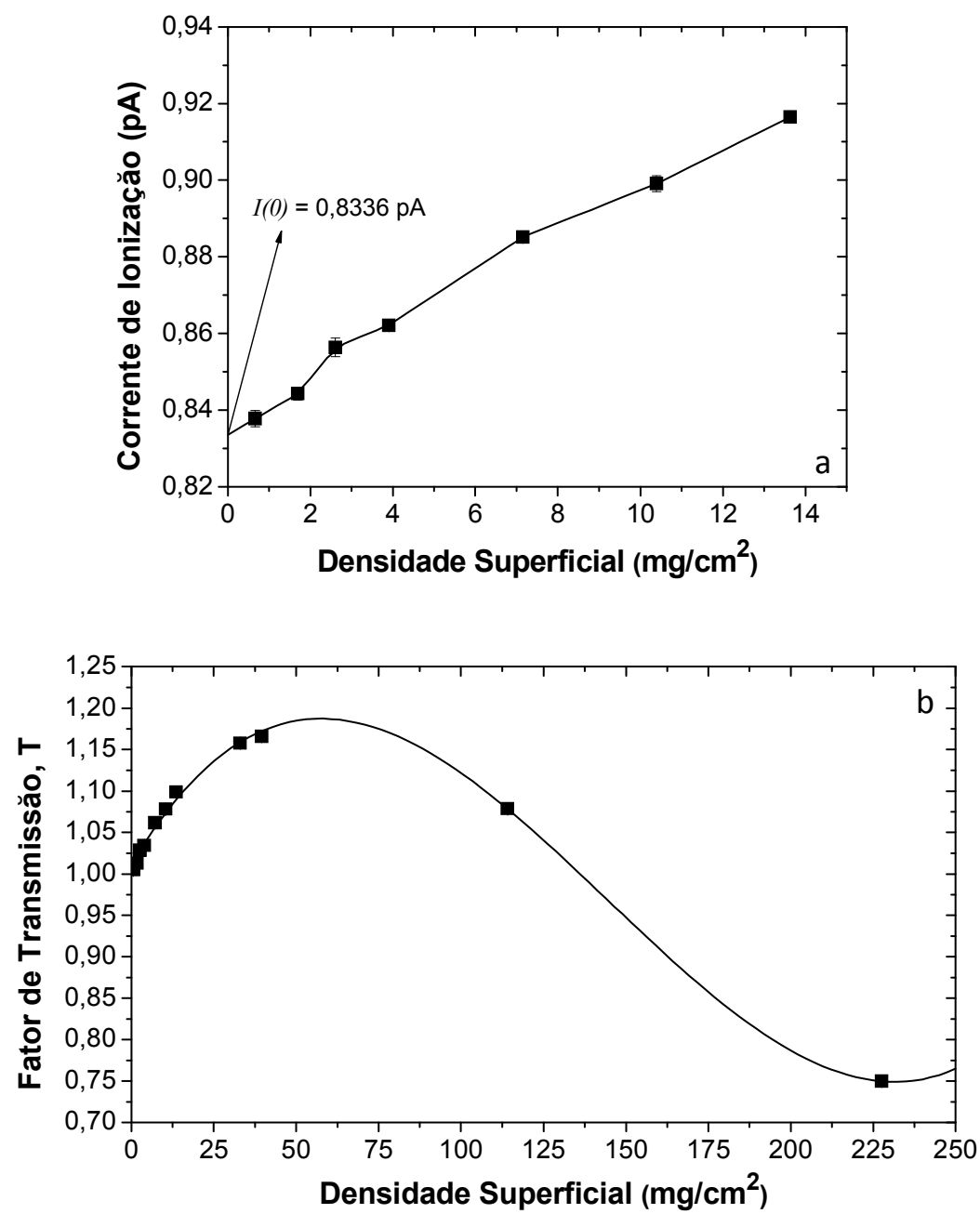

Figura 6.12 - Determinação dos fatores de transmissão no tecido, com a câmara de extrapolação Böhm com a janela de entrada de Hostaphan grafitado, e a fonte de ${ }^{90} \mathrm{Sr}^{90} \mathrm{Y}$ (1850 MBq, 1981): (a) obtenção da corrente de ionização $I(0)$; e (b) curva final dos fatores de transmissão; neste caso, foi utilizado o ajuste polinomial de 3 a ordem, e a incerteza máxima foi $0,4 \%$, não visível no gráfico. 
Tabela 6.11 - Fatores de transmissão obtidos com a câmara de extrapolação Böhm com as janelas de entrada de Mylar aluminizado e Hostaphan grafitado, e a fonte de ${ }^{90} \mathrm{Sr}+{ }^{90} \mathrm{Y}(1850 \mathrm{MBq}$ ).

\begin{tabular}{|c|c|c|c|c|c|c|}
\hline \multicolumn{2}{|c|}{ Tecido } & \multicolumn{3}{|c|}{ Fatores de Transmissão $T$} & \multirow{3}{*}{$\begin{array}{c}\text { Diferença } \\
\text { entre } \\
\text { A e B } \\
\text { (\%) } \\
\end{array}$} & \multirow{3}{*}{$\begin{array}{c}\text { Diferença } \\
\text { entre } \\
\text { A e C } \\
\text { (\%) } \\
\end{array}$} \\
\hline \multirow[b]{2}{*}{$\begin{array}{c}\text { Espessura } \\
(\mathrm{mm})\end{array}$} & \multirow[b]{2}{*}{$\begin{array}{c}\text { Densidade } \\
\text { Superficial } \\
\left(\mathrm{mg} / \mathrm{cm}^{2}\right) \\
\end{array}$} & \multirow{2}{*}{$\begin{array}{l}\text { Certificado } \\
\text { da } \\
\text { Fonte } \\
\text { (A) } \\
\end{array}$} & \multicolumn{2}{|c|}{ Este trabalho } & & \\
\hline & & & $\begin{array}{c}\text { Mylar } \\
\text { Aluminizado } \\
\text { (B) }\end{array}$ & $\begin{array}{l}\text { Hostaphan } \\
\text { Grafitado } \\
\text { (C) }\end{array}$ & & \\
\hline 0 & 0 & $1,000 \pm 0,010$ & $1,000 \pm 0,039$ & $1,000 \pm 0,023$ & 0,00 & 0,00 \\
\hline 0,02 & 2 & $1,029 \pm 0,011$ & $1,031 \pm 0,041$ & $1,025 \pm 0,024$ & 0,19 & $-0,38$ \\
\hline 0,04 & 4 & $1,046 \pm 0,011$ & $1,043 \pm 0,042$ & $1,037 \pm 0,024$ & $-0,29$ & $-0,86$ \\
\hline 0,05 & 5 & $1,053 \pm 0,011$ & $1,049 \pm 0,042$ & $1,044 \pm 0,024$ & $-0,38$ & $-0,86$ \\
\hline 0,07 & 7 & $1,068 \pm 0,011$ & $1,061 \pm 0,042$ & $1,055 \pm 0,024$ & $-0,66$ & $-1,22$ \\
\hline 0,10 & 10 & $1,084 \pm 0,011$ & $1,077 \pm 0,043$ & $1,071 \pm 0,025$ & $-0,65$ & $-1,20$ \\
\hline 0,20 & 20 & $1,122 \pm 0,012$ & $1,122 \pm 0,045$ & $1,117 \pm 0,026$ & 0,00 & $-0,45$ \\
\hline 0,50 & 50 & $1,175 \pm 0,012$ & $1,194 \pm 0,048$ & $1,185 \pm 0,027$ & 1,62 & 0,85 \\
\hline 1,00 & 100 & $1,121 \pm 0,012$ & $1,145 \pm 0,046$ & $1,122 \pm 0,026$ & 2,14 & 0,09 \\
\hline
\end{tabular}

Para a câmara com a janela de entrada de Mylar aluminizado, os fatores de transmissão no tecido obtidos mostraram concordância com os valores fornecidos no certificado da fonte, com uma diferença máxima de 2,14\% para a profundidade de $1 \mathrm{~mm}$ de tecido. No caso da janela de Hostaphan, os resultados também foram favoráveis, pois a diferença máxima obtida foi de $-1,22 \%$, para a profundidade de $0,07 \mathrm{~mm}$ de tecido.

\subsubsection{Taxas de Dose Absorvida de Fontes de ${ }^{90} \mathrm{Sr}+{ }^{90} \mathrm{Y}$}

Neste trabalho, as taxas de dose absorvida de três fontes de ${ }^{90} \mathrm{Sr}+{ }^{90} \mathrm{Y}$ foram determinadas. Para a câmara de extrapolação Böhm com janela de entrada de Mylar aluminizado, as taxas de dose absorvida foram obtidas em quatro condições diferentes. No caso da câmara com janela de entrada de Hostaphan, as taxas de dose absorvida foram obtidas em nove condições diferentes. A Tabela 6.12 mostra as condições para as quais as taxas de dose absorvida foram determinadas, com relação ao uso de filtro uniformizador de campo e distância fonte-detector, de acordo com condições estabelecidas em seus certificados de calibração, fornecidos pelo PTB (1981a; 1981b; 2005). 
Tabela 6.12 - Condições utilizadas para a determinação de taxas de dose absorvida para fontes de ${ }^{90} \mathrm{Sr}+{ }^{90} \mathrm{Y}$.

\begin{tabular}{|c|c|c|c|c|c|}
\hline \multirow{2}{*}{$\begin{array}{l}\text { Sistema Padrão } \\
\text { Secundário de } \\
\text { Radiação Beta }\end{array}$} & \multirow{2}{*}{$\begin{array}{c}\text { Atividade } \\
\text { da Fonte } \\
\text { (MBq) }\end{array}$} & \multirow{2}{*}{$\begin{array}{c}\text { Filtro } \\
\text { Uniformizador } \\
\text { de Campo }\end{array}$} & \multirow{2}{*}{$\begin{array}{c}\text { Distância } \\
\text { Fonte-Detector } \\
\text { (cm) }\end{array}$} & \multicolumn{2}{|c|}{ Janela de Entrada } \\
\hline & & & & $\begin{array}{c}\text { Mylar } \\
\text { Aluminizado }\end{array}$ & $\begin{array}{l}\text { Hostaphan } \\
\text { Grafitado }\end{array}$ \\
\hline \multirow{4}{*}{ BSS1 } & 74 & Sim & 30 & $x$ & $x$ \\
\hline & 1850 & Não & 11 & & $x$ \\
\hline & 1850 & Não & 30 & $x$ & $x$ \\
\hline & 1850 & Não & 50 & & $x$ \\
\hline \multirow{5}{*}{ BSS2 } & 460 & Não & 11 & & $\mathrm{X}$ \\
\hline & 460 & Não & 20 & & $x$ \\
\hline & 460 & Sim & 30 & $x$ & $x$ \\
\hline & 460 & Não & 30 & $\mathrm{X}$ & $x$ \\
\hline & 460 & Não & 50 & & $x$ \\
\hline
\end{tabular}

Para a determinação de todas as taxas de dose absorvida, a câmara de extrapolação Böhm foi posicionada a distâncias fonte-detector específicas (Tabela 6.12), a profundidade da câmara foi variada de $0,5 \mathrm{~mm}$ a $2,5 \mathrm{~mm}$ (em intervalos e 0,5 mm), e a tensão de polarização utilizada foi de $\pm 5 \mathrm{~V}$ a $\pm 25 \mathrm{~V}$ (obedecendo à condição de se manter um campo elétrico constante de $10 \mathrm{~V} / \mathrm{mm}$ ). Foram tomadas seis medições de carga elétrica, em cada polaridade de tensão, para cada curva de extrapolação, em ambos os casos de janela de entrada de Mylar aluminizado ou Hostaphan grafitado. Os tempos de coleta de carga foram os seguintes: $5 \mathrm{~min}$, para a fonte de $74 \mathrm{MBq} ; 1 \mathrm{~min}$, para a fonte de $1850 \mathrm{MBq}$, a $11 \mathrm{~cm}$ e $30 \mathrm{~cm}$ de distância fonte-detector; $2 \mathrm{~min}$, para a fonte de $1850 \mathrm{MBq}$, a $50 \mathrm{~cm} ; 2 \mathrm{~min}$, para a fonte de $460 \mathrm{MBq}$, a $11 \mathrm{~cm}, 20 \mathrm{~cm}$ e $30 \mathrm{~cm}$ (sem filtro); e $4 \mathrm{~min}$, para a fonte de $460 \mathrm{MBq}$, a $30 \mathrm{~cm}$ (com filtro) e a $50 \mathrm{~cm}$.

Inicialmente à obtenção de uma taxa de dose absorvida, é necessário se determinar uma curva de extrapolação, relacionando a corrente de ionização medida numa certa profundidade da câmara. Assim, para cada uma das condições mostradas na Tabela 6.12, foi elaborada uma curva de extrapolação a partir das irradiações.

A Figura 6.13 mostra as quatro curvas de extrapolação obtidas com a câmara de extrapolação Böhm com janela de entrada de Mylar aluminizado. Nas Fig. 6.14.a-c podem ser observadas as curvas de extrapolação para cada uma das três fontes de ${ }^{90} \mathrm{Sr}+{ }^{90} \mathrm{Y}$, com a câmara com janela de entrada de Hostaphan grafitado. Destas curvas, os coeficientes angulares, $B$, apresentados na Tabela 6.13 , foram obtidos, os quais foram aplicados aos 
cálculos para a determinação das taxas de dose absorvida. Analisando-se as Fig. 6.13 e 6.14.a-c, pode-se observar que a resposta da câmara apresenta linearidade em todo o intervalo de profundidade da câmara estudado, pois em todos os casos, o coeficiente de correlação linear, $\mathrm{R}^{2}$, foi superior a 0,99986.

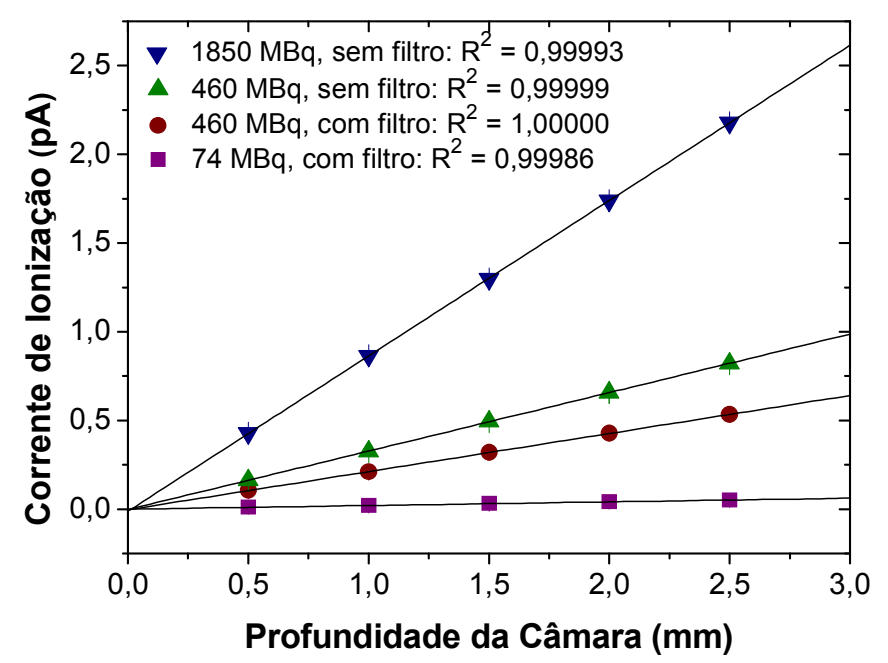

Figura 6.13 - Curvas de extrapolação da câmara de extrapolação Böhm, com janela de entrada de Mylar aluminizado, utilizando três fontes de ${ }^{90} \mathrm{Sr}+{ }^{90} \mathrm{Y}$, à distância fonte-detector de $30 \mathrm{~cm}$, e em condições específicas de uso de filtro uniformizador de campo. 

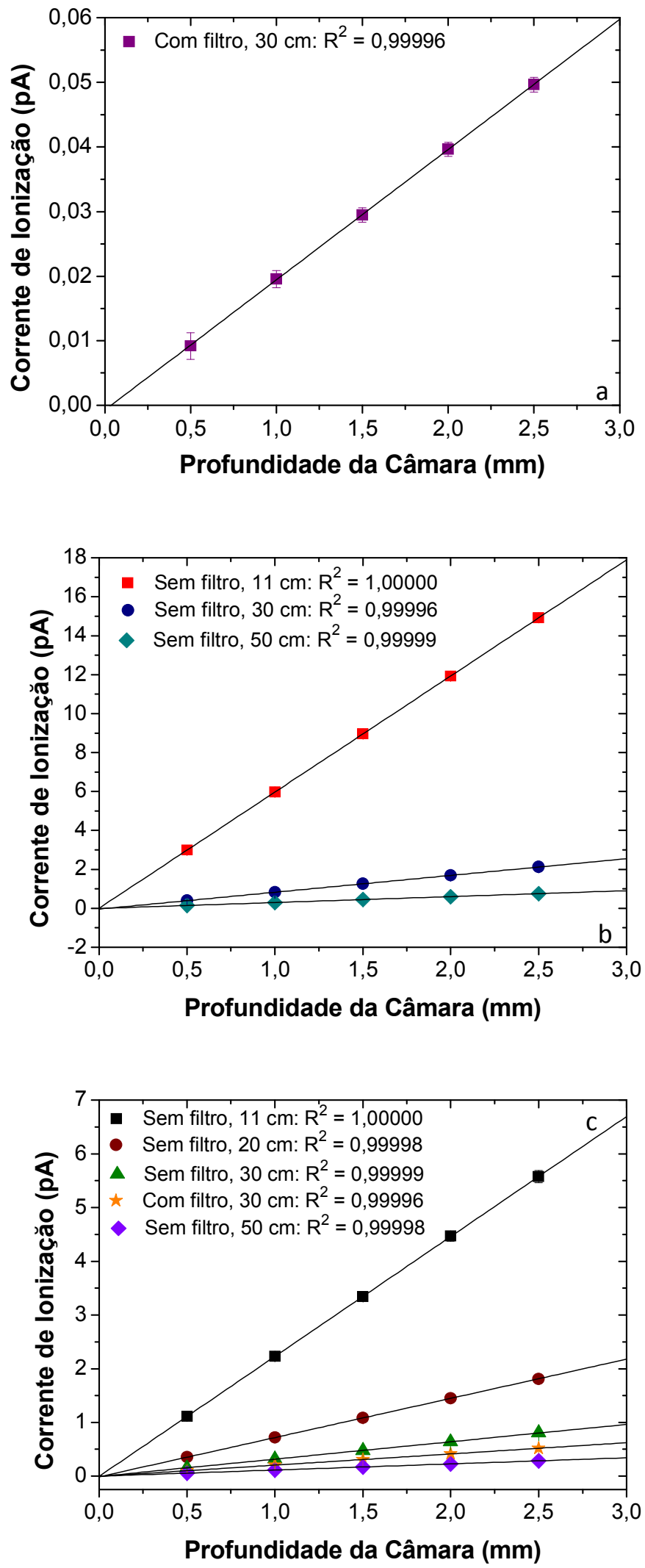

Figura 6.14 - Curvas de extrapolação para a câmara de extrapolação Böhm, com janela de entrada de Hostaphan, utilizando três fontes de ${ }^{90} \mathrm{Sr}+{ }^{90} \mathrm{Y}$ : (a) $74 \mathrm{MBq}$; (b) $1850 \mathrm{MBq}$; e (c) $460 \mathrm{MBq}$. 
Tabela 6.13 - Valores de coeficiente angular obtidos das curvas de extrapolação para cada uma das fontes de ${ }^{90} \mathrm{Sr}+{ }^{90} \mathrm{Y}$, em condições diferentes com relação ao uso de filtro e distância fonte-detector.

\begin{tabular}{|c|c|c|c|c|c|}
\hline \multirow{2}{*}{$\begin{array}{c}\text { Sistema } \\
\text { Padrão } \\
\text { Secundário } \\
\text { de Radiação } \\
\text { Beta }\end{array}$} & \multirow{2}{*}{$\begin{array}{l}\text { Atividade } \\
\text { da } \\
\text { Fonte } \\
\text { (MBq) }\end{array}$} & \multirow{2}{*}{$\begin{array}{c}\text { Filtro } \\
\text { Uniformizador } \\
\text { de Campo }\end{array}$} & \multirow{2}{*}{$\begin{array}{l}\text { Distância } \\
\text { Fonte- } \\
\text { Detector } \\
\text { (cm) }\end{array}$} & \multicolumn{2}{|c|}{$\begin{array}{l}\text { Coeficiente Angular } B \\
(\mathrm{pA} / \mathrm{m})\end{array}$} \\
\hline & & & & $\begin{array}{c}\text { Mylar } \\
\text { Aluminizado }\end{array}$ & $\begin{array}{l}\text { Hostaphan } \\
\text { Grafitado }\end{array}$ \\
\hline \multirow{4}{*}{ BSS1 } & 74 & Sim & 30 & $20,511 \pm 0,049$ & $20,171 \pm 0,073$ \\
\hline & 1850 & Não & 11 & - & $5964,0 \pm 5,8$ \\
\hline & 1850 & Não & 30 & $859,1 \pm 3,5$ & $864,6 \pm 3,3$ \\
\hline & 1850 & Não & 50 & - & $303,9 \pm 5,3$ \\
\hline \multirow{5}{*}{ BSS2 } & 460 & Não & 11 & - & $2557,3 \pm 1,8$ \\
\hline & 460 & Não & 20 & - & $770,5 \pm 1,7$ \\
\hline & 460 & Sim & 30 & $214,76 \pm 0,12$ & $222,2 \pm 6,6$ \\
\hline & 460 & Não & 30 & $329,7 \pm 1,2$ & $345,3 \pm 3,3$ \\
\hline & 460 & Não & 50 & - & $126,7 \pm 5,3$ \\
\hline
\end{tabular}

Utilizando os coeficientes angulares provenientes das curvas de extrapolação, as taxas de dose absorvida no ar e no tecido, foram determinadas, neste trabalho, por dois métodos: o método demonstrado por Caldas (1980), e o método demonstrado pela ISO 6980-2 (2004). A seguir, serão apresentados primeiramente os resultados obtidos com o primeiro método, e em seguida, os resultados obtidos com o segundo método, ambos para a janela de entrada de Mylar aluminizado.

De acordo com a Equação 4.13 (apresentada no item “4.4.4. Determinação de Taxas de Dose Absorvida"), a taxa de dose absorvida no tecido, $\dot{D}_{t}$, foi determinada, multiplicando-se a taxa de dose absorvida no ar no volume sensível da câmara, $\dot{D}_{a}$, a razão entre os poderes de freamento médios do tecido e do ar, $s_{t, a}$, e os fatores de correção $\boldsymbol{k}_{\boldsymbol{b} \boldsymbol{a}}$ e $\boldsymbol{k}_{\boldsymbol{f}}$. Entretanto, para se determinar a taxa de dose absorvida $\dot{D}_{t}$, foi necessário obter a taxa de dose absorvida $\dot{D}_{a}$, a qual foi calculada por meio da Equação 4.14. Esta Equação faz uso de diferentes fatores de correção (descritos nas Equações 4.15 e 4.16), e alguns deles foram obtidos experimentalmente ou calculados neste trabalho, enquanto outros foram utilizados de acordo com os valores fornecidos na literatura (apresentados na Tabela 5.2 do item “5.1.4. Determinação de Fatores de Correção"). Os fatores obtidos neste trabalho serão relatados a seguir. 
O fator de correção $\boldsymbol{k}_{\boldsymbol{B} \boldsymbol{r}}$, devido à emissão de Bremsstrahlung da fonte de radiação beta foi obtido experimentalmente para as três fontes de ${ }^{90} \mathrm{Sr}+{ }^{90} \mathrm{Y}$. Para a determinação deste fator, foram realizadas medições de corrente de ionização em duas condições: com a janela de entrada da câmara coberta por uma camada de Plexiglas, de $1 \mathrm{~cm}$ de espessura (para absorver toda a radiação beta), e com a janela de entrada sem cobertura nenhuma. A Fig. 6.15 mostra o arranjo experimental utilizado na determinação do fator de correção $\boldsymbol{k}_{B \boldsymbol{r}}$.

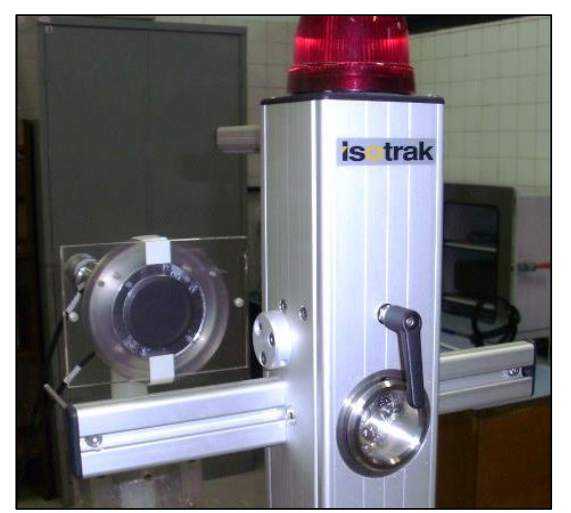

Figura 6.15 - Câmara de extrapolação Böhm, com janela de entrada de Hostaphan grafitado (coberta com uma placa de Plexiglas), posicionado no sistema BSS2, durante procedimento para determinação do fator de correção $\boldsymbol{k}_{\boldsymbol{B} \boldsymbol{r}}$.

Neste experimento, como o valor de corrente de ionização medido com a placa de Plexiglas foi muito baixo, foi necessário usar uma profundidade da câmara de $10 \mathrm{~mm}$, e assim, a tensão de polarização utilizada foi de $\pm 100 \mathrm{~V}$. Em todos os casos, foram feitas 10 medições de carga elétrica em cada polaridade e condição de uso da placa de Plexiglas; cada medição foi tomada nos tempos de coleta de carga de: 8 min (fonte de $74 \mathrm{MBq}$ ), 1 min (fonte de $1850 \mathrm{MBq}$ ), e $2 \mathrm{~min}$ (fonte de $460 \mathrm{MBq}$ ), respectivamente. A Tabela 6.14 apresenta os valores de corrente de ionização e fatores de correção $\boldsymbol{k}_{\boldsymbol{B} \boldsymbol{r}}$, obtidos em diferentes condições experimentais.

Tabela 6.14 - Fatores de correção $\boldsymbol{k}_{\boldsymbol{B} r}$, obtidos neste trabalho para três fontes de ${ }^{90} \mathrm{Sr}+{ }^{90} \mathrm{Y}$, e com a câmara de extrapolação Böhm com janela de entrada de Mylar aluminizado.

\begin{tabular}{|c|c|c|c|c|c|}
\hline \multirow[b]{2}{*}{$\begin{array}{l}\text { Atividade } \\
\text { da Fonte }\end{array}$} & \multirow{2}{*}{$\begin{array}{c}\text { Filtro } \\
\text { Uniformizador } \\
\text { de Campo }\end{array}$} & \multirow{2}{*}{$\begin{array}{l}\text { Distância } \\
\text { Fonte- } \\
\text { Detector } \\
\text { (cm) }\end{array}$} & \multicolumn{2}{|c|}{ Corrente de lonização (pA) } & \multirow[b]{2}{*}{$\begin{array}{c}\text { Fator de Correção } \\
\qquad k_{B r}\end{array}$} \\
\hline & & & $\begin{array}{c}\text { Câmara com } \\
\text { Plexiglas }\end{array}$ & $\begin{array}{c}\text { Câmara sem } \\
\text { Plexiglas }\end{array}$ & \\
\hline $74 \mathrm{MBq}$ & Sim & 30 & $0,014 \pm 0,012$ & $1,564 \pm 0,016$ & $0,991 \pm 0,010$ \\
\hline $1850 \mathrm{MBq}$ & Não & 11 & $0,028 \pm 0,003$ & $59,634 \pm 0,050$ & $0,999 \pm 0,008$ \\
\hline $460 \mathrm{MBq}$ & Não & 30 & $0,004 \pm 0,003$ & $6,257 \pm 0,003$ & $0,999 \pm 0,006$ \\
\hline
\end{tabular}


O fator de correção $\boldsymbol{k}_{\boldsymbol{i n h}}$, referente à inhomogeneidade do campo da radiação primária dentro do volume coletor, foi determinado por meio da Equação 5.2, relacionando-se a distância fonte-detector, e os raios do eletrodo coletor e das fontes. A Tabela 6.15 mostra os valores de $\boldsymbol{k}_{\boldsymbol{i n h}}$ obtidos neste trabalho com a câmara com janela de entrada de Mylar aluminizado, e os valores envolvidos na determinação deste fator de correção.

Tabela 6.15 - Fatores de correção $\boldsymbol{k}_{\boldsymbol{i n h}}$, obtidos neste trabalho para três fontes de ${ }^{90} \mathrm{Sr}+{ }^{90} \mathrm{Y}$, à distância fonte-detector de $30 \mathrm{~cm}$, e com a câmara de extrapolação Böhm com janela de entrada de Mylar aluminizado.

\begin{tabular}{|c|c|c|c|c|}
\hline $\begin{array}{l}\text { Atividade } \\
\text { da Fonte }\end{array}$ & $\begin{array}{c}\text { Distância } \\
\text { Fonte-Detector } \\
\text { (cm) }\end{array}$ & $\begin{array}{l}\text { Raio do Eletrodo } \\
\text { Coletor } \\
(\mathrm{cm})\end{array}$ & $\begin{array}{l}\text { Raio da Fonte } \\
(\mathrm{cm})\end{array}$ & $\begin{array}{c}\text { Fator de Correção } \\
\qquad k_{i n h}\end{array}$ \\
\hline $74 \mathrm{MBq}$ & \multirow{3}{*}{$30,00 \pm 0,05$} & \multirow{3}{*}{$1,579 \pm 0,001$} & $0,300 \pm 0,001$ & $1,0014 \pm 0,0044$ \\
\hline $1850 \mathrm{MBq}$ & & & & \\
\hline $460 \mathrm{MBq}$ & & & $0,500 \pm 0,001$ & $1,0014 \pm 0,0039$ \\
\hline
\end{tabular}

O fator de correção $\boldsymbol{k}_{\text {sat }}$, devido à falta de saturação da resposta da câmara, foi obtido pela Equação 5.3, utilizando o valor da eficiência de coleção de íons médio da câmara, determinado a partir das curvas de saturação com a fonte de ${ }^{90} \mathrm{Sr}+{ }^{90} \mathrm{Y}(1850 \mathrm{MBq}, 1981)$, demonstradas no item "6.1.1. Curvas de Saturação". O valor obtido para o fator de correção $\boldsymbol{k}_{\text {sat }}$, foi $(1,0018 \pm 0,0026)$.

Também foi calculado, neste trabalho, o fator de correção $\boldsymbol{k}_{\boldsymbol{a d}}$, referente às partículas beta espalhadas pelas paredes laterais da câmara; para isso, foi utilizada a Equação 5.4, a qual envolve a distância fonte-detector e a profundidade da câmara. A Tabela 6.16 mostra os valores de $\boldsymbol{k}_{\boldsymbol{a d}}$ obtidos, em cada profundidade diferente da câmara. Como este fator também foi determinado com a janela de entrada de Hostaphan, na Tabela 6.16 já podem ser observados os valores para outras distâncias fonte-detector, que não foram utilizadas com a janela de Mylar aluminizado, mas sim com a de Hostaphan grafitado.

O fator de correção $\boldsymbol{k}_{\boldsymbol{\rho}}$, devido à flutuação no valor da densidade do ar no volume da câmara, foi calculado pela Equação 5.5, relacionando-se a pressão e a temperatura do ar no momento da medição, e a pressão e a temperatura em condições de referência: 101,3 kPa e $20^{\circ} \mathrm{C}$. A Tabela 6.17 mostra os valores de $\boldsymbol{k}_{\boldsymbol{\rho}}$ obtidos neste trabalho. 
Tabela 6.16 - Fatores de correção $\boldsymbol{k}_{a d}$, obtidos neste trabalho para três fontes de ${ }^{90} \mathrm{Sr}+{ }^{90} \mathrm{Y}$, a distâncias fonte-detector diferentes, e para as cinco profundidades da câmara, $d$, utilizadas na curva de extrapolação; estas medições foram feitas com a câmara de extrapolação Böhm com janela de entrada de Mylar aluminizado e de Hostaphan grafitado.

\begin{tabular}{|c|c|c|c|c|c|c|}
\hline \multirow{2}{*}{$\begin{array}{l}\text { Sistema Padrão } \\
\text { Secundário de } \\
\text { Radiação Beta }\end{array}$} & \multirow{2}{*}{$\begin{array}{c}\text { Distância } \\
\text { Fonte-Detector } \\
\text { (cm) }\end{array}$} & \multicolumn{5}{|c|}{$\begin{array}{c}\text { Fator de Correção } \\
k_{a d} \\
\end{array}$} \\
\hline & & $d=0,05 \mathrm{~cm}$ & $d=0,10 \mathrm{~cm}$ & $d=0,15 \mathrm{~cm}$ & $d=0,20 \mathrm{~cm}$ & $d=0,25 \mathrm{~cm}$ \\
\hline \multirow{3}{*}{ BSS1 } & 11 & $1,0035 \pm 0,0064$ & $1,0062 \pm 0,0064$ & $1,0090 \pm 0,0064$ & $1,0117 \pm 0,0064$ & $1,0144 \pm 0,0064$ \\
\hline & 30 & $0,9999 \pm 0,0024$ & $0,9998 \pm 0,0024$ & $0,9997 \pm 0,0024$ & $0,9996 \pm 0,0023$ & $0,9995 \pm 0,0023$ \\
\hline & 50 & $0,9991 \pm 0,0014$ & $0,9983 \pm 0,0014$ & $0,9976 \pm 0,0014$ & $0,9968 \pm 0,0014$ & $0,9960 \pm 0,0014$ \\
\hline \multirow{4}{*}{ BSS2 } & 11 & $1,0035 \pm 0,0064$ & $1,0062 \pm 0,0064$ & $1,0090 \pm 0,0064$ & $1,0117 \pm 0,0064$ & $1,0144 \pm 0,0064$ \\
\hline & 20 & $1,0009 \pm 0,0035$ & $1,0017 \pm 0,0035$ & $1,0024 \pm 0,0035$ & $1,0031 \pm 0,0035$ & $1,0038 \pm 0,0035$ \\
\hline & 30 & $0,9999 \pm 0,0024$ & $0,9998 \pm 0,0024$ & $0,9997 \pm 0,0024$ & $0,9996 \pm 0,0023$ & $0,9995 \pm 0,0023$ \\
\hline & 50 & $0,9991 \pm 0,0014$ & $0,9983 \pm 0,0014$ & $0,9976 \pm 0,0014$ & $0,9968 \pm 0,0014$ & $0,9960 \pm 0,0014$ \\
\hline
\end{tabular}

Tabela 6.17 - Fatores de correção $\boldsymbol{k}_{\boldsymbol{\rho}}$, obtidos com a câmara de extrapolação Böhm com janela de entrada de Mylar aluminizado, para três fontes de ${ }^{90} \mathrm{Sr}+{ }^{90} \mathrm{Y}$, à distância fonte-detector de $30 \mathrm{~cm}$, e para cinco profundidades da câmara, $d$.

\begin{tabular}{|c|c|c|c|c|c|c|c|}
\hline \multirow{2}{*}{$\begin{array}{l}\text { Sistema Padrão } \\
\text { Secundário de } \\
\text { Radiação Beta }\end{array}$} & \multirow{2}{*}{$\begin{array}{c}\text { Atividade } \\
\text { da Fonte } \\
\text { (MBq) }\end{array}$} & \multirow{2}{*}{$\begin{array}{c}\text { Filtro } \\
\text { Uniformizador } \\
\text { de Campo }\end{array}$} & \multicolumn{5}{|c|}{$\begin{array}{c}\text { Fator de Correção } \\
k_{\rho} \\
\end{array}$} \\
\hline & & & $d=0,05 \mathrm{~cm}$ & $d=0,10 \mathrm{~cm}$ & $d=0,15 \mathrm{~cm}$ & $d=0,20 \mathrm{~cm}$ & $d=0,25 \mathrm{~cm}$ \\
\hline \multirow{2}{*}{ BSS1 } & 74 & Sim & $1,0922 \pm 0,0025$ & $1,0903 \pm 0,0025$ & $1,0931 \pm 0,0025$ & $1,0934 \pm 0,0025$ & $1,0935 \pm 0,0025$ \\
\hline & 1850 & Não & $1,1064 \pm 0,0025$ & $1,1060 \pm 0,0025$ & $1,1050 \pm 0,0025$ & $1,1049 \pm 0,0025$ & $1,1045 \pm 0,0025$ \\
\hline \multirow{2}{*}{ BSS2 } & 460 & Sim & $1,0831 \pm 0,0025$ & $1,0827 \pm 0,0025$ & $1,0847 \pm 0,0025$ & $1,0852 \pm 0,0025$ & $1,0854 \pm 0,0025$ \\
\hline & 460 & Não & $1,0926 \pm 0,0025$ & $1,0929 \pm 0,0025$ & $1,0956 \pm 0,0025$ & $1,0991 \pm 0,0025$ & $1,1006 \pm 0,0025$ \\
\hline
\end{tabular}


Os fatores de correção $\boldsymbol{k}_{\boldsymbol{b a}}, \boldsymbol{k}_{f}, \boldsymbol{k}_{d e}, \boldsymbol{k}_{\boldsymbol{h} u}, \boldsymbol{k}_{\text {gap }}$, e $\boldsymbol{k}_{\boldsymbol{e s p}}$, não foram calculados, mas os seus valores utilizados foram aqueles apresentados na Tabela 5.2.

Após se corrigir a corrente de ionização medida com cada uma das três fontes de ${ }^{90} \mathrm{Sr}+{ }^{90} \mathrm{Y}$, e com a janela de entrada de Mylar aluminizado, aplicando-se os fatores de correção específicos na Equação 4.15, e após se determinar os fatores necessários para a Equação 4.16, foi possível determinar a taxa de dose absorvida no ar no volume sensível da câmara, $\dot{D}_{a}$, por meio da Equação 4.14. Com o valor da taxa de dose $\dot{D}_{a}$, a taxa de dose no tecido no volume sensível da câmara, $\dot{D}_{t}$, foi obtida, utilizando-se a Equação 4.13. A Tabela 6.18 apresenta os valores das grandezas utilizadas na determinação destas duas taxas de dose. Os resultados obtidos para as taxas de dose $\dot{D}_{a}$ e $\dot{D}_{t}$ estão apresentados na Tabela 6.19.

Tabela 6.18 - Grandezas e seus valores utilizados na determinação das taxas de dose absorvida no ar, $\dot{D}_{a}$, e no tecido, $\dot{D}_{t}$, para três fontes de ${ }^{90} \mathrm{Sr}+{ }^{90} \mathrm{Y}$, utilizando a câmara de extrapolação Böhm com janela de entrada de Mylar aluminizado (CALDAS, 1980; ISO, 2004).

\begin{tabular}{ccccccc}
\hline Sistema Padrão & \multicolumn{6}{c}{ Grandezas/Valores } \\
\cline { 2 - 6 } $\begin{array}{c}\text { Secundário de } \\
\text { Radiação Beta }\end{array}$ & $\begin{array}{c}W \\
(\mathrm{eV})\end{array}$ & $\begin{array}{c}e \\
\left(10^{-9} \mathrm{C}\right)\end{array}$ & $\begin{array}{c}\left(\bar{W}_{0} / e\right) \\
(\mathrm{J} / \mathrm{C})\end{array}$ & $\begin{array}{c}\rho \\
\left(\mathrm{kg} / \mathrm{m}^{3}\right)\end{array}$ & $s_{t, a}$ & $a_{e f}{ }^{*}$ \\
\hline BSS1 & $33,73 \pm 0,15$ & $1,602 \pm 0,000$ & - & $1,1995 \pm 0,0005$ & $1,111 \pm 0,011$ & $7,354 \pm 0,002$ \\
\hline BSS2 & - & - & $33,83 \pm 0,06$ & $1,197 \pm 0,000$ & $1,110 \pm 0,005$ & \\
\hline
\end{tabular}

* A área efetiva do eletrodo coletor foi determinada experimentalmente, como descrito no item "6.2.2. Profundidade Nula Real e Área Efetiva".

Tabela 6.19 - Taxas de dose absorvida no ar, $\dot{D}_{a}$, e no tecido, $\dot{D}_{t}$, para as três fontes de ${ }^{90} \mathrm{Sr}+{ }^{90} \mathrm{Y}$, utilizando a câmara de extrapolação e janela de entrada de Mylar aluminizado, à distância fonte-detector de $30 \mathrm{~cm}$.

\begin{tabular}{ccccc}
\hline \multirow{2}{*}{$\begin{array}{c}\text { Sistema Padrão } \\
\text { Secundário de } \\
\text { Radiação Beta }\end{array}$} & $\begin{array}{c}\text { Atividade } \\
\text { da Fonte }\end{array}$ & $\begin{array}{c}\text { Uniformizador } \\
\text { de Campo }\end{array}$ & \multicolumn{2}{c}{$\begin{array}{c}\text { Taxa de Dose Absorvida } \\
(\mu \mathrm{Gy} / \mathrm{s})\end{array}$} \\
\cline { 3 - 5 } BSS1 & $74 \mathrm{MBq}$ & $\operatorname{Sim}$ & $\dot{D}_{a}$ & Tecido, $\dot{D}_{t}$ \\
\cline { 2 - 5 } & $1850 \mathrm{MBq}$ & $\mathrm{Não}$ & $32,78 \pm 0,04$ & $0,87 \pm 0,05$ \\
\hline \multirow{2}{*}{ BSS2 } & $460 \mathrm{MBq}$ & $\operatorname{Sim}$ & $8,24 \pm 0,44$ & $36,78 \pm 2,04$ \\
\cline { 2 - 5 } & $460 \mathrm{MBq}$ & Não & $12,64 \pm 0,67$ & $9,23 \pm 0,49$ \\
\hline
\end{tabular}


Após a obtenção das taxas de dose absorvida no ar e no tecido do volume sensível da câmara, foi possível obter a taxa de dose absorvida na superfície externa da câmara, $\dot{D}_{t}(0)$, utilizando a Equação 4.17. Para isso, foi necessário utilizar o fator de transmissão, $T$, equivalente à densidade superficial da janela de entrada da câmara. A Tabela 6.20 mostra os valores destes fatores de transmissão, que foram determinados utilizando a primeira parte da fórmula de correção da janela de Mylar para tecido (Equação 4.8), como descrito a seguir, e interpolando-se os valores de $T$ da tabela dos certificados de calibração de cada fonte:

$$
\begin{gathered}
t_{T}=\left(d_{J} \cdot c_{J}\right) \\
t_{T}=\left(0,7125 \times \frac{10}{10,8}\right) \\
t_{T}=0,66 \mathrm{mg} / \mathrm{cm}^{2}
\end{gathered}
$$

Tabela 6.20 - Fatores de transmissão, $T$, obtidos para a janela de entrada de Mylar aluminizado.

\begin{tabular}{cccc}
\hline $\begin{array}{c}\text { Sistema Padrão } \\
\begin{array}{c}\text { Secundário de } \\
\text { Radiação Beta }\end{array}\end{array}$ & $\begin{array}{c}\text { Atividade } \\
\text { da Fonte }\end{array}$ & $\begin{array}{c}\text { Filtro } \\
\text { Uniformizador } \\
\text { de Campo }\end{array}$ & $\begin{array}{c}\text { Fator de } \\
\text { Transmissão } \\
\boldsymbol{T}\end{array}$ \\
\hline \multirow{2}{*}{ BSS1 } & $74 \mathrm{MBq}$ & Sim & $1,006 \pm 0,010$ \\
\cline { 2 - 4 } & $1850 \mathrm{MBq}$ & Não & $1,010 \pm 0,010$ \\
\hline \multirow{2}{*}{ BSS2 } & $460 \mathrm{MBq}$ & Sim & $0,963 \pm 0,010$ \\
\cline { 2 - 4 } & $460 \mathrm{MBq}$ & Não & $0,947 \pm 0,010$ \\
\hline
\end{tabular}

A determinação das taxas de dose, $\dot{D}_{t}(0)$, permitiu a obtenção das taxas de dose absorvida no ar na superfície externa da câmara, $\dot{D}_{c}$. Na Tabela 6.21 podem ser observados os valores obtidos de taxa de dose absorvida no tecido, $\dot{D}_{t}(0)$, e no ar, $\dot{D}_{c}$.

Tabela 6.21 - Taxas de dose absorvida no tecido, $\dot{D}_{t}(0)$, e no ar, $\dot{D}_{c}$, para as três fontes de ${ }^{90} \mathrm{Sr}+{ }^{90} \mathrm{Y}$,

\begin{tabular}{|c|c|c|c|c|}
\hline \multirow{2}{*}{$\begin{array}{l}\text { Sistema Padrão } \\
\text { Secundário de } \\
\text { Radiação Beta }\end{array}$} & \multirow{2}{*}{$\begin{array}{l}\text { Atividade } \\
\text { da Fonte }\end{array}$} & \multirow{2}{*}{$\begin{array}{c}\text { Filtro } \\
\text { Uniformizador } \\
\text { de Campo }\end{array}$} & \multicolumn{2}{|c|}{$\begin{array}{c}\text { Taxa de Dose Absorvida } \\
(\mu G y / s)\end{array}$} \\
\hline & & & Tecido, $\dot{D}_{t}(0)$ & $\mathrm{Ar}, \dot{D}_{c}$ \\
\hline \multirow{2}{*}{ BSS1 } & $74 \mathrm{MBq}$ & Sim & $0,87 \pm 0,05$ & $0,78 \pm 0,04$ \\
\hline & $1850 \mathrm{MBq}$ & Não & $36,43 \pm 2,02$ & $32,79 \pm 1,85$ \\
\hline \multirow{2}{*}{ BSS2 } & $460 \mathrm{MBq}$ & Sim & $9,58 \pm 0,51$ & $8,63 \pm 0,46$ \\
\hline & $460 \mathrm{MBq}$ & Não & $14,97 \pm 0,80$ & $13,48 \pm 0,72$ \\
\hline
\end{tabular}
utilizando a câmara de extrapolação e janela de entrada de Mylar aluminizado, à distância fonte-detector de $30 \mathrm{~cm}$. 
As recomendações internacionais (BÖHM, 1986; ISO, 2004) estabelecem as condições para se determinar as taxas de dose absorvida a $0,07 \mathrm{~mm}$ de profundidade no tecido. Assim, a padronização dos resultados obtidos foi feita para esta espessura, a fim de se seguir estas recomendações.

No caso das duas fontes de ${ }^{90} \mathrm{Sr}+{ }^{90} \mathrm{Y}$ do sistema BSS1, as taxas de dose absorvida dadas nos seus certificados de calibração e nos resultados experimentais deste trabalho, referemse à profundidade nula, e por este motivo, elas foram convertidas para 0,07 $\mathrm{mm}$ de espessura de tecido. Para isso, os resultados para esta profundidade foram calculados corrigindo-se os valores de taxa de dose absorvida à profundidade nula para os fatores de transmissão dos certificados de calibração de ambas as fontes, e este procedimento foi adotado para se determinar as taxas de dose absorvida no ar e no tecido. Para a fonte de ${ }^{90} \mathrm{Sr}+{ }^{90} \mathrm{Y}$ do sistema BSS2, somente os resultados experimentais foram corrigidos para os fatores de transmissão, pois somente eles foram obtidos para profundidade nula (as taxas de dose absorvida fornecidas nos certificados da fonte do sistema BSS2 já foram fornecidas para $0,07 \mathrm{~mm}$ de espessura de tecido). A Tabela 6.22 mostra os valores de fatores de transmissão para os quais as taxas de dose absorvida foram corrigidas.

Tabela 6.22 - Fatores de transmissão, $T$, utilizados para a determinação das taxas de dose absorvida a $0 \mathrm{~mm}$ ou $0,07 \mathrm{~mm}$ de profundidade no tecido, obtidos para as fontes de ${ }^{90} \mathrm{Sr}+{ }^{90} \mathrm{Y}$ e para a janela de entrada de Mylar aluminizado (PTB, 1981a; 1981b; 2005).

\begin{tabular}{cccccc}
\hline \multirow{2}{*}{$\begin{array}{c}\text { Sistema Padrão } \\
\text { Secundário de } \\
\text { Radiação Beta }\end{array}$} & \multirow{2}{*}{$\begin{array}{c}\text { Atividade } \\
\text { da Fonte }\end{array}$} & \multirow{2}{*}{$\begin{array}{c}\text { Uniltro } \\
\text { Uniformizador } \\
\text { de Campo }\end{array}$} & \multicolumn{2}{c}{ Fator de Transmissão } \\
\cline { 4 - 6 } & & $\boldsymbol{d}=\mathbf{0} \mathbf{~ m m}$ & $\boldsymbol{d}=\mathbf{0 , 0 7} \mathbf{~ m m}$ \\
\hline \multirow{2}{*}{ BSS1 } & $74 \mathrm{MBq}$ & Sim & $1,000 \pm 0,010$ & $1,041 \pm 0,011$ \\
\cline { 2 - 5 } & $1850 \mathrm{MBq}$ & Não & $1,000 \pm 0,010$ & $1,068 \pm 0,011$ \\
\hline \multirow{2}{*}{ BSS2 } & $460 \mathrm{MBq}$ & Sim & $0,960 \pm 0,010$ & $1,000^{*}$ \\
\cline { 2 - 5 } & $460 \mathrm{MBq}$ & Não & $0,940 \pm 0,010$ & $1,000^{*}$ \\
\hline
\end{tabular}

* O certificado de calibração não apresenta incerteza para estes valores.

Após todos os cálculos e seus respectivos resultados relatados, foi possível determinar as taxas de dose absorvida no ar e no tecido, a $0 \mathrm{~mm}$ e a $0,07 \mathrm{~mm}$ de profundidade, assim como elas são fornecidas nos certificados de calibração. A Tabela 6.23 mostra uma comparação entre as taxas de dose absorvida finais obtidas experimentalmente neste trabalho, e as fornecidas nos certificados de calibração das fontes, no ar, a $0 \mathrm{~mm}$ e a 
0,07 $\mathrm{mm}$ de profundidade, enquanto a Tabela 6.24 mostra as taxas de dose absorvida, para as mesmas condições, porém no tecido. 
Tabela 6.23 - Taxas de dose absorvida para as fontes de ${ }^{90} \mathrm{Sr}+{ }^{90} \mathrm{Y}$ às profundidades de $0 \mathrm{~mm}$ e $0,07 \mathrm{~mm}$ no ar, utilizando a câmara de extrapolação e janela de entrada de Mylar aluminizado, à distância fonte-detector de $30 \mathrm{~cm}$.

\begin{tabular}{|c|c|c|c|c|c|c|c|}
\hline \multirow{2}{*}{$\begin{array}{l}\text { Sistema Padrão } \\
\text { Secundário de } \\
\text { Radiação Beta }\end{array}$} & \multirow{2}{*}{$\begin{array}{l}\text { Atividade } \\
\text { da Fonte }\end{array}$} & \multirow{2}{*}{$\begin{array}{c}\text { Filtro } \\
\text { Uniformizador } \\
\text { de Campo }\end{array}$} & \multicolumn{4}{|c|}{$\begin{array}{c}\text { Taxa de Dose Absorvida no Ar } \\
(\mu \mathrm{Gy} / \mathrm{s})\end{array}$} & \multirow{2}{*}{$\begin{array}{c}\text { Diferença } \\
\text { entre } \\
\text { C e D } \\
(\%) \\
\end{array}$} \\
\hline & & & $\begin{array}{c}\mathrm{A} \\
\text { Experimental } \\
(d=0 \mathrm{~mm}) \\
\end{array}$ & $\begin{array}{c}\text { B } \\
\text { Certificado } \\
(d=0 \mathrm{~mm}) \\
\end{array}$ & $\begin{array}{c}\mathrm{C} \\
\text { Experimental } \\
(d=0,07 \mathrm{~mm}) \\
\end{array}$ & $\begin{array}{c}\text { D } \\
\text { Certificado } \\
(d=0,07 \mathrm{~mm}) \\
\end{array}$ & \\
\hline \multirow{2}{*}{ BSS1 } & $74 \mathrm{MBq}$ & Sim & $0,779 \pm 0,043$ & $0,783 \pm 0,016$ & $0,811 \pm 0,046$ & $0,816 \pm 0,018$ & 0,60 \\
\hline & $1850 \mathrm{MBq}$ & Não & $32,79 \pm 1,85$ & $32,46 \pm 0,65$ & $35,02 \pm 2,00$ & $34,67 \pm 0,65$ & $-1,00$ \\
\hline \multirow{2}{*}{ BSS2 } & $460 \mathrm{MBq}$ & Sim & $8,63 \pm 0,46$ & $8,98 \pm 0,24$ & $8,28 \pm 0,45$ & $8,62 \pm 0,23$ & 4,06 \\
\hline & $460 \mathrm{MBq}$ & Não & $13,48 \pm 0,72$ & $14,32 \pm 0,38$ & $12,67 \pm 0,69$ & $13,46 \pm 0,36$ & 6,26 \\
\hline
\end{tabular}

Tabela 6.24 - Taxas de dose absorvida para as fontes de ${ }^{90} \mathrm{Sr}+{ }^{90} \mathrm{Y}$ às profundidades de $0 \mathrm{~mm}$ e $0,07 \mathrm{~mm}$ no tecido, utilizando a câmara de extrapolação e janela de entrada de Mylar aluminizado, à distância fonte-detector de $30 \mathrm{~cm}$.

\begin{tabular}{|c|c|c|c|c|c|c|c|}
\hline \multirow{2}{*}{$\begin{array}{l}\text { Sistema Padrão } \\
\text { Secundário de } \\
\text { Radiação Beta }\end{array}$} & \multirow{2}{*}{$\begin{array}{l}\text { Atividade } \\
\text { da Fonte }\end{array}$} & \multirow{2}{*}{$\begin{array}{c}\text { Filtro } \\
\text { Uniformizador } \\
\text { de Campo }\end{array}$} & \multicolumn{4}{|c|}{$\begin{array}{c}\text { Taxa de Dose Absorvida no Tecido } \\
(\mu \mathrm{G} / \mathrm{s})\end{array}$} & \multirow{2}{*}{$\begin{array}{c}\text { Diferença } \\
\text { entre } \\
\text { C e D } \\
\text { (\%) }\end{array}$} \\
\hline & & & $\begin{array}{c}\mathrm{A} \\
\text { Experimental } \\
(d=0 \mathrm{~mm}) \\
\end{array}$ & $\begin{array}{c}\text { B } \\
\text { Certificado } \\
(d=0 \mathrm{~mm}) \\
\end{array}$ & $\begin{array}{c}\mathrm{C} \\
\text { Experimental } \\
(d=0,07 \mathrm{~mm}) \\
\end{array}$ & $\begin{array}{c}\text { D } \\
\text { Certificado } \\
(d=0,07 \mathrm{~mm}) \\
\end{array}$ & \\
\hline \multirow{2}{*}{ BSS1 } & $74 \mathrm{MBq}$ & Sim & $0,866 \pm 0,048$ & $0,870 \pm 0,031$ & $0,901 \pm 0,050$ & $0,906 \pm 0,034$ & 0,60 \\
\hline & $1850 \mathrm{MBq}$ & Não & $36,43 \pm 2,02$ & $36,07 \pm 1,30$ & $38,91 \pm 2,19$ & $38,52 \pm 1,30$ & $-1,00$ \\
\hline \multirow{2}{*}{ BSS2 } & $460 \mathrm{MBq}$ & Sim & $9,57 \pm 0,51$ & $9,96 \pm 0,27$ & $9,19 \pm 0,50$ & $9,56 \pm 0,26$ & 4,06 \\
\hline & $460 \mathrm{MBq}$ & Não & $14,96 \pm 0,80$ & $15,90 \pm 0,42$ & $14,06 \pm 0,77$ & $14,94 \pm 0,39$ & 6,26 \\
\hline
\end{tabular}


A Tabela 6.24 mostra uma diferença máxima obtida de $6,26 \%$ na calibração da fonte de $460 \mathrm{MBq}$, sem filtro uniformizador de campo. As diferenças mostradas na Tabela 6.23 foram as mesmas da Tabela 6.24, pois o que difere a taxa de dose absorvida à profundidade nula da taxa de dose absorvida à profundidade de $0,07 \mathrm{~mm}$ é apenas o fator de transmissão (Tabela 6.22).

A análise e a discussão sobre os resultados de taxas de dose absorvida obtidos, bem como as diferenças entre as taxas determinadas e as fornecidas nos certificados de calibração das fontes, serão apresentadas ao final deste item.

A segunda etapa realizada para se determinar as taxas de dose absorvida no ar e no tecido, a $0 \mathrm{~mm}$ e a $0,07 \mathrm{~mm}$ de profundidade, foi utilizar o método descrito pela recomendação da ISO 6980-2 (2004). Este método, que foi utilizado seguindo-se a Equação 4.19, envolveu o uso de outros fatores de correção; alguns destes fatores foram obtidos, neste trabalho, por meio de cálculos (demonstrados na Tabela 5.2 do item "5.1.4. Determinação de Fatores de Correção"), enquanto outros foram utilizados com os valores fornecidos na literatura.

O fator de correção $\boldsymbol{k}_{\boldsymbol{a d v}}$, que também se relaciona à variação da densidade do ar, assim como o $\boldsymbol{k}_{\boldsymbol{\rho}}$, utilizado no método de Caldas (1980), foi obtido para cada uma das fontes de ${ }^{90} \mathrm{Sr}+{ }^{90} \mathrm{Y}$ e cada profundidade da câmara, quando da obtenção da curva de extrapolação, por meio da Equação 5.6. A Tabela 6.25 mostra os resultados obtidos para o fator de correção $\boldsymbol{k}_{\boldsymbol{a d v}}$.

Outro fator de correção calculado foi $\boldsymbol{k}_{\boldsymbol{d i}}$, devido à falta de uniformidade axial do campo de radiação beta. Este fator foi obtido utilizando-se a Equação 5.7, e seus resultados, para cada profundidade da câmara, podem ser observados na Tabela 6.26. Como este é um fator que depende apenas da distância fonte-detector e da profundidade da câmara, o mesmo fator é utilizado para as três fontes de ${ }^{90} \mathrm{Sr}+{ }^{90} \mathrm{Y}$, já que foi utilizada a mesma distância fonte-detector, de $30 \mathrm{~cm}$, para todas elas. 
Tabela 6.25 - Fatores de correção $\boldsymbol{k}_{a d v}$, obtidos com a câmara de extrapolação Böhm com janela de entrada de Mylar aluminizado, para três fontes de ${ }^{90} \mathrm{Sr}+{ }^{90} \mathrm{Y}$, à distância fonte-detector de $30 \mathrm{~cm}$, e para cinco profundidades da câmara, $d$.

\begin{tabular}{|c|c|c|c|c|c|c|c|}
\hline \multirow{2}{*}{$\begin{array}{l}\text { Sistema Padrão } \\
\text { Secundário de } \\
\text { Radiação Beta }\end{array}$} & \multirow{2}{*}{$\begin{array}{c}\text { Atividade } \\
\text { da Fonte } \\
\text { (MBq) }\end{array}$} & \multirow{2}{*}{$\begin{array}{c}\text { Filtro } \\
\text { Uniformizador } \\
\text { de Campo }\end{array}$} & \multicolumn{5}{|c|}{$\begin{array}{c}\text { Fator de Correção } \\
k_{a d v} \\
\end{array}$} \\
\hline & & & $d=0,05 \mathrm{~cm}$ & $d=0,10 \mathrm{~cm}$ & $d=0,15 \mathrm{~cm}$ & $d=0,20 \mathrm{~cm}$ & $d=0,25 \mathrm{~cm}$ \\
\hline \multirow{2}{*}{ BSS1 } & 74 & Sim & $1,1459 \pm 0,0012$ & $1,1546 \pm 0,0012$ & $1,1920 \pm 0,0012$ & $1,1976 \pm 0,0012$ & $1,2029 \pm 0,0012$ \\
\hline & 1850 & Não & $1,1916 \pm 0,0012$ & $1,1911 \pm 0,0012$ & $1,1851 \pm 0,0012$ & $1,1845 \pm 0,0012$ & $1,1896 \pm 0,0012$ \\
\hline \multirow{2}{*}{ BSS2 } & 460 & Sim & $1,0514 \pm 0,0012$ & $1,0460 \pm 0,0012$ & $1,0885 \pm 0,0012$ & $1,0887 \pm 0,0012$ & $1,0989 \pm 0,0012$ \\
\hline & 460 & Não & $1,1217 \pm 0,0012$ & $1,1215 \pm 0,0012$ & $1,1907 \pm 0,0012$ & $1,2429 \pm 0,0012$ & $1,2704 \pm 0,0012$ \\
\hline
\end{tabular}

Tabela 6.26 - Fatores de correção $\boldsymbol{k}_{d i}$, obtidos com a câmara de extrapolação Böhm com janela de entrada de Mylar aluminizado, para três fontes de ${ }^{90} \mathrm{Sr}+{ }^{90} \mathrm{Y}$, à distância fonte-detector de $30 \mathrm{~cm}$, e para cinco profundidades da câmara, $d$.

\begin{tabular}{|c|c|c|c|c|c|c|c|}
\hline \multirow{2}{*}{$\begin{array}{l}\text { Sistema Padrão } \\
\text { Secundário de } \\
\text { Radiação Beta }\end{array}$} & \multirow{2}{*}{$\begin{array}{c}\text { Atividade } \\
\text { da Fonte } \\
\text { (MBq) }\end{array}$} & \multirow{2}{*}{$\begin{array}{c}\text { Filtro } \\
\text { Uniformizador } \\
\text { de Campo }\end{array}$} & \multicolumn{5}{|c|}{$\begin{array}{c}\text { Fator de Correção } \\
\boldsymbol{k}_{d i}\end{array}$} \\
\hline & & & $d=0,05 \mathrm{~cm}$ & $d=0,10 \mathrm{~cm}$ & $d=0,15 \mathrm{~cm}$ & $d=0,20 \mathrm{~cm}$ & $d=0,25 \mathrm{~cm}$ \\
\hline BSS1/BSS2 & $74 / 1850 / 460$ & Não & $1,0021 \pm 0,0044$ & $1,0037 \pm 0,0028$ & $1,0054 \pm 0,0023$ & $1,0071 \pm 0,0020$ & $1,0087 \pm 0,0019$ \\
\hline
\end{tabular}


Os fatores de correção $\boldsymbol{k}_{\boldsymbol{B} \boldsymbol{r}}$ (devido ao Bremsstrahlung) e $\boldsymbol{k}_{\text {sat }}$ (devido à falta de saturação da corrente de ionização), também foram utilizados para corrigir a corrente de ionização medida no caso da taxa de dose absorvida pelo método da ISO 6980-2 (2004) e, neste caso, seus valores foram os mesmos já demonstrados anteriormente.

Com relação aos fatores de transmissão $\boldsymbol{k}_{a b s}, \boldsymbol{k}_{a c}, \boldsymbol{k}_{d e}, \boldsymbol{k}_{\boldsymbol{p} e}, \boldsymbol{k}_{b a}, \boldsymbol{k}_{e l}, \boldsymbol{k}_{\boldsymbol{h u}}, \boldsymbol{k}_{\boldsymbol{i n}}$, e $\boldsymbol{k}_{\boldsymbol{r} a}$, eles não foram calculados, mas os valores utilizados foram aqueles descritos por Böhm (BÖHM, 1986) ou pela ISO 6980-2 (2004), e que foram relacionados na Tabela 5.3.

Para se determinar a taxa de dose absorvida pelo método da ISO 6980-2 (2004), os valores das grandezas envolvidas na Equação 4.19 foram os mesmos já especificados na Tabela 6.18, com a diferença que neste método não foi utilizado um valor para $\bar{W}$ e outro para $e$, os quais foram utilizados apenas para o caso do método de Caldas (1980), mas sim apenas o valor de $\left(\bar{W}_{0} / e\right)$.

No caso deste método da ISO 6980-2 (2004), também foram utilizados os valores de fator de transmissão obtidos para a janela de entrada de Mylar aluminizado, da mesma forma usada na determinação das taxas de dose absorvida pelo método de Caldas (1980); neste caso, os valores do fator de transmissão foram os mesmos já demonstrados na Tabela 6.20.

Por este método (Equação 4.19), a determinação das taxas de dose no tecido $\dot{D}_{t}$, permitiu a obtenção das taxas de dose absorvida no tecido à profundidade de $0 \mathrm{~mm}$ (na superfície da janela da câmara), $\dot{D}_{t}(0)$. Na Tabela 6.27 podem ser observados os valores obtidos de taxa de dose absorvida no tecido $\dot{D}_{t}$, e no tecido à profundidade nula $\dot{D}_{t}(0)$.

Tabela 6.27 - Taxas de dose absorvida no tecido, $\dot{D}_{t}$, e no tecido à profundidade de $0 \mathrm{~mm} \dot{D}_{t}(0)$, para as três fontes de ${ }^{90} \mathrm{Sr}+{ }^{90} \mathrm{Y}$, utilizando a câmara de extrapolação e janela de entrada de Mylar aluminizado, à distância fonte-detector de $30 \mathrm{~cm}$.

\begin{tabular}{|c|c|c|c|c|}
\hline \multirow{2}{*}{$\begin{array}{l}\text { Sistema Padrão } \\
\text { Secundário de } \\
\text { Radiação Beta }\end{array}$} & \multirow{2}{*}{$\begin{array}{l}\text { Atividade } \\
\text { da Fonte }\end{array}$} & \multirow{2}{*}{$\begin{array}{c}\text { Filtro } \\
\text { Uniformizador } \\
\text { de Campo }\end{array}$} & \multicolumn{2}{|c|}{$\begin{array}{c}\text { Taxa de Dose Absorvida } \\
(\mu \mathrm{Gy} / \mathrm{s})\end{array}$} \\
\hline & & & Tecido, $\dot{D}_{t}$ & Ar, $\dot{D}_{t}(0)$ \\
\hline \multirow{2}{*}{ BSS1 } & $74 \mathrm{MBq}$ & Sim & $0,87 \pm 0,02$ & $0,87 \pm 0,02$ \\
\hline & $1850 \mathrm{MBq}$ & Não & $36,84 \pm 0,86$ & $36,49 \pm 0,92$ \\
\hline \multirow{2}{*}{ BSS2 } & $460 \mathrm{MBq}$ & Sim & $9,25 \pm 0,09$ & $9,60 \pm 0,14$ \\
\hline & $460 \mathrm{MBq}$ & Não & $14,20 \pm 0,14$ & $14,99 \pm 0,22$ \\
\hline
\end{tabular}


Por este método, também foram utilizados fatores de transmissão fornecidos nos certificados de calibração das fontes, para converter as taxas de dose absorvida de $0 \mathrm{~mm}$ a $0,07 \mathrm{~mm}$, ou de $0,07 \mathrm{~mm}$ a $0 \mathrm{~mm}$. Os fatores de transmissão usados neste caso foram os mesmos descritos na Tabela 6.22.

Assim, após se determinar os fatores de correção, se corrigir a corrente de ionização medida, e se determinar as taxas de dose absorvida da Tabela 6.27, pôde-se obter as taxas de dose absorvida no ar e no tecido, a $0 \mathrm{~mm}$ e a $0,07 \mathrm{~mm}$ de profundidade. A Tabela 6.28 mostra a comparação realizada entre as taxas de dose absorvida finais obtidas experimentalmente neste trabalho, e as fornecidas nos certificados de calibração das fontes, no $\mathrm{ar}$, a $0 \mathrm{~mm}$ e a $0,07 \mathrm{~mm}$ de profundidade, enquanto que na Tabela 6.29 podem ser observadas as taxas de dose absorvida, para as mesmas condições, porém no tecido.

A Tabela 6.29 mostra uma diferença máxima obtida de 11,98\% na calibração da fonte de $460 \mathrm{MBq}$, sem filtro uniformizador de campo, como também ocorreu no caso do método de Caldas (1980).

Todas as etapas e todos os procedimentos relatados até agora, neste item 6.1.7., foram realizados igualmente, em termos dos dois métodos de obtenção de taxa de dose absorvida, no ar e no tecido, e à profundidades de $0 \mathrm{~mm}$ e $0,07 \mathrm{~mm}$, para a câmara de extrapolação Böhm com janela de entrada de Hostaphan. A diferença entre o uso das duas janelas, é que no caso da de Hostaphan, as taxas de dose absorvida também foram obtidas para as três fontes de ${ }^{90} \mathrm{Sr}+{ }^{90} \mathrm{Y}$, mas agora para as nove condições diferentes (Tabela 6.12), abrangendo todas as condições descritas nos certificados de calibração destas três fontes.

Os coeficientes angulares obtidos das curvas de extrapolação (Fig. 6.12.a-c) realizadas com a câmara de extrapolação e janela de Hostaphan, foram aqueles já especificados na Tabela 6.13. 
Tabela 6.28 - Taxas de dose absorvida para as fontes de ${ }^{90} \mathrm{Sr}+{ }^{90} \mathrm{Y}$ à profundidades de $0 \mathrm{~mm}$ e $0,07 \mathrm{~mm}$ no ar, utilizando a câmara de extrapolação e janela de entrada de Mylar aluminizado, à distância fonte-detector de $30 \mathrm{~cm}$.

\begin{tabular}{|c|c|c|c|c|c|c|c|}
\hline \multirow{2}{*}{$\begin{array}{l}\text { Sistema Padrão } \\
\text { Secundário de } \\
\text { Radiação Beta }\end{array}$} & \multirow{2}{*}{$\begin{array}{l}\text { Atividade } \\
\text { da Fonte }\end{array}$} & \multirow{2}{*}{$\begin{array}{c}\text { Filtro } \\
\text { Uniformizador } \\
\text { de Campo }\end{array}$} & \multicolumn{4}{|c|}{$\begin{array}{l}\text { Taxa de Dose Absorvida no Ar } \\
(\mu \mathrm{Gy} / \mathrm{s})\end{array}$} & \multirow{2}{*}{ 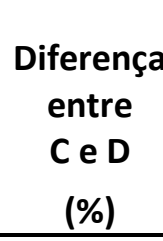 } \\
\hline & & & $\begin{array}{c}\text { A } \\
\text { Experimental } \\
(d=0 \mathrm{~mm}) \\
\end{array}$ & $\begin{array}{c}\text { B } \\
\text { Certificado } \\
(d=0 \mathrm{~mm}) \\
\end{array}$ & $\begin{array}{c}\mathrm{C} \\
\text { Experimental } \\
(d=0,07 \mathrm{~mm})\end{array}$ & $\begin{array}{c}\mathrm{D} \\
\text { Certificado } \\
(d=0,07 \mathrm{~mm})\end{array}$ & \\
\hline \multirow{2}{*}{ BSS1 } & $74 \mathrm{MBq}$ & Sim & $0,785 \pm 0,019$ & $0,783 \pm 0,016$ & $0,817 \pm 0,022$ & $0,816 \pm 0,018$ & $-0,11$ \\
\hline & $1850 \mathrm{MBq}$ & Não & $33,16 \pm 0,84$ & $32,46 \pm 0,65$ & $35,41 \pm 0,97$ & $34,67 \pm 0,65$ & $-2,10$ \\
\hline \multirow{2}{*}{ BSS2 } & $460 \mathrm{MBq}$ & Sim & $8,33 \pm 0,12$ & $8,98 \pm 0,24$ & $8,00 \pm 0,14$ & $8,62 \pm 0,23$ & 7,75 \\
\hline & $460 \mathrm{MBq}$ & Não & $12,79 \pm 0,18$ & $14,32 \pm 0,38$ & $12,02 \pm 0,21$ & $13,46 \pm 0,36$ & 11,98 \\
\hline
\end{tabular}

Tabela 6.29 - Taxas de dose absorvida para as fontes de ${ }^{90} \mathrm{Sr}+{ }^{90} \mathrm{Y}$ à profundidades de $0 \mathrm{~mm} \mathrm{e} \mathrm{0,07} \mathrm{mm}$ no tecido, utilizando a câmara de extrapolação e janela de entrada de Mylar aluminizado à distância fonte-detector de $30 \mathrm{~cm}$.

\begin{tabular}{|c|c|c|c|c|c|c|c|}
\hline \multirow{2}{*}{$\begin{array}{l}\text { Sistema Padrão } \\
\text { Secundário de } \\
\text { Radiação Beta }\end{array}$} & \multirow[b]{2}{*}{$\begin{array}{l}\text { Atividade } \\
\text { da Fonte }\end{array}$} & \multirow{2}{*}{$\begin{array}{c}\text { Filtro } \\
\text { Uniformizador } \\
\text { de Campo }\end{array}$} & \multicolumn{4}{|c|}{$\begin{array}{c}\text { Taxa de Dose Absorvida no Tecido } \\
(\mu \mathrm{G} / \mathrm{s})\end{array}$} & \multirow{2}{*}{$\begin{array}{c}\text { Diferença } \\
\text { entre } \\
\text { C e D } \\
(\%) \\
\end{array}$} \\
\hline & & & $\begin{array}{c}\text { A } \\
\text { Experimental } \\
(d=0 \mathrm{~mm}) \\
\end{array}$ & $\begin{array}{c}\text { B } \\
\text { Certificado } \\
(d=0 \mathrm{~mm}) \\
\end{array}$ & $\begin{array}{c}\mathrm{C} \\
\text { Experimental } \\
(d=0,07 \mathrm{~mm}) \\
\end{array}$ & $\begin{array}{c}\text { D } \\
\text { Certificado } \\
(d=0,07 \mathrm{~mm}) \\
\end{array}$ & \\
\hline \multirow{2}{*}{ BSS1 } & $74 \mathrm{MBq}$ & Sim & $0,872 \pm 0,019$ & $0,870 \pm 0,031$ & $0,907 \pm 0,022$ & $0,906 \pm 0,034$ & $-0,11$ \\
\hline & $1850 \mathrm{MBq}$ & Não & $36,84 \pm 0,86$ & $36,07 \pm 1,30$ & $39,35 \pm 1,00$ & $38,52 \pm 1,30$ & $-2,10$ \\
\hline \multirow{2}{*}{ BSS2 } & $460 \mathrm{MBq}$ & Sim & $9,25 \pm 0,09$ & $9,96 \pm 0,26$ & $8,88 \pm 0,13$ & $9,56 \pm 0,26$ & 7,75 \\
\hline & $460 \mathrm{MBq}$ & Não & $14,20 \pm 0,14$ & $15,90 \pm 0,39$ & $13,34 \pm 0,19$ & $14,94 \pm 0,39$ & 11,98 \\
\hline
\end{tabular}


O primeiro método utilizado na determinação de taxas de dose absorvida, para as três fontes de ${ }^{90} \mathrm{Sr}+{ }^{90} \mathrm{Y}$, com a câmara de extrapolação e a janela de Hostaphan, foi o método de Caldas (1980). Assim como no caso da janela de Mylar aluminizado, foram utilizados fatores de correção e foram determinadas inicialmente quatro taxas de dose absorvida: no ar dentro do volume sensível da câmara, $\dot{D}_{a}$ (Equação 4.14), no tecido dentro do volume sensível da câmara, $\dot{D}_{t}$ (Equação 4.13), no tecido na superfície externa da janela da câmara, $\dot{D}_{t}(0)$ (Equação 4.17), e no ar na superfície externa da janela da câmara, $\dot{D}_{c}$ (Equação 4.18).

O primeiro fator de correção obtido para a câmara de extrapolação foi o relacionado à presença de Bremsstrahlung, $\boldsymbol{k}_{\boldsymbol{B} \boldsymbol{r}}$, que foi obtido experimentalmente para cada fonte de ${ }^{90} \mathrm{Sr}+{ }^{90} \mathrm{Y}$, e cujos resultados, determinados pela Equação 5.1, podem ser observados na Tabela 6.30 .

O fator de correção $\boldsymbol{k}_{\boldsymbol{i n h}}$, foi o segundo fator a ser determinado. A Tabela 6.31 mostra os fatores de correção obtidos, por meio da Equação 5.2, para todas as condições de distância fonte-detector utilizadas.

O fator de correção $\boldsymbol{k}_{\text {sat }}$, também foi obtido, neste caso, assim como no caso da janela de entrada de Mylar aluminizado, a partir das curvas de saturação com a fonte de ${ }^{90} \mathrm{Sr}+{ }^{90} \mathrm{Y}$ (1850 MBq, 1981), demonstradas no item "6.1.1. Curvas de Saturação", e por meio da Equação 5.3. O valor obtido para o fator de correção $\boldsymbol{k}_{\text {sat }}$, foi $(1,0020 \pm 0,0022)$.

O fator de correção $\boldsymbol{k}_{\boldsymbol{a d}}$, também foi utilizado na determinação das taxas de dose absorvida das fontes de ${ }^{90} \mathrm{Sr}+{ }^{90} \mathrm{Y}$, com a câmara de extrapolação Böhm e janela de entrada de Hostaphan. Os valores obtidos para o fator $\boldsymbol{k}_{a d}$, utilizando-se a Equação 5.4, já foram mostrados na Tabela 6.16.

O último fator de correção calculado foi o $\boldsymbol{k}_{\boldsymbol{p}}$, por meio da Equação 5.5: Tabela 6.32. 
Tabela 6.30 - Fatores de correção $\boldsymbol{k}_{\boldsymbol{B} r}$, obtidos neste trabalho para três fontes de ${ }^{90} \mathrm{Sr}+{ }^{90} \mathrm{Y}$, e com a câmara de extrapolação Böhm com janela de entrada de Hostaphan grafitado.

\begin{tabular}{|c|c|c|c|c|c|}
\hline \multirow{2}{*}{$\begin{array}{l}\text { Atividade } \\
\text { da Fonte }\end{array}$} & \multirow{2}{*}{$\begin{array}{c}\text { Filtro } \\
\text { Uniformizador } \\
\text { de Campo }\end{array}$} & \multirow{2}{*}{$\begin{array}{c}\text { Distância } \\
\text { Fonte-Detector } \\
(\mathrm{cm})\end{array}$} & \multicolumn{2}{|c|}{ Corrente de Ionização (pA) } & \multirow{2}{*}{$\begin{array}{l}\text { Fator de Correção } \\
\qquad k_{B r}\end{array}$} \\
\hline & & & $\begin{array}{l}\text { Câmara com } \\
\text { Plexiglas }\end{array}$ & $\begin{array}{l}\text { Câmara sem } \\
\text { Plexiglas }\end{array}$ & \\
\hline $74 \mathrm{MBq}$ & Sim & 30 & $0,0025 \pm 0,0028$ & $0,1941 \pm 0,0019$ & $0,9869 \pm 0,0095$ \\
\hline $1850 \mathrm{MBq}$ & Não & 11 & $0,0272 \pm 0,0019$ & $57,164 \pm 0,0736$ & $0,9996 \pm 0,0013$ \\
\hline $460 \mathrm{MBq}$ & Não & 30 & $0,0036 \pm 0,0015$ & $3,1209 \pm 0,0018$ & $0,9989 \pm 0,0006$ \\
\hline
\end{tabular}

Tabela 6.31 - Fatores de correção $\boldsymbol{k}_{\text {inh }}$, obtidos neste trabalho para três fontes de ${ }^{90} \mathrm{Sr}+{ }^{90} \mathrm{Y}$, a distâncias fonte-detector diferentes, e com a câmara de extrapolação Böhm com janela de entrada de Hostaphan grafitado.

\begin{tabular}{|c|c|c|c|c|}
\hline $\begin{array}{l}\text { Sistema Padrão } \\
\text { Secundário de } \\
\text { Radiação Beta }\end{array}$ & $\begin{array}{c}\text { Distância } \\
\text { Fonte-Detector } \\
\text { (cm) } \\
\end{array}$ & $\begin{array}{l}\text { Raio do Eletrodo } \\
\text { Coletor } \\
(\mathrm{cm})\end{array}$ & $\begin{array}{c}\text { Raio da Fonte } \\
(\mathrm{cm})\end{array}$ & $\begin{array}{l}\text { Fator de Correção } \\
\qquad \boldsymbol{k}_{\text {inh }}\end{array}$ \\
\hline \multirow{3}{*}{ BSS1 } & $11,00 \pm 0,05$ & & \multirow{3}{*}{$0,300 \pm 0,001$} & $1,0104 \pm 0,0081$ \\
\hline & $30,00 \pm 0,05$ & & & $1,0014 \pm 0,0044$ \\
\hline & $50,00 \pm 0,05$ & & & $1,0005 \pm 0,0039$ \\
\hline \multirow{4}{*}{ BSS2 } & $11,00 \pm 0,05$ & $1,579 \pm 0,001$ & \multirow{4}{*}{$0,500 \pm 0,001$} & $1,0104 \pm 0,0087$ \\
\hline & $20,00 \pm 0,05$ & & & $1,0031 \pm 0,0052$ \\
\hline & $30,00 \pm 0,05$ & & & $1,0014 \pm 0,0039$ \\
\hline & $50,00 \pm 0,05$ & & & $1,0005 \pm 0,0030$ \\
\hline
\end{tabular}


Tabela 6.32 - Fatores de correção $\boldsymbol{k}_{\boldsymbol{\rho}}$, obtidos com a câmara de extrapolação Böhm com janela de entrada de Hostaphan grafitado, para três fontes de ${ }^{90} \mathrm{Sr}+{ }^{90} \mathrm{Y}$, e para cinco profundidades da câmara, $d$.

\begin{tabular}{|c|c|c|c|c|c|c|c|c|}
\hline \multirow{2}{*}{$\begin{array}{l}\text { Sistema Padrão } \\
\text { Secundário de } \\
\text { Radiação Beta }\end{array}$} & \multirow{2}{*}{$\begin{array}{c}\text { Atividade } \\
\text { da Fonte } \\
\text { (MBq) }\end{array}$} & \multirow{2}{*}{$\begin{array}{c}\text { Filtro } \\
\text { Uniformizador } \\
\text { de Campo }\end{array}$} & \multirow{2}{*}{$\begin{array}{l}\text { Distância } \\
\text { Fonte-Detector } \\
\text { (cm) }\end{array}$} & \multicolumn{5}{|c|}{$\begin{array}{c}\text { Fator de Correção } \\
k_{\rho}\end{array}$} \\
\hline & & & & $d=0,05 \mathrm{~cm}$ & $d=0,10 \mathrm{~cm}$ & $d=0,15 \mathrm{~cm}$ & $d=0,20 \mathrm{~cm}$ & $d=0,25 \mathrm{~cm}$ \\
\hline \multirow{4}{*}{ BSS1 } & 74 & Sim & 30 & $1,0958 \pm 0,0025$ & $1,0982 \pm 0,0025$ & $1,0992 \pm 0,0025$ & $1,0986 \pm 0,0025$ & $1,0941 \pm 0,0025$ \\
\hline & \multirow{3}{*}{1850} & Não & 11 & $1,0894 \pm 0,0025$ & $1,0893 \pm 0,0025$ & $1,0912 \pm 0,0025$ & $1,0908 \pm 0,0025$ & $1,0898 \pm 0,0025$ \\
\hline & & Não & 30 & $1,0914 \pm 0,0025$ & $1,0915 \pm 0,0025$ & $1,0912 \pm 0,0025$ & $1,0904 \pm 0,0025$ & $1,0909 \pm 0,0025$ \\
\hline & & Não & 50 & $1,0897 \pm 0,0025$ & $1,0892 \pm 0,0025$ & $1,0891 \pm 0,0025$ & $1,0885 \pm 0,0025$ & $1,0891 \pm 0,0025$ \\
\hline \multirow{5}{*}{ BSS2 } & \multirow{5}{*}{460} & Não & 11 & $1,0778 \pm 0,0025$ & $1,0765 \pm 0,0025$ & $1,0762 \pm 0,0025$ & $1,0765 \pm 0,0025$ & $1,0787 \pm 0,0025$ \\
\hline & & Não & 20 & $1,0813 \pm 0,0025$ & $1,0810 \pm 0,0025$ & $1,0801 \pm 0,0025$ & $1,0795 \pm 0,0025$ & $1,0786 \pm 0,0025$ \\
\hline & & Sim & 30 & $1,1011 \pm 0,0025$ & $1,0955 \pm 0,0025$ & $1,0941 \pm 0,0025$ & $1,0937 \pm 0,0025$ & $1,0941 \pm 0,0025$ \\
\hline & & Não & 30 & $1,1096 \pm 0,0025$ & $1,1091 \pm 0,0025$ & $1,1112 \pm 0,0025$ & $1,1091 \pm 0,0025$ & $1,1031 \pm 0,0025$ \\
\hline & & Não & 50 & $1,0800 \pm 0,0025$ & $1,0786 \pm 0,0025$ & $1,0782 \pm 0,0025$ & $1,0764 \pm 0,0025$ & $1,0773 \pm 0,0025$ \\
\hline
\end{tabular}


Os outros fatores de correção $\boldsymbol{k}_{b a}, \boldsymbol{k}_{f}, \boldsymbol{k}_{d e}, \boldsymbol{k}_{\boldsymbol{h} u}, \boldsymbol{k}_{g a p}$, e $\boldsymbol{k}_{\boldsymbol{e s p}}$ foram descritos por Caldas (1980), e mostrados na Tabela 5.2.

Após a aplicação dos fatores de correção à corrente de ionização medida (Equação 4.15), e outros fatores na Equação 4.16, as taxas de dose absorvida no $\operatorname{ar} \dot{D}_{a}$ e no tecido $\dot{D}_{t}$ foram obtidas por meio das Equações 4.14 e 4.13 , respectivamente, e podem ser observadas na Tabela 6.33. As grandezas utilizadas foram já apresentadas na Tabela 6.18.

Tabela 6.33 - Taxas de dose absorvida no ar, $\dot{D}_{a}$, e no tecido, $\dot{D}_{t}$, para as três fontes de ${ }^{90} \mathrm{Sr}+{ }^{90} \mathrm{Y}$, utilizando a câmara de extrapolação e janela de entrada de Hostaphan grafitado.

\begin{tabular}{|c|c|c|c|c|c|}
\hline \multirow{2}{*}{$\begin{array}{l}\text { Sistema Padrão } \\
\text { Secundário de } \\
\text { Radiação Beta }\end{array}$} & \multirow{2}{*}{$\begin{array}{l}\text { Atividade } \\
\text { da Fonte }\end{array}$} & \multirow{2}{*}{$\begin{array}{c}\text { Filtro } \\
\text { Uniformizador } \\
\text { de Campo } \\
\end{array}$} & \multirow{2}{*}{$\begin{array}{c}\text { Distância } \\
\text { Fonte-Detector } \\
(\mathrm{cm}) \\
\end{array}$} & \multicolumn{2}{|c|}{$\begin{array}{c}\text { Taxa de Dose Absorvida } \\
(\mu \mathrm{Gy} / \mathrm{s})\end{array}$} \\
\hline & & & & Ar, $\dot{D}_{a}$ & Tecido, $\dot{D}_{t}$ \\
\hline \multirow{4}{*}{ BSS1 } & $74 \mathrm{MBq}$ & Sim & 30 & $0,76 \pm 0,04$ & $0,85 \pm 0,05$ \\
\hline & \multirow{3}{*}{$1850 \mathrm{MBq}$} & Não & 11 & $229,6 \pm 12,7$ & $257,7 \pm 14,4$ \\
\hline & & Não & 30 & $32,99 \pm 1,79$ & $37,02 \pm 2,05$ \\
\hline & & Não & 50 & $11,59 \pm 0,62$ & $13,00 \pm 0,71$ \\
\hline \multirow{5}{*}{ BSS2 } & \multirow{5}{*}{$460 \mathrm{MBq}$} & Não & 11 & $98,87 \pm 5,39$ & $110,81 \pm 6,07$ \\
\hline & & Não & 20 & $29,58 \pm 1,59$ & $33,16 \pm 1,79$ \\
\hline & & Sim & 30 & $8,52 \pm 0,46$ & $9,55 \pm 0,51$ \\
\hline & & Não & 30 & $13,23 \pm 0,75$ & $14,84 \pm 0,84$ \\
\hline & & Não & 50 & $4,85 \pm 0,26$ & $5,44 \pm 0,29$ \\
\hline
\end{tabular}

Para a obtenção das taxas de dose absorvida no $\operatorname{ar} \dot{D}_{a}$ e no tecido $\dot{D}_{t}$, foi possível se determinar a taxa de dose $\dot{D}_{t}(0)$, também no tecido, por meio da Equação 4.17, utilizando-se o fator de transmissão, $T$, equivalente à densidade superficial da janela de entrada da câmara. A Tabela 6.34 mostra os valores destes fatores de transmissão, que foram determinados da mesma forma que no caso da janela de Mylar aluminizado, ou seja, utilizando a primeira parte da fórmula de correção da janela de Hostaphan para tecido (Equação 4.8), como descrito a seguir, e interpolando-se os valores de $T$ da tabela dos certificados de calibração de cada fonte:

$$
\begin{gathered}
t_{T}=\left(d_{J} \cdot c_{J}\right) \\
t_{T}=\left(0,72 \times \frac{10}{10,8}\right) \\
t_{T}=0,67 \mathrm{mg} / \mathrm{cm}^{2}
\end{gathered}
$$


Tabela 6.34 - Fatores de transmissão, $T$, obtidos para a janela de entrada de Hostaphan grafitado.

\begin{tabular}{cccc}
\hline $\begin{array}{c}\text { Sistema Padrão } \\
\text { Secundário de } \\
\text { Radiação Beta }\end{array}$ & $\begin{array}{c}\text { Atividade } \\
\text { da Fonte }\end{array}$ & $\begin{array}{c}\text { Filtro } \\
\text { Uniformizador } \\
\text { de Campo }\end{array}$ & $\begin{array}{c}\text { Fator de } \\
\text { Transmissão } \\
\boldsymbol{T}\end{array}$ \\
\hline \multirow{3}{*}{ BSS1 } & $74 \mathrm{MBq}$ & Sim & $1,006 \pm 0,010$ \\
\cline { 2 - 4 } & \multirow{3}{*}{$1850 \mathrm{MBq}$} & Não & $1,009 \pm 0,010$ \\
\cline { 2 - 3 } & & Não & $1,010 \pm 0,010$ \\
\cline { 2 - 3 } & & Não & $1,010 \pm 0,010$ \\
\cline { 2 - 3 } BSS2 & $460 \mathrm{MBq}$ & Não & $0,940 \pm 0,010$ \\
\cline { 2 - 3 } & & São & $0,947 \pm 0,010$ \\
\cline { 2 - 3 } & & Não & $0,963 \pm 0,010$ \\
\cline { 2 - 3 } & & Não & $0,947 \pm 0,010$ \\
\hline
\end{tabular}

A partir das taxas de dose absorvida no tecido $\dot{D}_{t}(0)$, foi possível se determinar as taxas de dose no ar $\dot{D}_{c}$ : Tabela 6.35 .

Tabela 6.35 - Taxas de dose absorvida no tecido, $\dot{D}_{t}(0)$, e no ar, $\dot{D}_{c}$, para as três fontes de ${ }^{90} \mathrm{Sr}+{ }^{90} \mathrm{Y}$, utilizando a câmara de extrapolação e janela de entrada de Hostaphan grafitado.

\begin{tabular}{|c|c|c|c|c|c|}
\hline \multirow{2}{*}{$\begin{array}{l}\text { Sistema Padrão } \\
\text { Secundário de } \\
\text { Radiação Beta }\end{array}$} & \multirow{2}{*}{$\begin{array}{l}\text { Atividade } \\
\text { da Fonte }\end{array}$} & \multirow{2}{*}{$\begin{array}{c}\text { Filtro } \\
\text { Uniformizador } \\
\text { de Campo }\end{array}$} & \multirow{2}{*}{$\begin{array}{l}\text { Distância } \\
\text { Fonte-Detector } \\
\text { (cm) }\end{array}$} & \multicolumn{2}{|c|}{$\begin{array}{c}\text { Taxa de Dose Absorvida } \\
(\mu \mathrm{Gy} / \mathrm{s})\end{array}$} \\
\hline & & & & $\mathrm{Ar}, \dot{D}_{t}(0)$ & Tecido, $\dot{D}_{c}$ \\
\hline \multirow{4}{*}{ BSS1 } & $74 \mathrm{MBq}$ & Sim & 30 & $0,85 \pm 0,05$ & $0,76 \pm 0,04$ \\
\hline & \multirow{3}{*}{$1850 \mathrm{MBq}$} & Não & 11 & $255,3 \pm 14,3$ & $229,8 \pm 13,1$ \\
\hline & & Não & 30 & $36,66 \pm 2,03$ & $33,00 \pm 1,85$ \\
\hline & & Não & 50 & $12,87 \pm 0,70$ & $11,59 \pm 0,64$ \\
\hline \multirow{5}{*}{ BSS2 } & \multirow{5}{*}{$460 \mathrm{MBq}$} & Não & 11 & $117,92 \pm 6,46$ & $106,14 \pm 5,83$ \\
\hline & & Não & 20 & $35,03 \pm 1,89$ & $31,53 \pm 1,71$ \\
\hline & & Sim & 30 & $9,91 \pm 0,53$ & $8,92 \pm 0,48$ \\
\hline & & Não & 30 & $15,67 \pm 0,89$ & $14,11 \pm 0,80$ \\
\hline & & Não & 50 & $5,68 \pm 0,31$ & $5,12 \pm 0,28$ \\
\hline
\end{tabular}

Utilizando-se o mesmo procedimento das medições com a câmara com janela de entrada de Mylar aluminizado, foram determinadas as taxas de dose absorvida no ar e no tecido, para $0 \mathrm{~mm}$ e a $0,07 \mathrm{~mm}$ de profundidade no ar ou tecido. Para isso, foram utilizados os fatores de transmissão fornecidos nos certificados de calibração das fontes de ${ }^{90} \mathrm{Sr}^{90} \mathrm{Y}$, de acordo com a Tabela 6.36. As taxas de dose absorvida finais, obtidas pelo método de Caldas (1980), no ar e no tecido, podem ser observadas nas Tabelas 6.37 e 6.38, respectivamente. 
Tabela 6.36 - Fatores de transmissão, $T$, utilizados para a determinação das taxas de dose absorvida a $0 \mathrm{~mm}$ ou $0,07 \mathrm{~mm}$ de profundidade no tecido, obtidos para fontes de ${ }^{90} \mathrm{Sr}+{ }^{90} \mathrm{Y}$ e para a janela de entrada de Hostaphan grafitado (PTB, 1981a; 1981b; 2005).

\begin{tabular}{|c|c|c|c|c|c|}
\hline \multirow{2}{*}{$\begin{array}{l}\text { Sistema Padrão } \\
\text { Secundário de } \\
\text { Radiação Beta }\end{array}$} & \multirow{2}{*}{$\begin{array}{l}\text { Atividade } \\
\text { da Fonte }\end{array}$} & \multirow{2}{*}{$\begin{array}{c}\text { Filtro } \\
\text { Uniformizador } \\
\text { de Campo }\end{array}$} & \multirow{2}{*}{$\begin{array}{c}\text { Distância } \\
\text { Fonte-Detector } \\
\text { (cm) }\end{array}$} & \multicolumn{2}{|c|}{$\begin{array}{c}\text { Fator de Transmissão } \\
\boldsymbol{T} \\
\end{array}$} \\
\hline & & & & $d=0 \mathrm{~mm}$ & $d=0,07 \mathrm{~mm}$ \\
\hline \multirow{4}{*}{ BSS1 } & $74 \mathrm{MBq}$ & Sim & 30 & $1,000 \pm 0,010$ & $1,041 \pm 0,011$ \\
\hline & \multirow{3}{*}{$1850 \mathrm{MBq}$} & Não & 11 & $1,000 \pm 0,010$ & $1,070 \pm 0,011$ \\
\hline & & Não & 30 & $1,000 \pm 0,010$ & $1,068 \pm 0,011$ \\
\hline & & Não & 50 & $1,000 \pm 0,010$ & $1,060 \pm 0,011$ \\
\hline \multirow{5}{*}{ BSS2 } & \multirow{5}{*}{$460 \mathrm{MBq}$} & Não & 11 & $0,930 \pm 0,010$ & $1,000^{*}$ \\
\hline & & Não & 20 & $0,940 \pm 0,010$ & $1,000^{*}$ \\
\hline & & Sim & 30 & $0,960 \pm 0,010$ & $1,000^{*}$ \\
\hline & & Não & 30 & $0,940 \pm 0,010$ & $1,000^{*}$ \\
\hline & & Não & 50 & $0,950 \pm 0,010$ & $1,000^{*}$ \\
\hline
\end{tabular}

* O certificado de calibração não apresenta incerteza para estes valores.

A Tabela 6.38 mostra uma diferença máxima obtida de 3,0\% na calibração da fonte de $1850 \mathrm{MBq}$, sem filtro uniformizador de campo, à distância fonte-detector de $11 \mathrm{~cm}$. As diferenças mostradas na Tabela 6.37 foram as mesmas da Tabela 6.38, da mesma forma que no caso da janela de Mylar aluminizado, pois a diferença entre a taxa de dose absorvida à profundidade nula da taxa de dose absorvida a 0,07 $\mathrm{mm}$ de profundidade é apenas o fator de transmissão (Tabela 6.36).

Após a obtenção das taxas de dose absorvida pelo método descrito por Caldas (1980), foi a vez de se determinar as taxas de dose pelo método da ISO 6980-2 (2004). Da mesma forma que para a janela de entrada de Mylar aluminizado, foram inicialmente determinados os fatores de correção, e então as taxas de dose puderam ser obtidas.

O fator de correção $\boldsymbol{k}_{\boldsymbol{a d v}}$ foi obtido por meio da Equação 5.6 para cada uma das fontes de ${ }^{90} \mathrm{Sr}+{ }^{90} \mathrm{Y}$ e para cada profundidade da câmara, e seus valores podem ser observados na Tabela 6.39.

O fator de correção $\boldsymbol{k}_{d i}$ foi obtido utilizando-se a Equação 5.7, e seus resultados, para cada profundidade da câmara, podem ser observados na Tabela 6.40 . 
Tabela 6.37 - Taxas de dose absorvida para as fontes de ${ }^{90} \mathrm{Sr}+{ }^{90} \mathrm{Y}$ à profundidades de $0 \mathrm{~mm}$ e $0,07 \mathrm{~mm}$ no ar, utilizando a câmara de extrapolação e janela de entrada de Hostaphan grafitado.

\begin{tabular}{|c|c|c|c|c|c|c|c|c|}
\hline \multirow{2}{*}{$\begin{array}{l}\text { Sistema Padrão } \\
\text { Secundário de } \\
\text { Radiação Beta }\end{array}$} & \multirow[b]{2}{*}{$\begin{array}{l}\text { Atividade } \\
\text { da Fonte }\end{array}$} & \multirow{2}{*}{$\begin{array}{c}\text { Filtro } \\
\text { Uniformizador } \\
\text { de Campo }\end{array}$} & \multirow[b]{2}{*}{$\begin{array}{c}\text { Distância } \\
\text { Fonte-Detector } \\
\text { (cm) }\end{array}$} & \multicolumn{4}{|c|}{$\begin{array}{c}\text { Taxa de Dose Absorvida no Ar } \\
(\mu \mathrm{Gy} / \mathrm{s})\end{array}$} & \multirow{2}{*}{$\begin{array}{c}\text { Diferença } \\
\text { entre } \\
\text { C e D } \\
(\%)\end{array}$} \\
\hline & & & & $\begin{array}{c}\text { A } \\
\text { Experimental } \\
(d=0 \mathrm{~mm})\end{array}$ & $\begin{array}{c}\text { B } \\
\text { Certificado } \\
(d=0 \mathrm{~mm})\end{array}$ & $\begin{array}{c}\mathrm{C} \\
\text { Experimental } \\
(d=0,07 \mathrm{~mm})\end{array}$ & $\begin{array}{c}\text { D } \\
\text { Certificado } \\
(d=0,07 \mathrm{~mm})\end{array}$ & \\
\hline \multirow{4}{*}{ BSS1 } & $74 \mathrm{MBq}$ & Sim & 30 & $0,763 \pm 0,043$ & $0,783 \pm 0,082$ & $0,794 \pm 0,045$ & $0,816 \pm 0,018$ & 2,77 \\
\hline & \multirow{3}{*}{$1850 \mathrm{MBq}$} & Não & 11 & $229,8 \pm 13,1$ & $236,6 \pm 2,5$ & $245,8 \pm 14,2$ & $253,2 \pm 5,7$ & 2,99 \\
\hline & & Não & 30 & $33,00 \pm 1,85$ & $32,46 \pm 0,34$ & $35,24 \pm 2,01$ & $34,67 \pm 0,65$ & $-1,62$ \\
\hline & & Não & 50 & $11,59 \pm 0,64$ & $11,52 \pm 0,12$ & $12,28 \pm 0,70$ & $12,21 \pm 0,23$ & $-0,59$ \\
\hline \multirow{5}{*}{ BSS2 } & \multirow{5}{*}{$460 \mathrm{MBq}$} & Não & 11 & $106,1 \pm 5,8$ & $104,5 \pm 2,6$ & $98,71 \pm 5,52$ & $97,21 \pm 2,45$ & $-1,52$ \\
\hline & & Não & 20 & $31,53 \pm 1,70$ & $32,06 \pm 0,81$ & $29,64 \pm 1,63$ & $30,14 \pm 0,76$ & 1,67 \\
\hline & & Sim & 30 & $8,92 \pm 0,48$ & $8,98 \pm 0,23$ & $8,56 \pm 0,47$ & $8,62 \pm 0,22$ & 0,61 \\
\hline & & Não & 30 & $14,11 \pm 0,80$ & $14,32 \pm 0,36$ & $13,26 \pm 0,77$ & $13,46 \pm 0,34$ & 1,52 \\
\hline & & Não & 50 & $5,12 \pm 0,28$ & $4,97 \pm 0,12$ & $4,86 \pm 0,27$ & $4,72 \pm 0,12$ & $-2,94$ \\
\hline
\end{tabular}


Tabela 6.38 - Taxas de dose absorvida para as fontes de ${ }^{90} \mathrm{Sr}+{ }^{90} \mathrm{Y}$ às profundidades de $0 \mathrm{~mm}$ e $0,07 \mathrm{~mm}$ no tecido, utilizando a câmara de extrapolação e janela de entrada de Hostaphan grafitado.

\begin{tabular}{|c|c|c|c|c|c|c|c|c|}
\hline \multirow{2}{*}{$\begin{array}{c}\text { Sistema } \\
\text { Padrão } \\
\text { Secundário de } \\
\text { Radiação Beta }\end{array}$} & \multirow[b]{2}{*}{$\begin{array}{l}\text { Atividade } \\
\text { da Fonte }\end{array}$} & \multirow{2}{*}{$\begin{array}{c}\text { Filtro } \\
\text { Uniformizador } \\
\text { de Campo }\end{array}$} & \multirow[b]{2}{*}{$\begin{array}{c}\text { Distância } \\
\text { Fonte-Detector } \\
\text { (cm) }\end{array}$} & \multicolumn{4}{|c|}{$\begin{array}{l}\text { Taxa de Dose Absorvida no Tecido } \\
(\mu \mathrm{G} / \mathrm{s})\end{array}$} & \multirow{2}{*}{$\begin{array}{c}\text { Diferença } \\
\text { entre } \\
\text { C e D } \\
(\%)\end{array}$} \\
\hline & & & & $\begin{array}{c}A \\
\text { Experimental } \\
(d=0 \mathrm{~mm})\end{array}$ & $\begin{array}{c}\text { B } \\
\text { Certificado } \\
(d=0 \mathrm{~mm})\end{array}$ & $\begin{array}{c}\text { C } \\
\text { Experimental } \\
(d=0,07 \mathrm{~mm})\end{array}$ & $\begin{array}{c}\text { D } \\
\text { Certificado } \\
(d=0,07 \mathrm{~mm})\end{array}$ & \\
\hline \multirow{4}{*}{ BSS1 } & $74 \mathrm{MBq}$ & Sim & 30 & $0,848 \pm 0,042$ & $0,870 \pm 0,017$ & $0,883 \pm 0,049$ & $0,906 \pm 0,034$ & 2,77 \\
\hline & \multirow{3}{*}{$1850 \mathrm{MBq}$} & Não & 11 & $255,3 \pm 14,32$ & $262,9 \pm 5,3$ & $273,1 \pm 15,6$ & $281,3 \pm 10,5$ & 2,99 \\
\hline & & Não & 30 & $36,66 \pm 2,03$ & $36,07 \pm 0,72$ & $39,16 \pm 2,20$ & $38,52 \pm 1,30$ & $-1,62$ \\
\hline & & Não & 50 & $12,87 \pm 0,70$ & $12,80 \pm 0,26$ & $13,64 \pm 0,77$ & $13,56 \pm 0,46$ & $-0,59$ \\
\hline \multirow{5}{*}{ BSS2 } & \multirow{5}{*}{$460 \mathrm{MBq}$} & Não & 11 & $117,8 \pm 6,5$ & $116,0 \pm 2,9$ & $109,6 \pm 6,1$ & $107,9 \pm 2,8$ & $-1,52$ \\
\hline & & Não & 20 & $35,00 \pm 1,89$ & $35,59 \pm 0,90$ & $32,90 \pm 1,81$ & $33,45 \pm 0,81$ & 1,67 \\
\hline & & Sim & 30 & $9,90 \pm 0,53$ & $9,96 \pm 0,25$ & $9,51 \pm 0,52$ & $9,56 \pm 0,26$ & 0,61 \\
\hline & & Não & 30 & $15,66 \pm 0,89$ & $15,90 \pm 0,40$ & $14,72 \pm 0,85$ & $14,94 \pm 0,39$ & 1,52 \\
\hline & & Não & 50 & $5,68 \pm 0,31$ & $5,51 \pm 0,14$ & $5,39 \pm 0,30$ & $5,24 \pm 0,15$ & $-2,94$ \\
\hline
\end{tabular}


Tabela 6.39 - Fatores de correção $\boldsymbol{k}_{a d v}$, obtidos com a câmara de extrapolação Böhm com janela de entrada de Hostaphan grafitado, para as três fontes de ${ }^{90} \mathrm{Sr}+{ }^{90} \mathrm{Y}$, e para cinco profundidades da câmara, $d$.

\begin{tabular}{|c|c|c|c|c|c|c|c|c|}
\hline \multirow{2}{*}{$\begin{array}{c}\text { Sistema } \\
\text { Padrão } \\
\text { Secundário de } \\
\text { Radiação Beta }\end{array}$} & \multirow{2}{*}{$\begin{array}{l}\text { Atividade } \\
\text { da Fonte }\end{array}$} & \multirow{2}{*}{$\begin{array}{c}\text { Filtro } \\
\text { Uniformizador } \\
\text { de Campo }\end{array}$} & \multirow{2}{*}{$\begin{array}{c}\text { Distância } \\
\text { Fonte-Detector } \\
\text { (cm) }\end{array}$} & \multicolumn{5}{|c|}{$\begin{array}{c}\text { Fator de Correção } \\
k_{a d v} \\
\end{array}$} \\
\hline & & & & $d=0,05 \mathrm{~cm}$ & $d=0,10 \mathrm{~cm}$ & $d=0,15 \mathrm{~cm}$ & $d=0,20 \mathrm{~cm}$ & $d=0,25 \mathrm{~cm}$ \\
\hline \multirow{4}{*}{ BSS1 } & $74 \mathrm{MBq}$ & Sim & 30 & $1,1355 \pm 0,0012$ & $1,1424 \pm 0,0012$ & $1,1536 \pm 0,0012$ & $1,1375 \pm 0,0012$ & $1,1373 \pm 0,0012$ \\
\hline & \multirow{3}{*}{$1850 \mathrm{MBq}$} & Não & 11 & $1,1334 \pm 0,0012$ & $1,1334 \pm 0,0012$ & $1,1654 \pm 0,0012$ & $1,1756 \pm 0,0012$ & $1,1536 \pm 0,0012$ \\
\hline & & Não & 30 & $1,1602 \pm 0,0012$ & $1,1655 \pm 0,0012$ & $1,1498 \pm 0,0012$ & $1,1542 \pm 0,0012$ & $1,1697 \pm 0,0012$ \\
\hline & & Não & 50 & $1,1586 \pm 0,0012$ & $1,1528 \pm 0,0012$ & $1,1578 \pm 0,0012$ & $1,1579 \pm 0,0012$ & $1,1581 \pm 0,0012$ \\
\hline \multirow{5}{*}{ BSS2 } & \multirow{5}{*}{$460 \mathrm{MBq}$} & Não & 11 & $0,9714 \pm 0,0012$ & $0,9704 \pm 0,0012$ & $0,9595 \pm 0,0012$ & $0,9702 \pm 0,0012$ & $0,9921 \pm 0,0012$ \\
\hline & & Não & 20 & $0,9639 \pm 0,0012$ & $0,9743 \pm 0,0012$ & $0,9632 \pm 0,0012$ & $0,9469 \pm 0,0012$ & $0,9307 \pm 0,0012$ \\
\hline & & Sim & 30 & $1,1970 \pm 0,0012$ & $1,1297 \pm 0,0012$ & $1,1132 \pm 0,0012$ & $1,1024 \pm 0,0012$ & $1,1135 \pm 0,0012$ \\
\hline & & Não & 30 & $1,3058 \pm 0,0012$ & $1,2955 \pm 0,0012$ & $1,3177 \pm 0,0012$ & $1,3060 \pm 0,0012$ & $1,2187 \pm 0,0012$ \\
\hline & & Não & 50 & $0,9732 \pm 0,0012$ & $0,9619 \pm 0,0012$ & $0,9506 \pm 0,0012$ & $0,9397 \pm 0,0012$ & $0,9710 \pm 0,0012$ \\
\hline
\end{tabular}

Tabela 6.40 - Fatores de correção $\boldsymbol{k}_{d i}$, obtidos com a câmara de extrapolação Böhm com janela de entrada de Hostaphan grafitado, para três fontes de ${ }^{90} \mathrm{Sr}+{ }^{90} \mathrm{Y}$, e para cinco profundidades da câmara, $d$.

\begin{tabular}{|c|c|c|c|c|c|c|c|}
\hline \multirow{2}{*}{$\begin{array}{l}\text { Sistema Padrão } \\
\text { Secundário de } \\
\text { Radiação Beta }\end{array}$} & \multirow{2}{*}{$\begin{array}{l}\text { Atividade } \\
\text { da Fonte }\end{array}$} & \multirow{2}{*}{$\begin{array}{l}\text { Distância } \\
\text { Fonte- } \\
\text { Detector } \\
\text { (cm) }\end{array}$} & \multicolumn{5}{|c|}{$\begin{array}{c}\text { Fator de Correção } \\
k_{d i} \\
\end{array}$} \\
\hline & & & $d=0,05 \mathrm{~cm}$ & $d=0,10 \mathrm{~cm}$ & $d=0,15 \mathrm{~cm}$ & $d=0,20 \mathrm{~cm}$ & $d=0,25 \mathrm{~cm}$ \\
\hline \multirow{3}{*}{ BSS1 } & \multirow{3}{*}{$\begin{array}{l}74 \mathrm{MBq} / \\
1850 \mathrm{MBq}\end{array}$} & 11 & $1,0056 \pm 0,0061$ & $1,0102 \pm 0,0051$ & $1,0147 \pm 0,0048$ & $1,0193 \pm 0,0047$ & $1,0238 \pm 0,0046$ \\
\hline & & 30 & $1,0021 \pm 0,0044$ & $1,0037 \pm 0,0028$ & $1,0054 \pm 0,0023$ & $1,0071 \pm 0,0020$ & $1,0087 \pm 0,0019$ \\
\hline & & 50 & $1,0012 \pm 0,0042$ & $1,0022 \pm 0,0024$ & $1,0032 \pm 0,0018$ & $1,0042 \pm 0,0015$ & $1,0052 \pm 0,0014$ \\
\hline \multirow{4}{*}{ BSS2 } & \multirow{4}{*}{$460 \mathrm{MBq}$} & 11 & $1,0056 \pm 0,0061$ & $1,0102 \pm 0,0051$ & $1,0147 \pm 0,0048$ & $1,0193 \pm 0,0047$ & $1,0238 \pm 0,0046$ \\
\hline & & 20 & $1,0031 \pm 0,0047$ & $1,0056 \pm 0,0034$ & $1,0081 \pm 0,0029$ & $1,0106 \pm 0,0028$ & $1,0131 \pm 0,0027$ \\
\hline & & 30 & $1,0021 \pm 0,0044$ & $1,0037 \pm 0,0028$ & $1,0054 \pm 0,0023$ & $1,0071 \pm 0,0020$ & $1,0087 \pm 0,0019$ \\
\hline & & 50 & $1,0012 \pm 0,0042$ & $1,0022 \pm 0,0024$ & $1,0032 \pm 0,0018$ & $1,0042 \pm 0,0015$ & $1,0052 \pm 0,0014$ \\
\hline
\end{tabular}


Os fatores de correção $\boldsymbol{k}_{\boldsymbol{B} \boldsymbol{r}}$ e $\boldsymbol{k}_{\boldsymbol{s} a t}$ também foram utilizados, e seus resultados já foram demonstrados na explicação sobre o método de Caldas (1980), neste mesmo item. Com relação aos fatores de transmissão $\boldsymbol{k}_{a b s}, \boldsymbol{k}_{\boldsymbol{a c}}, \boldsymbol{k}_{\boldsymbol{d e}}, \boldsymbol{k}_{\boldsymbol{p} \boldsymbol{e}}, \boldsymbol{k}_{\boldsymbol{b a}}, \boldsymbol{k}_{\boldsymbol{e l}}, \boldsymbol{k}_{\boldsymbol{h} u}, \boldsymbol{k}_{\boldsymbol{i n}}$, e $\boldsymbol{k}_{\boldsymbol{r a}}$, eles não foram calculados, mas os seus valores, descritos por Böhm (1986) ou pela ISO 6980-2 (2004), já foram mostrados na Tabela 5.3.

As grandezas utilizadas para se determinar as taxas de dose absorvida (Equação 4.19) pelo método da ISO, já tiveram seus valores apresentados na Tabela 6.18. Pelo método da ISO 6980-2 (2004), foi possível determinar as taxas de dose absorvida no tecido $\dot{D}_{t}$, e as taxas de dose absorvida, também no tecido, mas a $0 \mathrm{~mm}$ de profundidade $\dot{D}_{t}(0)$. Na Tabela 6.41 estão listados os valores obtidos para estas duas taxas de dose absorvida.

Tabela 6.41 - Taxas de dose absorvida no tecido, $\dot{D}_{t}$, e no tecido à profundidade de $0 \mathrm{~mm} \dot{D}_{t}(0)$, para as três fontes de ${ }^{90} \mathrm{Sr}+{ }^{90} \mathrm{Y}$, utilizando a câmara de extrapolação e janela de entrada de Hostaphan grafitado.

\begin{tabular}{|c|c|c|c|c|c|}
\hline \multirow{2}{*}{$\begin{array}{l}\text { Sistema Padrão } \\
\text { Secundário de } \\
\text { Radiação Beta }\end{array}$} & \multirow{2}{*}{$\begin{array}{l}\text { Atividade } \\
\text { da Fonte }\end{array}$} & \multirow{2}{*}{$\begin{array}{c}\text { Filtro } \\
\text { Uniformizador } \\
\text { de Campo }\end{array}$} & \multirow{2}{*}{$\begin{array}{c}\text { Distância } \\
\text { Fonte-Detector } \\
\text { (cm) }\end{array}$} & \multicolumn{2}{|c|}{$\begin{array}{c}\text { Taxa de Dose Absorvida } \\
(\mu \mathrm{Gy} / \mathrm{s})\end{array}$} \\
\hline & & & & Ar, $\dot{D}_{t}$ & Tecido, $\dot{D}_{t}(0)$ \\
\hline \multirow{4}{*}{ BSS1 } & $74 \mathrm{MBq}$ & Sim & 30 & $0,85 \pm 0,02$ & $0,85 \pm 0,02$ \\
\hline & \multirow{3}{*}{$1850 \mathrm{MBq}$} & Não & 11 & $255,8 \pm 5,6$ & $253,4 \pm 6,1$ \\
\hline & & Não & 30 & $37,08 \pm 0,85$ & $36,72 \pm 0,92$ \\
\hline & & Não & 50 & $13,03 \pm 0,29$ & $12,90 \pm 0,31$ \\
\hline \multirow{5}{*}{ BSS2 } & \multirow{5}{*}{$460 \mathrm{MBq}$} & Não & 11 & $110,0 \pm 1,1$ & $117,0 \pm 1,7$ \\
\hline & & Não & 20 & $33,16 \pm 0,35$ & $35,03 \pm 0,53$ \\
\hline & & Sim & 30 & $9,56 \pm 0,11$ & $9,93 \pm 0,15$ \\
\hline & & Não & 30 & $14,86 \pm 0,31$ & $15,70 \pm 0,37$ \\
\hline & & Não & 50 & $5,45 \pm 0,07$ & $5,69 \pm 0,10$ \\
\hline
\end{tabular}

Após se determinar as taxas de dose absorvida descritas na Tabela 6.41, foi possível a obtenção das taxas de dose absorvida no ar e no tecido, a $0 \mathrm{~mm}$ e a 0,07 mm de profundidade. A Tabela 6.42 mostra uma comparação feita entre as taxas de dose absorvida finais obtidas experimentalmente neste trabalho, e as fornecidas nos certificados de calibração das fontes, no ar, a $0 \mathrm{~mm}$ e a 0,07 $\mathrm{mm}$ de profundidade, enquanto que na Tabela 6.43 podem ser observadas as taxas de dose absorvida, para as mesmas condições, porém no tecido. 
Tabela 6.42 - Taxas de dose absorvida para as fontes de ${ }^{90} \mathrm{Sr}+{ }^{90} \mathrm{Y}$ às profundidades de $0 \mathrm{~mm}$ e $0,07 \mathrm{~mm}$ no ar, utilizando a câmara de extrapolação e janela de entrada de Hostaphan grafitado.

\begin{tabular}{|c|c|c|c|c|c|c|c|c|}
\hline \multirow{2}{*}{$\begin{array}{l}\text { Sistema Padrão } \\
\text { Secundário de } \\
\text { Radiação Beta }\end{array}$} & \multirow[b]{2}{*}{$\begin{array}{l}\text { Atividade } \\
\text { da Fonte }\end{array}$} & \multirow{2}{*}{$\begin{array}{c}\text { Filtro } \\
\text { Uniformizador } \\
\text { de Campo }\end{array}$} & \multirow[b]{2}{*}{$\begin{array}{l}\text { Distância } \\
\text { Fonte-Detector } \\
\text { (cm) }\end{array}$} & \multicolumn{4}{|c|}{$\begin{array}{c}\text { Taxa de Dose Absorvida no Ar } \\
(\mu \mathrm{Gy} / \mathrm{s})\end{array}$} & \multirow{2}{*}{$\begin{array}{c}\text { Diferença } \\
\text { entre } \\
\text { C e D } \\
(\%)\end{array}$} \\
\hline & & & & $\begin{array}{c}\text { A } \\
\text { Experimental } \\
(d=0 \mathrm{~mm})\end{array}$ & $\begin{array}{c}\text { B } \\
\text { Certificado } \\
(d=0 \mathrm{~mm})\end{array}$ & $\begin{array}{c}C \\
\text { Experimental } \\
(d=0,07 \mathrm{~mm})\end{array}$ & $\begin{array}{c}\text { D } \\
\text { Certificado } \\
(d=0,07 \mathrm{~mm})\end{array}$ & \\
\hline \multirow{4}{*}{ BSS1 } & $74 \mathrm{MBq}$ & Sim & 30 & $0,769 \pm 0,019$ & $0,783 \pm 0,016$ & $0,800 \pm 0,022$ & $0,816 \pm 0,018$ & 2,00 \\
\hline & \multirow{3}{*}{$1850 \mathrm{MBq}$} & Não & 11 & $230,22 \pm 0,05$ & $236,6 \pm 4,8$ & $246,3 \pm 6,4$ & $253,2 \pm 5,7$ & 2,79 \\
\hline & & Não & 30 & $33,37 \pm 0,84$ & $32,46 \pm 0,65$ & $35,64 \pm 0,97$ & $34,67 \pm 0,65$ & $-2,72$ \\
\hline & & Não & 50 & $11,73 \pm 0,28$ & $11,52 \pm 0,23$ & $12,43 \pm 0,33$ & $12,21 \pm 0,23$ & $-1,82$ \\
\hline \multirow{5}{*}{ BSS2 } & \multirow{5}{*}{$460 \mathrm{MBq}$} & Não & 11 & $99,13 \pm 1,43$ & $104,5 \pm 2,6$ & $92,19 \pm 1,66$ & $97,21 \pm 2,45$ & 5,45 \\
\hline & & Não & 20 & $29,87 \pm 0,45$ & $32,06 \pm 0,87$ & $28,08 \pm 0,52$ & $30,14 \pm 0,81$ & 7,31 \\
\hline & & Sim & 30 & $8,62 \pm 0,13$ & $8,98 \pm 0,24$ & $8,27 \pm 0,15$ & $8,62 \pm 0,23$ & 4,18 \\
\hline & & Não & 30 & $13,39 \pm 0,32$ & $14,32 \pm 0,38$ & $12,58 \pm 0,33$ & $13,46 \pm 0,36$ & 6,98 \\
\hline & & Não & 50 & $4,91 \pm 0,08$ & $4,97 \pm 0,14$ & $4,67 \pm 0,09$ & $4,72 \pm 0,13$ & 1,11 \\
\hline
\end{tabular}


Tabela 6.43 - Taxas de dose absorvida para as fontes de ${ }^{90} \mathrm{Sr}+{ }^{90} \mathrm{Y}$ às profundidades de $0 \mathrm{~mm}$ e $0,07 \mathrm{~mm}$ no tecido, utilizando a câmara de extrapolação e janela de entrada de Hostaphan grafitado.

\begin{tabular}{|c|c|c|c|c|c|c|c|c|}
\hline \multirow{2}{*}{$\begin{array}{l}\text { Sistema Padrão } \\
\text { Secundário de } \\
\text { Radiação Beta }\end{array}$} & \multirow[b]{2}{*}{$\begin{array}{l}\text { Atividade } \\
\text { da Fonte }\end{array}$} & \multirow{2}{*}{$\begin{array}{c}\text { Filtro } \\
\text { Uniformizador } \\
\text { de Campo }\end{array}$} & \multirow[b]{2}{*}{$\begin{array}{c}\text { Distância } \\
\text { Fonte-Detector } \\
\text { (cm) }\end{array}$} & \multicolumn{4}{|c|}{$\begin{array}{l}\text { Taxa de Dose Absorvida no Tecido } \\
(\mu \mathrm{G} / \mathrm{s})\end{array}$} & \multirow{2}{*}{$\begin{array}{c}\text { Diferença } \\
\text { entre } \\
\text { C e D } \\
\text { (\%) }\end{array}$} \\
\hline & & & & $\begin{array}{c}\text { A } \\
\text { Experimental } \\
(d=0 \mathrm{~mm})\end{array}$ & $\begin{array}{c}\text { B } \\
\text { Certificado } \\
(d=0 \mathrm{~mm})\end{array}$ & $\begin{array}{c}C \\
\text { Experimental } \\
(d=0,07 \mathrm{~mm})\end{array}$ & $\begin{array}{c}\text { D } \\
\text { Certificado } \\
(d=0,07 \mathrm{~mm})\end{array}$ & \\
\hline \multirow{4}{*}{ BSS1 } & $74 \mathrm{MBq}$ & Sim & 30 & $0,854 \pm 0,021$ & $0,870 \pm 0,017$ & $0,889 \pm 0,066$ & $0,906 \pm 0,034$ & 1,91 \\
\hline & \multirow{3}{*}{$1850 \mathrm{MBq}$} & Não & 11 & $255,8 \pm 6,1$ & $262,9 \pm 5,3$ & $273,68 \pm 0,19$ & $281,31 \pm 0,10$ & 2,79 \\
\hline & & Não & 30 & $37,08 \pm 0,93$ & $36,07 \pm 0,72$ & $39,60 \pm 2,92$ & $38,52 \pm 1,23$ & $-2,72$ \\
\hline & & Não & 50 & $13,03 \pm 0,31$ & $12,79 \pm 0,26$ & $13,81 \pm 1,02$ & $13,56 \pm 0,46$ & $-1,82$ \\
\hline \multirow{5}{*}{ BSS2 } & \multirow{5}{*}{$460 \mathrm{MBq}$} & Não & 11 & $110,0 \pm 1,6$ & $116,0 \pm 2,9$ & $102,3 \pm 7,4$ & $107,9 \pm 2,8$ & 5,45 \\
\hline & & Não & 20 & $33,16 \pm 0,50$ & $35,59 \pm 0,96$ & $31,17 \pm 2,27$ & $33,45 \pm 0,81$ & 7,31 \\
\hline & & $\operatorname{Sim}$ & 30 & $9,56 \pm 0,15$ & $9,96 \pm 0,26$ & $9,18 \pm 0,67$ & $9,56 \pm 0,26$ & 4,18 \\
\hline & & Não & 30 & $14,86 \pm 0,35$ & $15,90 \pm 0,43$ & $13,97 \pm 1,03$ & $14,94 \pm 0,39$ & 6,96 \\
\hline & & Não & 50 & $5,45 \pm 0,09$ & $5,51 \pm 0,15$ & $5,18 \pm 0,38$ & $5,24 \pm 0,15$ & 1,12 \\
\hline
\end{tabular}


A Tabela 6.43 mostra uma diferença máxima obtida de 7,31\% na determinação da taxa de dose absorvida para a fonte de $460 \mathrm{MBq}$, sem filtro uniformizador de campo, à distância fonte-detector de $20 \mathrm{~cm}$.

Em 1988, o NBS (PRUITT e col., 1988), atualmente conhecido como NIST, apresentou um relatório sobre seus serviços de calibração e, neste guia, eles demonstraram o uso de uma câmara de extrapolação Böhm para calibrar as fontes de radiação beta do sistema BSS1. As taxas de dose absorvida no tecido, à profundidade nula, foram apresentadas como resultados de calibrações realizadas no NBS e no PTB. As diferenças obtidas entre as calibrações das fontes pelos dois laboratórios foram: 1,58\% para a fonte de $74 \mathrm{MBq}$, e 1,38\% (distância fonte-detector de $11 \mathrm{~cm}), 1,00 \%(30 \mathrm{~cm})$, e 0,40\% (50 cm) para a fonte de $1850 \mathrm{MBq}$.

O NIST, em 2010, relatou resultados de calibração de fontes de ${ }^{90} \mathrm{Sr}+{ }^{90} \mathrm{Y}$ dos sistemas BSS1 e BSS2, e os comparou com as taxas de dose absorvidas fornecidas pelo PTB nos certificados de calibração de cada fonte. Para as fontes de ${ }^{90} \mathrm{Sr}+{ }^{90} \mathrm{Y}$ do sistema BSS1, as diferenças na calibração (taxas de dose absorvida obtidas na superfície) foram aquelas já apresentadas no relatório do NBS. Para a fonte de ${ }^{90} \mathrm{Sr}+{ }^{90} \mathrm{Y}$ do sistema BSS2 (460 MBq), as diferenças na calibração (taxas de dose absorvida obtidas a 0,07 $\mathrm{mm}$ de profundidade) foram: 1,55\% (11 cm), 1,39\% (20 cm), 0,98\% (30 cm, sem filtro), 1,87 (30 cm, com filtro), e $0,71 \%(50 \mathrm{~cm})$ (NIST, 2010).

Outros resultados também podem ser observados numa intercomparação realizada pelos laboratórios do PTB e VNIIM (BEHRENS e col., 2011). Para a fonte de ${ }^{90} \mathrm{Sr}^{90} \mathrm{Y}$ do sistema BSS2, com filtro, à distância fonte-detector de $30 \mathrm{~cm}$, e determinada a 0,07 $\mathrm{mm}$ de profundidade no tecido, a diferença obtida nas calibrações foi 1,23\%. No presente trabalho, a diferença obtida para a fonte de ${ }^{90} \mathrm{Sr}^{9}{ }^{90} \mathrm{Y}$ de $460 \mathrm{MBq}$ foi inferior à apresentada por Behrens e col. (2011) no caso da janela de Hostaphan e pelo método de Caldas (1980). Nos outros casos, a diferença obtida neste trabalho foi superior à apresentada entre o PTB e o VNIIM.

Em 2013, Bakshi e col. publicaram os resultados de comparação entre taxas de dose absorvida realizadas no Radiological Physics \& Advisory Division (RP \& AD) do Bhabha Atomic Research Centre (BARC) e no PTB. As calibrações, realizadas para a fonte de ${ }^{90} \mathrm{Sr}+{ }^{90} \mathrm{Y}$ do 
sistema BSS2 (460 MBq), apresentaram as seguintes diferenças: 1,22\% (11 cm), 2,13\% $(20 \mathrm{~cm}), 1,39 \%$ (30 cm, com filtro) e 0,69\% (50 cm) (BAKSHI e col., 2013).

Comparando-se os resultados das diferenças obtidas neste trabalho com as diferenças obtidos pelo NBS (PRUITT e col., 1988), estas foram inferiores com relação à fonte de $74 \mathrm{MBq}$ e para a janela de Mylar aluminizado. Para esta mesma fonte, a diferença deste trabalho foi superior à obtida pelo NBS no caso da janela de Hostaphan. Para a fonte de $1850 \mathrm{MBq}$, o resultado deste trabalho coincidiu exatamente com o valor da diferença obtida pelo NBS, de 1,00\%, no caso da janela de Mylar aluminizado, e pelo método de Caldas (1980). Nos outros casos, as diferenças deste trabalho foram superiores às do NBS, mas ainda assim foram consideradas aceitáveis, pois o maior valor foi de $-2,72 \%$, para a janela de Hostaphan e o método ISO 6980-2 (2004).

Fazendo-se uma comparação entre as diferenças obtidas pelo NIST, em 2010 (NIST, 2010), com as diferenças obtidas e mostradas neste item, os valores deste trabalho foram inferiores ou iguais no caso das fontes de $74 \mathrm{MBq}$ (Mylar aluminizado, pelos dois métodos), de $1850 \mathrm{MBq}$ (Mylar aluminizado e método de Caldas (1980)) e de 460 MBq (Hostaphan, $11 \mathrm{~cm}$, método de Caldas (1980); Hostaphan, $30 \mathrm{~cm}$, com filtro, método de Caldas (1980)). Nas outras condições de janela de entrada e método adotado, as diferenças obtidas neste trabalho foram superiores às apresentadas pelo NIST (2010).

Comparando-se as diferenças percentuais deste trabalho com as apresentadas por Bakshi e col. (2013), este trabalho apresentou diferenças inferiores para a fonte de ${ }^{90} \mathrm{Sr}+{ }^{90} \mathrm{Y}$ de $460 \mathrm{MBq}$ para os casos de janela de Hostaphan, às distâncias fonte-detector de $20 \mathrm{~cm}$ e $30 \mathrm{~cm}$ (com filtro), pelo método de Caldas (1980). Nas outras condições, os resultados deste trabalho foram superiores aos apresentados por Bakshi e col. (2013).

A fim de se analisar as taxas de dose absorvida obtidas pelo método de Caldas (1980) e pelo método da ISO 6980-2 (2004), com as duas janelas de entrada da câmara de extrapolação Böhm, de Mylar aluminizado e de Hostaphan grafitado, foi feita uma comparação entre estes resultados, obtidos neste trabalho, e eles podem ser observados na Tabela 6.44. 
Tabela 6.44 - Taxas de dose absorvida obtidas experimentalmente, neste trabalho, para as fontes de ${ }^{90} \mathrm{Sr}+{ }^{90} \mathrm{Y}$ às profundidades de $0,07 \mathrm{~mm}$ no tecido, utilizando-se a câmara de extrapolação e as janelas de entrada de Mylar aluminizado e de Hostaphan grafitado.

\begin{tabular}{|c|c|c|c|c|c|c|c|}
\hline \multirow{3}{*}{$\begin{array}{l}\text { Sistema Padrão } \\
\text { Secundário de } \\
\text { Radiação Beta }\end{array}$} & \multirow{3}{*}{$\begin{array}{l}\text { Atividade } \\
\text { da Fonte }\end{array}$} & \multirow{3}{*}{$\begin{array}{c}\text { Filtro } \\
\text { Uniformizador } \\
\text { de Campo }\end{array}$} & \multirow{3}{*}{$\begin{array}{c}\text { Distância } \\
\text { Fonte-Detector } \\
(\mathrm{cm})\end{array}$} & \multicolumn{4}{|c|}{$\begin{array}{l}\text { Taxa de Dose Absorvida no Tecido }(0,07 \mathrm{~mm}) \\
(\mu \mathrm{Gy} / \mathrm{s})\end{array}$} \\
\hline & & & & \multicolumn{2}{|c|}{$\begin{array}{c}\text { Método } 1 \\
\text { Caldas (1980) }\end{array}$} & \multicolumn{2}{|c|}{$\begin{array}{l}\text { Método } 2 \\
\text { ISO (2004) }\end{array}$} \\
\hline & & & & $\begin{array}{l}\text { Mylar Aluminizado } \\
\text { (A) }\end{array}$ & $\begin{array}{l}\text { Hostaphan Grafitado } \\
\text { (B) }\end{array}$ & $\begin{array}{l}\text { Mylar Aluminizado } \\
\text { (C) }\end{array}$ & $\begin{array}{l}\text { Hostaphan Grafitado } \\
\text { (D) }\end{array}$ \\
\hline \multirow{4}{*}{ BSS1 } & $74 \mathrm{MBq}$ & Sim & 30 & $0,901 \pm 0,050$ & $0,883 \pm 0,049$ & $0,907 \pm 0,022$ & $0,889 \pm 0,066$ \\
\hline & \multirow{3}{*}{$1850 \mathrm{MBq}$} & Não & 11 & - & $273,1 \pm 15,6$ & - & $273,68 \pm 0,20$ \\
\hline & & Não & 30 & $38,9 \pm 2,2$ & $39,16 \pm 2,20$ & $39,34 \pm 1,00$ & $39,60 \pm 2,92$ \\
\hline & & Não & 50 & - & $13,64 \pm 0,77$ & - & $13,81 \pm 1,02$ \\
\hline \multirow{5}{*}{ BSS2 } & \multirow{5}{*}{$460 \mathrm{MBq}$} & Não & 11 & - & $109,6 \pm 6,1$ & - & $102,3 \pm 7,4$ \\
\hline & & Não & 20 & - & $32,90 \pm 1,81$ & - & $31,17 \pm 2,27$ \\
\hline & & Sim & 30 & $9,19 \pm 0,50$ & $9,51 \pm 0,52$ & $8,88 \pm 0,13$ & $9,18 \pm 0,67$ \\
\hline & & Não & 30 & $14,06 \pm 0,77$ & $14,72 \pm 0,85$ & $13,34 \pm 0,19$ & $13,97 \pm 1,03$ \\
\hline & & Não & 50 & - & $5,39 \pm 0,30$ & - & $5,18 \pm 0,38$ \\
\hline
\end{tabular}


Analisando-se a Tabela 6.44 , foi possível fazer uma comparação entre os resultados obtidos do ponto de vista de material de janela de entrada utilizado. Na Tabela 6.45 são mostradas as diferenças obtidas nesta comparação, para o caso no qual foram determinadas as taxas de dose absorvida para as duas janelas.

É possível também fazer-se uma comparação em termos de método utilizado para determinação das taxas de dose absorvida, e então as diferenças podem ser observadas na Tabela 6.46 .

Tabela 6.45 - Diferenças obtidas entre as taxas de dose absorvida utilizando dois materiais de janela de entrada: Mylar aluminizado e Hostaphan grafitado, por dois métodos diferentes.

\begin{tabular}{|c|c|c|c|c|c|}
\hline \multirow{2}{*}{$\begin{array}{c}\text { Sistema } \\
\text { Padrão } \\
\text { Secundário de } \\
\text { Radiação Beta }\end{array}$} & \multirow[b]{2}{*}{$\begin{array}{l}\text { Atividade } \\
\text { da Fonte }\end{array}$} & \multirow[b]{2}{*}{$\begin{array}{c}\text { Filtro } \\
\text { Uniformizador } \\
\text { de Campo }\end{array}$} & \multirow[b]{2}{*}{$\begin{array}{l}\text { Distância } \\
\text { Fonte- } \\
\text { Detector } \\
\text { (cm) }\end{array}$} & $\begin{array}{c}\text { Método } 1 \\
\text { Caldas (1980) }\end{array}$ & $\begin{array}{c}\text { Método } 2 \\
\text { ISO (2004) }\end{array}$ \\
\hline & & & & $\begin{array}{c}\text { Diferença } \\
\text { entre }(A) \text { e (B) } \\
(\%)\end{array}$ & $\begin{array}{c}\text { Diferença } \\
\text { entre (C) e (D) } \\
(\%)\end{array}$ \\
\hline \multirow{2}{*}{ BSS1 } & $74 \mathrm{MBq}$ & Sim & 30 & 2,04 & 2,02 \\
\hline & $1850 \mathrm{MBq}$ & Não & 30 & 0,63 & 0,64 \\
\hline \multirow{2}{*}{ BSS2 } & \multirow{2}{*}{$460 \mathrm{MBq}$} & Sim & 30 & 3,43 & 3,42 \\
\hline & & Não & 30 & 4,67 & 4,68 \\
\hline
\end{tabular}

Tabela 6.46- Diferenças obtidas entre as taxas de dose absorvida utilizando dois métodos diferentes: Caldas (1980) e ISO 6980-2 (2004), com janelas de entrada de materiais diferentes.

\begin{tabular}{|c|c|c|c|c|c|}
\hline \multirow{2}{*}{$\begin{array}{c}\text { Sistema } \\
\text { Padrão } \\
\text { Secundário } \\
\text { de Radiação } \\
\text { Beta }\end{array}$} & \multirow{2}{*}{$\begin{array}{l}\text { Atividade } \\
\text { da Fonte }\end{array}$} & \multirow{2}{*}{$\begin{array}{c}\text { Filtro } \\
\text { Uniformizador } \\
\text { de Campo }\end{array}$} & \multirow{2}{*}{$\begin{array}{l}\text { Distância } \\
\text { Fonte- } \\
\text { Detector } \\
\text { (cm) }\end{array}$} & $\begin{array}{c}\text { Mylar } \\
\text { Aluminizado }\end{array}$ & $\begin{array}{c}\text { Hostaphan } \\
\text { Grafitado }\end{array}$ \\
\hline & & & & $\begin{array}{c}\text { Diferença } \\
\text { entre }(A) \text { e }(C) \\
(\%)\end{array}$ & $\begin{array}{c}\text { Diferença } \\
\text { entre (B) e (D) } \\
(\%)\end{array}$ \\
\hline \multirow{4}{*}{ BSS1 } & $74 \mathrm{MBq}$ & Sim & 30 & 0,66 & 0,68 \\
\hline & \multirow{3}{*}{$1850 \mathrm{MBq}$} & Não & 11 & - & 0,19 \\
\hline & & Não & 30 & 1,11 & 1,13 \\
\hline & & Não & 50 & - & 1,25 \\
\hline \multirow{5}{*}{ BSS2 } & \multirow{5}{*}{$460 \mathrm{MBq}$} & Não & 11 & - & 7,07 \\
\hline & & Não & 20 & - & 5,55 \\
\hline & & Sim & 30 & 3,55 & 3,55 \\
\hline & & Não & 30 & 4,67 & 5,36 \\
\hline & & Não & 50 & - & 4,17 \\
\hline
\end{tabular}


Analisando-se a Tabela 6.45, que mostra as diferenças obtidas entre as taxas de dose absorvida em termos de material de janela de entrada utilizado, pode-se observar que a câmara de extrapolação Böhm pode ser utilizada com efetividade tanto com janela de Mylar aluminizado como de Hostaphan grafitado, porque a maior diferença obtida entre os dois materiais foi de 4,67\%, para o caso da fonte de ${ }^{90} \mathrm{Sr}+{ }^{90} \mathrm{Y}$ de $460 \mathrm{MBq}$, sem filtro uniformizador de campo.

Com relação às diferenças obtidas do ponto de vista de método utilizado para a determinação de taxas de dose absorvida (Tabela 6.46), a maior diferença foi de 4,67\% entre o método 1 e o método 2, e janela de Mylar aluminizado, e foi de 7,07\% entre o método 1 e o 2, e janela de Hostaphan grafitado.

Observando-se as Tabelas 6.45 e 6.46, pode-se observar que os maiores valores de diferença ocorreram para o caso da fonte de ${ }^{90} \mathrm{Sr}+{ }^{90} \mathrm{Y}$ de $460 \mathrm{MBq}$, independente da utilização ou não de filtro uniformizador de campo e da distância fonte-detector. O mesmo já havia sido observado nas diferenças entre as taxas de dose absorvida (Tabelas 24, 29, 38 e 43), o que solidifica ainda mais a conclusão de que a falta de alinhamento entre fonte, filtro e detector, do sistema BSS2, pode interferir na determinação das taxas de dose absorvida para este fonte de ${ }^{90} \mathrm{Sr}+{ }^{90} \mathrm{Y}$.

De modo geral, analisando-se as taxas de dose absorvida obtidas neste presente trabalho, pode-se concluir que para as fontes de ${ }^{90} \mathrm{Sr}^{90} \mathrm{Y}$ do sistema BSS1 (74 MBq e $1850 \mathrm{MBq}$ ), as diferenças obtidas foram satisfatórias, porque, levando-se em conta todos os resultados obtidos para estas duas fontes, com as duas janelas de entrada e pelos dois métodos, a diferença variou de $-0,11 \%$ ( $74 \mathrm{MBq}$, janela de Mylar aluminizado e método da ISO (ISO, 2004)) a 2,99\% (1850 MBq, $11 \mathrm{~cm}$, janela de Hostaphan grafitado e método de Caldas (CALDAS, 1980)).

Com relação à fonte de ${ }^{90} \mathrm{Sr}+{ }^{90} \mathrm{Y}$ do sistema BSS2 (460 MBq), analisando-se as taxas de dose absorvida obtidas em todas as situações e condições (de janela e de método), as diferenças variaram de 0,61\% (30 cm, com filtro, janela de Hostaphan grafitado e método de Caldas (1980)) a 11,98\% (30 cm, com filtro, janela de Mylar aluminizado e método da ISO 6980-2 (2004). Particularmente no caso desta fonte, as diferenças foram superiores às diferenças das fontes do sistema BSS1. 
Concluindo a análise deste item do trabalho, também foi possível se fazer uma observação geral, ou seja, levando-se em conta as três fontes de ${ }^{90} \mathrm{Sr}+{ }^{90} \mathrm{Y}$ : neste caso, tornase evidente que o melhor resultado obtido neste trabalho, para todas as taxas de dose absorvida, em termos dos dois materiais de janela e dos dois métodos, foram os resultados obtidos com a câmara de extrapolação com janela de entrada de Hostaphan e pelo método de Caldas (1980)).

Um procedimento de calibração de fontes de ${ }^{90} \mathrm{Sr}+{ }^{90} \mathrm{Y}$, utilizando-se a câmara de extrapolação Böhm como sistema padrão primário, foi elaborado e pode ser encontrado, e descrito em detalhes, no Apêndice A.

\subsubsection{Tempo de Estabilização}

O teste do tempo de estabilização da resposta da câmara de extrapolação foi realizado apenas na condição da câmara com janela de entrada de Hostaphan grafitado.

Este teste foi realizado tomando-se medições após intervalos de tempo de $15 \mathrm{~min}, 1 \mathrm{~h}$ e 2 h, de acordo com a recomendação internacional IEC 60731 (2011). Para este teste, foi utilizada a fonte de ${ }^{90} \mathrm{Sr}+{ }^{90} \mathrm{Y}$ do sistema BSS1, de $1850 \mathrm{MBq}$, a uma distância fonte-detector de $30 \mathrm{~cm}$; a profundidade da câmara foi mantida fixa em $1 \mathrm{~mm}$, e a tensão de polarização aplicada ao eletrodo coletor foi de $\pm 10 \mathrm{~V}$. A Tabela 6.47 mostra os resultados obtidos para o teste do tempo de estabilização. Como a recomendação da IEC 60731 (2011) estabelece que a corrente de ionização medida após 15 min e após 2 h não deve exceder 0,5\% do valor medido após 1h, então os resultados da corrente de ionização foram normalizados para a corrente medida em $1 \mathrm{~h}$. Na polaridade positiva, a corrente de ionização variou de $(0,6565 \pm 0,0011) \mathrm{pA}$, para o tempo de $120 \mathrm{~min}$, a $(0,6648 \pm 0,0011) \mathrm{pA}$, para o tempo de 15 min. Na polaridade negativa, a corrente de ionização variou de $-(0,8593 \pm 0,0017)$ pA, para o tempo de $120 \mathrm{~min}$, a $-(0,8613 \pm 0,0017) \mathrm{pA}$, para o tempo de $60 \mathrm{~min}$.

A variação máxima obtida para a resposta da câmara de extrapolação Böhm foi 0,83\% no tempo de 120 min e na polaridade positiva. Embora a IEC 60731 (2011) recomende uma variação máxima de $0,5 \%$, esta variação na resposta da câmara de extrapolação foi considerada aceitável, visto que a câmara já vinha sendo utilizada anteriormente com a janela de Mylar aluminizado, e nesta condição, ela apresentou boa reprodutibilidade na sua resposta, gerando um desvio padrão pequeno nas medições. 
Tabela 6.47 - Teste de tempo de estabilização realizado com a câmara de extrapolação Böhm com janela de entrada de Hostaphan grafitado, utilizando-se a fonte de ${ }^{90} \mathrm{Sr}+{ }^{90} \mathrm{Y}(1850 \mathrm{MBq}$, 1981).

\begin{tabular}{ccc}
\hline $\begin{array}{c}\text { Tempo } \\
(\text { min) }\end{array}$ & $\begin{array}{c}\text { Corrente de lonização Normalizada para } \\
\text { Tempo de } 60 \text { min } \\
\text { Polaridade } \\
\text { Positiva }\end{array}$ & $\begin{array}{c}\text { Pogativa } \\
\text { Negate }\end{array}$ \\
\hline 15 & $1,0042 \pm 0,0017$ & $0,9980 \pm 0,0020$ \\
\hline 60 & $1,0000 \pm 0,0017$ & $1,0000 \pm 0,0020$ \\
\hline 120 & $0,9917 \pm 0,0017$ & $0,9977 \pm 0,0020$ \\
\hline
\end{tabular}

\subsection{Caracterização de Três Câmaras de Ionização em Feixes de Radiação BETA}

Como a câmara de extrapolação Böhm consiste num instrumento relativamente pesado (7 kg), e por este motivo não é fácil de manuseá-la fora do laboratório, e altamente sensível à umidade, torna-se interessante ter um método alternativo para dosimetria rotineira dos feixes de radiação beta, tanto para ser utilizado no $\mathrm{LCl}$, como em casos de se realizar dosimetria fora do laboratório, como por exemplo em clínicas, hospitais ou outros laboratórios. Assim, três câmaras de ionização de placas paralelas (C1, C2 e C3) foram caracterizadas a fim de se verificar e comparar seus comportamentos em campos padrões secundários de radiação beta e, assim, serem aplicadas como sistemas padrões de trabalho. Neste item serão apresentados os testes realizados e os resultados obtidos com as três câmaras de ionização de placas paralelas.

\subsubsection{Curvas de Saturação}

Utilizando-se diferentes condições experimentais, foi obtida uma curva de saturação para cada uma das três câmaras de ionização; a tensão de operação, nos três casos, foi variada de $-300 \mathrm{~V}$ a $+300 \mathrm{~V}$ (em intervalos de $50 \mathrm{~V}$ ), e dez medições de carga elétrica foram coletadas em cada polaridade. Na Tabela 6.48 são apresentadas estas condições, e na Fig. 6.16 as curvas obtidas. 
Tabela 6.48-Condições experimentais utilizadas na determinação das curvas de saturação, e correntes de ionização médias obtidas para ambas as polaridades de tensão.

\begin{tabular}{|c|c|c|c|c|c|c|}
\hline \multirow{2}{*}{$\begin{array}{l}\text { Câmara } \\
\text { de } \\
\text { lonização }\end{array}$} & \multirow{2}{*}{$\begin{array}{c}\text { Fonte } \\
\text { de } \\
\text { Radiação }\end{array}$} & \multirow{2}{*}{$\begin{array}{c}\text { Distância } \\
\text { Fonte-Detector } \\
\text { (cm) }\end{array}$} & \multirow{2}{*}{$\begin{array}{c}\text { Tempo de } \\
\text { Coleta de Carga } \\
\text { (s) }\end{array}$} & \multicolumn{2}{|c|}{$\begin{array}{c}\text { Corrente de Ionização } \\
\text { (pA) }\end{array}$} & \multirow{2}{*}{$\begin{array}{c}\text { Coeficiente } \\
\text { de Variação } \\
\text { Máximo } \\
\text { (\%) }\end{array}$} \\
\hline & & & & $\begin{array}{l}\text { Polaridade } \\
\text { Positiva }\end{array}$ & $\begin{array}{l}\text { Polaridade } \\
\text { Negativa }\end{array}$ & \\
\hline $\mathrm{C} 1$ & $\begin{array}{c}\text { Aplicador } \\
\text { NIST }\end{array}$ & 1 & 30 & $46,10 \pm 0,04$ & $-51,98 \pm 0,03$ & 0,9 \\
\hline $\mathrm{C} 2$ & $\begin{array}{c}1850 \mathrm{MBq} \\
\mathrm{BSS} 1\end{array}$ & 30 & 10 & $1,32 \pm 0,07$ & $-1,48 \pm 0,08$ & 1,8 \\
\hline C3 & $\begin{array}{c}1850 \mathrm{MBq} \\
\text { BSS1 }\end{array}$ & 30 & 60 & $0,89 \pm 0,09$ & $-1,02 \pm 0,08$ & 3,6 \\
\hline
\end{tabular}

O efeito de polaridade das três câmaras de ionização foi obtido pela Equação 6.1 ; o resultado foi um efeito de polaridade máximo (entre todas as tensões) para as câmaras C1, C2 e C3, respectivamente, de: 6,02\% (250 V), 6,30\% (50 V), e 6,33\% (50 V). De acordo com a explicação fornecida no item 6.1.1, apesar destes efeitos de polaridade serem superiores ao limite recomendado pela norma IEC 60731 (2011), de 1,0\%, eles são aceitáveis por se tratar de exposição à radiação beta.

A eficiência de coleção de íons para cada câmara de ionização foi obtida levando-se em conta os valores de carga para ambas as polaridades de tensão (Equação 4.5). Para a câmara C1, as medições mostraram uma eficiência de coleção de íons de 99,90\%, para a câmara C2 uma eficiência de 99,97\%, e para a câmara C3, de 99,44\%; estes resultados mostraram-se dentro do limite recomendado pela IEC 60731 (2011), que estabelece um valor mínimo de 99\%. A partir dos resultados da determinação da eficiência de coleção de íons, pode-se obter os valores de perda por recombinação iônica de 0,10\%, 0,03\% e 0,54\%, para as câmaras C1, C2 e C3, respectivamente, o que pode ser considerado satisfatório porque está abaixo do limite recomendado pela norma IEC 60731 (2011), de 1,0\%. 


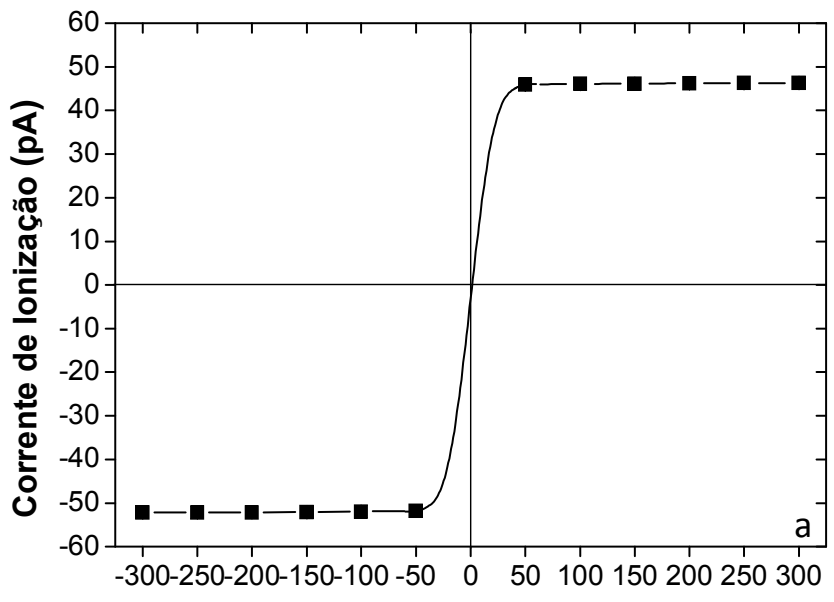

Tensão de Polarização (V)
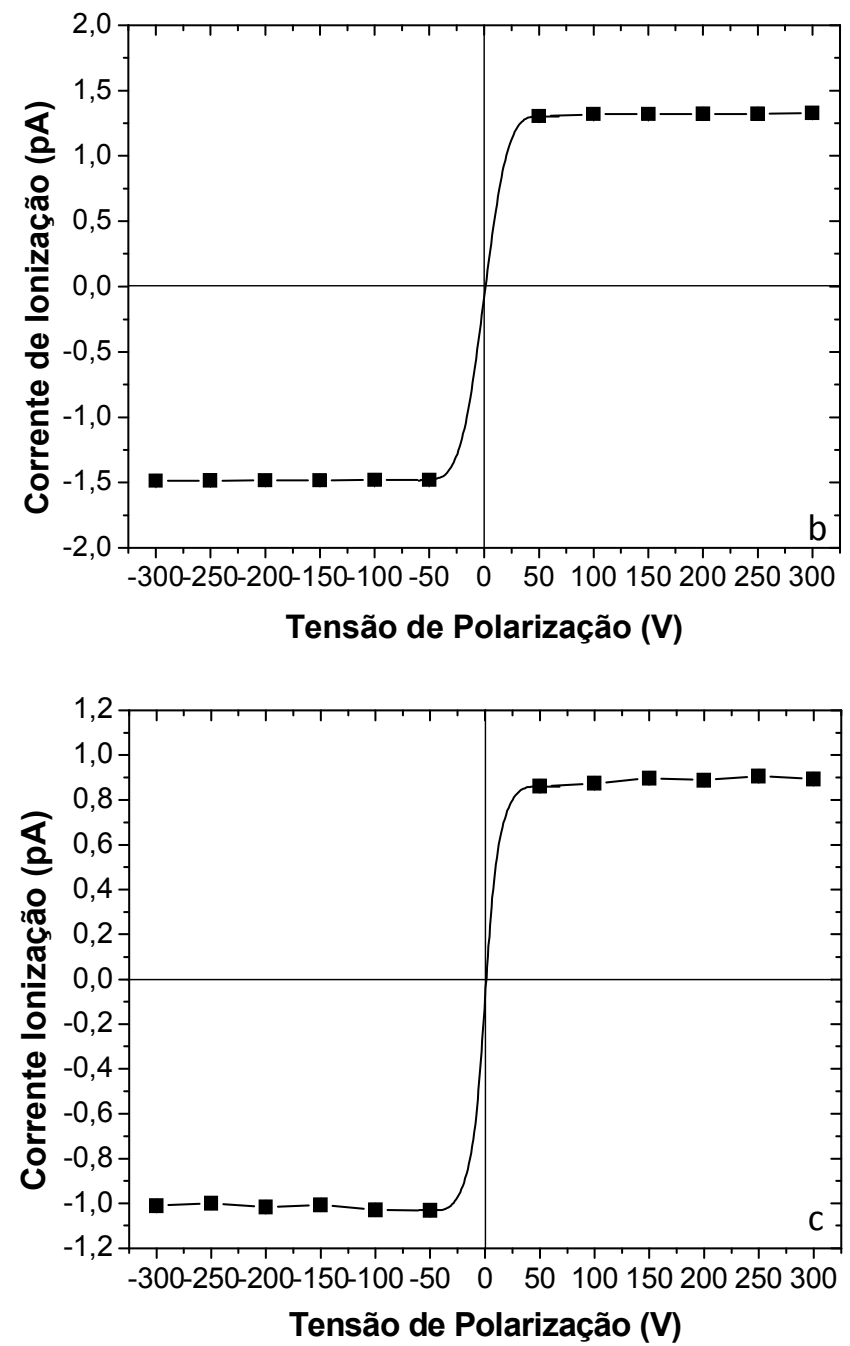

Figura 6.16-Curvas de saturação obtidas para as três câmaras de ionização estudadas neste trabalho: (a) C1; (b) C2; e (c) C3. 


\subsubsection{Corrente de Fuga}

A verificação da presença de corrente de fuga pré-irradiação no sistema (eletrômetro + cabo + câmara de ionização), sem irradiação, foi realizada para as três câmaras de ionização. Assim como no caso da câmara de extrapolação Böhm, as medições de carga foram tomadas durante $20 \mathrm{~min}$, sem exposição das câmaras a qualquer fonte de radiação. A tensão aplicada foi a mesma para as três câmaras: $+300 \mathrm{~V}$. Os resultados obtidos foram de 0,02\%, 0,01\% e 0,04\%, para as câmaras C1, C2 e C3, respectivamente. Levando-se em conta que a norma IEC 60731 (2011) recomenda o limite de 0,5\% do maior valor medido em um experimento com radiação, pode-se concluir que nos três casos a fuga da corrente de ionização foi desprezível.

\subsubsection{Estabilidade de Resposta}

A estabilidade da resposta das três câmaras de ionização foi estudada quando elas foram expostas a uma fonte de controle de ${ }^{90} \mathrm{Sr}+{ }^{90} \mathrm{Y}$ (33 MBq, 1988), posicionada sobre cada uma das câmaras de ionização. A Fig. 6.17 mostra o arranjo experimental utilizado no caso da câmara C3. Foi utilizado o mesmo procedimento para os três casos: tensão de polarização de $\pm 300 \mathrm{~V}$, e tempo de coleta de carga de $60 \mathrm{~s}$ para cada medição. Para o teste de repetibilidade, foram tomadas dez medições de carga elétrica, e para o teste de reprodutibilidade, várias séries de testes de repetibilidade foram realizadas. As Fig. 6.18.a-c mostram o estudo de reprodutibilidade da resposta das três câmaras de ionização C1, C2 e C3. A Tabela 6.49 mostra os resultados obtidos para ambos os testes e para as três câmaras de ionização, em comparação com os limites recomendados pela norma IEC 60731 (2011).

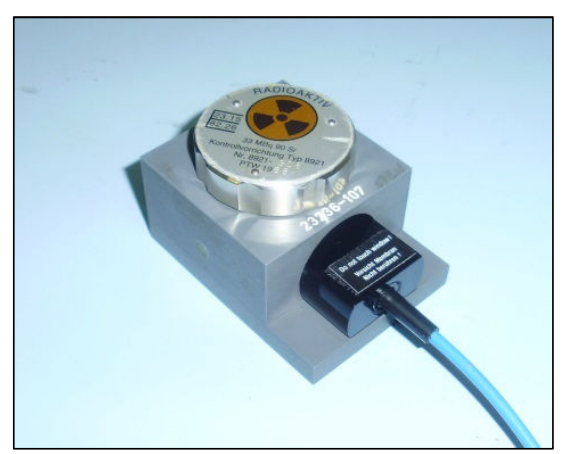

Figura 6.17 - Câmara de ionização C3 durante o experimento de estabilidade de resposta da câmara, com a fonte de controle de ${ }^{90} \mathrm{Sr}+{ }^{90} \mathrm{Y}$ posicionada sobre ela. 

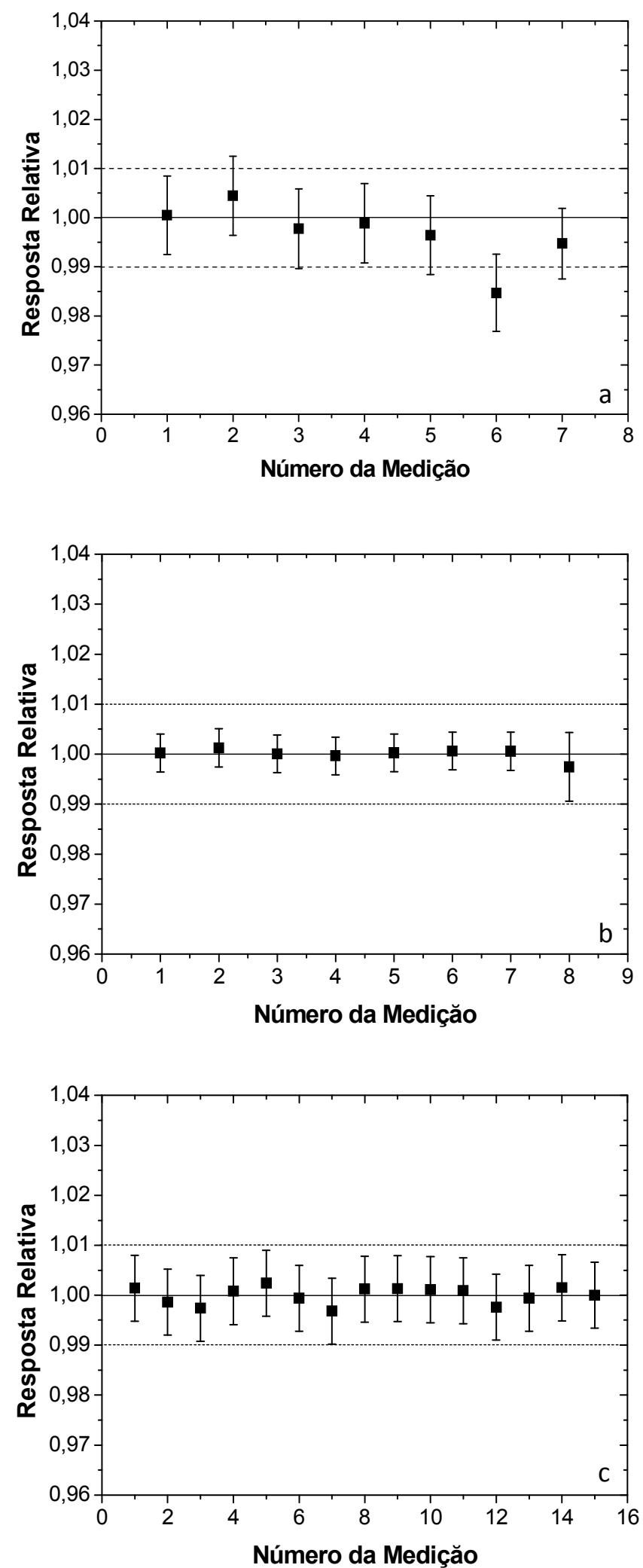

Figura 6.18 - Teste de estabilidade da resposta de três câmaras de ionização: (a) C1; (b) C2; e (c) C3, utilizando uma fonte de controle de ${ }^{90} \mathrm{Sr}+{ }^{90} \mathrm{Y}$. As linhas pontilhadas mostram os limites recomendados pela norma IEC 60731 (2011), de 0,5\% para o teste de reprodutibilidade. 
Tabela 6.49 - Testes de repetibilidade e reprodutibilidade da resposta de três câmaras de ionização, realizados com uma fonte de controle de ${ }^{90} \mathrm{Sr}+{ }^{90} \mathrm{Y}$.

\begin{tabular}{ccccc}
\hline Testes & IEC 60731 (2011) & Câmara C1 & Câmara C2 & Câmara C3 \\
\hline Repetibilidade & $0,30 \%$ & $0,17 \%$ & $0,07 \%$ & $0,20 \%$ \\
\hline Reprodutibilidade & $0,50 \%$ & $2,26 \%$ & $0,26 \%$ & $0,26 \%$ \\
\hline
\end{tabular}

De acordo com a Tabela 6.49, pode-se concluir que as três câmaras de ionização estudadas apresentam repetibilidade e reprodutibilidade de suas respostas conforme 0 recomendado pela norma IEC 60731 (2011), apresentando estabilidade e assim uma maior confiabilidade em suas medições, com exceção da câmara de ionização C1, cujo resultado para o teste de reprodutibilidade excedeu o limite recomendado numa das medições. Ainda assim, esta câmara foi utilizada em outros testes, pois apresentava desvio padrão baixo em suas medições.

\subsubsection{Linearidade de Resposta}

A linearidade da resposta das câmaras de ionização foi estudada em relação às medições de carga coletada em função do tempo de irradiação, sob as mesmas condições experimentais. Para tal, foi utilizada a fonte de controle de ${ }^{90} \mathrm{Sr}^{90}{ }^{90} \mathrm{Y}(33 \mathrm{MBq}, 1988)$ e o tempo de irradiação num intervalo de $30 \mathrm{~s}$ a $240 \mathrm{~s}$; foram tomadas dez medições de carga elétrica, e a tensão de polarização utilizada foi de $\pm 300 \mathrm{~V}$.

A Fig. 6.19 apresenta o resultado deste estudo para as três câmaras de ionização, sob as mesmas condições. Os coeficientes de variação máximos obtidos para cada uma das câmaras foi 0,5\% (C1) e 0,07\% (C2 e C3). Pode-se observar, pela Fig. 6.19, que as três câmaras de ionização apresentam resposta linear em função do tempo de radiação, pois o coeficiente de correlação, $R^{2}$, nos três casos, foi igual a 1,000. 


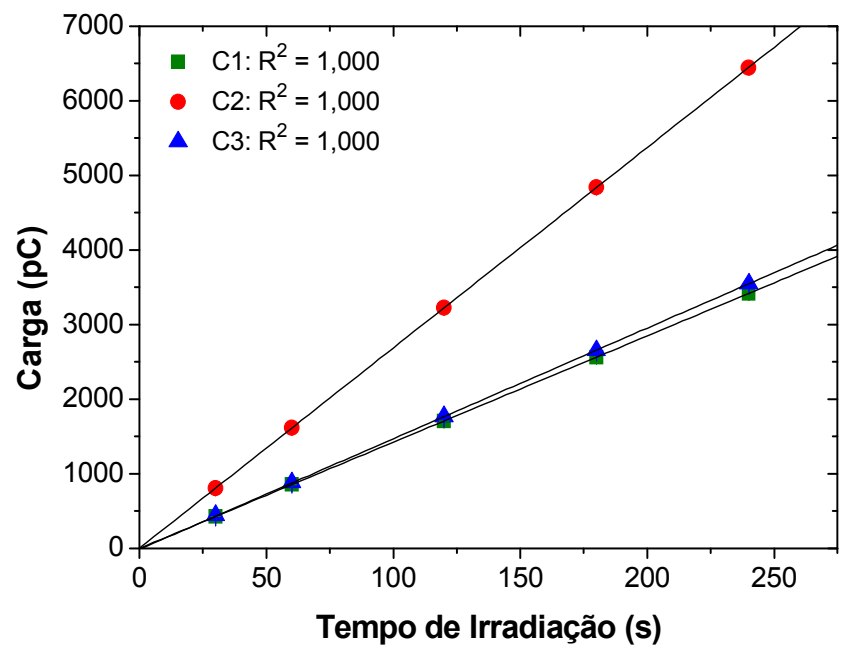

Figura 6.19 - Linearidade de resposta das três câmaras de ionização de placas paralelas, utilizando a fonte de controle de ${ }^{90} \mathrm{Sr}+{ }^{90} \mathrm{Y}$.

\subsubsection{Outros Testes}

A seguir, serão apresentados os resultados de testes de caracterização que foram realizados com uma ou duas câmaras de ionização de placas paralelas.

\subsubsection{Tempo de Estabilização}

Para o teste do tempo de estabilização, foram utilizadas as câmaras C1 e C2. Ele foi realizado de acordo com a recomendação internacional IEC 60731 (2011), tomando-se medições após $15 \mathrm{~min}, 1 \mathrm{~h}$ e $2 \mathrm{~h}$. As duas câmaras de ionização foram expostas à fonte de controle de ${ }^{90} \mathrm{Sr}+{ }^{90} \mathrm{Y} \mathrm{e}$, durante as medições, a tensão de polarização aplicada à câmara foi de $\pm 300 \mathrm{~V}$.

Assim como no caso da câmara de extrapolação Böhm, os valores de corrente de ionização obtidos foram normalizados para a corrente medida em $1 \mathrm{~h}$, uma vez que a IEC 60731 (2011) recomenda que a corrente de ionização medida após 15 min e após 2 h não deve exceder $0,5 \%$ do valor medido após 1 h. No caso da câmara de ionização $\mathrm{C} 1$, a corrente de ionização variou da seguinte maneira: de $(42,22 \pm 0,21)$ pA, em 120 min, a $(42,37 \pm 0,21) \mathrm{pA}$, em $15 \mathrm{~min}$, para a polaridade positiva, e de $-(47,36 \pm 0,26) \mathrm{pA}$, em $120 \mathrm{~min}$, a $-(47,49 \pm 0,26) \mathrm{pA}$, em $15 \mathrm{~min}$, para a polaridade negativa. Para a câmara C2, a corrente de ionização variou: de $(23,81 \pm 0,23)$ pA, em $120 \mathrm{~min}$, a $(23,84 \pm 0,23)$ pA, em $15 \mathrm{~min}$, para a polaridade positiva, e de $-(25,42 \pm 0,24) \mathrm{pA}$, em $120 \mathrm{~min}$, a 
$-(25,42 \pm 0,24) \mathrm{pA}$, em $15 \mathrm{~min}$, para a polaridade negativa. A Tabela 6.50 mostra os resultados obtidos neste estudo, para as duas câmaras de ionização, e em ambas as polaridades de tensão.

Tabela 6.50 - Teste de tempo de estabilização realizado com as câmaras de ionização $C 1$ e C2, utilizando-se a fonte de controle de ${ }^{90} \mathrm{Sr}+{ }^{90} \mathrm{Y}$ (33 MBq, 1988).

\begin{tabular}{ccccc}
\hline \multirow{2}{*}{$\begin{array}{c}\text { Tempo } \\
\text { (min) }\end{array}$} & \multicolumn{2}{c}{ Corrente de lonização Normalizada para Tempo de 60 min } \\
\cline { 2 - 5 } & \multicolumn{2}{c}{ Câmara C1 } & \multicolumn{2}{c}{ Câmara C2 } \\
\cline { 2 - 5 } & $\begin{array}{c}\text { Polaridade } \\
\text { Positiva }\end{array}$ & $\begin{array}{c}\text { Polaridade } \\
\text { Negativa }\end{array}$ & $\begin{array}{c}\text { Polaridade } \\
\text { Positiva }\end{array}$ & $\begin{array}{c}\text { Polaridade } \\
\text { Negativa }\end{array}$ \\
\hline 15 & $1,0014 \pm 0,0011$ & $0,9940 \pm 0,0060$ & $1,0006 \pm 0,0010$ & $1,0005 \pm 0,0010$ \\
\hline 60 & $1,0000 \pm 0,0011$ & $1,0000 \pm 0,0060$ & $1,0000 \pm 0,0010$ & $1,0000 \pm 0,0010$ \\
\hline 120 & $0,9980 \pm 0,0011$ & $0,9913 \pm 0,0060$ & $0,9990 \pm 0,0010$ & $1,0003 \pm 0,0000$ \\
\hline
\end{tabular}

Para a câmara de ionização C1, foi obtida uma variação máxima de resposta de $0,2 \%$ no tempo de 120 min e na polaridade positiva, enquanto que para a câmara C2, esta variação foi de $0,1 \%$, também no tempo de 120 min e na polaridade positiva. De acordo com a norma IEC 60731 (2011), a variação da resposta da câmara, durante o teste de tempo de estabilização, não deve exceder $0,5 \%$, e o resultado para a câmara C1 excedeu este limite, mas ainda assim foi considerado aceitável (como ocorreu com a câmara de extrapolação Böhm) devido ao fato desta câmara apresentar reprodutibilidade na sua resposta em todos os testes realizados com ela. Para a câmara C2, a variação apresentou-se dentro do limite estabelecido pela IEC 60731 (2011).

\subsubsection{Dependência Angular}

A dependência angular foi estudada para se determinar a resposta das câmaras de ionização como função da radiação incidente em pequenos ângulos ao longo do eixo perpendicular à janela de entrada e, assim, verificar a influência de pequenos erros de posicionamento da câmara. Este teste foi realizado para as câmaras de ionização C1 e C2, movidas de maneira rotacional, aplicando-se uma tensão de polarização de $\pm 300 \mathrm{~V}$. No caso da câmara C1, os ângulos foram variados num intervalo de $-16^{\circ}$ a $+16^{\circ}$, em passos de $4^{\circ}$; para a câmara C2, os ângulos foram variados de $-15^{\circ}$ a $+15^{\circ}$, sendo que de $0^{\circ}$ a $10^{\circ}$ eles foram variados em intervalos de $2^{\circ}$, e para os ângulos restantes, em passos de $5^{\circ}$. No caso da 
câmara C1, ela foi irradiada com o aplicador NIST, a uma distância fonte-detector de $4 \mathrm{~cm}$. A câmara C2 foi exposta à fonte de ${ }^{90} \mathrm{Sr}+{ }^{90} \mathrm{Y}(1850 \mathrm{MBq})$, à distância fonte-detector de $11 \mathrm{~cm}$. Em ambas as câmaras, o tempo de coleta de carga, para cada medição, foi de $60 \mathrm{~s}$. $\mathrm{Na}$ Fig. 6.20 podem ser observados os arranjos experimentais utilizados durante este experimento, com as câmaras C1 e C2 posicionadas sobre um goniômetro. A Tabela 6.51 mostra os resultados obtidos, para o teste de dependência angular, normalizados para o ângulo de $0^{\circ}$, para as câmaras $\mathrm{C} 1$ e C2; estes resultados permitiram a elaboração dos gráficos da Fig. 6.21, que mostram o comportamento da resposta das câmaras C1 e C2, quando expostas à feixes de radiação beta.
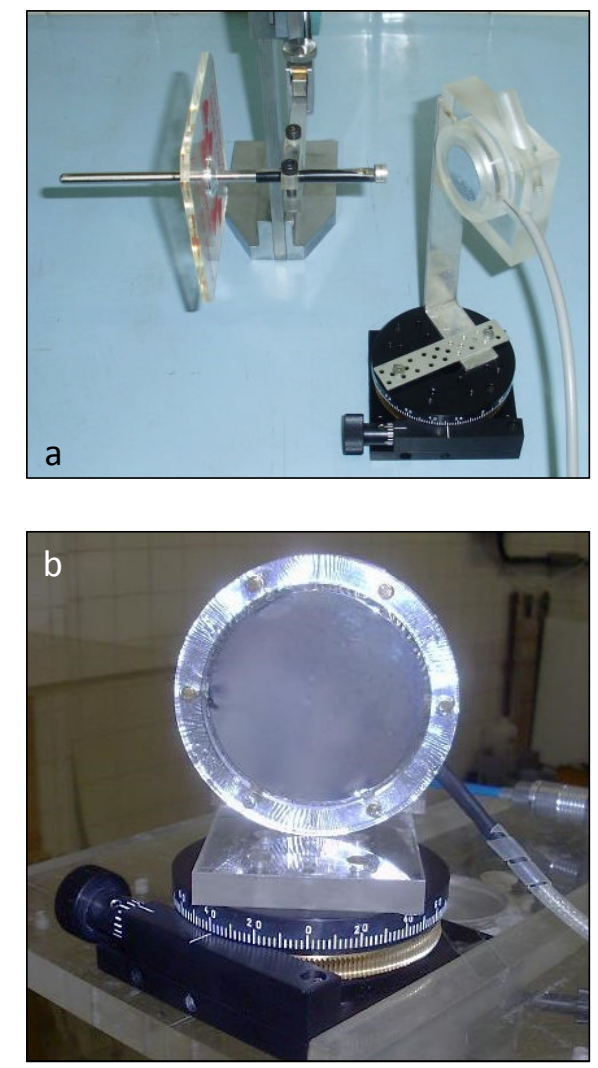

Figura 6.20 - Arranjos experimentais utilizados no teste de dependência angular da resposta das câmaras: (a) C1, irradiada com o aplicador NIST; e (b) C2, irradiada no sistema BSS1. 
Tabela 6.51 - Resposta relativa das câmaras de ionização C1 e C2 em função do ângulo de $0^{\circ}$.

\begin{tabular}{|c|c|c|c|}
\hline \multicolumn{2}{|c|}{ Câmara de lonização C1 } & \multicolumn{2}{|c|}{ Câmara de Ionização C2 } \\
\hline $\begin{array}{c}\text { Ângulo de } \\
\text { Incidência } \\
\left({ }^{\circ}\right)\end{array}$ & Resposta Relativa & $\begin{array}{c}\text { Ângulo de } \\
\text { Incidência } \\
\left({ }^{\circ}\right)\end{array}$ & Resposta Relativa \\
\hline \multirow{2}{*}{-16} & \multirow{2}{*}{$1,0298 \pm 0,0110$} & -30 & $1,041 \pm 0,013$ \\
\hline & & -25 & $1,028 \pm 0,013$ \\
\hline \multirow{2}{*}{-12} & \multirow{2}{*}{$1,0202 \pm 0,0111$} & -20 & $1,018 \pm 0,013$ \\
\hline & & -15 & $1,008 \pm 0,013$ \\
\hline \multirow{2}{*}{-8} & \multirow{2}{*}{$1,0072 \pm 0,0111$} & -10 & $1,004 \pm 0,013$ \\
\hline & & -8 & $1,001 \pm 0,013$ \\
\hline \multirow{2}{*}{-4} & \multirow{2}{*}{$1,0014 \pm 0,0112$} & -6 & $1,001 \pm 0,013$ \\
\hline & & -4 & $0,999 \pm 0,013$ \\
\hline \multirow{3}{*}{0} & \multirow{3}{*}{$1,0000 \pm 0,0112$} & -2 & $1,001 \pm 0,013$ \\
\hline & & 0 & $1,000 \pm 0,013$ \\
\hline & & 2 & $1,002 \pm 0,013$ \\
\hline \multirow{2}{*}{4} & \multirow{2}{*}{$1,0000 \pm 0,0112$} & 4 & $1,003 \pm 0,013$ \\
\hline & & 6 & $1,005 \pm 0,013$ \\
\hline \multirow{2}{*}{8} & \multirow{2}{*}{$0,9914 \pm 0,0112$} & 8 & $1,009 \pm 0,013$ \\
\hline & & 10 & $1,011 \pm 0,013$ \\
\hline \multirow{2}{*}{12} & \multirow{2}{*}{$0,9933 \pm 0,0112$} & 15 & $1,021 \pm 0,013$ \\
\hline & & 20 & $1,034 \pm 0,013$ \\
\hline \multirow{2}{*}{16} & \multirow{2}{*}{$0,9939 \pm 0,0112$} & 25 & $1,044 \pm 0,013$ \\
\hline & & 30 & $1,067 \pm 0,012$ \\
\hline
\end{tabular}



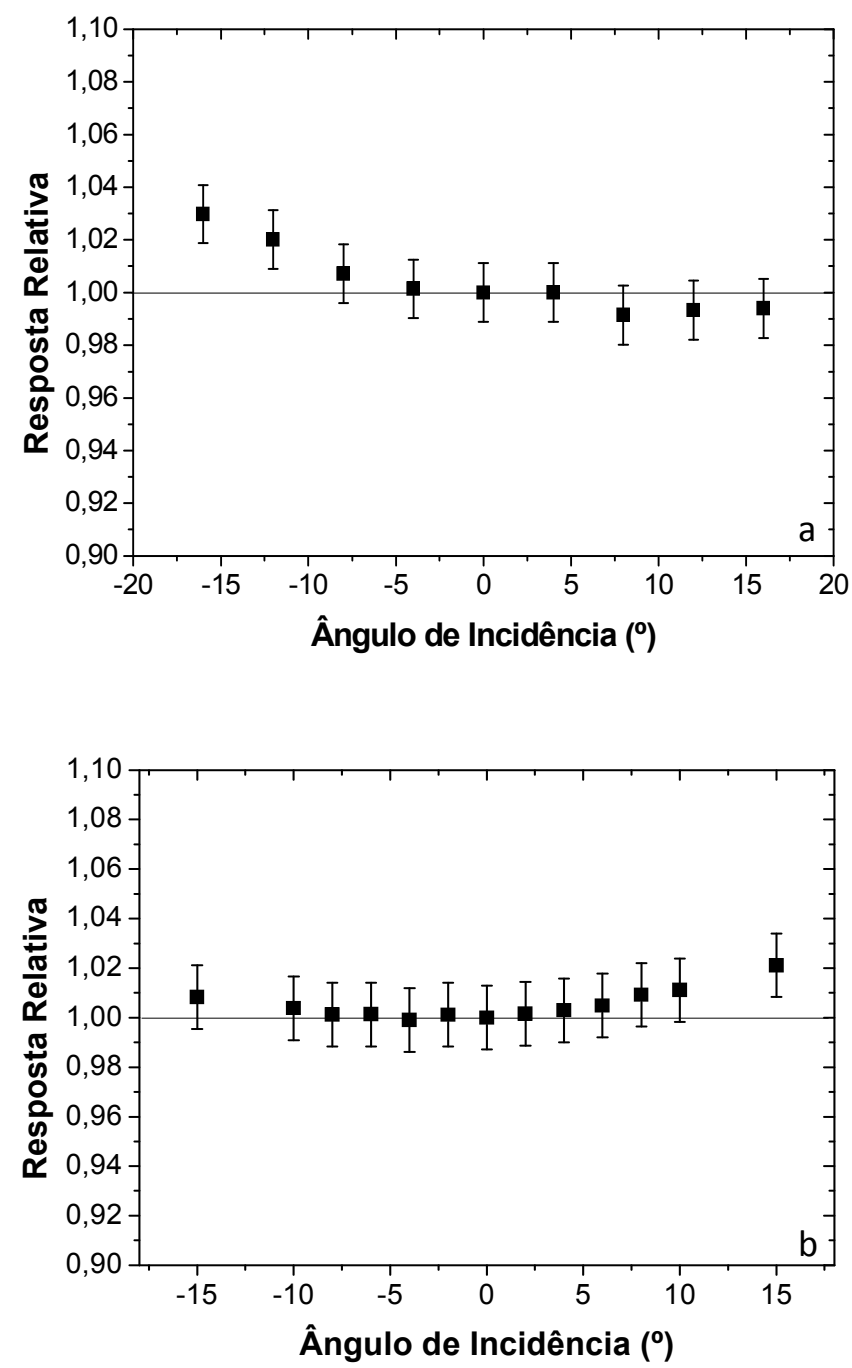

Figura 6.21 - Resultados obtidos no teste de dependência angular, realizados com as câmaras de ionização: (a) C1, irradiada com o aplicador NIST $\left({ }^{90} \mathrm{Sr}+{ }^{90} \mathrm{Y}\right)$; e (b) $\mathrm{C} 2$, irradiada com a fonte de ${ }^{90} \mathrm{Sr}+{ }^{90} \mathrm{Y}$ do sistema BSS1 (1850 MBq, 1981).

De acordo com a norma IEC 60731 (2011), a resposta da câmara não pode apresentar variação maior que $1 \%$ do valor medido para $0^{\circ}$, quando a irradiação é feita com raios $X$. No caso da câmara C1, a maior variação entre os ângulos foi exatamente $3,0 \%$, no caso do ângulo de $-16^{\circ}$, e na polaridade negativa. Para a câmara $C 2$, o resultado foi de $2,1 \%$, no ângulo de $+15^{\circ}$, e na polaridade positiva. Como não há uma norma que recomende um limite para o teste de dependência angular em casos nos quais a câmara de ionização é irradiada em feixes de radiação beta, os resultados foram considerados aceitáveis.

Este teste não foi realizado para a câmara C3, pois não foi possível posicionar a câmara sobre o goniômetro utilizado nos testes de dependência angular. 


\subsubsection{Calibração das Câmaras de lonização C2 e C3}

As câmaras de ionização C2 e C3 foram calibradas usando as fontes de ${ }^{90} \mathrm{Sr}+{ }^{90} \mathrm{Y},{ }^{85} \mathrm{Kr}$ e ${ }^{147} \mathrm{Pm}$ do sistema BSS2 (usando filtro uniformizador de campo), intervalos de tempo de irradiação, respectivamente, de $60 \mathrm{~s}, 30 \mathrm{~s}$ e $300 \mathrm{~s}$ (câmara C2), e de $120 \mathrm{~s}, 60 \mathrm{~s}$ e $900 \mathrm{~s}$ (câmara C3), e distâncias fonte-detector de $30 \mathrm{~cm}, 30 \mathrm{~cm}$ e $20 \mathrm{~cm}$.

Neste procedimento, foram obtidos coeficientes de calibração para todas as fontes. Os resultados deste estudo podem ser observados na Tabela 6.52. Com relação às medições com a câmara C2, o coeficiente de variação máximo obtido foi 3,04\%, e para a câmara C3 foi de $2,90 \%$. Os coeficientes de calibração demonstraram que as duas câmaras de ionização estudadas apresentam alta dependência energética para radiação beta, como pode ser melhor observado por meio dos gráficos da Fig. 6.22, que mostram o comportamento das duas câmaras de ionização quando expostas a feixes de radiação beta de diferentes energias.

Tabela 6.52 - Coeficientes de calibração obtidos para as duas câmaras de ionização de placas paralelas C2 e C3.

\begin{tabular}{|c|c|c|c|c|c|}
\hline \multirow[b]{2}{*}{$\begin{array}{c}\text { Fonte } \\
\text { de } \\
\text { Radiação }\end{array}$} & \multirow[b]{2}{*}{$\begin{array}{l}\text { Energia } \\
\text { Média } \\
\text { (MeV) }\end{array}$} & \multicolumn{2}{|c|}{ Câmara C2 (16/03/2011) } & \multicolumn{2}{|c|}{ Câmara C3 (16/06/2011) } \\
\hline & & $\begin{array}{c}\text { Taxa de Dose } \\
\text { Absorvida } \\
(\mu G y / s)\end{array}$ & $\begin{array}{c}\text { Coeficiente de } \\
\text { Calibração } \\
\left(\mu \mathrm{Gy} \cdot \mathrm{s}^{-1} / \mathrm{pA}\right)\end{array}$ & $\begin{array}{c}\text { Taxa de Dose } \\
\text { Absorvida } \\
(\mu G y / s)\end{array}$ & $\begin{array}{c}\text { Coeficiente de } \\
\text { Calibração } \\
\left(\mu G y . s^{-1} / p A\right)\end{array}$ \\
\hline${ }^{90} \mathrm{Sr}+{ }^{90} \mathrm{Y}$ & 0,800 & $9,081 \pm 0,140$ & $16,481 \pm 0,155$ & $9,027 \pm 0,140$ & $77,984 \pm 0,377$ \\
\hline${ }^{85} \mathrm{Kr}$ & 0,150 & $26,483 \pm 0,500$ & $17,178 \pm 0,504$ & $26,062 \pm 0,500$ & $89,349 \pm 0,539$ \\
\hline${ }^{147} \mathrm{Pm}$ & 0,060 & $0,697 \pm 0,050$ & $49,786 \pm 0,083$ & $0,629 \pm 0,050$ & $37,865 \pm 1,141$ \\
\hline
\end{tabular}



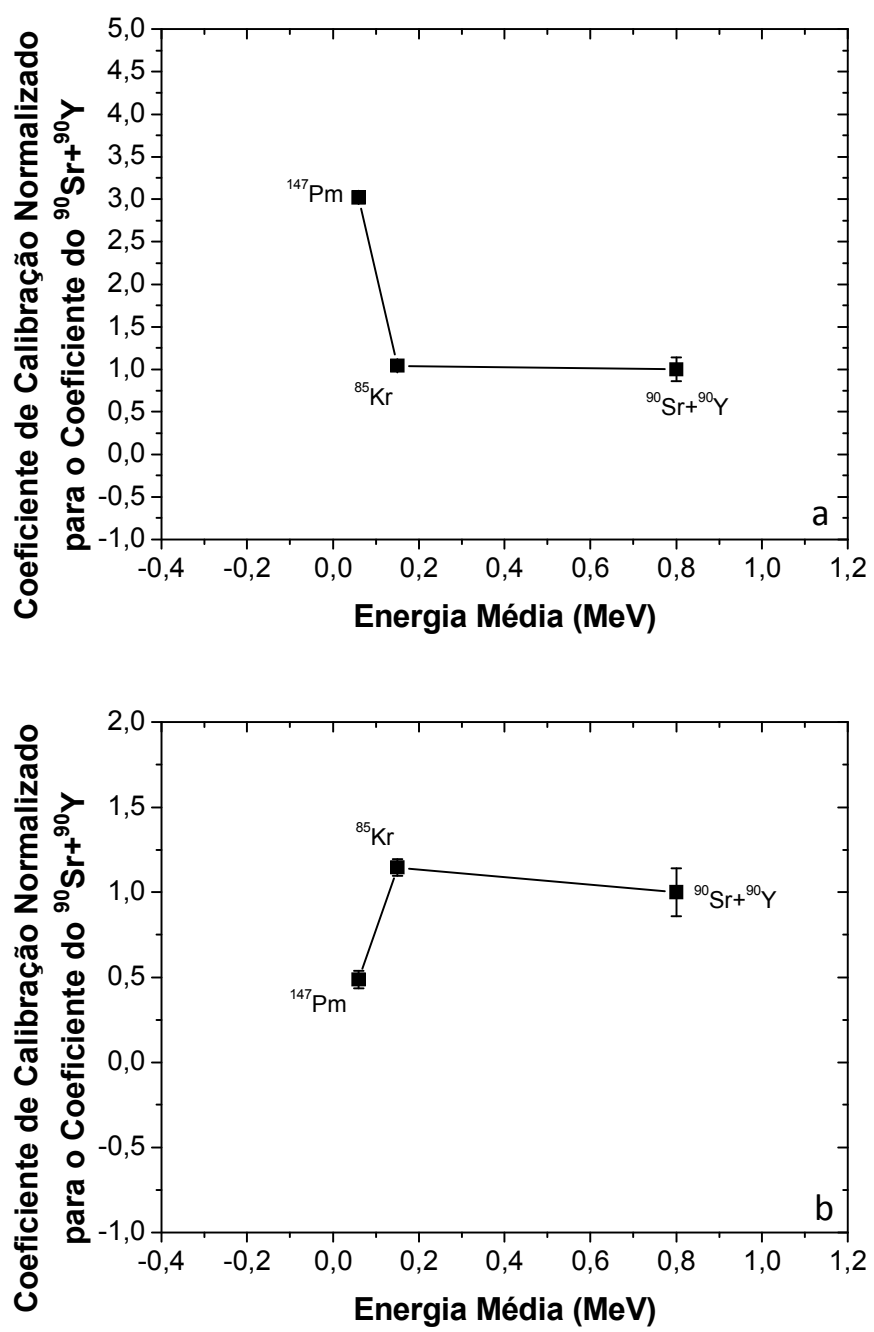

Figura 6.22 - Comportamento da resposta das câmaras de ionização: (a) C2; e (b) C3, quando irradiadas em feixes padrões secundários de fontes de radiação beta de diferentes energias.

\subsubsection{Variação da Resposta em Função da Distância Fonte-Detector}

O estudo de variação da resposta da câmara em função da distância fonte-detector foi realizado para as câmaras C1 e C2. A câmara C1 foi exposta ao aplicador NIST, a dez distâncias diferentes de $0 \mathrm{~cm}$ a 4,0 cm, e o tempo de coleta de carga foi de $60 \mathrm{~s}$. No caso da câmara $\mathrm{C} 2$, a fonte de ${ }^{90} \mathrm{Sr}+{ }^{90} \mathrm{Y}(1850 \mathrm{MBq})$ foi exposta à câmara em distâncias fontedetector de $10 \mathrm{~cm}$ a $55 \mathrm{~cm}$ (16 distâncias), e o tempo de coleta de carga foi $10 \mathrm{~s}$ para as dez primeiras distâncias, e de $30 \mathrm{~s}$, para as seis distâncias restantes.

A corrente de ionização obtida com a câmara C1 variou de $(409,412 \pm 0,096)$ pA a $(5,120 \pm 0,065)$ pA, e o coeficiente de variação máximo obtido foi 0,48\% (para a distância fonte-detector de 2,0 cm). Para a câmara C2, a variação da corrente de ionização foi de 
$(34,161 \pm 0,046)$ pA a $(1,155 \pm 0,045)$ pA, e o coeficiente de variação máximo foi $0,31 \%$ (para a distância fonte-detector de $20 \mathrm{~cm}$ ). A Fig. 6.23 apresenta o comportamento da corrente de ionização em função da distância fonte-detector para as câmaras de ionização C1 e C2.
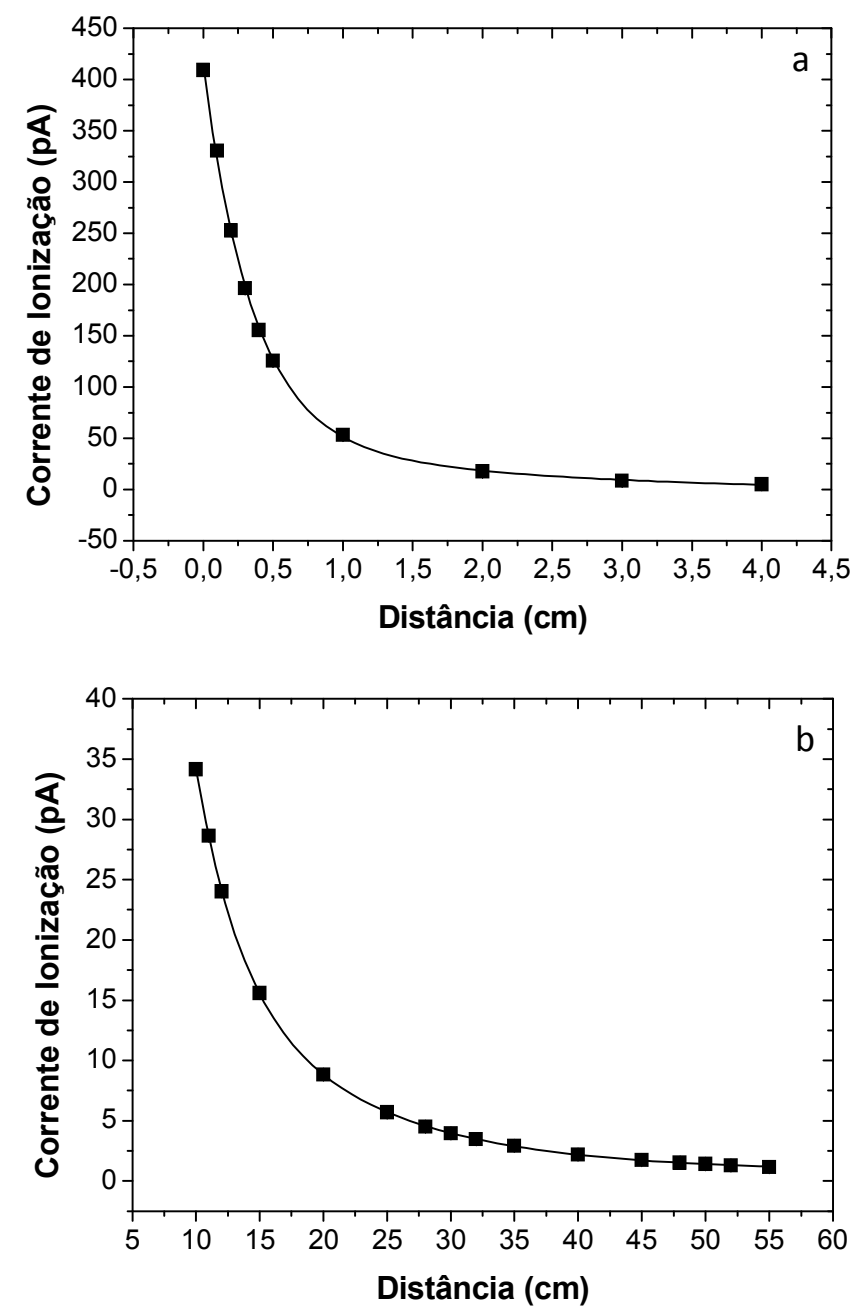

Figura 6.23 - Estudo de variação da resposta da câmara em função da distância fonte-detector, realizado para as câmaras: (a) C1, irradiada com o aplicador NIST $\left({ }^{90} \mathrm{Sr}+{ }^{90} \mathrm{Y}\right)$; e (b) C2, irradiada com a fonte de ${ }^{90} \mathrm{Sr}+{ }^{90} \mathrm{Y}$ do sistema BSS1 (1850 MBq, 1981).

Os resultados obtidos neste estudo para as duas câmaras de ionização de placas paralelas, C1 e C2, mostraram que suas respostas seguem a lei do inverso do quadrado da distância e, por este motivo, os detectores de radiação beta podem ser calibrados em distâncias diferentes das especificadas nos certificados de calibração das fontes.

Este estudo foi realizado só com as câmaras C1 e C2; ele não foi feito utilizando a câmara C3, pois devido ao fato do volume sensível dela ser muito pequeno $\left(0,20 \mathrm{~cm}^{3}\right)$, as 
medições foram muito baixas, mesmo em intervalos de tempo de coleta de carga grandes, o que aumentou as incertezas associadas consideravelmente.

\subsubsection{Determinação de Taxas de Dose Absorvida para Aplicadores Dermatológicos}

A câmara de ionização de placas paralelas C1 foi estudada em relação à possibilidade de seu uso em controle de qualidade de aplicadores clínicos de ${ }^{90} \mathrm{Sr}+{ }^{90} \mathrm{Y}$.

Três aplicadores clínicos dermatológicos, A1, A2 e A3 (especificados na Tabela 5.6) foram calibrados utilizando o aplicador NIST como referência. Um fator de calibração foi obtido para a câmara de ionização quando exposta ao aplicador NIST, levando-se em conta a taxa de dose absorvida do aplicador NIST (fornecida em seu certificado de calibração e corrigida para o decaimento radioativo), e a corrente de ionização medida.

As medições foram tomadas para os aplicadores A1, A2 e A3 mantendo-se a câmara de ionização fisicamente em contato com a fonte (distância nula); o tempo de coleta de carga destas medições foi de 60 s. Aplicando-se o fator de calibração da câmara de ionização (para o aplicador NIST) às medições obtidas para os aplicadores A1, A2 e A3, suas taxas de dose absorvida foram determinadas, e podem ser observadas na Tabela 6.53. Os valores obtidos neste trabalho foram comparados com um trabalho prévio, no qual as taxas de dose absorvida foram determinadas usando-se uma mini-câmara de extrapolação como instrumento de referência (OLIVEIRA, 2005).

Tabela 6.53 - Taxas de dose absorvida obtidas para aplicadores clínicos dermatológicos de ${ }^{90} \mathrm{Sr}+{ }^{90} \mathrm{Y}$, utilizando o aplicador NIST como referência, e em comparação com resultados obtidos em um trabalho prévio.

\begin{tabular}{|c|c|c|}
\hline \multirow{2}{*}{$\begin{array}{l}\text { Aplicador } \\
\text { Clínico } \\
\mathrm{de}^{90} \mathrm{Sr}^{90} \mathrm{Y}\end{array}$} & \multicolumn{2}{|c|}{ Taxa de Dose Absorvida (Gy/s) } \\
\hline & $\begin{array}{l}\text { Trabalho } \\
\text { Anterior }\end{array}$ & Este Trabalho \\
\hline A1 & $0,0195 \pm 0,0040$ & $0,0154 \pm 0,0031$ \\
\hline $\mathrm{A} 2$ & $0,0218 \pm 0,0045$ & $0,0169 \pm 0,0034$ \\
\hline A3 & $0,0297 \pm 0,0060$ & $0,0207 \pm 0,0041$ \\
\hline
\end{tabular}

Levando-se em conta que a incerteza expandida fornecida no certificado de calibração do aplicador NIST é de $12 \%$, e que as incertezas descritas pelos certificados das fontes (fabricantes) são de $20 \%$ para aplicadores dermatológicos, as incertezas e as diferenças obtidas entre as taxas de dose absorvida são aceitáveis. 


\subsection{Dosimetria da RADIAÇÃo BETA UTILIZANDO TÉCNICAS LUMINESCENTES}

Apesar da opção principal de utilização de câmara de ionização de placas paralelas em dosimetria de feixes, uma outra alternativa pode ser necessária, uma vez que há locais onde o manuseio do conjunto câmara de ionização, cabos e eletrômetro fora do ambiente de laboratórios de metrologia não é possível. Sendo assim, uma boa opção é a realização de dosimetria de feixes de radiação beta utilizando técnicas luminescentes como termoluminescência (TL) e luminescência opticamente estimulada (LOE). Será apresentada a seguir uma aplicação destas técnicas em calibração de aplicadores clínicos e um outro estudo de detectores para dosimetria beta.

\subsubsection{Desenvolvimento de uma Metodologia na Forma Postal para Calibração de Aplicadores Clínicos}

Neste item serão apresentados os resultados obtidos ao longo do desenvolvimento de uma metodologia para calibração de aplicadores clínicos, desde o estudo para a seleção do melhor material até a formação do sistema dosimétrico e o seu envio na forma postal.

\subsubsection{Calibração de Aplicadores Clínicos $\mathrm{de}^{90} \mathrm{Sr}+{ }^{90} \mathrm{Y}$}

Levando-se em conta que um dos objetivos deste projeto consistia no desenvolvimento de um sistema dosimétrico postal para calibração de aplicadores clínicos de ${ }^{90} \mathrm{Sr}+{ }^{90} \mathrm{Y}$, foi necessário inicialmente escolher qual material dosimétrico deveria ser utilizado neste sistema. Para isso, foi realizado um estudo com seis materiais diferentes: cinco como dosímetros TL (CaSO 4 :Dy + Teflon (20 mg), $\mathrm{CaSO}_{4}: \mathrm{Dy}+$ Teflon (50 mg), LiF:Mg,Ti, $\mathrm{CaF}_{2}: \mathrm{Dy}$, e $\left.\mathrm{CaF}_{2}: \mathrm{Mn}\right)$ e um como dosímetro $\mathrm{LOE}\left(\mathrm{Al}_{2} \mathrm{O}_{3}: \mathrm{C}, \mathrm{NanoDot}\right)$. As características destes materiais são mostradas na Tabela 5.4. O procedimento de avaliação da resposta TL dos dosímetros foi realizado utilizando-se o sistema medidor de termoluminescência da Harshaw, modelo 3500 (Fig. 5.4), e no caso da resposta LOE, o sistema medidor da Landauer (Fig. 5.6.a).

Nesta etapa para a escolha do material a ser utilizado no sistema postal, curvas de dose-resposta foram obtidas para todos os materiais, utilizando o aplicador NIST como fonte de referência. No caso da resposta TL, as amostras foram irradiadas com doses absorvidas de 5 Gy a 20 Gy. Os detectores LOE foram irradiados com doses de 3 Gy a 10 Gy. As curvas 
de dose-resposta, obtidas à distância nula entre fonte e detector, podem ser observadas na Fig. 6.24. As amostras $\mathrm{TL}_{\text {de }} \mathrm{CaSO}_{4}: \mathrm{Dy}(50 \mathrm{mg}$ ) apresentaram comportamento linear em todo o intervalo de dose, bem como as amostras $\mathrm{LOE}$ de $\mathrm{Al}_{2} \mathrm{O}_{3}: \mathrm{C}$.
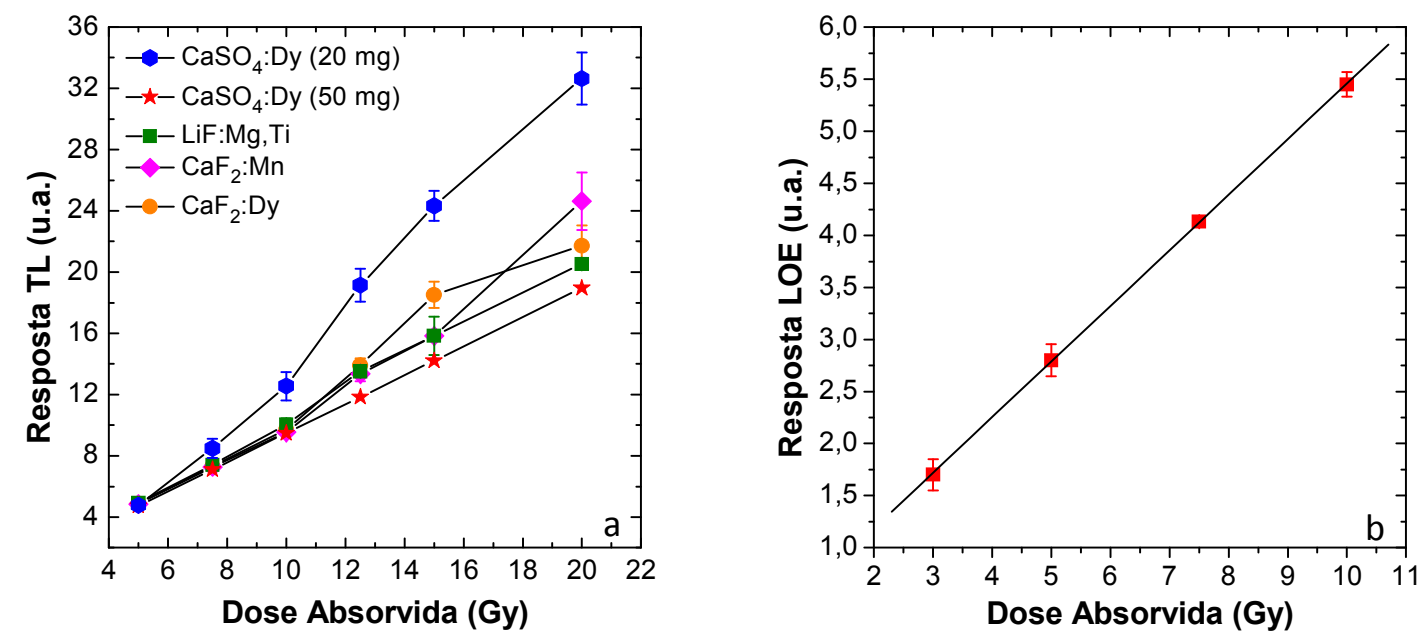

Figura 6.24 - Curvas de dose-resposta obtidas para: (a) amostras TL; e (b) detectores LOE.

Após a determinação das curvas de dose-resposta, as amostras foram irradiadas com os aplicadores clínicos A1, A2 e A3, durante 330 s (A1 e A2) e 300 s (A3). Por meio das curvas de dose-resposta, as taxas de dose absorvida para estes aplicadores foram determinadas para cada material estudado.

Este estudo foi concluído após a comparação entre as taxas de dose absorvida obtidas experimentalmente e aquelas fornecidas pelos certificados de calibração das fontes A1 e A3 (o aplicador A2 não possui certificado original). Analisando-se os resultados obtidos, pode-se observar que o material que apresentou a menor diferença entre a calibração feita neste estudo e a realizada pelo fabricante foi o $\mathrm{LiF}: \mathrm{Mg}, \mathrm{Ti}$, apresentando $10 \%$ de diferença para o aplicador $\mathrm{A} 1$ e $-4 \%$ para o $\mathrm{A} 3$. Os dois segundos melhores materiais foram $\mathrm{CaF}_{2}: \mathrm{Mn}$ e $\mathrm{CaSO}_{4}$ :Dy $(20 \mathrm{mg})$, com diferenças de $-4 \%$ e $-16 \%$, e $-16 \%$ e $-13 \%$, para os aplicadores $\mathrm{A} 1$ e A3, respectivamente.

Levando-se em conta que para dosimetria beta o ideal é que o dosímetro tenha a característica de ser fino, uma vez que a radiação beta tem baixo poder de penetração, o material escolhido para ser utilizado no sistema dosimétrico postal foi o $\mathrm{CaSO}_{4}: \mathrm{Dy}(20 \mathrm{mg})$, que ainda possui a vantagem de ser produzido no IPEN. 


\subsubsection{Formação de um Sistema Dosimétrico TL Postal com CaSO $\mathrm{CH}_{4}$}

Utilizando-se amostras de $\mathrm{CaSO}_{4}: \mathrm{Dy}(20 \mathrm{mg})$, foi desenvolvido um sistema dosimétrico TL para calibração de aplicadores clínicos de ${ }^{90} \mathrm{Sr}+{ }^{90} \mathrm{Y}$. Inicialmente, este sistema foi testado em cinco hospitais de São Paulo, a fim de se verificar a sua viabilidade e a eficácia na calibração das fontes, e a compreensão do procedimento de irradiação por parte dos operadores das fontes.

O conjunto dosimétrico é composto, além de 16 amostras TL, por: cronômetro, luvas, suporte de alumínio para armazenamento dos dosímetros antes e após as irradiações, suporte de polimetilmetacrilato (PMMA) para fixar as amostras durante a irradiação, pinça, formulário para ser preenchido com informações sobre a fonte, e um procedimento de irradiação. A Fig. 6.25 mostra o sistema dosimétrico TL desenvolvido e seus principais itens.

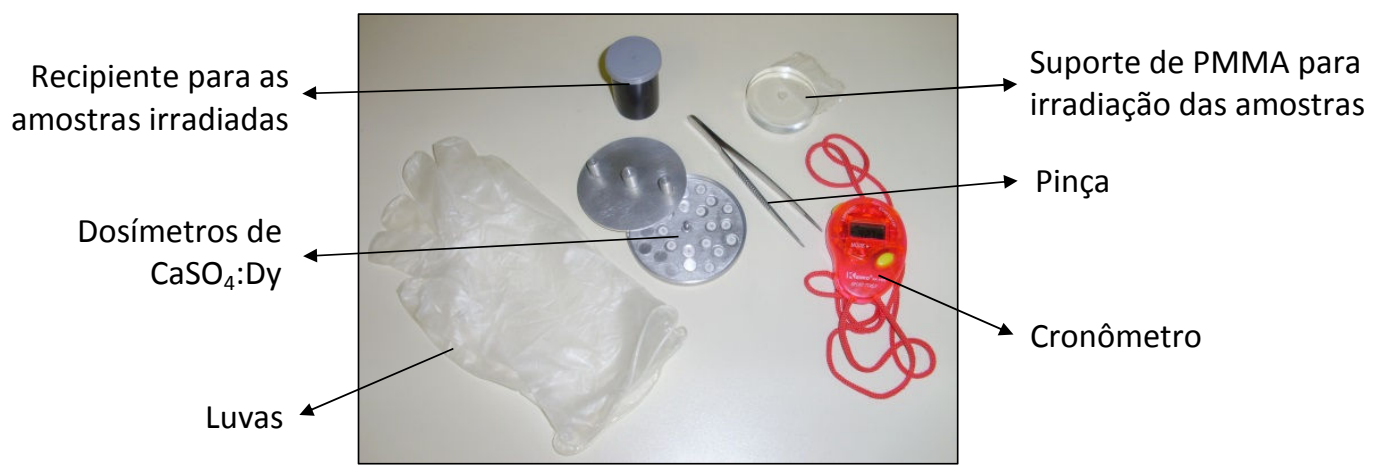

Figura 6.25 - Sistema dosimétrico postal TL com dosímetros de $\mathrm{CaSO}_{4}$ :Dy.

Durante o procedimento de irradiação, cada pastilha foi posicionada no suporte de PMMA e irradiada à distância nula entre fonte-detector; entre cada dosímetro e a fonte, foi utilizado um filme plástico de densidade superficial de $1,095 \mathrm{mg} / \mathrm{cm}^{2}$, a fim de evitar uma possível contaminação da amostra. Os dosímetros foram irradiados em intervalos de tempo de $180 \mathrm{~s}$ a $360 \mathrm{~s}$, dependendo da atividade de cada fonte, em cada hospital, sendo que duas amostras do conjunto não foram irradiadas, para servirem de amostras de controle.

Foram calibrados 14 aplicadores clínicos de ${ }^{90} \mathrm{Sr}+{ }^{90} \mathrm{Y}$ de cinco departamentos de radioterapia de hospitais, cujas características são mostradas na Tabela 5.7. A resposta TL das amostras irradiadas com estes aplicadores foi analisada no LCI logo após a chegada das amostras ao IPEN, sempre no mesmo dia das irradiações. Após a análise da resposta TL, foi emitido um certificado de calibração para cada fonte. Para a calibração dos aplicadores 
clínicos, foi utilizada a curva de dose-resposta demonstrada no item anterior para as amostras de $\mathrm{CaSO}_{4}: \mathrm{Dy}(20 \mathrm{mg}$ ), quando foram irradiadas utilizando o aplicador NIST como sistema padrão.

A Tabela 6.54 mostra as taxas de dose absorvidas obtidas para os aplicadores dos hospitais visitados. O desvio padrão máximo em todas as medidas foi 8\% (aplicador 9). Comparando-se os valores obtidos experimentalmente com os fornecidos nos certificados das fontes, pode-se observar que a diferença máxima foi de $-36 \%$ (provavelmente devido a uma considerável falta de uniformidade na superfície do aplicador no qual é depositado o material radioativo) para o aplicador 6 , e as mínimas foram -8\% e $8 \%$ para os aplicadores 4 e 9, respectivamente. Levando-se em conta que a incerteza expandida para o aplicador NIST é $12 \%$, e as incertezas dos certificados de calibração do fabricante são de $20 \%$ para os aplicadores dermatológicos e de $30 \%$ para os oftálmicos, as diferenças e as incertezas obtidas neste trabalho podem ser consideradas satisfatórias. Além disso, os resultados estão de acordo com os obtidos por Soares (1995), que comparou a calibração feita pelo NIST com a realizada pela Amersham, e obteve diferenças entre $-12 \%$ e $-27 \%$.

Tabela 6.54- Taxas de dose absorvida obtidas para aplicadores clínicos de cinco hospitais de São Paulo.

\begin{tabular}{ccccc}
\hline \multirow{2}{*}{$\begin{array}{c}\text { Aplicador } \\
\text { Clínico }\end{array}$} & Fonte & \multicolumn{2}{c}{ Taxa de Dose Absorvida (Gy/s) } & Diferença \\
\cline { 3 - 4 } & & Certificado & Este Trabalho & (\%) \\
\hline $\mathbf{1}$ & Dermatológico & $0,0279 \pm 0,0056$ & $0,0359 \pm 0,0072$ & -22 \\
\hline $\mathbf{2}$ & Oftálmico & $0,0256 \pm 0,0077$ & $0,0335 \pm 0,0101$ & -23 \\
\hline $\mathbf{3}$ & Dermatológico & $0,0207 \pm 0,0041$ & $0,0227 \pm 0,0045$ & -9 \\
\hline $\mathbf{4}$ & Dermatológico & $0,0207 \pm 0,0041$ & $0,0225 \pm 0,0045$ & -8 \\
\hline $\mathbf{5}$ & Oftálmico & $0,0207 \pm 0,0062$ & $0,0255 \pm 0,0076$ & -19 \\
\hline $\mathbf{6}$ & Dermatológico & $0,0412 \pm 0,0082$ & $0,0648 \pm 0,0130$ & -36 \\
\hline $\mathbf{7}$ & Dermatológico & $0,0463 \pm 0,0093$ & $0,0683 \pm 0,0137$ & -32 \\
\hline $\mathbf{8}$ & Oftálmico & $0,0430 \pm 0,0127$ & $0,0649 \pm 0,0195$ & -34 \\
\hline $\mathbf{9}$ & Oftálmico & $0,0155 \pm 0,0046$ & $0,0143 \pm 0,0043$ & 8 \\
\hline $\mathbf{1 0}$ & Dermatológico & $0,0119 \pm 0,0024$ & $0,0170 \pm 0,0034$ & -30 \\
\hline $\mathbf{1 1}$ & Oftálmico & $0,0306 \pm 0,0092$ & $0,0403 \pm 0,0121$ & -24 \\
\hline $\mathbf{1 2}$ & Dermatológico & $0,0325 \pm 0,0065$ & $0,0445 \pm 0,0089$ & -27 \\
\hline $\mathbf{1 3}$ & Oftálmico & $0,0140 \pm 0,0042$ & $0,0129 \pm 0,0034$ & 8 \\
\hline $\mathbf{1 4}$ & Oftálmico & $0,0313 \pm 0,0094$ & $0,0401 \pm 0,0120$ & -22 \\
\hline
\end{tabular}


Considerando os resultados obtidos e a possibilidade de uso do sistema dosimétrico, ele foi enviado (via postal) ao Departamento de Física da Universidade Federal de Sergipe (UFS), para a calibração (pelos operadores) de três aplicadores clínicos de ${ }^{90} \mathrm{Sr}+{ }^{90} \mathrm{Y}$ da Amersham International, Inglaterra, com certificados de calibração do The Radiochemical Centre, Amersham: um dermatológico (2A) e dois oftálmicos (4A e 5A); estes três aplicadores foram descritos na Tabela 5.8. Os dosímetros $\mathrm{TL}$ de $\mathrm{CaSO}_{4}$ :Dy $(20 \mathrm{mg})$ foram irradiados pelo operador seguindo o procedimento de irradiação (enviado junto ao sistema). Após as irradiações, o sistema foi devolvido ao IPEN pelo correio e as amostras foram avaliadas no $\mathrm{LCl}$.

Os aplicadores clínicos foram calibrados utilizando-se a mesma curva de dose-resposta do aplicador NIST demonstrada na Fig. 6.24 (para $\mathrm{CaSO}_{4}$ :Dy fino). O tempo de irradiação das amostras para cada aplicador foi: $10 \mathrm{~min}(1 \mathrm{~A}), 6 \mathrm{~min}(2 \mathrm{~A})$ e $8 \mathrm{~min}(3 \mathrm{~A})$. A Tabela 6.55 apresenta as características destas fontes e os resultados obtidos neste estudo.

Tabela 6.55 - Características dos aplicadores clínicos da UFS e taxas de dose absorvida obtidas neste trabalho.

\begin{tabular}{|c|c|c|c|c|c|}
\hline \multirow[b]{2}{*}{$\begin{array}{l}\text { Aplicador } \\
\text { Clínico }\end{array}$} & \multicolumn{2}{|c|}{ Informações Originais } & \multicolumn{2}{|c|}{ Taxa de Dose Absorvida (Gy/s) } & \multirow[b]{2}{*}{$\begin{array}{c}\text { Diferença } \\
(\%) \\
\end{array}$} \\
\hline & $\begin{array}{c}\text { Taxa de Dose } \\
\text { Absorvida } \\
\text { (Gy/s) }\end{array}$ & $\begin{array}{l}\text { Data de } \\
\text { Calibração }\end{array}$ & Certificado & Este Trabalho & \\
\hline $2 \mathrm{~A}$ & $0,018 \pm 0,004$ & 27.11.1973 & $0,0070 \pm 0,0014$ & $0,0076 \pm 0,0015$ & $-7,9$ \\
\hline $4 \mathrm{~A}$ & $0,022 \pm 0,017$ & 27.11.1973 & $0,0087 \pm 0,0026$ & $0,0189 \pm 0,0059$ & $-54,0$ \\
\hline $5 A$ & $0,027 \pm 0,008$ & 14.01.1992 & $0,0167 \pm 0,0050$ & $0,0227 \pm 0,0076$ & $-26,4$ \\
\hline
\end{tabular}

Pode-se concluir que a diferença mínima entre as calibrações realizadas pelo fabricante e no LCl (por meio do sistema postal) foi obtida para o aplicador dermatológico, enquanto que para os aplicadores oftálmicos, estas diferenças foram maiores (máxima de $-54,0 \%$ ). Embora a diferença de $-26,4 \%$ seja aceitável do ponto de vista de outros estudos (SOARES, 1995), a de $-54,0 \%$ foi considerada alta demais, e isso pode ter ocorrido devido a alguns fatores como: pequenos erros durante o procedimento de irradiação, o posicionamento da fonte sobre o detector, e a disposição do material na superfície da fonte, o qual pode não ser homogêneo. 


\subsubsection{Formação de um Sistema Dosimétrico $T L / L O E$ Postal com $\mathrm{Al}_{2} \mathrm{O}_{3}: \mathrm{C}$}

Após se verificar a possibilidade de uso do sistema dosimétrico postal, desejou-se aprimorar este sistema já existente incluindo a técnica LOE, como uma nova proposta para a calibração de aplicadores clínicos de ${ }^{90} \mathrm{Sr}+{ }^{90} \mathrm{Y}$. Para isso, decidiu-se utilizar amostras de $\mathrm{Al}_{2} \mathrm{O}_{3}: \mathrm{C}$, Rexon, como dosímetros num novo sistema dosimétrico. A escolha de detectores de $\mathrm{Al}_{2} \mathrm{O}_{3}: \mathrm{C}$ foi feita baseada no fato dele ser um material já bem estudado tanto pela técnica TL como pela técnica LOE; assim, um sistema dosimétrico poderia ser elaborado com um material que responderia às duas técnicas luminescentes desejadas.

Inicialmente, os dosímetros de $\mathrm{Al}_{2} \mathrm{O}_{3}: \mathrm{C}$ foram caracterizados com relação às suas respostas TL e LOE; estes testes de caracterização foram realizados com 40 dosímetros (20 TL e 20 LOE).

O primeiro estudo foi a reprodutibilidade das respostas TL e LOE das amostras. Para tal, os detectores foram irradiados com uma dose absorvida de $100 \mathrm{mGy}$, com a fonte de ${ }^{90} \mathrm{Sr}+{ }^{90} \mathrm{Y}$ do sistema BSS1 (1850 MBq, 1981), a uma distância fonte-detector de $11 \mathrm{~cm}$. Este procedimento foi seguido para ambas as técnicas luminescentes cinco vezes (cinco ciclos) de irradiação, análise da resposta (leitura) e tratamento térmico para reutilização $\left(400^{\circ} \mathrm{C}\right.$ durante $1 \mathrm{~h}$ ). A avaliação da resposta TL das amostras foi feita utilizando-se o sistema medidor de TL da Harshaw, modelo 3500 (Fig. 5.4), enquanto que a análise da resposta LOE foi obtida por meio do sistema medidor de LOE DOIN-L001, da UFPE (Fig. 5.6.b).

Para a resposta $\mathrm{TL}$ dos detectores de $\mathrm{Al}_{2} \mathrm{O}_{3}: \mathrm{C}$, a reprodutibilidade foi de $3,6 \%$, e 0 desvio padrão máximo das medições foi de $5,1 \%$. No caso da resposta $L O E$, os detectores apresentaram uma reprodutibilidade de resposta de 4,3\%, com um desvio padrão máximo nas medições de 6,5\%.

Os resultados obtidos neste teste demonstraram o bom desempenho dos detectores em feixes de radiação beta e a boa reprodutibilidade de resposta TL e LOE do material.

O segundo teste de caracterização realizado foi o da determinação da dose mínima detectável (ou limite inferior de deteç̧ão), que foi determinado estudando-se a variação entre as leituras TL e LOE de detectores não irradiados. Como esta dose mínima é uma propriedade dosimétrica do material, a sua determinação é importante para se caracterizar as amostras. $\mathrm{O}$ resultado obtido para os detectores de $\mathrm{Al}_{2} \mathrm{O}_{3}: \mathrm{C}$ foi $0,20 \mathrm{mGy}$ para os dosímetros TL, e 2,85 mGy para os dosímetros LOE. 
Considerando que estas amostras serão utilizadas para dosimetria da radiação beta de aplicadores clínicos de ${ }^{90} \mathrm{Sr}+{ }^{90} \mathrm{Y}$, e que neste caso as doses não são consideradas baixas (de 1 Gy a 15 Gy), a dose mínima detectável obtida pode ser considerada aceitável.

A dependência da resposta TL e LOE dos detectores de $\mathrm{Al}_{2} \mathrm{O}_{3}: \mathrm{C}$ com a energia da fonte foi outro estudo realizado. Os detectores foram irradiados com duas fontes de radiação beta do sistema BSS2, de acordo com as condições especificadas na Tabela 6.56. O desvio padrão máximo obtido nas medições TL foi de 8,6\% $\left({ }^{85} \mathrm{Kr}\right)$, e nas medições LOE foi de $7,8 \%\left({ }^{85} \mathrm{Kr}\right)$.

Tabela 6.56 - Condições de irradiação (sistema BSS2) e resultados obtidos no estudo de dependência energética dos detectores de $\mathrm{Al}_{2} \mathrm{O}_{3}: \mathrm{C}$.

\begin{tabular}{|c|c|c|c|c|c|c|}
\hline \multirow{2}{*}{$\begin{array}{c}\text { Fonte } \\
\text { de } \\
\text { Radiação }\end{array}$} & \multirow{2}{*}{$\begin{array}{c}\text { Filtro } \\
\text { Uniformizador } \\
\text { de Campo }\end{array}$} & \multirow{2}{*}{$\begin{array}{c}\text { Dose } \\
\text { Absorvida } \\
\text { (mGy) }\end{array}$} & \multirow{2}{*}{$\begin{array}{l}\text { Distância } \\
\text { Fonte- } \\
\text { Detector } \\
\text { (cm) } \\
\end{array}$} & \multirow{2}{*}{$\begin{array}{l}\text { Energia } \\
\text { Beta } \\
\text { Média } \\
\text { (MeV) } \\
\end{array}$} & \multicolumn{2}{|c|}{$\begin{array}{c}\text { Resposta Normalizada em Relação } \\
\text { à Fonte de }{ }^{90} \mathrm{Sr}+{ }^{90} \mathrm{Y}\end{array}$} \\
\hline & & & & & $\mathrm{TL}$ & LOE \\
\hline${ }^{90} \mathrm{Sr}+{ }^{90} \mathrm{Y}$ & Não & 10 & 30 & 0,80 & $1,0000 \pm 0,0005$ & $1,0000 \pm 0,0001$ \\
\hline${ }^{85} \mathrm{Kr}$ & Sim & 10 & 30 & 0,14 & $0,3360 \pm 0,0002$ & $0,8608 \pm 0,0002$ \\
\hline
\end{tabular}

Os resultados obtidos mostraram a dependência energética alta de ambas as respostas TL e LOE em feixes de radiação beta.

Foram estudadas, também, as respostas TL e LOE dos detectores em função da dose absorvida; essas curvas de dose-resposta foram obtidas nas mesmas condições para as duas técnicas luminescentes. Os dosímetros de $\mathrm{Al}_{2} \mathrm{O}_{3}: \mathrm{C}$ foram irradiados num intervalo de dose de $1 \mathrm{~Gy}$ a $15 \mathrm{~Gy}$, em passos de $1 \mathrm{~Gy}$ (de $1 \mathrm{~Gy}$ a $5 \mathrm{~Gy}$ ), e em passos de 2,5 Gy (de 5 Gy a $15 \mathrm{~Gy}$ ). Para o procedimento de irradiação, os dosímetros foram expostos ao aplicador NIST $\left({ }^{90} \mathrm{Sr}+{ }^{90} \mathrm{Y}\right)$, à distância fonte-detector de $11 \mathrm{~cm}$. No caso da resposta TL, o desvio parão máximo obtido em todas as medições (para todos os detectores e as nove doses absorvida) foi de $8,3 \%$ (nas medições para a dose de $10 \mathrm{~Gy}$ ), enquanto que para a resposta $\mathrm{LOE}$, o desvio padrão máximo obtido foi de 7,0\% (também para a dose de $10 \mathrm{~Gy}$ ). As curvas de dose-resposta obtidas podem ser observadas na Fig. 6.26. 

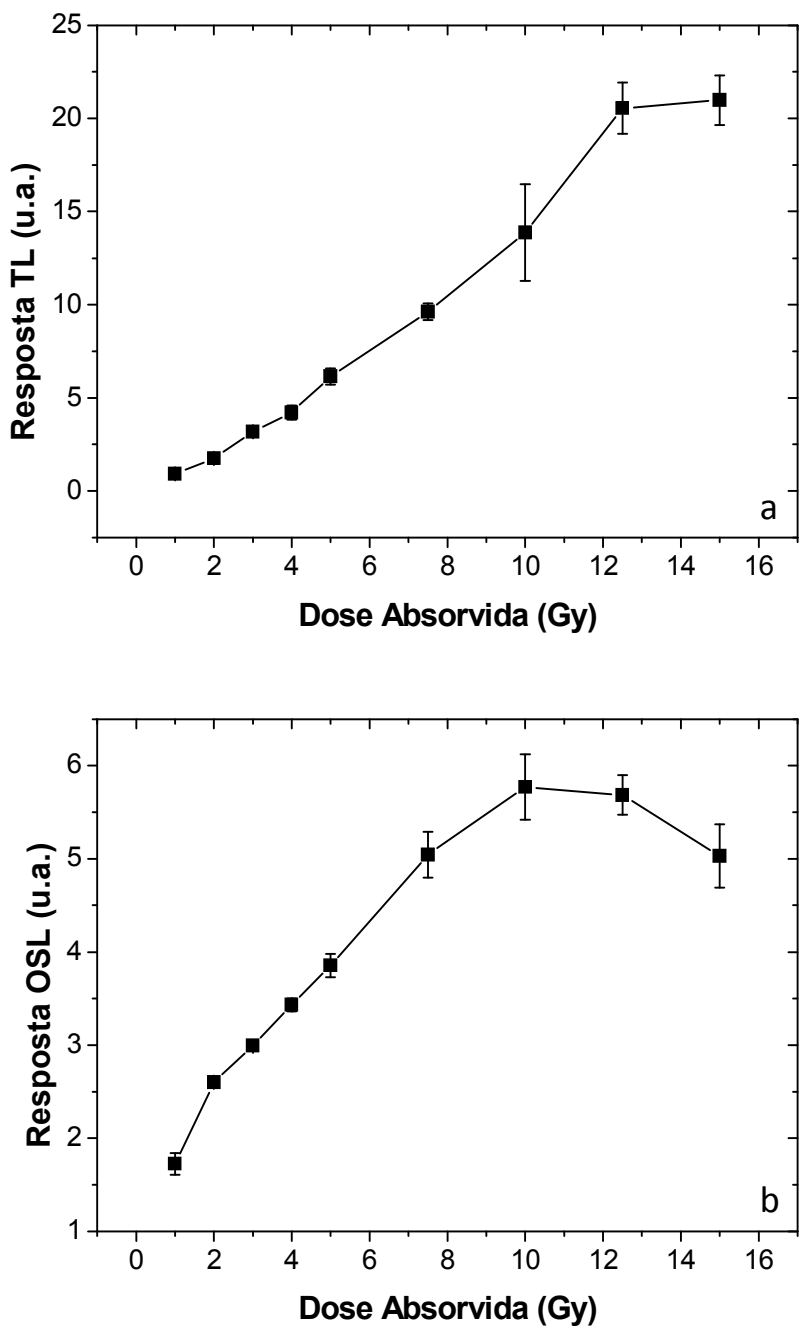

Figura 6.26 - Curvas de dose-resposta dos detectores de $\mathrm{Al}_{2} \mathrm{O}_{3}: \mathrm{C}$, expostos à fonte de ${ }^{90} \mathrm{Sr}+{ }^{90} \mathrm{Y}$ (1850 MBq, 1981): (a) TL; e (b) LOE.

A curva de dose-resposta obtida para os dosímetros TL foi similar à apresentada por Chitambo (CHITAMBO, 2004) no intervalo de dose estudado neste trabalho (de 1 Gy a $15 \mathrm{~Gy})$; ele estudou o mesmo detector e o irradiou com a mesma fonte $\left({ }^{90} \mathrm{Sr}+{ }^{90} \mathrm{Y}\right)$, em um intervalo de dose de $1 \mathrm{~Gy}$ a $50 \mathrm{~Gy}$.

Com relação aos resultados para os dosímetros LOE, a curva de dose-resposta apresentou linearidade de 2 Gy a 7,5 Gy, considerando as incertezas. Pinto e colaboradores (2008) usaram amostras de outro fabricante (detectores Dot, Landauer), mas também de $\mathrm{Al}_{2} \mathrm{O}_{3}: \mathrm{C}$, os quais foram irradiados com ${ }^{90} \mathrm{Sr}+{ }^{90} \mathrm{Y}$, em um intervalo de dose de $0,1 \mathrm{mGy}$ a 10 mGy. Os resultados obtidos por Pinto e colaboradores (2008) apresentaram linearidade no intervalo total de dose estudado. 
Após o processo de caracterização da resposta TL e LOE, por meio dos testes descritos anteriormente (reprodutibilidade, dose mínima detectável, dependência energética e curvas de dose-resposta), com os quais se verificou a viabilidade do uso de amostras de $\mathrm{Al}_{2} \mathrm{O}_{3}: \mathrm{C}$ na calibração de aplicadores clínicos de ${ }^{90} \mathrm{Sr}+{ }^{90} \mathrm{Y}$, utilizando-se duas técnicas luminescentes, um novo sistema dosimétrico postal pôde ser desenvolvido.

O sistema dosimétrico postal, apresentado no item 6.3.1.2, utilizando dosímetros TL de $\mathrm{CaSO}_{4}$ :Dy pôde ser aprimorado e agora as amostras foram substituídas por $\mathrm{Al}_{2} \mathrm{O}_{3}: \mathrm{C}$, e a calibração pode ser feita utilizando-se mais uma técnica, a LOE.

Um procedimento de irradiação dos detectores TL e LOE foi elaborado passo a passo, enfatizando fatores importantes, como as recomendações sobre a proteção dos operadores dos aplicadores clínicos, e os passos da calibração destas fontes, incluindo o cálculo do tempo de irradiação dos detectores. Um formulário de coleta de dados também foi desenvolvido para ser preenchido pelo responsável pelas fontes, com informações relacionadas a cada aplicador (e para o preenchimento dos certificados de calibração de cada fonte a ser emitido pelo IPEN). Além disso, uma folha de conferência de itens do sistema dosimétrico também foi enviada. Estes três documentos, juntamento com os componentes do sistema dosimétrico postal TL e LOE, foram organizados numa caixa organizadora de plástico, e podem ser observados na Fig. 6.27.

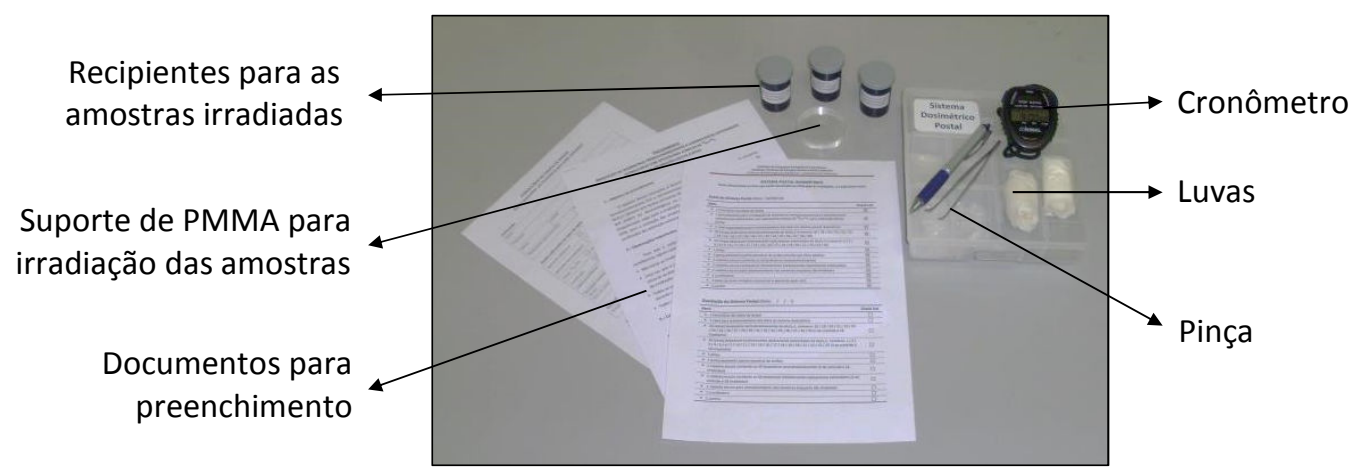

Figura 6.27 - Sistema dosimétrico postal TL/LOE, utilizando-se dosímetros de $\mathrm{Al}_{2} \mathrm{O}_{3}: \mathrm{C}$.

Após o desenvolvimento do sistema dosimétrico postal, ele foi enviado ao Departamento de Física da Universidade Federal de Sergipe, onde foi feita a irradiação dos detectores TL e LOE de $\mathrm{Al}_{2} \mathrm{O}_{3}: \mathrm{C}$, com cinco aplicadores clínicos de ${ }^{90} \mathrm{Sr}+{ }^{90} \mathrm{Y}$ (descritos na Tabela 5.8), em intervalos de tempos diferentes, de $3 \mathrm{~min}$ a $9 \mathrm{~min}$, dependendo da atividade 
da fonte. Durante as irradiações, uma distância nula entre a fonte e o detector foi utilizada. Das 20 amostras TL, 15 foram irradiadas (três com cada fonte) e cinco foram mantidas como dosímetros de controle; no caso dos detectores LOE, foi adotado o mesmo procedimento.

Logo após as irradiações, o sistema dosimétrico postal retornou ao IPEN, onde as respostas TL e LOE foram avaliadas, uma nova taxa de dose absorvida foi determinada para cada aplicador clínico de ${ }^{90} \mathrm{Sr}+{ }^{90} \mathrm{Y}$ (utilizando as curvas de dose-resposta TL e LOE obtidas com o aplicador NIST), e os certificados de calibração foram emitidos. As taxas de dose absorvida obtidas podem ser observadas na Tabela 6.57. Em todas as medições TL, o desvio padrão máximo obtido foi 7,9\% (aplicador 4), e nas medições LOE foi 5,7\% (aplicador 4).

Tabela 6.57 - Taxas de dose absorvida obtidas para os aplicadores clínicos de ${ }^{90} \mathrm{Sr}+{ }^{90} \mathrm{Y}$, utilizando o sistema dosimétrico postal TL/LOE.

\begin{tabular}{|c|c|c|c|c|c|c|c|}
\hline \multirow[b]{2}{*}{ Fonte } & \multirow{2}{*}{$\begin{array}{c}\text { Tempo } \\
\text { de } \\
\text { Irradiação } \\
\text { (min) }\end{array}$} & \multicolumn{3}{|c|}{ Taxa de Dose Absorvida (mGy/s) } & \multirow{2}{*}{$\begin{array}{c}\text { Diferença } \\
\text { entre } \\
\text { A e B } \\
(\%) \\
\end{array}$} & \multirow{2}{*}{$\begin{array}{c}\text { Diferença entre } \\
\text { Certificado e } \\
\text { Valor TL (A) } \\
(\%)\end{array}$} & \multirow{2}{*}{$\begin{array}{c}\text { Diferença entre } \\
\text { Certificado e } \\
\text { Valor LOE (B) } \\
(\%)\end{array}$} \\
\hline & & Certificado & $\begin{array}{c}\text { Este Trabalho } \\
\text { (A) } \\
\text { (Técnica TL) }\end{array}$ & $\begin{array}{l}\text { Este Trabalho } \\
\text { (B) } \\
\text { (Técnica LOE) }\end{array}$ & & & \\
\hline $1 \mathrm{~A}$ & 9 & $5,61 \pm 1,12$ & $7,47 \pm 1,50$ & $7,51 \pm 1,51$ & 0,5 & 33,2 & 33,9 \\
\hline $2 \mathrm{~A}$ & 8 & $16,89 \pm 3,38$ & $13,53 \pm 2,89$ & $9,99 \pm 2,07$ & $-26,2$ & $-19,9$ & $-40,8$ \\
\hline $3 A$ & 6 & $8,91 \pm 2,67$ & $6,98 \pm 2,16$ & $5,27 \pm 1,58$ & $-24,5$ & $-21,7$ & $-40,8$ \\
\hline $4 \mathrm{~A}$ & 6 & $21,12 \pm 6,34$ & $13,64 \pm 4,34$ & $15,59 \pm 4,76$ & 14,3 & $-35,6$ & $-26,2$ \\
\hline $5 A$ & 3 & $26,01 \pm 7,80$ & $23,90 \pm 7,17$ & $27,74 \pm 8,34$ & 16,1 & $-8,1$ & $-6,6$ \\
\hline
\end{tabular}

As taxas de dose absorvida obtidas neste trabalho foram comparadas àquelas descritas pelos certificados de calibração originais dos aplicadores clínicos. Além disso, uma comparação foi feita para as técnicas TL e LOE.

Devido ao fato dos aplicadores clínicos precisarem ser limpos após o seu uso (para eliminar riscos de doenças por contaminação), sabe-se que esta ação algumas vezes pode remover parte do material da fonte ou de sua capa protetora (afinando-a). Por esta razão, a superfície da fonte pode não ser homogênea, o que pode causar alteração e diferenças nas medições e, por fim, na determinação das taxas de dose absorvida.

Os resultados obtidos apresentaram diferenças em relação às taxas de dose absorvida dos certificados, as quais são aceitáveis considerando as incertezas dos certificados de calibração.

Todos os resultados da comparação, em porcentagem, podem ser considerados relativamente altos, mas este fato pode ter ocorrido por vários fatores. Estes aplicadores clínicos apresentam incertezas associadas altas às taxas de dose absorvida nos seus 
certificados de calibração originais (20\% para aplicadores dermatológicos e $30 \%$ para aplicadores oftálmicos, da Amersham). O aplicador NIST (sistema de referência) apresenta uma incerteza relativamente alta também, de $12 \%$. Como os procedimentos de irradiação não são tão simples, pequenos erros podem ocorrer durante a irradiação das amostras, como por exemplo, no tempo de irradiação ou no posicionamento da fonte sobre cada amostra.

Assim, levando-se em conta todos estes fatores, pode-se concluir que os resultados obtidos estiveram dentro do esperado, mesmo porque eles concordam com aqueles apresentados na Tabela 6.54 (de $-36 \%$ a 8\%), com as taxas de dose absorvida dos aplicadores calibrados dos hospitais, utilizando-se o sistema dsimétrico com dosímetros de $\mathrm{CaSO}_{4}$ :Dy.

As taxas de dose absorvida emitidas pelo IPEN e especificadas nos certificados de calibração (as determinadas neste trabalho pelas técnicas TL e LOE), possibilitaram determinar as que serão utilizadas pela UFS em suas atividades com o aplicador, que foram obtidas a partir dos valores médios obtidos pelas técnicas TL e LOE. Estas taxas de dose absorvida finais, uma para cada aplicador clínico, são mostradas na Tabela 6.58, e foram especificadas nos certificados de calibração que o IPEN enviou para a UFS.

Ao final deste trabalho, pode-se encontrar um procedimento geral para utilização do sistema postal, o Apêndice B. Nele, são mostrados todos os documentos envolvidos no processo de calibração de aplicadores clínicos, como o procedimento de irradiação dos detectores TL e LOE (Apêndice B.1), o formulário de coleta de dados (Apêndice B.2), e a folha de conferência de itens do sistema (Apêndice B.3). Além disso, um modelo do certificado de calibração emitido pelo IPEN pode ser observado no Apêndice B.4.

Tabela 6.58 - Taxas de dose absorvida finais obtidas para os aplicadores clínicos de ${ }^{90} \mathrm{Sr}+{ }^{90} \mathrm{Y}$, utilizando o sistema dosimétrico postal TL/LOE.

\begin{tabular}{cc}
\hline Fonte & $\begin{array}{c}\text { Taxa de Dose Absorvida } \\
\text { (mGy/s) }\end{array}$ \\
\hline $1 \mathrm{~A}$ & $7,49 \pm 2,13$ \\
\hline $2 \mathrm{~A}$ & $11,76 \pm 3,55$ \\
\hline $3 \mathrm{~A}$ & $6,12 \pm 2,68$ \\
\hline $4 \mathrm{~A}$ & $14,62 \pm 6,44$ \\
\hline $5 \mathrm{~A}$ & $25,82 \pm 10,99$ \\
\hline
\end{tabular}




\subsubsection{Caracterização e Comparação de Detectores de Radiação Beta em Campos Padrões}

Diferentes detectores TL (16 de $\mathrm{CaSO}_{4}: \mathrm{Dy}\left(20 \mathrm{mg}\right.$ ), e 10 de $\mathrm{Al}_{2} \mathrm{O}_{3}: \mathrm{C}$, Rexon) e LOE (38 de $\mathrm{Al}_{2} \mathrm{O}_{3}: \mathrm{C}$ NanoDot, Landauer, e 8 de $\mathrm{Al}_{2} \mathrm{O}_{3}: \mathrm{C}$, Rexon) foram caracterizados em feixes padrões secundários dos sistemas BSS1 e BSS2, para o estudo de seus comportamentos quando expostos a estes campos, e a verificação de sua utilidade em dosimetria da radiação beta. Para as medições da resposta TL das amostras de $\mathrm{CaSO}_{4}$ :Dy $(20 \mathrm{mg})$, foi utilizado o sistema leitor TL Harshaw TLD Reader, modelo 3500, para a resposta TL e LOE dos detectores de $\mathrm{Al}_{2} \mathrm{O}_{3}: \mathrm{C}$, Rexon, o sistema medidor de TL e LOE Risoe, acoplado a um sistema de controle, modelo Risoe TL/OSL-DA-200, e para as medições LOE dos detectores $\mathrm{Al}_{2} \mathrm{O}_{3}: \mathrm{C}$ NanoDot, o sistema leitor Landauer, modelo microStar.

\subsubsection{Reprodutibilidade de Resposta}

$\mathrm{O}$ estudo de reprodutibilidade da resposta foi realizado para as amostras de $\mathrm{CaSO}_{4}: \mathrm{Dy}$ (20 mg) e de $\mathrm{Al}_{2} \mathrm{O}_{3}: \mathrm{C}$, Rexon, com a técnica $\mathrm{TL}$, e de $\mathrm{Al}_{2} \mathrm{O}_{3}: \mathrm{C}$ NanoDot, Landauer, e $\mathrm{Al}_{2} \mathrm{O}_{3}: \mathrm{C}$, Rexon, com a técnica LOE. Os resultados foram obtidos após cinco séries de irradiações, medições e tratamentos para reutilização (de acordo com a Tabela 5.4). No caso das amostras de $\mathrm{CaSO}_{4}:$ Dy, elas foram irradiadas com a fonte de ${ }^{90} \mathrm{Sr}^{90}{ }^{90} \mathrm{Y}$ do sistema BSS1 (1850 MBq, 1981, sem filtro, e distância fonte-detector de $11 \mathrm{~cm}$ ), com dose absorvida de $1 \mathrm{~Gy}$; a reprodutibilidade foi de 7,1\%, e o desvio padrão máximo das medições foi 8,7\%.

As amostras de $\mathrm{Al}_{2} \mathrm{O}_{3}: \mathrm{C}$, Rexon, foram irradiadas sob as mesmas condições dos dosímetros de $\mathrm{CaSO}_{4}: \mathrm{Dy}$, com uma dose absorvida de $10 \mathrm{mGy}$; No caso das respostas TL e LOE dos detectores de $\mathrm{Al}_{2} \mathrm{O}_{3}: \mathrm{C}$, Rexon, a reprodutibilidade foi 3,2\% (desvio padrão máximo de $3,9 \%$ ) e $4,1 \%$ (desvio padrão máximo de $4,8 \%$ ), respectivamente. Para a resposta TL das amostras da Rexon, o resultado da reprodutibilidade foi compatível com o limite apresentado pelo Comitê de Avaliação dos Serviços de Monitoração Individual Externa, CASMIE (IRD/CNEN, 1995), de 7,5\% para detectores irradiados com $10 \mathrm{mGy}$.

No caso dos detectores de $\mathrm{Al}_{2} \mathrm{O}_{3}: \mathrm{C}$, Landauer, eles foram irradiados com a fonte de ${ }^{90} \mathrm{Sr}+{ }^{90} \mathrm{Y}$ do sistema BSS2 (460 MBq, 2004, com filtro, à distância fonte-detector de $30 \mathrm{~cm}$ ), com uma dose absorvida de $10 \mathrm{mGy}$. Para a resposta LOE dos detectores $\mathrm{Al}_{2} \mathrm{O}_{3}: \mathrm{C}$ NanoDot, 
Landauer, a reprodutibilidade obtida foi de 3,6\%, e o desvio padrão máximo nas medições foi de $3,1 \%$.

\subsubsection{Curvas Típicas de Emissão TL}

Foram obtidas curvas de emissão $\mathrm{TL}$ dos detectores de $\mathrm{CaSO}_{4}$ :Dy $\left(20 \mathrm{mg}\right.$ ) e de $\mathrm{Al}_{2} \mathrm{O}_{3}: \mathrm{C}$, Rexon. No caso do primeiro material, a curva de emissão foi resultado de uma irradiação com a fonte de ${ }^{90} \mathrm{Sr}^{90}{ }^{90} \mathrm{Y}$ do sistema BSS1 (1850 MBq, 1981), com uma dose absorvida de 1 Gy. Na Fig. 6.28.a, pode-se observar a curva de emissão TL do $\mathrm{CaSO}_{4}$ :Dy (20 mg), obtida num intervalo de temperatura de $120^{\circ} \mathrm{C}$ a $255^{\circ} \mathrm{C}$, e apresentando um pico dosimétrico principal em aproximadamente $220^{\circ} \mathrm{C}$, como obtido por Cecatti e Caldas (2006).
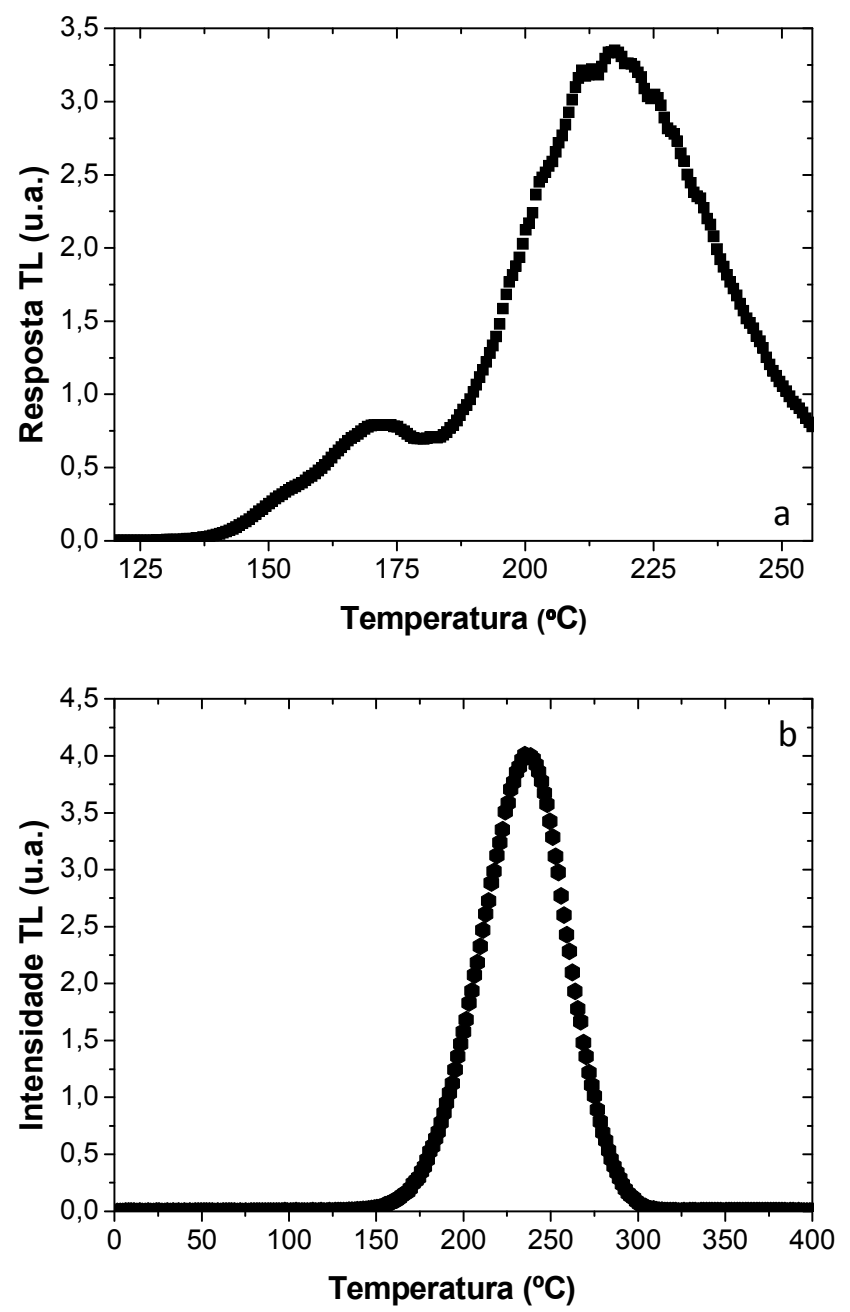

Figura 6.28 - Curvas de emissão TL para amostras irradiadas com fonte de ${ }^{90} \mathrm{Sr}+{ }^{90} \mathrm{Y}(1850 \mathrm{MBq}, 1981$, $1 \mathrm{~Gy})$ : (a) $\mathrm{CaSO}_{4}:$ Dy $(20 \mathrm{mg})$; e (b) $\mathrm{Al}_{2} \mathrm{O}_{3}: \mathrm{C}$, Rexon. 
No caso das amostras de $\mathrm{Al}_{2} \mathrm{O}_{3}: \mathrm{C}$, Rexon, a curva de emissão foi obtida após exposição dos detectores à mesma fonte de radiação beta utilizada para $\mathrm{CaSO}_{4}$ : $\mathrm{Dy}(20 \mathrm{mg})$, para a dose absorvida de 400 mGy. A Fig. 6.28.b apresenta a curva de emissão para este material com o pico em aproximadamente $235^{\circ} \mathrm{C}$, discordando da informação especificada no catálogo dos detectores (REXON, 2009), de que o pico dosimétrico aparece em $185^{\circ} \mathrm{C}$, embora eles tenham usado uma temperatura máxima de $270^{\circ} \mathrm{C}$, e neste trabalho de $400^{\circ} \mathrm{C}$; neste caso, foi utilizada a mesma taxa de aquecimento especificada no catálogo dos detectores: $10^{\circ} \mathrm{C} / \mathrm{s}$. A temperatura recomendada foi testada, mas não foi possível visualizar o pico nesta condição.

\subsubsection{Curva de Decaimento do Sinal LOE}

A curva de decaimento do sinal $L O E$ foi verificada para os detectores de $\mathrm{Al}_{2} \mathrm{O}_{3}: \mathrm{C}$, Rexon, quando expostos à radiação beta da fonte de ${ }^{90} \mathrm{Sr}+{ }^{90} \mathrm{Y}$ do sistema BSS1 (1850 MBq, 1981), com uma dose absorvida de 400 mGy, como no caso da TL. Na Fig. 6.29 pode ser observado o decaimento do sinal LOE do material estudado.

Para os detectores $\mathrm{LOE}$ de $\mathrm{Al}_{2} \mathrm{O}_{3}: \mathrm{C}$, NanoDot, Landauer, não pôde ser obtida uma curva de decaimento nas mesmas condições obtidas para as amostras da Rexon (ou seja, durante uma única leitura), pois o sistema leitor da Landauer fornece as leituras sem mostrar a curva de decaimento do sinal, como acontece no sistema leitor LOE da Risoe.

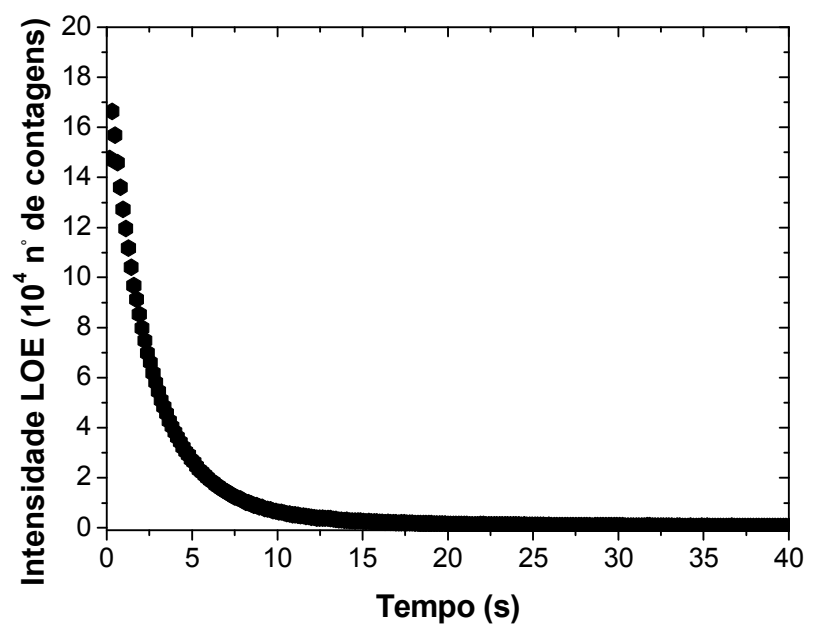

Figura 6.29 - Curva de decaimento LOE de detectores de $\mathrm{Al}_{2} \mathrm{O}_{3}: \mathrm{C}$, Rexon, irradiados com fonte de ${ }^{90} \mathrm{Sr}+{ }^{90} \mathrm{Y}(1850 \mathrm{MBq}, 1981,400 \mathrm{mGy})$. 


\subsubsection{Curvas de Dose-Resposta}

A resposta TL em função da dose absorvida foi obtida para as amostras de $\mathrm{CaSO}_{4}: \mathrm{Dy}$ (20 mg) da maneira descrita no item 6.3.1.1, irradiando-as num intervalo de dose de 5 Gy a 20 Gy, com o aplicador clínico NIST, à distância nula entre fonte-detector. Assim, a curva de dose-resposta deste material foi obtida. A Fig. 6.30.a mostra a curva de dose-resposta obtida (e esperada para este material), com comportamento linear até 10 Gy e a partir daí supralinearidade. 0 desvio padrão máximo obtido nas medições foi 7,4\%. 0 resultado obtido foi semelhante àquele observado nas medições no caso das amostras de $\mathrm{CaSO}_{4}: \mathrm{Dy}$, irradiadas também com um intervalo de dose absorvida de 5 Gy a 20 Gy (como descrito no item 6.3.1.1).

Com relação às amostras de $\mathrm{Al}_{2} \mathrm{O}_{3}: \mathrm{C}$, Rexon, elas foram irradiadas em intervalos de doses absorvidas de 0,01 mGy a 0,4 mGy com a fonte de ${ }^{90} \mathrm{Sr}+{ }^{90} \mathrm{Y}$ do sistema BSS2, sem filtro (460 MBq, 2005), e de $1 \mathrm{mGy}$ a $400 \mathrm{mGy}$ com a fonte de ${ }^{90} \mathrm{Sr}^{9}{ }^{90} \mathrm{Y}$ do sistema BSS1 (1850 MBq, 1981), à distância fonte-detector de $30 \mathrm{~cm}$. Na Fig. 6.30.b pode ser observada a curva de dose-resposta para os detectores de $\mathrm{Al}_{2} \mathrm{O}_{3}: \mathrm{C}$. O desvio padrão máximo obtido neste caso foi $6,1 \%$. Chitambo (2004) observou linearidade deste material (até aproximadamente $10 \mathrm{Gy)}$ quando irradiado com o mesmo material, porém em doses mais altas. Akselrod e col. (1996), embora tenham usado outro material comercial de $\mathrm{Al}_{2} \mathrm{O}_{3}: \mathrm{C}$, observaram linearidade da resposta TL de $1 \mathrm{mGy}$ a $400 \mathrm{mGy}$, como no caso deste trabalho.
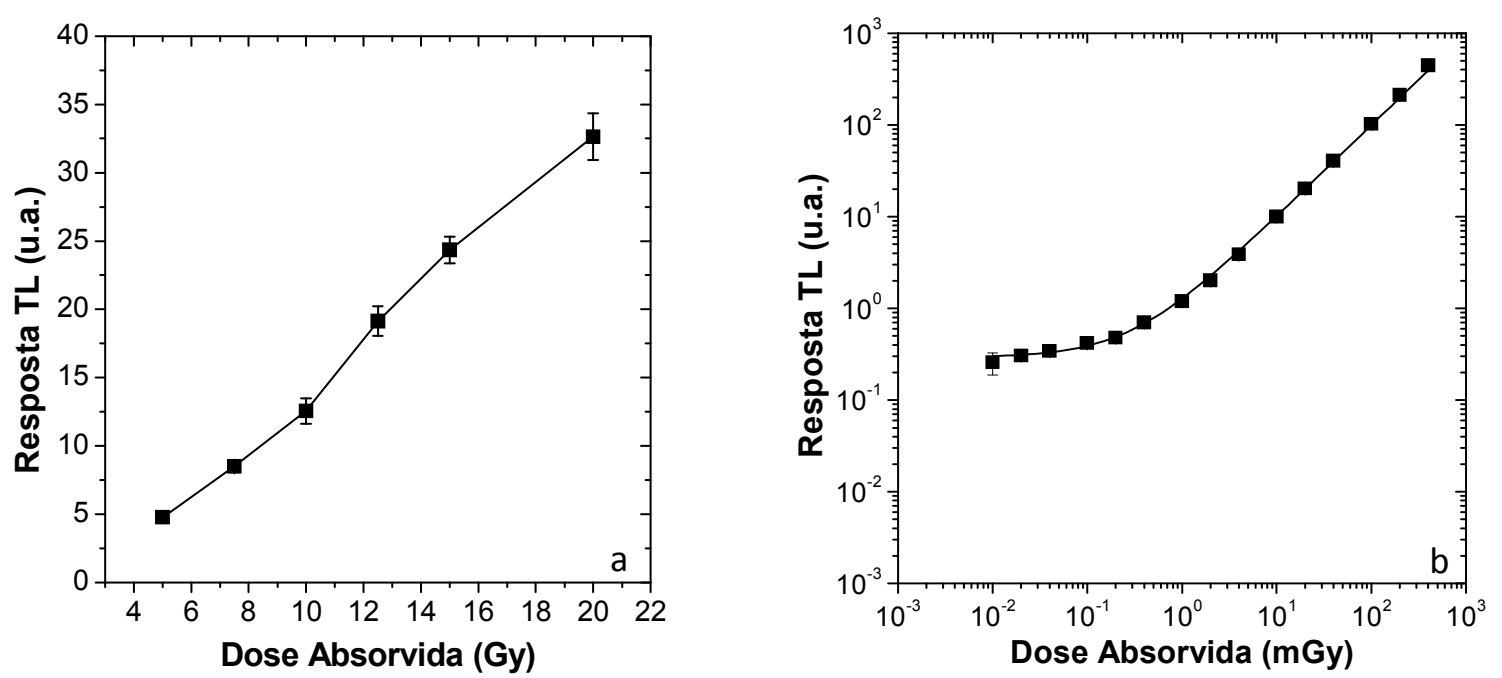

Figura 6.30 - Curvas de dose-resposta obtidas para os detectores TL: (a) $\mathrm{CaSO}_{4}: \mathrm{Dy}$ (20 mg); e (b) $\mathrm{Al}_{2} \mathrm{O}_{3}: \mathrm{C}$, Rexon. 
Um estudo da resposta LOE em função da dose absorvida foi realizado para os dois tipos de detectores comerciais de $\mathrm{Al}_{2} \mathrm{O}_{3}: \mathrm{C}$ : Rexon e Landauer.

A curva de dose-resposta para os detectores de $\mathrm{Al}_{2} \mathrm{O}_{3}: \mathrm{C}$, Rexon, foi obtida seguindo-se as mesmas condições adotadas para este estudo no caso da resposta TL do mesmo material. A Fig. 6.31.a mostra o resultado obtido; neste caso, em todas as medições o desvio padrão máximo foi $7,1 \%$.

No caso dos detectores comerciais da Landauer, eles foram expostos à fonte de ${ }^{90} \mathrm{Sr}+{ }^{90} \mathrm{Y}$ do sistema BSS1 (1850 MBq, 1981) e irradiados num intervalo de dose absorvida de $1 \mathrm{mGy}$ a $1 \mathrm{~Gy}$, à distância fonte-detector de $11 \mathrm{~cm}$. O comportamento destes detectores no estudo de sua linearidade foi semelhante ao obtido por Pinto e colaboradores (2011), embora este estudo anterior tenha sido num intervalo de dose maior (de 0,5 mGy a 2,0 Gy). A Fig. 6.31.b apresenta a curva de dose-resposta obtida para os detectores de $\mathrm{Al}_{2} \mathrm{O}_{3}: \mathrm{C}$, NanoDot, Landauer. Em todas as medições com este material, o desvio padrão máximo obtido foi $6,9 \%$.
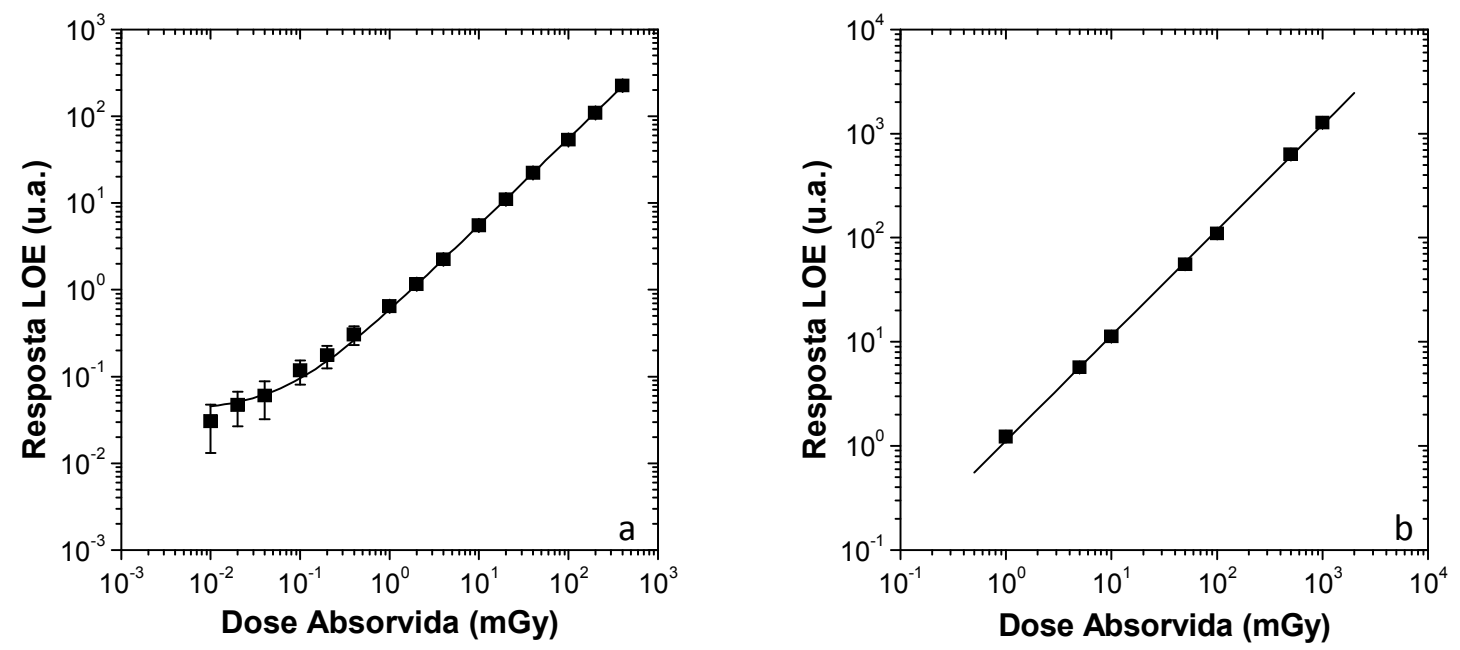

Figura 6.31-Curvas de dose-resposta obtidas para os detectores LOE de $\mathrm{Al}_{2} \mathrm{O}_{3}: \mathrm{C}$ : (a) Rexon; e (b) NanoDot, Landauer.

\subsubsection{Dose Mínima Detectável}

A dose mínima detectável foi obtida com relação à resposta TL para amostras de $\mathrm{CaSO}_{4}$ :Dy $(20 \mathrm{mg})$, e com relação às respostas $\mathrm{TL}$ e $\mathrm{LOE}$ dos dosímetros de $\mathrm{Al}_{2} \mathrm{O}_{3}: \mathrm{C}$, Rexon.

No caso das amostras de $\mathrm{CaSO}_{4}: \mathrm{Dy}$, a dose mínima detectável foi determinada por meio do estudo da variabilidade da resposta TL das amostras quando não irradiadas. O limite 
foi $56 \mu \mathrm{Gy}$, apresentando a mesma ordem de magnitude dos resultados obtidos por Campos e Lima (1987).

No caso dos detectores de $\mathrm{Al}_{2} \mathrm{O}_{3}: \mathrm{C}$, Rexon, foi utilizado o método gráfico de obtenção da dose mínima detectável. Para tal, os detectores foram irradiados com a fonte de ${ }^{90} \mathrm{Sr}+{ }^{90} \mathrm{Y}$ do sistema BSS2, sem utilização de filtro (460 MBq, 2005), a uma distância fonte-detector de $30 \mathrm{~cm}$. Neste caso, os detectores foram irradiados a doses muito baixas (intervalo de $0,1 \mathrm{mGy}$ a 4,0 mGy), até a resposta à dose absorvida indicar o início de resposta constante. Para a dose mínima detectável das amostras Rexon, agora com relação à resposta LOE, o procedimento foi o mesmo que para o sinal TL. Na Fig. 6.32.a-b podem ser observadas as doses mínimas detectáveis obtidas para as respostas TL e LOE das amostras da Rexon.
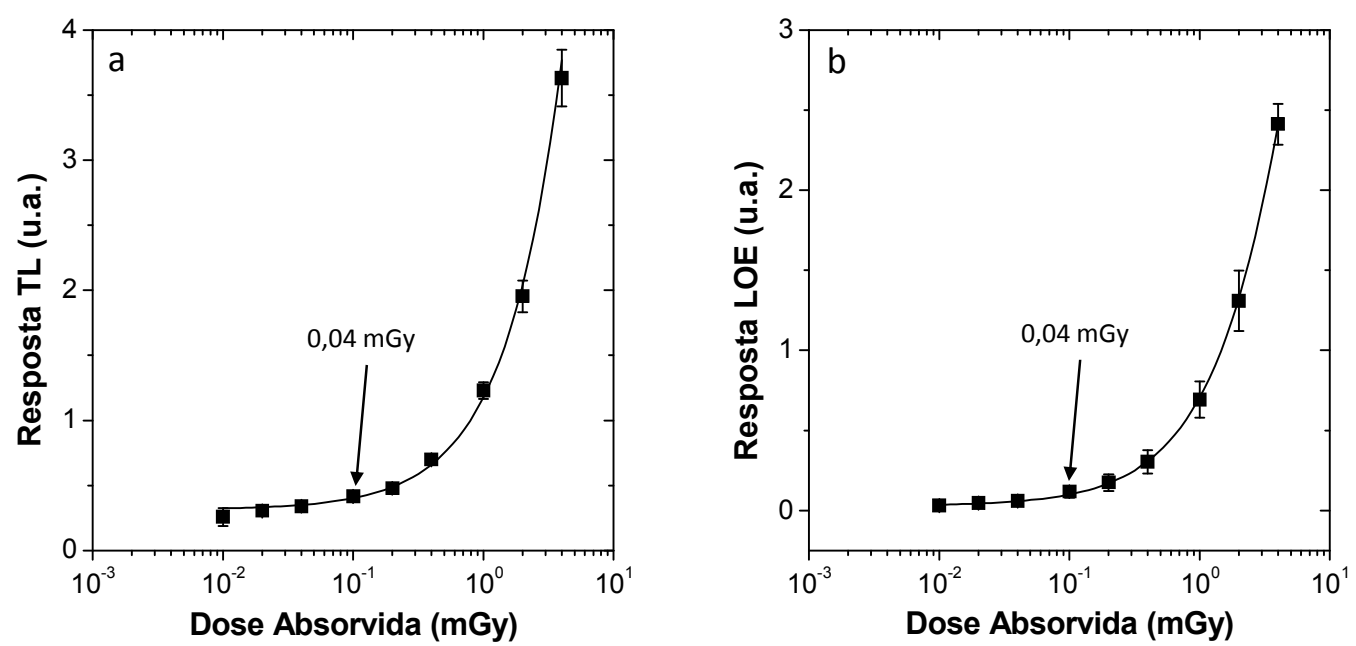

Figura 6.32 - Doses mínimas detectáveis obtidas para detectores de $\mathrm{Al}_{2} \mathrm{O}_{3}: \mathrm{C}$, Rexon: (a) resposta TL; e (b) resposta LOE.

A dose mínima detectável obtida, para ambos os casos TL e LOE, foi 0,04 mGy. Em todas as medições, o desvio padrão máximo no caso da resposta TL foi 5,92\%, e no caso da resposta LOE foi 7,12\%.

Esta característica dosimétrica não foi obtida neste trabalho para os detectores de $\mathrm{Al}_{2} \mathrm{O}_{3}: \mathrm{C}$, NanoDot, Landauer, pois ela já havia sido determinada anteriormente por Pinto (2010), que foi de 0,13 mGy. 


\subsubsection{Dependência Energética}

O estudo da dependência da resposta TL com a energia foi realizado para os dosímetros de $\mathrm{CaSO}_{4}: \mathrm{Dy}(20 \mathrm{mg})$ e $\mathrm{Al}_{2} \mathrm{O}_{3}: \mathrm{C}$, Rexon, e, no caso da resposta $\mathrm{LOE}$, com os dosímetros de $\mathrm{Al}_{2} \mathrm{O}_{3}: \mathrm{C}$, dos fabricantes Rexon e Landauer.

Para o estudo da dependência energética com a resposta $\mathrm{TL}$, as amostras de $\mathrm{CaSO}_{4}$ :Dy (20 mg) foram irradiadas com as três fontes do sistema BSS2, com diferentes doses absorvidas: ${ }^{90} \mathrm{Sr}+{ }^{90} \mathrm{Y}$ (2 mGy), ${ }^{85} \mathrm{Kr}$ (6 mGy) e ${ }^{147} \mathrm{Pm}$ (25 mGy), a distâncias fonte-detector de $30 \mathrm{~cm}, 30 \mathrm{~cm}$ e $20 \mathrm{~cm}$, respectivamente. Nestas medições, o desvio padrão máximo obtido foi $4,3 \%$. Os detectores de $\mathrm{Al}_{2} \mathrm{O}_{3}: \mathrm{C}$, Rexon, foram irradiados com as mesmas fontes e distâncias de calibração, porém, com doses absorvidas diferentes: ${ }^{90} \mathrm{Sr}+{ }^{90} \mathrm{Y}(10 \mathrm{mGy}),{ }^{85} \mathrm{Kr}$ (10 mGy) e ${ }^{147} \mathrm{Pm}$ (615 mGy). Neste caso, as doses absorvidas foram diferentes, pois na época destas medições o laboratório estava disponível pelo dia todo, então os tempos de irradiação puderam ser maiores. Neste caso, o desvio padrão máximo obtido foi 5,4\%.

A dependência da resposta LOE com a energia da radiação beta foi obtida irradiandose os detectores de $\mathrm{Al}_{2} \mathrm{O}_{3}: \mathrm{C}$, dos fabricantes Rexon e Landauer, também com as fontes do sistema BSS2, e às mesmas distâncias de calibração utilizadas no caso do estudo da resposta TL. Para as amostras da Rexon, as doses absorvidas utilizadas foram as mesmas que no caso da $\mathrm{TL}$, e as medições apresentaram desvio padrão máximo de 6,0\%. Para as amostras da Landauer, as doses absorvidas foram: $10 \mathrm{mGy}\left({ }^{90} \mathrm{Sr}+{ }^{90} \mathrm{Y}\right), 10 \mathrm{mGy}\left({ }^{85} \mathrm{Kr}\right)$ e $165 \mathrm{mGy}\left({ }^{147} \mathrm{Pm}\right)$, e o desvio padrão máximo obtido foi $4,4 \%$.

Os resultados obtidos neste estudo, em todas as condições de material e técnica luminescente, demonstraram a alta dependência das respostas TL e LOE com a energia das fontes de radiação beta utilizadas. Esta alta dependência energética foi verificada anteriormente por Pinto e colaboradores (2008), no caso das amostras de $\mathrm{Al}_{2} \mathrm{O}_{3}: \mathrm{C}$, Landauer, quando expostas aos mesmos feixes de radiação.

\subsubsection{Variação da Resposta LOE em Função da Distância Fonte-Detector}

O estudo de variação da resposta em relação à distância fonte-detector foi realizado também com os materiais luminescentes, além das câmaras de ionização já estudadas. Para tal, os detectores escolhidos para este estudo foram os de $\mathrm{Al}_{2} \mathrm{O}_{3}: \mathrm{C}, \mathrm{NanoDot}$, Landauer. 
Para a verificação da resposta com a distância, os detectores LOE foram posicionados às distâncias próximas das de calibração $(11 \mathrm{~cm}, 20 \mathrm{~cm}$ e $30 \mathrm{~cm})$, que foram variadas num intervalo de $10 \mathrm{~cm}$ a $55 \mathrm{~cm}$; eles foram irradiados com a fonte de ${ }^{90} \mathrm{Sr}+{ }^{90} \mathrm{Y}$ do sistema BSS1 (1850 MBq, 1981). Na Fig. 6.33 pode ser observada a curva obtida neste estudo, na qual o desvio padrão máximo obtido foi 5,2\%.

Os resultados obtidos neste experimento mostraram que a resposta LOE dos detectores NanoDot segue a lei do inverso do quadrado da distância fonte-detector, assim como foi demonstrado no item 6.1.5, utilizando-se a câmara de extrapolação Böhm, o que permite ao LCl calibrar modelos e tipos diferentes de detectores de radiação, principalmente em escalas diferentes.

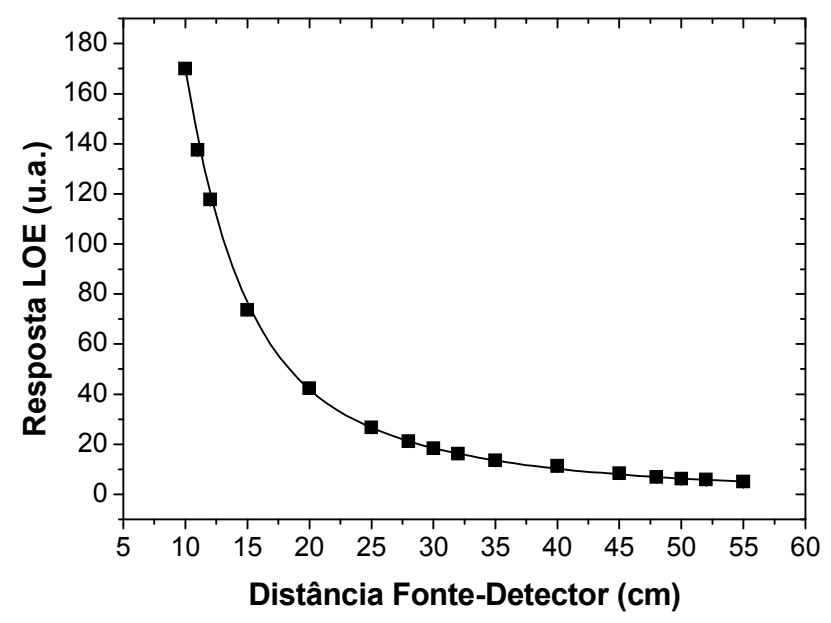

Figura 6.33 - Variação da resposta LOE em função da distância fonte-detector, utilizando-se os detectores de $\mathrm{Al}_{2} \mathrm{O}_{3}: \mathrm{C}$, NanoDot, Landauer, e a fonte de ${ }^{90} \mathrm{Sr}+{ }^{90} \mathrm{Y}$ do sistema BSS1 (1850 MBq, 1981). 


\section{CONCLUSÕES}

As etapas necessárias, bem como os experimentos realizados para o estabelecimento de um sistema de padronização primária no Laboratório de Calibração de Instrumentos (LCl) do IPEN, para calibração e dosimetria de fontes de radiação beta $\left({ }^{90} \mathrm{Sr}+{ }^{90} \mathrm{Y}\right)$, foram realizados e demonstrados neste trabalho.

O instrumento estabelecido no LCl como sistema padrão primário em radiação beta, foi a câmara de extrapolação Böhm, objeto principal de estudo. Esta câmara foi caracterizada com relação à sua resposta em feixes de radiação beta de ${ }^{90} \mathrm{Sr}+{ }^{90} \mathrm{Y}$, utilizandose duas janelas de entrada de materiais diferentes: Mylar aluminizado e Hostaphan grafitado, por meio de testes como: curva de saturação, profundidade nula real, corrente de fuga, estabilidade de resposta, variação da resposta em função da distância fonte-detector e tempo de estabilização (este último foi realizado apenas com a janela de Hostaphan grafitado). Em todos estes testes, a câmara apresentou desempenho e resposta adequados e esperados para seu uso em campos padrões de radiação beta, dentro dos limites recomendados pela norma IEC 60731 (2011), com exceção do teste de reprodutibilidade da resposta para o caso da câmara com janela de Hostaphan grafitado, cujo limite de variação é de $0,5 \%$, mas neste caso a maior variação foi de $0,52 \%$. Mesmo com esta variação, a câmara foi considerada estável e muito adequada para um laboratório de calibração, pois em todas as suas medições os desvios padrões foram considerados aceitáveis e em pouco tempo de estabilização já era possível a sua utilização com efetividade.

Utilizando-se a câmara Böhm, foram determinadas duas das principais características (e mais decisivas do conjunto de experimentos com a câmara Böhm) das fontes de radiação beta: fatores de transmissão no tecido e taxas de dose absorvida. Os fatores de transmissão no tecido tiveram seus resultados compatíveis com os fornecidos nos certificados de calibração das fontes, e satisfatórios, apresentando diferenças num intervalo de $0 \%$ a 2,1\%, para a janela de Mylar aluminizado, e de $0 \%$ a 1,2\% para a janela de Hostaphan grafitado.

No caso da câmara com janela de Mylar aluminizado, foram determinadas as taxas de dose absorvida no ar e no tecido, às profundidades nula e de $0,07 \mathrm{~mm}$, para quatro 
condições diferentes, para as três fontes $\mathrm{de}^{90} \mathrm{Sr}+{ }^{90} \mathrm{Y}$ dos dois sistemas padrões secundários de radiação beta do IPEN, os sistemas BSS1 e BSS2; estas condições foram seguidas de acordo com o certificado de calibração das fontes, com relação à distância fonte-detector e uso de filtro uniformizador de campo. Para a câmara de extrapolação com janela de Hostaphan grafitado, foram determinadas as taxas de dose absorvida para todas as condições das três fontes de ${ }^{90} \mathrm{Sr}+{ }^{90} \mathrm{Y}$. Para a determinação das taxas de dose absorvida destas fontes (procedimento de calibração), foram estudados e utilizados dois métodos diferentes: o método de Caldas (1980) e o método da ISO 6980-2(2004).

No caso da câmara com janela de Mylar aluminizado, as taxas de dose absorvida no ar e no tecido variaram num intervalo de $0,6 \%$ a $6,3 \%$ utilizando-se o método de Caldas, e de $-0,1 \%$ a $12,0 \%$ utilizando-se o método da ISO. No caso da janela de entrada de Hostaphan grafitado, as taxas de dose absorvida variaram de $-0,6 \%$ a 3,0\% com o método de Caldas (1980), e de -1,8\% a 7,3\% com o método da ISO 6980-2 (2004).

Dentre todas as diferenças entre as taxas de dose absorvida, as obtidas com a janela de Hostaphan grafitado e o método de Caldas (1980) foram consideradas as mais adequadas, pois os resultados deixam claro que estas são as duas melhores condições para se determinar estas taxas de dose absorvida. Pôde-se observar que, no caso das fontes do sistema BSS1, as diferenças entre as taxas de dose absorvida foram as menores, enquanto que para a fonte do sistema BSS2, as diferenças foram maiores. É provável que isso se deva ao fato de haver uma pequena falta de alinhamento entre a fonte e o filtro uniformizador de campo, que pôde ser observado no sistema BSS2. Embora tenha se tentado solucionar este problema, ele persistiu. Entretanto, de modo geral, foi possível se verificar a viabilidade do uso desta câmara de extrapolação para padronização primária, devido às pequenas diferenças entre as taxas de dose absorvida obtidas.

Ao longo deste trabalho, três câmaras de ionização foram ainda caracterizadas em feixes de radiação beta de energias diferentes. Esta caracterização visou à verificação da possibilidade de uso de câmaras de ionização de placas paralelas convencionais para controle de qualidade de fontes de radiação, como por exemplo os aplicadores clínicos de ${ }^{90} \mathrm{Sr}+{ }^{90} \mathrm{Y}$. Os testes de caracterização realizados foram: curva de saturação, corrente de fuga, estabilidade de resposta, linearidade de resposta, tempo de estabilização, dependência angular e variação da resposta em função da distância fonte-detector. 
Os testes de caracterização das câmaras de ionização demonstraram o bom comportamento destas câmaras quando expostas aos campos padrões de radiação beta. O experimento no qual foi utilizada a câmara C1 para calibrar aplicadores clínicos mostrou que é possível se aplicar uma câmara de ionização convencional na calibração de aplicadores clínicos, pois as diferenças obtidas $(26,6 \%, 29,0 \%$ e 43,5\%, para os aplicadores A1, A2 e A3, respectivamente) entre as taxas de dose absorvida neste trabalho com as de um estudo prévio podem ser aceitáveis quando são levadas em conta as incertezas presentes nos certificados de calibração dos aplicadores (12\% para o NIST e $20 \%$ para os outros aplicadores).

Foram estudados materiais dosimétricos diferentes, com relação à sua resposta, quando expostos a feixes de radiação beta. Os materiais foram: $\mathrm{CaSO}_{4}: \mathrm{Dy}+$ Teflon $(20 \mathrm{mg})$,

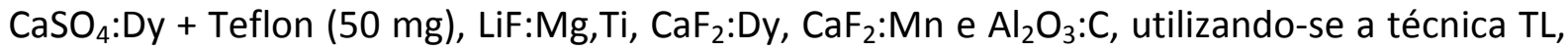
e $\mathrm{Al}_{2} \mathrm{O}_{3}: \mathrm{C}$ (NanoDot e Rexon), com a técnica LOE. Inicialmente estes dosímetros foram caracterizados por meio da elaboração de curvas de dose-resposta, para se determinar o melhor dosímetro para a formação de um sistema dosimétrico TL.

Após a escolha do $\mathrm{CaSO}_{4}: \mathrm{Dy}+$ Teflon $(20 \mathrm{mg})$, este sistema foi estabelecido e testado em cinco hospitais diferentes de radioterapia da cidade de São Paulo, visando ao treinamento dos funcionários com relação ao uso do sistema e aos procedimentos de irradiação. Nesta fase do trabalho, foram calibrados 14 aplicadores clínicos, e as diferenças entre as taxas de dose absorvida obtidas foram $8 \%$ e $-8 \%$ (diferenças mínimas) e -36\% (diferença máxima), as quais foram adequadas, comparando estes resultados com estudos prévios e levando-se em conta que as incertezas do fabricante Amersham (laboratório de calibração próprio) são de $20 \%$ para aplicadores dermatológicos e 30\% para aplicadores oftálmicos. Após esta etapa, o sistema foi enviado de maneira postal à UFS, para calibração de três aplicadores clínicos, cujas diferenças foram -7,9\% (aplicador dermatológico), e -26,4\% e -54,0\% (aplicadores oftálmicos).

Com o objetivo de agregar a dosimetria LOE ao sistema dosimétrico postal, e melhorar a diferença alta previamente obtida, amostras de $\mathrm{Al}_{2} \mathrm{O}_{3}: \mathrm{C}$ foram estudadas em feixes de radiação beta, utilizando-se as técnicas TL e LOE, para verificar sua possibilidade de aplicação no sistema dosimétrico postal. Para isso, os detectores foram novamente enviados à UFS, para calibração agora de 5 aplicadores clínicos diferentes. 
Os resultados obtidos nas calibrações dos aplicadores da UFS apresentaram diferenças que variaram de $-8,1 \%$ a $-35,6 \%$ para a técnica $T L$, e de $-6,6 \%$ a $-40,8 \%$ para a técnica $L O E$. Assim, o sistema postal pôde ser estabelecido de maneira eficiente, pois embora apenas a diferença de $-40,8 \%$ seja ainda considerada alta, outras diferenças foram baixas (se relacionadas às incertezas dos certificados de calibração). Além disso, pôde-se concluir que o sistema pode ser enviado para outros lugares, pois o usuário das fontes da UFS, que fez as irradiações, relatou facilidade no momento de seguir os procedimentos de irradiação e calibração dos dosímetros, o que permite concluir que é possível se utilizar este sistema de maneira postal.

Assim, analisando-se o desenvolvimento deste trabalho e as etapas realizadas e cumpridas, pode-se concluir que os objetivos foram alcançados. 


\section{APÊNDICE A}

\section{* Procedimento para utilização da Câmara de Extrapolação Böhm para Calibração de Fontes de ${ }^{90} \mathrm{Sr}^{90} \mathrm{Y}$}

A seguir, será apresentada, passo a passo, a descrição com as etapas necessárias para um procedimento de calibração de fontes de ${ }^{90} \mathrm{Sr}+{ }^{90} \mathrm{Y}$.

\section{A.1 - Objetivo}

O objetivo desta instrução de trabalho é descrever o procedimento de determinação de taxas de dose absorvida de fontes de radiação beta de ${ }^{90} \mathrm{Sr}+{ }^{90} \mathrm{Y}$, utilizando-se a câmara de extrapolação Böhm como sistema padrão primário, no Laboratório de Calibração de Instrumentos do IPEN (LCI).

\section{A.2 - Campo de Aplicação}

Estas informações aplicam-se ao uso da câmara de extrapolação Böhm e das fontes de radiação de ${ }^{90} \mathrm{Sr}+{ }^{90} \mathrm{Y}$ no $\mathrm{LCl}$ :

- Quem: Tecnologista, tecnólogo, técnico ou estagiário do LCl;

- Quando: Na data de calibração dos instrumentos, de acordo com a agenda do LCl;

- Onde: No Laboratório de Calibração de Instrumentos com Radiação Beta.

\section{A.3 - Procedimento}

\section{A.3.1 - Condições e Recursos Necessários}

- Presença de um tecnologista, técnico ou estagiário com conhecimentos em Proteção Radiológica e apto para realizar o procedimento de calibração;

- Câmara de extrapolação Böhm, PTW, modelo 23392, com janela de entrada de Hostaphan grafitado;

- Eletrômetro Keithley, modelo 6517B; 
- Dois cabos para conexão da câmara de extrapolação ao eletrômetro: um cabo para a aplicação da tensão de polarização, e outro para coletar medições de corrente de ionização;

- Fonte de radiação beta de ${ }^{90} \mathrm{Sr}+{ }^{90} \mathrm{Y}$ a ser calibrada;

- Instrumentos para monitoração das condições ambientais: termômetro, barômetro e higrômetro;

- Instrumentos para controle das condições ambientais: sistema de ar-condicionado e desumidificador;

- Arranjos e suportes para o posicionamento da câmara de extrapolação Böhm e da fonte de ${ }^{90} \mathrm{Sr}+{ }^{90} \mathrm{Y}$ a ser calibrada;

- Microcomputador com impressora;

- Planilhas eletrônicas para realização dos cálculos necessários para a determinação da taxa de dose absorvida, dos fatores de correção e das incertezas associadas;

- Documento modelo para a emissão do certificado de calibração.

\section{A.3.2 - Cuidados Especiais}

Por se tratar de um trabalho com fontes de radiação, é obrigatório o uso de dosímetro. Além disso, deve-se utilizar avental, luvas e protetor facial de acrílico, este último devendo ser utilizado toda vez que o executor do procedimento entrar dentro da sala onde estiver posicionada e câmara de extrapolação e a fonte de radiação.

Como serão tomadas medições de carga elétrica/corrente de ionização com radiação beta, que algumas vezes poderão ser de ordem de grandeza pequena, é necessário um controle rigoroso das condições ambientais do laboratório, uma vez que qualquer pequena alteração pode acarretar uma variação muito grande entre uma medição e outra.

\section{A.3.3 - Descrição das Atividades}

\section{A.3.3.1 - Testes iniciais}

A seguir serão descritas as etapas de realização de testes iniciais, de verificação da resposta da câmara de extrapolação: 
a. Ligar o sistema de ar-condicionado e o desumidificador no mínimo $48 \mathrm{~h}$ antes do início das medições, para que as condições ambientais se tornem favoráveis às medições com radiação beta (temperatura entre $20^{\circ} \mathrm{C}$ e $24^{\circ} \mathrm{C}$, e umidade entre $50 \%$ e $60 \%$ );

b. Ligar o eletrômetro Keithley, acoplar os dois cabos conectores ao eletrômetro e deixar o sistema estabilizando $24 \mathrm{~h}$ antes de iniciar as medições (o eletrômetro deve permanecer no dessecador, junto com a câmara, durante o tempo em que não estiver sendo usado);

c. Posicionar a câmara de extrapolação Böhm no seu suporte, conectá-la ao eletrômetro, por meio dos dois cabos, e deixar o sistema estabilizando por $1 \mathrm{~h}$ antes das medições;

d. Ajustar a profundidade da câmara, aplicar a tensão de polarização desejada (dependendo da profundidade da câmara a ser utilizada, de modo que seja mantido um campo elétrico constante de $10 \mathrm{~V} / \mathrm{mm}$ ), e deixar o sistema estabilizar por $10 \mathrm{~min}$;

e. Fazer o teste de corrente de fuga pré-irradiação durante $20 \mathrm{~min}$, coletando-se duas medições de carga elétrica: uma medição inicial, no momento em que a carga começar a ser coletada, e outra medição após $20 \mathrm{~min}$. Se não houver corrente de fuga, prosseguir com as medições;

$\checkmark$ Caso ocorra a presença de fuga da corrente, deve-se desligar/desconectar o sistema câmara de extrapolação + cabos + eletrômetro e limpar os respectivos conectores com álcool isopropílico, utilizando um lenço de papel. Ligar o sistema novamente, esperar estabilizar e repetir as medições realizadas anteriormente. Caso o problema persista, colocar o conjunto câmara + cabos + eletrômetro em ambiente com sílica, dentro do dessecador, por aproximadamente 24 h. Após este tempo, religar o sistema, esperar estabilizar e repetir as medições descritas no item " $\mathrm{e}$ ";

f. Fazer o teste de repetibilidade, para verificar se a câmara está apresentando estabilidade na resposta: posicionar a câmara de extrapolação à distância de calibração desejada, ajustar a profundidade da câmara, expor a câmara à fonte de radiação, aplicar a tensão de polarização desejada à câmara (dependendo da profundidade da câmara), e deixar estabilizar por $10 \mathrm{~min}$;

Se a resposta da câmara não apresentar estabilidade, deixar o sistema estabilizando por mais tempo antes de iniciar as medições. Então, repetir o item "f". 


\section{A.3.3.2 - Medições para a curva de extrapolação}

Os itens a seguir descrevem o roteiro necessário para se obter uma curva de extrapolação, necessária para a determinação da taxa de dose absorvida:

a. Após a realização dos itens "a-f", ajustar a primeira profundidade da câmara (recomenda-se fazer uma curva de extrapolação nas profundidades de $0,5 \mathrm{~mm}$ a $2,5 \mathrm{~mm}$ $(0,5 \mathrm{~mm} / \pm 5 \mathrm{~V}, 1,0 \mathrm{~mm} / \pm 10 \mathrm{~V}, 1,5 \mathrm{~mm} / \pm 15 \mathrm{~V}, 2,0 \mathrm{~mm} / \pm 20 \mathrm{~V}, 2,5 \mathrm{~mm} / \pm 25 \mathrm{~V}))$, aplicar a tensão de polarização desejada (positiva), e deixar o sistema estabilizar por $10 \mathrm{~min}$;

b. Iniciar as medições, coletando-se 10 medições de carga elétrica a um tempo de coleta específico, por exemplo, de $1 \mathrm{~min}$, dependendo da atividade da fonte;

c. Ainda com a câmara exposta à fonte, trocar a polaridade da câmara para a negativa e esperar o sistema estabilizar por $10 \mathrm{~min}$;

d. Iniciar as medições com polaridade negativa, coletando-se 10 medições de carga elétrica no mesmo intervalo de tempo utilizado na etapa " $b$ ";

e. Anular a exposição da câmara à fonte, trocar a profundidade da câmara, ajustar no eletrômetro e aplicar a tensão de polarização desejada (negativa), expor a câmara à fonte e esperar o sistema estabilizar por $10 \mathrm{~min}$;

f. Iniciar as medições, coletando-se 10 medições de carga elétrica;

g. Ainda com a câmara exposta à fonte, trocar a polaridade da câmara para a positiva e esperar o sistema estabilizar por $10 \mathrm{~min}$;

h. Iniciar as medições;

i. Repetir as etapas "e- $h$ " em todas as profundidades da câmara restantes.

\section{A.3.3.3 - Determinação da Taxa de Dose Absorvida}

A seguir serão relatadas as etapas de determinação da taxa de dose absorvida, mostrando as Equações necessárias:

a. Inserir todas as medições coletadas numa planilha, de modo a obter as correntes de ionização necessárias para se fazer um gráfico da corrente em função da profundidade da câmara, do qual sairá o valor do coeficiente angular da curva, $B$; 
b. Aplicar o valor do coeficiente angular obtido na Equação 4.14, já descrita no item 4.4.4 deste trabalho (será utilizada a mesma numeração das Equações), para a obtenção da taxa de dose absorvida no ar dentro do volume sensível da câmara, $\dot{D}_{a}$ :

$$
\dot{D}_{a}=\frac{\bar{W}}{e} \cdot \frac{k^{\prime}}{a_{e f} \cdot \rho} \cdot \frac{d}{d l}(I \cdot k(\ell))
$$

onde: $\bar{W}$ é a energia média dispendida pelas partículas ionizantes na formação de um par de íons no ar, $e$ é a carga elementar, $a_{e f}$ é a área efetiva do eletrodo coletor, $\rho$ é a densidade do ar, $\frac{d}{d l}(I . k(\ell))$ é a derivada da função corrente de ionização corrigida para $k(\ell)$ (representa o coeficiente angular, $B$, da curva de extrapolação), onde $\ell$ é a profundidade da câmara, e $k$ e $k$ ' são produtos entre fatores de correção diferentes, de acordo com as Equações 4.15 e 4.16:

$$
\begin{gathered}
k=k_{B r} \cdot k_{d e} \cdot k_{h u} \cdot k_{g a p} \cdot k_{e s p} \cdot k_{i n h} \\
k^{\prime}=k_{s a t} \cdot k_{a d} \cdot k_{\rho}
\end{gathered}
$$

Os fatores de correção das Equações 4.15 e 4.16 são relativos a:

- $\boldsymbol{k}_{\boldsymbol{B} \boldsymbol{r}}$ - emissão de Bremsstrahlung da fonte de radiação beta (este fator pode ser obtido experimentalmente);

- $\boldsymbol{k}_{d e}$ - decaimento radioativo da fonte;

- $\boldsymbol{k}_{\boldsymbol{h u}}$ - umidade relativa do ar;

- $\boldsymbol{k}_{\text {gap }}$ - ranhura entre o eletrodo coletor e o anel de guarda (falta do retroespalhador, deformação do volume coletor);

- $\boldsymbol{k}_{\boldsymbol{e s p}}$ - partículas beta espalhadas pelo material na vizinhança da fonte e da câmara;

- $\boldsymbol{k}_{\boldsymbol{i n h}}$ - inhomogeneidade do campo da radiação primária dentro do volume coletor, e depende da distância entre a fonte e a câmara, e das dimensões dos raios da fonte e do eletrodo coletor da câmara;

- $\boldsymbol{k}_{\text {sat }}$ - falta de saturação, ou perda de ionização, devido à recombinação colunar e volumétrica;

- $\boldsymbol{k}_{\boldsymbol{a d}}$ - partículas beta espalhadas pelas paredes laterais;

- $\boldsymbol{k}_{\boldsymbol{\rho}}$ - densidade do ar. 
c. Após a obtenção da taxa de dose absorvida $\dot{D}_{a}$, deve-se determinar a taxa de dose absorvida no tecido dentro do volume sensível da câmara, $\dot{D}_{t}$, obtida pela Equação 4.13:

$$
\dot{D}_{t}=\dot{D}_{a} \cdot s_{t, a} \cdot k_{b a} \cdot k_{f}
$$

onde: $s_{t, a}$ é a razão entre os poderes de freamento médios do tecido e do ar, e ocorre a presença de mais dois fatores de correção:

- $\boldsymbol{k}_{\boldsymbol{b} \boldsymbol{a}}$ - diferença no retroespalhamento entre o material do tecido e do eletrodo coletor;

- $\boldsymbol{k}_{f}$ - espessura e material da folha de entrada, e para normalização para uma folha de

Após a determinação de $\dot{D}_{t}$, pode-se calcular a taxa de dose absorvida no tecido na superfície externa da janela da câmara, $\dot{D}_{t}(0)$, por meio da razão entre a taxa de dose no tecido no volume da câmara, $\dot{D}_{t}$, e o fator de transmissão equivalente à densidade superficial da janela de entrada da câmara, $T$ (o qual é determinado pelo gráfico dos fatores de transmissão finais em função da densidade superficial, equivalente ao tecido, de absorvedores de espessuras diferentes), como pode ser observado na Equação 4.17:

$$
\dot{D}_{t}(0)=\frac{\dot{D}_{t}}{T}
$$

Concluindo, por meio da quarta etapa, é possível se determinar a taxa de dose absorvida no ar na superfície externa da janela da câmara, $\dot{D}_{c}$, que consiste na razão entre a taxa de dose no tecido na superfície externa da câmara, $\dot{D}_{t}(0)$, e a razão entre os poderes de freamento médios do tecido e do ar, $s_{t, a}$, como mostra a Equação 4.18:

$$
\dot{D}_{c}=\frac{\dot{D}_{t}(0)}{S_{t, a}}
$$

Para a determinação das diferentes taxas de dose absorvida descritas acima, deve-se utilizar os valores das grandezas que podem ser extraídos da Tabela 6.8 deste trabalho, reproduzida a seguir como Tabela A.1: 
Tabela A.1 - Grandezas e seus valores utilizados na determinação das taxas de dose absorvida no ar, $\dot{D}_{a}$, e no tecido, $\dot{D}_{t}$, para três fontes de ${ }^{90} \mathrm{Sr}+{ }^{90} \mathrm{Y}$, utilizando a câmara de extrapolação Böhm com janela de entrada de Hostaphan grafitado (CALDAS, 1980; ISO, 2004).

\begin{tabular}{cccccc}
\hline $\begin{array}{c}\text { Sistema Padrão } \\
\text { Secundário de } \\
\text { Radiação Beta }\end{array}$ & $\begin{array}{c}\bar{W} \\
(\mathrm{eV})\end{array}$ & $\begin{array}{c}e \\
\left(10^{-9} \mathrm{C}\right)\end{array}$ & $\begin{array}{c}\rho \\
\left(\mathrm{kg} / \mathrm{m}^{3}\right)\end{array}$ & $S_{t, a}$ & $\begin{array}{c}a_{e f}{ }^{*} \\
\left(10^{-4} \mathrm{~m}^{2}\right)\end{array}$ \\
\hline BSS1 & $33,73 \pm 0,15$ & $1,602 \pm 0,000$ & $1,1995 \pm 0,0005$ & $1,111 \pm 0,011$ & \\
\hline BSS2 & - & - & $1,197 \pm 0,000$ & $1,110 \pm 0,005$ & $7,354 \pm 0,002$ \\
\hline
\end{tabular}

${ }^{*}$ A área efetiva do eletrodo coletor foi determinada experimentalmente, como descrito no item "6.2.2. Profundidade Nula Real e Área Efetiva".

Os fatores de transmissão, a serem utilizados na Equação 4.17, devem ser utilizados conforme os valores a seguir (já mostrados na Tabela 6.34, como Tabela A.2):

Tabela A.2 - Fatores de transmissão, $T$, obtidos para a janela de entrada de Hostaphan grafitado.

\begin{tabular}{cccc}
\hline $\begin{array}{c}\text { Sistema Padrão } \\
\text { Secundário de } \\
\text { Radiação Beta }\end{array}$ & Fonte & $\begin{array}{c}\text { Filtro } \\
\text { Uniformizador } \\
\text { de Campo }\end{array}$ & $\begin{array}{c}\text { Fator de } \\
\text { Transmissão }\end{array}$ \\
\hline \multirow{3}{*}{ BSS1 } & $74 \mathrm{MBq}$ & Sim & $1,006 \pm 0,010$ \\
\cline { 2 - 4 } & \multirow{3}{*}{$1850 \mathrm{MBq}$} & Não & $1,009 \pm 0,010$ \\
\cline { 3 - 4 } & & Não & $1,010 \pm 0,010$ \\
\cline { 2 - 4 } & & Não & $1,010 \pm 0,010$ \\
\cline { 2 - 4 } BSS2 & $460 \mathrm{MBq}$ & Não & $0,940 \pm 0,010$ \\
\cline { 3 - 4 } & & São & $0,947 \pm 0,010$ \\
\cline { 2 - 4 } & & Não & $0,963 \pm 0,010$ \\
\cline { 2 - 4 } & & Não & $0,947 \pm 0,010$ \\
\hline & & &
\end{tabular}

\section{A.3.3.4 - Fatores de Correção}

Os fatores de correção apresentados no item A.3.3.3 serão definidos a seguir, bem como os valores a serem utilizados para alguns deles, e as Equações necessárias para a obtenção de outros (apresentadas no item 5.1.4):

a. O fator de correção devido à emissão de Bremsstrahlung da fonte de radiação beta, $\boldsymbol{k}_{\boldsymbol{B} \boldsymbol{r}}$, deve ser determinado experimentalmente medindo-se cargas elétricas com a câmara exposta a um feixe de radiação apenas com a janela de entrada, e cargas elétricas com a janela coberta por uma placa de Plexiglas de $1 \mathrm{~cm}$ de espessura. Assim, o valor da 
corrente de ionização medida corresponde à emissão de Bremsstrahlung. De acordo com Caldas (1980), este fator pode ser determinado por meio da Equação 5.1:

$$
k_{B r}=1-\frac{I_{B r}}{I}
$$

onde: $I$ é a corrente de ionização medida sem o absorvedor de acrílico, e $I_{B r}$ é a corrente de ionização medida com o absorvedor de acrílico.

b. O fator que corrige a corrente de ionização para a inhomogeneidade do campo da radiação primária dentro do volume coletor, $\boldsymbol{k}_{\boldsymbol{i n h}}$, pode ser obtido utilizando-se a Equação 5.2 (CALDAS, 1980):

$$
k_{i n h}=\frac{1-\frac{r_{3}^{2}}{2}}{1-\frac{r_{3}^{2}}{2}-\frac{r_{2}^{2}}{2}}, \quad \text { com } \quad r_{2}=\frac{a_{2}}{a} \quad \text { e } \quad r_{3}=\frac{a_{3}}{a}
$$

onde: $a$ é a distância entre a fonte e a câmara, durante as medições, $a_{2}$ é o raio do eletrodo coletor da câmara, e $a_{3}$ é o raio da fonte.

c. O fator de correção aplicado à corrente de ionização devido à falta de saturação da resposta da câmara, no seu volume sensível, $\boldsymbol{k}_{\text {sat }}$, é determinado pela Equação 5.3 (CALDAS, 1980):

$$
k_{\text {sat }}=\frac{1}{f}
$$

onde: $f$ é a eficiência de coleção de íons da câmara.

Para a calibração de fontes de ${ }^{90} \mathrm{Sr}+{ }^{90} \mathrm{Y}$, deve ser utilizado o valor de $(1,0018 \pm 0,0026)$ para este fator de correção.

d. A correção para os efeitos da parede da câmara é representada pelo fator, $\boldsymbol{k}_{\boldsymbol{a d}}$, que depende da distância entre a fonte e a câmara de extrapolação, e da profundidade, como é observado na Equação 5.4 (CALDAS, 1980):

$$
k_{a d}=\frac{a+d}{a} \cdot\left(1-3,5 \cdot 10^{-2} d\right)
$$

onde: $a$ é a distância fonte-detector, e $d$ é a profundidade da câmara. 
e. O fator de correção para a variação na densidade do ar no volume sensível da câmara de extrapolação, $\boldsymbol{k}_{\boldsymbol{\rho}}$, é dado pela Equação 5.5 (CALDAS, 1980):

$$
k_{\rho}=\frac{p_{0} \cdot T}{p \cdot T_{0}}
$$

onde: $p_{0}$ é a pressão do ar $(101,3 \mathrm{kPa})$ e $T_{0}$ é a temperatura $\left(20^{\circ} \mathrm{C}\right)$, em condições de referência, $p$ é a pressão e $T$ é a temperatura durante a medição.

No caso dos fatores de correção descritos até agora $\left(\boldsymbol{k}_{\boldsymbol{B} r}, \boldsymbol{k}_{\boldsymbol{i n h}}, \boldsymbol{k}_{\text {sat }}, \boldsymbol{k}_{a d}, \boldsymbol{k}_{\boldsymbol{\rho}}\right)$, os valores a serem utilizados para eles deverão ser os mesmos apresentados nas Tabelas $6.14,6.15,6.16$ e 6.17 deste trabalho.

f. Os fatores de correção que não foram obtidos neste trabalho experimentalmente ou por meio de Equações (já definidos no item “4.4.4. Determinação de Taxas de Dose Absorvida"), são aqueles cujos valores foram especificados por Caldas (1980), e que já foram mostrados na Tabela 5.2 (como Tabela A.3), que é reproduzida a seguir. Com relação ao fator de correção para a umidade do ar, o valor adotado neste trabalho foi o mesmo demonstrado por Rogers e Ross (1988).

Tabela A.3 - Fatores de correção utilizados neste trabalho e seus respectivos valores (CALDAS, 1980).

\begin{tabular}{cc}
\hline Fator de Correção & Valor \\
\hline $\boldsymbol{k}_{\boldsymbol{b a}}$ & $1,0100 \pm 0,0003$ \\
\hline $\boldsymbol{k}_{\boldsymbol{f}}$ & 1 \\
\hline $\boldsymbol{k}_{\boldsymbol{d e}}$ & 1 \\
\hline $\boldsymbol{k}_{\boldsymbol{h u}}$ & $0,9970 \pm 0,0005$ \\
\hline $\boldsymbol{k}_{g a p}$ & 1 \\
\hline $\boldsymbol{k}_{e s p}$ & 1 \\
\hline
\end{tabular}

No caso do fator de correção para o decaimento da fonte, $\boldsymbol{k}_{\boldsymbol{d e}}$, ele pode ser adotado como sendo igual a 1, quando não for obtido por meio de cálculo. A taxa de dose absorvida presente no certificado original de cada fonte pode ter o seu valor calculado para a data da medição por meio da própria fórmula do decaimento radioativo e, desta maneira, não é necessário se calcular o fator de correção específico para isso $\left(\boldsymbol{k}_{d e}\right)$. 


\section{APÊNDICE B}

\section{* Procedimento para utilização do Sistema Postal}

A seguir, serão apresentados os documentos necessários para o cumprimento de um procedimento de utilização do sistema postal, para calibração de aplicadores clínicos de ${ }^{90} \mathrm{Sr}+{ }^{90} \mathrm{Y}$ : procedimento de irradiação de dosímetros TL e LOE, formulário de coleta de dados sobre a instituição e o aplicador, e folha para verificação dos itens do sistema dosimétrico postal. Ao final, será mostrado, também, o modelo de certificado de calibração adotado para ser emitido pelo $\mathrm{LCl}$ às instituições que tiverem seus aplicadores calibrados. 


\section{B.1 - Procedimento de Irradiação}

\section{PROCEDIMENTO}

\section{IRRADIAÇÃO DE DOSÍMETROS TERMOLUMINESCENTES E LUMINESCENTES OPTICAMENTE ESTIMULADOS COM APLICADORES CLÍNICOS DE ${ }^{90} \mathrm{Sr}+{ }^{90} \mathrm{Y}$, PARA CALIBRAÇÃO DESTAS FONTES}

\section{1 - Objetivo do procedimento}

O objetivo destas instruções é descrever o procedimento de irradiação de amostras termoluminescentes ( $T L$ ) e luminescentes opticamente estimuladas (LOE), comerciais, de $\mathrm{Al}_{2} \mathrm{O}_{3}: \mathrm{C}$ (Rexon) com fontes emissoras de radiação beta de ${ }^{90} \mathrm{Sr}+{ }^{90} \mathrm{Y}$, os aplicadores clínicos, que podem ser dermatológicos ou oftálmicos e são utilizados em procedimentos de braquiterapia. Logo após a irradiação das amostras, o sistema postal deverá ser enviado ao IPEN, para a avaliação das amostras TL e LOE para, em seguida, ocorrer a emissão dos certificados de calibração referentes a cada fonte calibrada.

\section{2 - Observações importantes}

Para que a calibração dos aplicadores clínicos de ${ }^{90} \mathrm{Sr}+{ }^{90} \mathrm{Y}$ forneça resultados satisfatórios, alguns cuidados devem ser tomados, como:

- Não iniciar as irradiações sem ler atentamente as instruções;

- Uma vez que o processo de calibração de aplicadores clínicos com dosímetros TL e LOE inicia-se na etapa de irradiação das amostras, é de fundamental importância que o tempo de irradiação das amostras com um aplicador específico seja corretamente calculado;

- Todas as amostras TL e LOE para um mesmo aplicador devem ser irradiadas exatamente durante o mesmo tempo;

- Todas as etapas do procedimento devem ser devidamente seguidas.

\section{3 - Cuidados especiais}

Por serem fontes radioativas com altas taxas de dose, devem ser tomados cuidados especiais no manuseio dos aplicadores clínicos para diminuir a dose absorvida na pele, especialmente nas mãos e nos olhos do operador, como medida de segurança. Assim, as irradiações não devem ser realizadas sem a utilização de luvas, avental e protetor facial de acrílico para os olhos e a face (ou pelo menos óculos protetores de acrílico). 


\section{4 - Procedimento}

\section{1 - Condições e Recursos Necessários}

Responsável pelas fontes ou outra pessoa, indicada pelo responsável, que possua conhecimentos em Proteção Radiológica, para realizar as irradiações dos dosímetros TL com os aplicadores clínicos de ${ }^{90} \mathrm{Sr}+{ }^{90} \mathrm{Y}$;

$\checkmark 20$ amostras TL e 20 detectores $\mathrm{LOE}$ de $\mathrm{Al}_{2} \mathrm{O}_{3}: \mathrm{C}$, Rexon, previamente calibradas no IPEN e que compõem o sistema postal dosimétrico;

$\checkmark$ Pinça para o manuseio das pastilhas de $\mathrm{Al}_{2} \mathrm{O}_{3}: \mathrm{C}$;

Suporte em acrílico para as amostras ("porta-amostras" ou "porta-dosímetros"), recoberto com um filme plástico para que seja evitado o contato direto entre cada amostra e a fonte;

$\checkmark$ Cronômetro;

$\checkmark$ Instrumento para medições das condições ambientais: barômetro, termômetro e higrômetro, se possível;

Luvas cirúrgicas para proteção das mãos;

$\checkmark$ Protetor facial de acrílico ou óculos protetores de acrílico (Fig. B.1);

Avental para proteção do corpo;

$\checkmark$ Formulário de coleta de dados referentes à Instituição e aos aplicadores de ${ }^{90} \mathrm{Sr}+{ }^{90} \mathrm{Y}$;

Formulário de verificação dos itens que compõem o sistema dosimétrico postal.

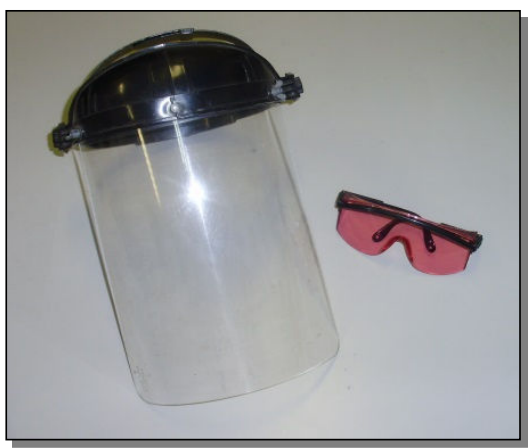

Figura B.1 - Protetor facial de acrílico e óculos protetores de acrílico, para utilização durante o manuseio das fontes de ${ }^{90} \mathrm{Sr}+{ }^{90} \mathrm{Y}$. 


\section{2 - Descrição das Atividades}

1. Preencher cuidadosamente o formulário de coleta de dados, pois os dados da Instituição e dos aplicadores clínicos (Fig. B.2) serão colocados nos certificados de calibração das fontes;
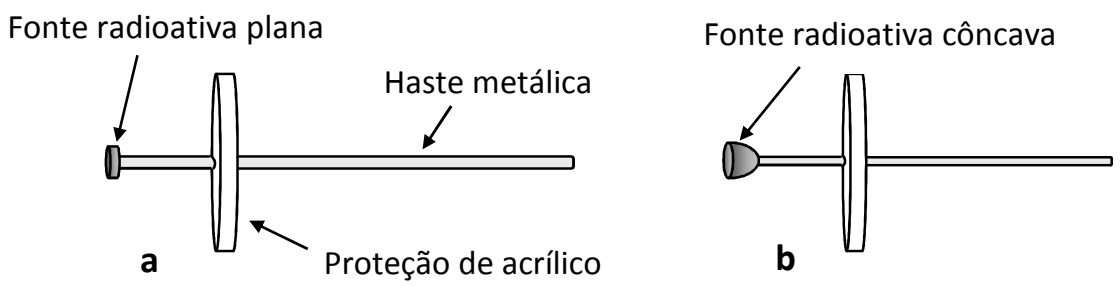

Figura B.2 - Esquema de aplicadores clínicos convencionais: (a) dermatológico; e (b) oftálmico.

2. Calcular o tempo de irradiação das amostras, que depende da taxa de dose absorvida na data de referência fornecida pelo certificado de calibração de cada aplicador:

a) Inicialmente, deve-se calcular a taxa de dose absorvida da fonte para a data da irradiação utilizando-se a expressão:

$$
\dot{D}(t)=\dot{D}_{0} \cdot e^{-\frac{\ln 2 \cdot \Delta t}{T_{1 / 2}}}
$$

onde: $\dot{D}_{0}$ é a taxa de dose absorvida fornecida pelo certificado de calibração do aplicador, na sua data de referência; $\dot{D}(t)$ é a nova taxa de dose absorvida a ser calculada, na data da medição (data na qual as pastilhas serão irradiadas); $\Delta t$ corresponde ao intervalo de tempo entre a data da taxa de dose absorvida inicial (do certificado) e a data com relação à qual se deseja determinar a nova taxa de dose absorvida; e $T_{1 / 2}$ é a meia-vida do radioisótopo ${ }^{90} \mathrm{Sr}+{ }^{90} \mathrm{Y}(28,8$ anos);

b) Utilizando-se a taxa de dose absorvida obtida, pode-se calcular o tempo de irradiação para uma determinada dose, que deve ser de aproximadamente $3 \mathrm{~Gy}$.

3. Como o sistema dosimétrico postal contém 20 amostras para cada técnica luminescente (TL e LOE), 2 delas devem ser utilizadas sempre como controle (sem ser irradiadas) e as 18 pastilhas restantes devem ser divididas para todos os aplicadores a serem calibrados, para ambas as técnicas (exemplo: se temos 6 aplicadores clínicos, então 3 amostras devem ser irradiadas com cada aplicador); 
4. Anotar a quantidade de pastilhas a serem irradiadas com cada fonte no formulário, bem como os números especificados nelas;

5. Colocar o aplicador clínico em um suporte segurando-o pela sua haste, de modo que a fonte fique posicionada horizontalmente sobre o dosímetro TL ou LOE a ser irradiado (como mostra a Fig. B.3 como um exemplo), e este sistema deve ficar, se possível, atrás de uma blindagem de acrílico ou de vidro como proteção do operador contra a radiação beta do aplicador;

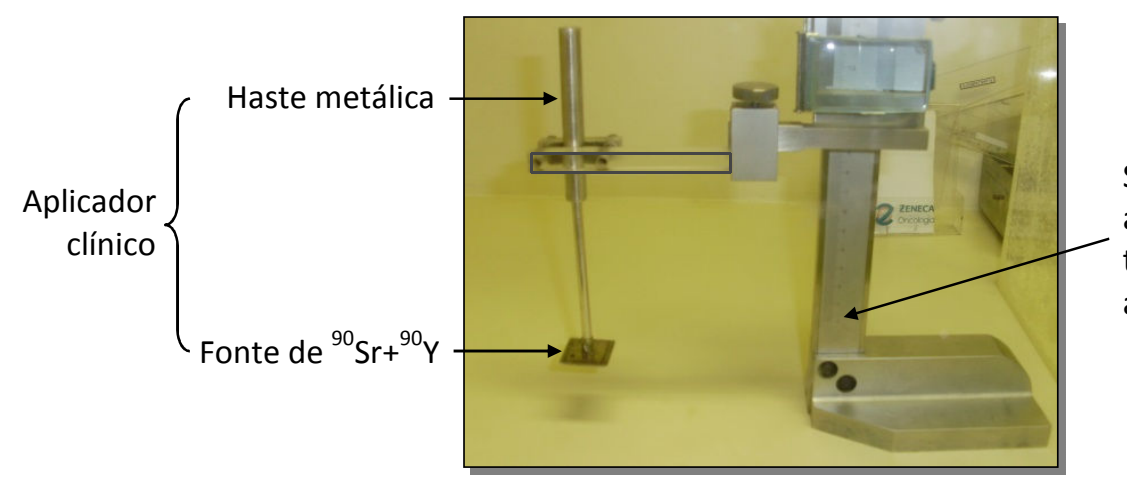

Suporte para posicionamento do aplicador clínico (contém um trilho que permite a mudança de altura do aplicador)

Figura B.3 - Exemplo de um arranjo experimental para o posicionamento do aplicador clínico sobre o dosímetro termoluminescente.

6. Retirar o porta-amostra da caixa do sistema dosimétrico, que está envolto por um filme plástico, retirar o filme cuidadosamente e inserir, com a pinça, uma pastilha no orifício do porta-amostra (Fig. B.4.a), colocando novamente, em seguida, o filme plástico sobre a amostra e de maneira a não formar bolhas sobre ela, de acordo com a Fig. B.4.b (ao inserir a pastilha no suporte, ela deve ser fixada com o número para baixo, de maneira que a amostra seja irradiada pelo lado sem número);
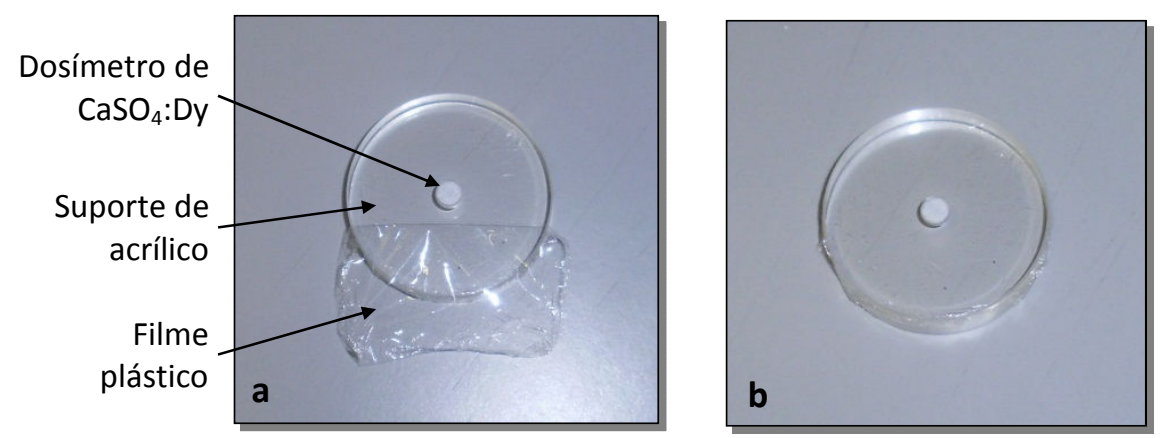

Figura B.4 - Suporte de acrílico contendo um dosímetro termoluminescente: (a) ao remover uma parte do filme plástico para posicionamento do dosímetro; e (b) com o filme plástico sobre o dosímetro, para o procedimento de irradiação.

7. Posicionar o aplicador verticalmente sobre a amostra, de acordo com a Fig. B.5, e irradiála durante o intervalo de tempo calculado (o cronômetro deve ser acionado exatamente 
no momento em que a superfície da fonte toca o filme plástico do suporte - lembrar que o tempo de irradiação deve ser exatamente o mesmo para cada um dos dosímetros);

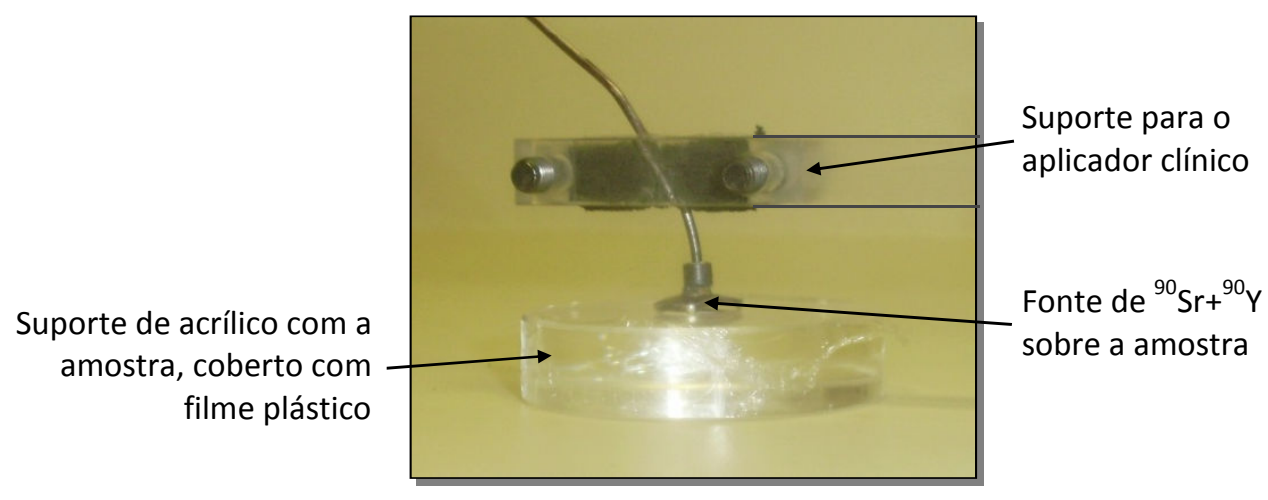

Figura B.5 - Exemplo de um procedimento de irradiação: um dosímetro termoluminescente está sendo irradiado por um aplicador oftálmico de ${ }^{90} \mathrm{Sr}+{ }^{90} \mathrm{Y}$ (com haste curva).

8. Após a irradiação de cada dosímetro, ele deve ser guardado imediatamente no suporte de dosímetros, para que a amostra irradiada não seja exposta à luz;

9. Após a irradiação de todas as amostras e do preenchimento dos formulários e da lista de itens do sistema dosimétrico (que deve ser preenchida para verificação da presença de todos os itens no sistema dosimétrico a ser devolvido), eles devem ser enviados ao IPEN.

10. Tomar cuidado para não expor as amostras irradiadas à luz, principalmente no caso dos detectores LOE.

Para dúvidas, contactar Patrícia de Lara Antonio:

Telefone (IPEN): 011-3133-9652

E-mail: patrilan@ipen.br 


\section{B.2 - Formulário de Coleta de Dados}

\section{FORMULÁRIO DE COLETA DE DADOS \\ (Favor preencher um formulário para cada aplicador)}

Instituição

\begin{tabular}{|l|l|l|l|l|}
\hline Nome: & \multicolumn{2}{l|}{ CNPJ: } \\
\hline Endereço: & Cidade: & Estado: & CEP: & Telefone: \\
\hline Bairro: & \multicolumn{1}{|l|}{ Telefone: } & E-mail: & \\
\hline Responsável (para contato): & &
\end{tabular}

Dados referentes ao tipo de aplicador

Aplicador Oftálmico $\square$ Obs.

\begin{tabular}{|l|l}
\hline Aplicador Dermatológico $\square$ & $\square$ Obs.:
\end{tabular}

\begin{tabular}{ll|l|l}
\hline Fonte: ${ }^{90} \mathrm{Sr}^{90} \mathrm{Y} \quad \square \operatorname{Sim} \quad \square$ Não & Em caso de outra fonte, especificar:
\end{tabular}

\begin{tabular}{ll} 
Certificado: $\square \operatorname{sim} \square$ Não & Instituição: \\
\hline
\end{tabular}

\begin{tabular}{|l|l|l|}
\hline Fabricante/Marca: & Modelo: & Dimensão: \\
\hline Atividade nominal: & Taxa de dose absorvida: & Data de referência: \\
\hline
\end{tabular}

Início de utilização da fonte:

Condições durante o procedimento de irradiação dos dosímetros

\begin{tabular}{|l|l|l|l|}
\hline Temperatura: & Pressão: & Umidade relativa do ar: & Horário:
\end{tabular}

\section{Dados referentes ao experimento}

Número de amostras termoluminescentes (TL) irradiadas com este aplicador:

Amostras TL irradiadas (especificar pelo número de cada uma delas):

Número de detectores luminescentes opticamente estimulados (LOE) irradiadas com este aplicador:

Amostras LOE irradiadas (especificar pelo número de cada uma delas):

Tempo de irradiação utilizado para cada dosímetro:

Data do procedimento de irradiação dos dosímetros:

Data de avaliação dos dosímetros no IPEN: 


\section{B.3 - Documento de verificação de Itens do Sistema Dosimétrico Postal}

Instituto de Pesquisas Energéticas e Nucleares,

Comissão Nacional de Energia Nuclear (IPEN/CNEN-SP)

Gerência de Metrologia das Radiações - Laboratório de Calibração

\section{SISTEMA DOSIMÉTRICO POSTAL}

Favor verificar todos os itens que serão devolvidos ao IPEN após as irradiações, e a data deste envio

Envio do Sistema Postal (Data: / / ):

\begin{tabular}{|c|c|c|}
\hline \multicolumn{2}{|c|}{ Itens } & \multirow{2}{*}{$\frac{\text { Check List }}{\square}$} \\
\hline$x$ & 1 formulário de coleta de dados & \\
\hline$x$ & $\begin{array}{l}1 \text { procedimento para a irradiação de dosímetros termoluminescentes e luminescentes } \\
\text { opticamente estimulados com aplicadores clínicos de }{ }^{90} \mathrm{Sr}+{ }^{90} \mathrm{Y} \text {, para calibração destas fontes }\end{array}$ & $\bigotimes$ \\
\hline$x$ & 1 caixa organizadora para armazenamento dos itens do sistema postal dosimétrico & $\bigotimes$ \\
\hline$x$ & $\begin{array}{l}20 \text { (vinte) dosímetros termoluminescentes de } \mathrm{Al}_{2} \mathrm{O}_{3}: \mathrm{C} \text { (números: } 26 \text { / } 29 \text { / } 30 \text { / } 31 \text { / } 32 \text { / } 33 \text { / } 34 \\
\text { / } 35 \text { / } 36 \text { / } 37 \text { / } 39 \text { / } 40 \text { / } 41 \text { / } 42 \text { / } 44 \text { / } 45 \text { / } 46 \text { / } 47 \text { / } 48 \text { / 49) }\end{array}$ & $\bigotimes$ \\
\hline$x$ & $\begin{array}{l}20 \text { (vinte) detectores luminescentes opticamente estimulados de } \mathrm{Al}_{2} \mathrm{O}_{3}: \mathrm{C} \text { (números: } 1 / 2 \text { / } 3 \text { / } 4 \\
/ 5 / 6 / 7 / 10 / 11 / 14 / 15 / 16 / 17 / 18 / 19 / 20 / 21 / 22 / 23 / 25 \text { ) }\end{array}$ & $\bigotimes$ \\
\hline$x$ & 1 pinça & $\bigotimes$ \\
\hline$x$ & 1 porta-dosímetro (porta-amostra) de acrílico envolto por filme plástico & 区 \\
\hline$x$ & 1 caixinha escura contendo os 20 dosímetros termoluminescentes & $\bigotimes$ \\
\hline$x$ & 1 caixinha escura contendo os 20 detectores luminescentes opticamente estimulados & 区 \\
\hline$x$ & 1 caixinha escura para armazenamento das amostras enquanto são irradiadas & 区 \\
\hline$x$ & 1 cronômetro & $\bigotimes$ \\
\hline$x$ & 2 pares de luvas cirúrgicas (monitorar e descartar após uso) & $\bigotimes$ \\
\hline$x$ & 1 caneta & $\bigotimes$ \\
\hline
\end{tabular}

Devolução do Sistema Postal (Data: / / ):

\begin{tabular}{|c|c|c|}
\hline \multicolumn{2}{|c|}{ Itens } & \multirow{2}{*}{$\frac{\text { Check List }}{\square}$} \\
\hline$x$ & 1 formulário de coleta de dados & \\
\hline$x$ & 1 caixa para armazenamento dos itens do sistema dosimétrico & $\square$ \\
\hline$x$ & $\begin{array}{l}20 \text { (vinte) dosímetros termoluminescentes de } \mathrm{Al}_{2} \mathrm{O}_{3}: \mathrm{C} \text {, números: } 26 \text { / } 29 \text { / } 30 \text { / } 31 \text { / } 32 \text { / } 33 \text { / } 34 \\
\text { / } 35 \text { / } 36 \text { / } 37 \text { / } 39 \text { / } 40 \text { / } 41 \text { / } 42 \text { / } 44 \text { / } 45 \text { / } 46 \text { / } 47 \text { / } 48 \text { / } 49 \text { de controle e } 18 \text { irradiados) }\end{array}$ & $\square$ \\
\hline$x$ & $\begin{array}{l}20 \text { (vinte) detectores luminescentes opticamente estimulados de } \mathrm{Al}_{2} \mathrm{O}_{3}: \mathrm{C} \text {, números: } 1 \text { / } 2 \text { / } 3 \text { / } 4 \\
\text { / } 5 \text { / } 6 \text { / } 7 \text { / } 10 / 11 \text { / } 14 \text { / } 15 / 16 / 17 \text { / } 18 \text { / } 19 \text { / } 20 \text { / } 21 \text { / } 22 \text { / } 23 \text { / } 25 \text { ( } \text { de controle e } 18 \\
\text { irradiados) }\end{array}$ & $\square$ \\
\hline$x$ & 1 pinça & $\square$ \\
\hline$x$ & 1 porta-dosímetro (porta-amostra) de acrílico & $\square$ \\
\hline$x$ & $\begin{array}{l}1 \text { caixinha escura contendo os } 20 \text { dosímetros termoluminescentes ( } 2 \text { de controle e } 18 \\
\text { irradiados) }\end{array}$ & $\square$ \\
\hline$x$ & $\begin{array}{l}1 \text { caixinha escura contendo os } 20 \text { detectores luminescentes opticamente estimulados ( } 2 \text { de } \\
\text { controle e } 18 \text { irradiados) }\end{array}$ & $\square$ \\
\hline$x$ & 1 caixinha escura para armazenamento das amostras enquanto são irradiadas & $\square$ \\
\hline$x$ & 1 cronômetro & $\square$ \\
\hline$x$ & 1 caneta & $\square$ \\
\hline
\end{tabular}




\section{REFERÊNCIAS BIBLIOGRÁFICAS}

ABNT, Associação Brasileira de Normas Técnicas. Guia para Expressão da Incerteza da Medição. 3a Ed. Brasileira em Língua Portuguesa. Rio de Janeiro: ABNT, INMETRO, SBM, 2003.

AHMED, S.N. Physics and Engineering of Radiation Detection. Oxford: Academic Press, Elsevier, 2007.

AKSELROD, M.S.; MCKEEVER, S.W.S.; MOSCOVITCH, M.; EMFIETZIGLOU, D.; DURHAM, J.R.; SOARES, C.G. A thin-layer $\mathrm{Al}_{2} \mathrm{O}_{3}$ beta TL detector. Radiat. Prot. Dosim., v. 66, n. 1-4, p. 105-110, 1996.

AKSELROD, A.; AKSELROD, M.S.; AGERSNAP LARSEN, N.; BANERJEE, D.; B $\emptyset$ TTER-JENSEN, L.; CHRISTENSEN, P.; LUCAS, A.C.; MCKEEVER, S.W.S.; YODER, R.C. Optically stimulated luminescence response of $\mathrm{Al}_{2} \mathrm{O}_{3}$ to beta radiation. Radiat. Prot. Dosim., v. 85, n. 1-4, p. 125-128, 1999.

ALBERTAZZI, A.; SOUSA, A.R. Fundamentos de Metrologia Científica e Industrial. $1^{\text {a }}$ ed. Barueri, São Paulo: Editora Manole, 2008.

AMBROSI, P.; BUCHHOLZ, G.; HELMSTÄDTER, K. The PTB Beta Secondary Standard BSS2 for radiation protection. J. Instr., v. 2, p. 1-33, 2007.

ANTONIO, P.L.; CALDAS, L.V.E. Development of a dosimetric postal system to calibration of ${ }^{90} \mathrm{Sr}+{ }^{90} \mathrm{Y}$ clinical applicators. Radioproteção, v. 2, n. 16 e 17, p. 123-134, 2009.

ANTONIO, P.L.; CARVALHO, V.S.; CALDAS, L.V.E. Comparison of calibration results for an extrapolation chamber obtained with different ${ }^{90} \mathrm{Sr}+{ }^{90} \mathrm{Y}$ secondary standard sources.

Appl. Radiat. Isot., v. 70, p. 388-391, 2012a.

ANTONIO, P.L.; OLIVEIRA, M.L.; CALDAS, L.V.E. Thin $\mathrm{CaSO}_{4}$ :Dy thermoluminescent dosimeters for calibration of ${ }^{90} \mathrm{Sr}+{ }^{90} \mathrm{Y}$ applicators. Appl. Radiat. Isot., v. 70, p. 790-793, 2012b.

ATTIX, F.H. Introduction to Radiological Physics and Radiation Dosimetry. Mörlenbach: WILEY-VCH Verlag GmbH\& Co., 2004.

AYDIN, T.; DEMIRTAS, H.; AYDIN, S. TL/OSL studies of $\mathrm{Li}_{2} \mathrm{~B}_{4} \mathrm{O}_{7}: \mathrm{Cu}$ dosimetric phosphors. Radiat. Meas., in Press, 2013.

BAKSHI, A.K.; VANDANA, S.; PALANI SELVAM, T.; CHOUGAONKAR, M.P.; MAYYA, Y.S. Measurement of the output of ISO recommended beta sources with an extrapolation chamber. Radiat. Meas., v. 53-54, p. 50-55, 2013 
BAMBYNEK, M. Development of a multi-electrode extrapolation chamber as a prototype of a primary standard for the realization of the unit of the absorbed dose to water for beta brachytherapy sources. Nucl. Instr. Meth. Phys. Res. A, v. 492, p. 264-275, 2002.

BEHRENS, R.; HELMSTÄDTER, K.; AMBROSI, P.; BORDY, J.-M.; LECANTE, C.; BOVI, M.; JOKELAINEN, I.; SOARES, C.G.; SAULL, P.R.B.; KHARITONOV, I.A.; FEDINA, S.; KUROSAWA, T.; KATO, M. International comparison of extrapolation chamber measurements of the absorbed dose rate in tissue for beta radiation - EUROMET project $n$. 739: Final Report. Metrologia, v. 44, p. 1-27, 2007.

BEHRENS, R.; FEDINA, S.; OBORIN, A. Direct comparison of extrapolation chamber measurements of the absorbed dose rate for beta radiation between PTB (Germany) and VNIIM (Russia). Metrologia, v. 48, p. 317-323, 2011.

BOAG, J.W. Ionization chambers. In: KASE, K.R.; BJARNGARD, B.E.; ATTIX, F. The Dosimetry of Ionizing Radiation. Orlando: Academic Press Inc., 1987.

BÖHM, J.; HILLION, P.; SIMOEN, J.P. Intercomparison of the PTB and LMRI standards in beta dosimetry. In: Proceedings of the VIII Congrèss International de la Société Française de Radioprotection. March 23-26, Saclay, 1976.

BÖHM, J. The National Primary Standard of the PTB for realizing the unit of the absorbed dose rate to tissue for beta radiation. Braunschweig, Germany: Physikalisch-Technische Bundesanstalt, PTB-Dos-13: 1986.

BÖHM, J.; SCHNEIDER, U. Review of extrapolation chamber measurements of beta rays and low energy X rays. Radiat. Prot. Dosim., v. 14, n. 2, p. 193-198, 1986.

BÖHM, J. Standardisation, calibration and type-testing in skin dosimetry. Radiat. Prot. Dosim., v. 39, n. 1/3, p. 95-100, 1991.

BÖHM, J.; ALBERT, W.G.; SWINTH, K.L.; SOARES, C.G.; McDONALD, J.C.; THOMPSON, I.M.G.; KRAMER, H.-M. ISO recommended reference radiations for the calibration and proficiency testing of dosemeters and dose rate meters used in radiation protection. Radiat. Prot. Dosim., v. 86, n. 2, p. 87-105, 1999.

BØTTER-JENSEN, L.; McKEEVER, W.S.; WINTLE, A.G. Optically Stimulated Luminescence Dosimetry. Amsterdam: Elsevier, 2003.

BRUNZENDORF, J. Depth-dose curves of the beta reference fields ${ }^{147} \mathrm{Pm},{ }^{85} \mathrm{Kr}$ and ${ }^{90} \mathrm{Sr} /{ }^{90} \mathrm{Y}$ produced by the beta secondary standard BSS2. Radiat. Prot. Dosim., v. 151, n. 2, p. 211217,2012 a.

BRUNZENDORF, J. Determination of depth-dose curves in beta dosimetry. Radiat. Prot. Dosim., v. 151, n. 2, p. 203-210, 2012b.

CALDAS, L.V.E. Alguns métodos de calibração e de dosimetria da radiação beta. São Paulo: 1980. Tese (Doutoramento) - Instituto de Física, Universidade de São Paulo. 
CALDAS, L.V.E.; ECKERL, H.; DREXLER, G. Thermoluminescence properties of the Vinten extremity dosemeters. Radiat. Prot. Dosim., v. 11, n. 4, p. 267-271, 1985.

CALDAS, L.V.E. Performance characteristics of an extrapolation chamber for beta radiation detection. Appl. Radiat. Isot., v. 37, n. 9, p. 988-990, 1986.

CALDAS, L.V.E. Comunicação particular. 2012.

CAMPOS, L.L.; LIMA, M.F. Thermoluminescent $\mathrm{CaSO}_{4}$ :Dy teflon pellets for beta radiation detection. Radiat. Prot. Dosim., v. 18, n. 2, p. 95-97, 1987.

CAMPOS, L.L. Graphite mixed $\mathrm{CaSO}_{4}$ :Dy TL dosemeters for beta radiation dosimetry. Radiat. Prot. Dosim., v. 48, n. 2, p. 205-207, 1993.

CAMPOS, L.L. Termoluminescência de materiais e sua aplicação em dosimetria da radiação. Cerâmica, v. 44, n. 290, p. 244-251, 1998.

CECATTI, S.G.P.; CALDAS, L.V.E. Preliminary dosimetric characterization of thermoluminescence materials for beta radiation monitoring at Nuclear Medicine services. Radiat. Prot. Dosim., v. 120, n. 1-4, p. 307-311, 2006.

CHITAMBO, M.L. Concerning secondary thermoluminescence peaks in $\alpha-\mathrm{Al}_{2} \mathrm{O}_{3}: \mathrm{C}$. South Afr. J. Sci., v. 100, p. 524-527, 2004.

DARLEY, P.J.; CHARLES, M.W.; HART, C.D.; WELLS, J.; COLEBY, M.S.E. Dosimetry of planar and punctiform beta sources using an automated extrapolation chamber and radiochromic dye films. Radiat. Prot. Dosim., v. 39, n. 1/3, p.61-66, 1991.

DE ALMEIDA, C.E.; DeWERD, L.A.; JÄRVINEN, H.; SOARES, C. Guidelines for the calibration of low energy photon sources and beta-ray brachytherapy sources. SSDL Newsletter, n. 43, p. 4-25, 2000.

DeBLOIS, F.; ABDEL-RAHMAN, W.; SEUNTJENS, J.P.; PODGORSAK, E.B. Measurement of absorbed dose with a bone-equivalent extrapolation chamber. Med. Phys., v. 29, n. 3, p. 433-440, 2002.

DIAS, S. K. Desenvolvimento de uma câmara de extrapolação como instrumento de referência para dosimetria de radiação beta. São Paulo: 1996. Tese (Doutoramento) Instituto de Pesquisas Energéticas e Nucleares, Universidade de São Paulo.

DING, G.X.; MALCOLM, A.W. An optically stimulated luminescence dosimeter for measuring patient exposure from imaging guidance procedures. Phys. Med. Biol., v. 58, p. 5885-5897, 2013.

DURHAM, J.S.; ZHANG, X.; PAYNE, F.; AKSELROD, M.S. Design of a finger ring extremity dosemeter based on OSL readout of $\alpha-\mathrm{Al}_{2} \mathrm{O}_{3}:$ C. Radiat. Prot. Dosim., v. 101, n. 1-4, p. 65-68, 2002. 
FAILLA, G. The measurement of tissue dose in terms of the same unit for all ionizing radiations. Radiology, v. 29, p. 202-215, 1937.

FRIEDELL, H.L.; THOMAS, C.I.; KROHMER, J.S. Beta-ray application to the eye: with the description of an applicator utilizing ${ }^{90} \mathrm{Sr}$ and its clinical use. Am. J. Ophthalmol., v. 33, n. 4, p. 525-535, 1950.

FURETTA, C. Handbook of Thermoluminescence. Singapore: World Scientific Publishing Co. Pte. Ltd, 2003.

FURETTA, C. Questions and Answers on Thermoluminescence (TL) and Optically Stimulated Luminescence (OSL). Singapore: World Scientific Publishing Co. Pte. Ltd, 2008.

GENNA, S.; LAUGHLIN, J.S. Absolute calibration of a cobalt-60 gamma-ray beam. Radiology, v. 65, n. 3, p. 394-407, 1955.

GENNA, S.; HOROWITZ, E.B.; LAUGHLIN, J.S. Absolute intensity calibration of $130 \mathrm{keVp}$ to 250 keVp X-ray beams. Radiat. Res., v. 5, n. 5, p. 608-609, 1956.

GÖKSU, H.Y.; BAILIFF, I.K.; BØTTER-JENSEN, L.; BRODSKI, L.; HÜTT, G.; STONEHAM, D. Interlaboratory beta source calibration using TL and OSL on natural quartz. Radiat. Meas., v. 24, n. 4, p. 479-483, 1995.

GONZÁLEZ, P.R.; AZORÍN, J. Thermoluminescent response of LiF:Mg,Cu,P+PTFE prepared in Mexico to ${ }^{90} \mathrm{Sr} /{ }^{90} \mathrm{Y}$ beta particles. Radiat. Phys. Chem., v. 61, n. 3-6, p. 425-427, 2001.

GUERRA, A.B. Estabelecimento e controle de qualidade de feixes padrões de radiação $X$ para calibração de instrumentos, nível mamografia. São Paulo: 2001. Tese (Doutoramento) - Instituto de Pesquisas Energéticas e Nucleares, Universidade de São Paulo.

HELMSTÄDTER, K.; BÖHM, J.; AMBROSI, P.; FOMINYCH, V.; RUMYANTSEVA, E.; FEDINA, S. Comparison of extrapolation chamber measurements of the absorbed dose rate for beta radiation between VNIIM (Russia) and PTB (Germany). Metrologia, v. 41, n. 1A, p. 1-13, 2004.

HOLMES, S.M.; MICKA, J.A.; DeWERD, L.A. Ophthalmic applicators: an overview of calibrations following the change to SI units. Med. Phys., v. 36, n. 5, p. 1473-1477, 2009.

IAEA, INTERNATIONAL ATOMIC ENERGY AGENCY. Calibration of dose meters used in radiotherapy. Vienna: IAEA, 1994 (Technical Report Series, n. 374).

IAEA, INTERNATIONAL ATOMIC ENERGY AGENCY. Absorbed dose determination in external beam radiotherapy: an international code of practice for dosimetry based on standards of absorbed dose to water. Vienna: IAEA, 2000a (Technical Report Series, n. 398).

IAEA, INTERNATIONAL ATOMIC ENERGY AGENCY. Calibration of radiation protection monitoring instruments. IAEA: Vienna, 2000b (Safety Report Series, n. 16). 
IAEA, INTERNATIONAL ATOMIC ENERGY AGENCY. Calibration of photon and beta ray sources used in brachytherapy. Vienna: IAEA, 2002 (IAEA-TECDOC-1274).

ICRU, INTERNATIONAL COMMISSION ON RADIATION UNITS AND MEASUREMENTS. Determination of dose equivalents resulting from external radiation sources. v. $1, n$. 1 , Bethesda, M.D.: ICRU, 1985 (ICRU Report n. 39).

ICRU, INTERNATIONAL COMMISSION ON RADIATION UNITS AND MEASUREMENTS. Dosimetry of beta-rays and low-energy photons for brachytherapy with sealed sources. v. 4, n. 2, Bethesda, M.D.: ICRU, 2004 (ICRU Report n. 72).

ICRU, INTERNATIONAL COMMISSION ON RADIATION UNITS AND MEASUREMENTS. Fundamental quantities and units for ionizing radiation. v. 11, n. 1, Bethesda, M.D.: ICRU, 2011 (ICRU Report n. 85).

IEC, INTERNATIONAL ELECTROTECHNICAL COMMISSION. Medical electrical equipment dosimeters with ionization chambers as used in radiotherapy. Genève: IEC, 2011 (IEC 60731).

INMETRO, INSTITUTO NACIONAL DE METROLOGIA, QUALIDADE E TECNOLOGIA. Vocabulário Internacional de Metrologia: Conceitos Fundamentais e Gerais e Termos Associados. 1a ed. Rio de Janeiro: Luso-Brasileira - INMETRO, 2012.

IRD/CNEN, Instituto de Radioproteção e Dosimetria, Comissão Nacional de Energia Nuclear. Critérios para certificação de um serviço de monitoração individual externa. Comitê de Avaliação de Serviços de Monitoração Individual Externa (CASMIE/IRD): Rio de Janeiro, 1995 (IRD-RT no 001.01/95).

ISO, INTERNATIONAL ORGANIZATION FOR STANDARDIZATION. Nuclear energy - Reference beta-particle radiation - Part 2: Calibration fundamentals related to basic quantities characterizing the radiation fields. Genève: ISO, 2004 (ISO/FDIS 6980-2:2004).

ISO, INTERNATIONAL ORGANIZATION FOR STANDARDIZATION. Nuclear energy - Reference beta-particle radiation - Part 3: Calibration of area and personal dosemeters and the determination of their response as a function of beta radiation energy and angle of incidence. Genève: ISO, 2006 (ISO/FDIS 6980-3:2006).

JOHNS, H.E.; CUNNINGHAM, J.R. The Physics of Radiology. 3a ed. Springfield, Illinois: Charles C. Thomas, Publisher, 1974.

JURSINIC, P.A. Characterization of optically stimulated luminescence dosimeters, OSLDs, for clinical dosimetric measurements. Med. Phys., v. 34, p. 4594-4604, 2007.

KALLE FOLIEN. Datenblatt - Hostaphan (Catálogo). 8642 7.500. 504 LV, s/ data.

KNOLL, G.F. Radiation Detection and Measurement. 3a ed. New: York: John Wiley \& Sons, 2000. 
KOLLAARD, R.P.; DRIES, W.J.F.; VAN KLEFFENS, H.J.; AALBERS, T.H.L.; VAN DER MAREL, H.; MARIJNISSEN, H.P.A.; PIESSENS, M.; SCHAART, D.R.; VROOME, H. Recommendations on detectors and quality control procedures for brachytherapy beta sources. Radiat. Oncol., v. 78, n. 2, p. 223-229, 2006.

LEDERMAN, M. Some applications of radioactive isotopes in ophthalmology. Brit. J. Radiol., v. 29, n. 339, p. 1-13, 1956.

LOEVINGER, R. Extrapolation chamber for the measurement of beta sources. R. Scien. Ins., v. 24, n. 10, p. 907-914, 1953.

LOEVINGER, R.; TROTT, N.G. Design and operation of an extrapolation chamber with removable electrodes. Int. J. Appl. Radiat. Isot., v. 17, p. 103-111, 1966.

MAIA, A.F. Padronização de feixes de metodologia dosimétrica em tomografia computadorizada. São Paulo: 2005. Tese (Doutoramento) - Instituto de Pesquisas Energéticas e Nucleares, Universidade de São Paulo.

MANCOSU, P.; CANTONE, M.C.; VERONESE, I.; GIUSSANI, A. Spatial distribution of beta extremity doses in nuclear medicine: A feasibility study with thin $\alpha-\mathrm{Al}_{2} \mathrm{O}_{3}: \mathrm{C}$ TLDs. Phys. Med., v. 26, n. 1, p. 44-48, 2010.

MANSON, D.J.; VELKLEY, D.; PURDY, J.A.; OLIVER, G.D. Measurements of surface dose using buildup curves obtained with an extrapolation chamber. Radiology, v. 115, n. 2, p. 473-474, 1975.

MARSHALL, M.; DOCHERTY, J. Measurement of skin dose from low energy beta and gamma radiation using thermoluminescent discs. Phys. Med. Biol., v. 16, p. 503-510, 1971.

MAYLES, P.; NAHUM, A.; ROSENWALD, J.C. Handbook of Radiotherapy Physics - Theory and Practice. New York: Taylor \& Francis Group, 2007.

McKEEVER, S.W.S. Thermoluminescence in Solids. Cambridge: Cambridge University Press, 1985.

McKEEVER, S.W.S.; MOSCOVITCH, M.; TOWNSEND, P.D. Thermoluminescence Dosimetry Materials: Properties and Uses. Ashford: Nuclear Technology Publishing, 1995.

McKeEVER, S.W.S. Optically stimulated luminescence dosimetry. Nucl. Instr. Meth. Phys. Res. B, v. 184, p. 29-54, 2001.

McKEEVER, S.W.S. Optically stimulated luminescence: A brief overview. Radiat. Meas., v. 46, p. 1336-1341, 2011.

NASCIMENTO, L.F.; SALDARRIAGA, C.V.; VANHAVERE, F.; D'AGOSTINO, E.; DEFRAENE, G.; DE DEENE, Y. Characterization of OSL $\mathrm{Al}_{2} \mathrm{O}_{3}: \mathrm{C}$ droplets for medical dosimetry. Radiat. Meas., In Press, 2013. 
NIST, NATIONAL INSTITUTE OF STANDARDS AND TECHNOLOGY. Calibration Laboratories: Technical guide for ionizing radiation measurements. Washington: U.S. Government Printing Office, 2004 (NIST Handbook 150-2D).

NIST, NATIONAL INSTITUTE OF STANDARDS AND TECHNOLOGY. Ionizing Radiation Division: Protection-level beta particle source \& instrument calibrations. IRD-P-10, p. 1-39, 2010.

OLIVEIRA, M.L.; CALDAS, L.V.E. Performance of different thermoluminescence dosemeters in ${ }^{90} \mathrm{Sr}+{ }^{90} \mathrm{Y}$ radiation fields. Radiat. Prot. Dosim., v. 111, n. 1, p. 17-20, 2004.

OLIVEIRA, M. L. Desenvolvimento de um sistema de referência e de uma metodologia para calibração de aplicadores oftálmicos utilizados em braquiterapia. São Paulo: 2005. Tese (Doutoramento) - Instituto de Pesquisas Energéticas e Nucleares, Universidade de São Paulo.

OLIVEIRA, M.L.; CALDAS, L.V.E. Performance of thin $\mathrm{CaSO}_{4}$ : Dy pellets for calibration of a ${ }^{90} \mathrm{Sr}+{ }^{90}$ Y source. Nucl. Instr. Meth. Phys. Res. A, v. 580, p. 293-295, 2007.

OLKO, P. Advantages and disadvantages of luminescence dosimetry. Radiat. Meas., v. 45, n. 3-6, p. 506-511, 2010.

OWEN, B. Factors for converting beta-ray dose rates measured in air to dose rates in tissue. Phys. Med. Biol. v. 18, p. 355-368, 1973.

PINTO, T.N.O.; CECATTI, S.G.P.; GRONCHI, C.G.; CALDAS, L.V.E. Application of the OSL technique for beta dosimetry. Radiat. Meas., v. 43, p. 332-334, 2008.

PINTO, T.N.C.O. Metodologia dosimétrica para extremidades em indivíduos ocupacionalmente expostos à radiação beta por meio da técnica de luminescência opticamente estimulada. São Paulo: 2010. Tese (Doutoramento) - Instituto de Pesquisas Energéticas e Nucleares, Universidade de São Paulo.

PINTO, T.N.O.; ANTONIO, P.L.; CALDAS, L.V.E. Measuring TL and OSL of beta radioisotopes inside a glove box at a Radiopharmacy Laboratory. Radiat. Meas., v. 46, n. 12, p. 1847-1850, 2011.

PODGORSǍK, E.B. Radiation Oncology Physics: a Handbook for Teachers and Students. Vienna: International Atomic Energy Agency (IAEA), 2005.

PODGORSǍK, E.B. Radiation Physics for Medical Physicists. 2a ed. New York: Springer, 2010.

PRUITT, J.S.; SOARES, C.G.; EHRLICH, M. NBS measurement services: calibration of betaparticle radiation instrumentation and sources. Natl. Bur. Stand. (U.S.), Special Publication 250-21. Washington: U.S. Government Printing Office, 1988.

PTB, PHYSIKALISCH-TECHNISCHE BUNDESANSTALT. Calibration certificate of ${ }^{90} \mathrm{Sr}^{90}$ source. PTB-6.61/37, Braunschweig, 1981a. 
PTB, PHYSIKALISCH-TECHNISCHE BUNDESANSTALT. Calibration certificate of ${ }^{90} \mathrm{Sr}+{ }^{90} \mathrm{Y}$ source. PTB-6.61/25, Braunschweig, 1981b.

PTB, PHYSIKALISCH-TECHNISCHE BUNDESANSTALT. Calibration certificate of ${ }^{90} \mathrm{Srt}^{90} \mathrm{Y}$ source. PTB-6.34-BSS2_04, Braunschweig, 2005.

PTW, PHYSIKALISCH-TECHNISCHE WERKSTÄTTEN. Instruction Manual - Extrapolation chamber according to Böhm, Type 23392. Freiburg: PTW, 2002.

PTW, Physikalisch-Technische Werkstätten. PTW Unidos - Instruction Manuals and Data Sheets for Ionization Chambers and Radioactive Check Devices - Ionization Chamber Type 23344. Freiburg, 2003.

QUAST, U.; BÖHM, J.; KAULICH, T.W. Clinical beta radiation dosimetry for brachytherapy in terms of absorbed dose to water ISO new work item proposal for international standardization. Cardiovasc. Radiat. Med., v. 3, p. 209-212, 2002.

RAVICHANDRAN, R.; BINUKUMAR, J.P.; SIVAKUMAR, S.S.; KRISHNAMURTHY, K.; DAVIS, C.A. Extrapolation chamber mounted on Perspex for calibration of high energy photon and electron beams from a clinical linear accelerator. J. Med. Phys., v. 34, n. 1, p. 31-36, 2009.

REXON, TLD Systems, Inc. TLD-500 Technical Specifications - Aluminum Oxide $\left(\mathrm{Al}_{2} \mathrm{O}_{3}: \mathrm{C}\right)$, 2009.

ROGERS, D.W.O; ROSS, C.K. The role of humidity and other correction factors in the AAPM TG-21 dosimetry protocol. Med. Phys., v. 15, n. 40, p. 40-48, 1988.

ROSA, L.A.R.; CALDAS, L.V.E.; CUNHA, P.G. Thermoluminescence characteristics of ultra-thin $\mathrm{CaSO}_{4}$ :Dy beta radiation detection. Radiat. Prot. Dosim., v. 14, n. 4, p. 329-331, 1986.

ROSA, L.A.R. Dosimetria Termoluminescente aplicada à Física Médica. Departamento de Física Médica, Instituto de Radioproteção e Dosimetria (IRD), Comissão Nacional de Energia Nuclear (CNEN), 2000.

SCAFF, L.A.M. Bases Físicas da Radiologia: Diagnóstico e Terapia. São Paulo: Sarvier, 1979.

SCHARMANN, A.; BÖHM, M. Basic concepts of thermoluminescence. In: OBERHOFER, M.; SCHARMANN, A. Health Physics and Radiation Protection. Techniques and management of personal thermoluminescence dosimetry services. Dordrecht, The Netherlands: Kluwer Academic Publishers, v. 2, 1993.

SELBACH, H.-J.; SOARES, C.G. New developments on primary standards for brachytherapy at the National Institute of Standards and Technology and the Physikalisch-Technische Bundesanstalt. In: Proceedings Series of an International Symposium on Standards and codes of practice in medical radiation dosimetry. Vienna: IAEA, 2003.

SILVA, E.A.B.; CALDAS, L.V.E. Application of extrapolation chambers in low-energy X-rays as reference systems. Appl. Radiat. Isot., v. 70, p. 1411-1416, 2012. 
SINCLAIR, W.K.; TROTT, N.G. The construction and measurement of beta-ray applicators for use in ophthalmology. Brit. J. Radiol., v. 29, n. 339, p. 15-23, 1956.

SOARES, C.G. Calibration of ophthalmic applicators at NIST: A revised approach. Med. Phys., v. 18, n. 4, p. 787-793, 1991.

SOARES, C.G.; PRUITT, J.S. Measurement quality assurance for beta particle calibrations at NIST. In: Proceedings of the Workshop on Measurement Quality Assurance for lonizing Radiation. March 16-18, Gaithersburg, 1993.

SOARES, C.G. Comparison of NIST and manufacturer calibrations of ${ }^{90} \mathrm{Sr}+{ }^{90} \mathrm{Y}$ ophthalmic applicators. Med. Phys., v. 22, n. 9, p. 1487-1493, 1995.

SOARES, C.G.; VYNCKIER, S.; JÄRVINEN, H.; CROSS, W.G.; SIPILÄ, P.; FLÜHS, D.; SCHAEKEN, B.; MOURTADA, F.A.; BASS, G.A.; WILLIAMS, T.T. Dosimetry of beta-ray ophthalmic applicators: Comparison of different measurements methods. Med. Phys., v. 28, n. 7, p. 1373-1384, 2001.

SOARES, C.G.; DOUYSSET, G.; MITCH, M.G. Primary standards and dosimetry protocols for brachytherapy sources. Metrologia, n. 46, p. 80-98, 2009.

SOUZA, C.N.; CALDAS, L.V.E.; SIBATA, H.; HO, A.K.; SHIN, K.H. Two new parallel-plate ionization chambers for electron beam dosimetry. Radiat. Meas., v. 26, n. 1, p. 65-74, 1996.

STABIN, M.G. Radiation Protection and Dosimetry - an Introduction to Health Physics. New York: Springer, 2008.

UCHRIN, G. Beta dosimetry, different solutions. Radiat. Prot. Dosim., v. 17, p. 99-104, 1986.

VAN DER MAREL, J.; VAN DIJK, E. Development of a dutch primary standard for beta emitting brachytherapy sources. In: Proceedings Series of an International Symposium on Standards and codes of practice in medical radiation dosimetry. Vienna: IAEA, 2003.

VIM, Vocabulário Internacional de Metrologia: Conceitos Fundamentais e Gerais e Termos associados. 1a ed. Inmetro: Rio de Janeiro, 2012.

YUKIHARA, E.G.; McKEEVER, S.W.S. Optically stimulated luminescence (OSL) dosimetry in medicine. Phys. Med. Biol., v. 53, p. 351-379, 2008.

YUKIHARA, E.G.; GASPARIAN, P.B.R.; SAWAKUCHI, G.O.; RUAN, C.; AHMAD, S.; KALAVAGUNTA, C.; CLOUSE, W.J.; SAHOO, N.; TITT, U. Medical applications of optically stimulated luminescence dosimeters (OLDs). Radiat. Meas., v. 45, n. 3-6, p. 658-662, 2010. 


\section{ANEXO A}

\section{* Lista de Trabalhos desenvolvidos ao longo do Doutorado}

\section{A.1 - Artigos completos publicados em Periódicos}

1. ANTONIO, P.L.; XAVIER, M.; CALDAS, L.V.E. Determination of transmission factors in tissue using a standard extrapolation chamber. Radiation Physics and Chemistry, v. 95, p. 38-43, 2014.

2. SARDAR, M.; SOUZA, D.N.; TUFAIL, M.; CALDAS, L.V.E.; ANTONIO, P.L.; CARVALHO, A.B. TL Behavior of Topaz-glass Composite in Various Irradiation Fields. Health Physics, v. 105, p. 150-155, 2013.

3. ANTONIO, P.L.; CALDAS, L.V.E. Performance of a parallel plate ionization chamber in beta radiation dosimetry. Radioproteç̧ão (S. João da Talha), v. 2, p. 157-166, 2012.

4. PINTO, T.C.N.O.; ANTONIO, P.L.; CALDAS, L.V.E. Measuring TL and OSL of beta radioisotopes inside a glove box at a Radiopharmacy Laboratory. Radiation Measurements, v. 46, p. 1847-1850, 2011.

5. ANTONIO, P.L.; CALDAS, L.V.E. Application of a dosimetric system for calibration of ${ }^{90} \mathrm{Sr}+{ }^{90} \mathrm{Y}$ sources used In brachytherapy. Radiation Measurements, v. 46, p. 2025-2027, 2011.

6. ANTONIO, P.L.; PINTO, T.N.O.; CALDAS, L.V.E. Comparação entre medições (TL e LOE) numa simulação de operação de calibração de aplicadores clínicos. Revista Brasileira de Pesquisa e Desenvolvimento, v. 13, p. 89-94, 2011.

\section{A.2 - Trabalhos completos publicados em Anais de Congressos}

1. ANTONIO, P.L.; PINTO, T.C.N.O.; GRONCHI, C.C.; MASCARENHAS, Y.M.; CALDAS, L.V.E. Application of the OSL technique for determination of the useful calibration distance ranges for beta radiation detector. In: IRPA13 - 13th International Congress of the International Radiation Protection Association, 2012, Glasgow, Escócia. IRPA13 Abstracts, 2012.

2. ANTONIO, P.L.; SILVA, R.M.V.; SOUZA, D.N.; CALDAS, L.V.E. Calibration of ${ }^{90} \mathrm{Sr}+{ }^{90} \mathrm{Y}$ sources used for betatheraphy, using a postal kit of thermoluminescent dosimeters. In: IRPA13 - International Congress of the International Radiation Protection Association, 2012, Glasgow, Escócia.

IRPA13 Abstracts, 2012.

3. ANTONIO, P.L.; XAVIER, M.; CALDAS, L.V.E. Preliminary tests of a commercial extrapolation chamber for utilization as a beta radiation standard system. In: PROTEÇÃO 2012 - 20 Congresso Português de Proteção contra Radiações / 3 o Congresso de Proteção contra Radiações dos Países e Comunidades de Língua Portuguesa, 2012, Lisboa, Portugal. Atas da Proteção 2012, p. 1-6, 2012. 
4. ANTONIO, P.L.; CALDAS, L.V.E. Performance of a parallel plate ionization chamber in beta radiation dosimetry. In: RADIO 2011 - International Joint Conference - II Congresso de Proteção contra Radiações da Comunidade dos Países de Língua Portuguesa, II Congresso Brasileiro de Proteção Radiológica e V Congresso Internacional de Radioproteção Industrial, 2011, Recife. CD e Livro de Resumos, 2011.

5. BENAVENTE, J.A.; REYNALDO, S.R.; ANTONIO, P.L.; MEIRA-BELO, L.C.; CALDAS, L.V.E.; SILVA, T.A. Metodologia para comparação laboratorial de campos de referência de radiação beta de ${ }^{90} \mathrm{Sr} /{ }^{90} \mathrm{Y},{ }^{85} \mathrm{Kr}$ e ${ }^{147} \mathrm{Pm}$. In: Metrologia 2011 - 60 Congresso Brasileiro de Metrologia, 2011, Natal, RN. Book of Abstractcs / CD Proceedings, 2011.

6. GROPPO, D.P.; ANTONIO, P.L.; CALDAS, L.V.E. Performance tests for characterization of reutilized dosimetric material of disposable extremity dosimeters. In: Metrologia 2011 - 60 Congresso Brasileiro de Metrologia, 2011, Natal, RN. Book of Abstracts / CD Proceedings, 2011.

7. ANTONIO, P.L.; CALDAS, L.V.E. A superficial ionization chamber in standard beta radiation beams. In: Metrologia 2011 - 60 Congresso Brasileiro de Metrologia, 2011, Natal, RN. Book of Abstracts / CD Proceedings, 2011.

8. ANTONIO, P.L.; PINTO, T.C.N.O.; CALDAS, L.V.E. Comparação entre medições (TL e LOE) numa simulação de operação de calibração de aplicadores clínicos. In: I Simpósio de Dosimetria de Estado Sólido e suas Aplicações, 2010, Recife. Anais do SDS 2010, 2010.

9. ANTONIO, P.L.; PINTO, T.C.N.O.; CALDAS, L.V.E. TL and OSL techniques for calibration of ${ }^{90} \mathrm{Sr}+{ }^{90} \mathrm{Y}$ clinical applicators. In: Third European IRPA Congress, 2010, Helsinque - Finlândia. Abstracts / Proceedings, 2010.

10. ANTONIO, P.L.; PINTO, T.C.N.O.; CALDAS, L.V.E. Estudo comparativo da resposta TL e LOE de diferentes materiais na calibração de fontes utilizadas em betaterapia. In: XV Congresso Brasileiro de Física Médica, 2010, Aracaju. CD-Rom Anais, 2010.

11. ANTONIO, P.L.; CALDAS, L.V.E. Characterization of a parallel plate ionization chamber for the quality control of clinical applicators. In: International Symposium on Standards, Applications and Quality Assurance in Medical Radiation Dosimetry (IDOS), 2010, Viena - Áustria. Standards, Applications and Quality Assurance in Medical Radiation Dosimetry (IDOS), Proceedings of an International Symposium, v. 1, Vienna, 9-12 November 2010.

\section{A.3 - Resumos publicados em Anais de Congressos}

1. ANTONIO, P.L.; XAVIER, M.; CALDAS, L.V.E. Böhm extrapolation chamber: study of its behavior in beta radiation fields at the Calibration Laboratory of IPEN. In: 1st International Conference on Dosimetry and its Applications, 2013, Praga, República Tcheca. Book of Abstracts, p. 146-146, 2013. 
2. PINTO, T.C.N.O.; ANTONIO, P.L.; GRONCHI, C.C.; CALDAS, L.V.E. OSL signal fading of nanoDot detectors induced by different light conditions. In: 17th International Conference on Solid State Dosimetry, SSD17, 2013, Recife, Brasil. Abstract Book, p. 61-61, 2013.

3. ANTONIO, P.L.; PINTO, T.C.N.O.; SILVA, R.M.V.; SOUZA, D.N.; CALDAS, L.V.E. The use of the TL and OSL phenomena for determination of absorbed dose rates of ${ }^{90} \mathrm{Sr}+{ }^{90} \mathrm{Y}$ sources by a postal method. In: 17th International Conference on Solid State Dosimetry, SSD17, 2013, Recife, Brasil. Book of Abstracts, p. 114-114, 2013.

4. ANTONIO, P.L.; PINTO, T.C.N.O.; GRONCHI, C.C.; CALDAS, L.V.E. Commercial $\mathrm{Al}_{2} \mathrm{O}_{3}: \mathrm{C}$ detectors in standard beta radiation beams, using TL and OSL techniques. In: LUMDETR 2012 - 8th International Conference on Luminescent Detectors and Transformers of lonizing Radiation, 2012, Halle (Saale), Alemanha. Book of Abstracts, p. P-Thu-48-P-Thu-48, 2012.

5. ANTONIO, P.L.; XAVIER, M.; CALDAS, L.V.E. Determination of transmission factors in tissue using a standard extrapolation chambe. In: ISRP 12 - 12th International Symposium on Radiation Physics, 2012, Rio de Janeiro, Brasil. Abstracts, p. 1-1, 2012.

6. ANTONIO, P.L.; CALDAS, L.V.E. Calibration of radiation monitors at different source-detector distances in standard ${ }^{90} \mathrm{Sr}+{ }^{90} \mathrm{Y}$ beams. In: International Conference on Medical Physics 2011 (ICMP2011) / XVI Brazilian Congress of Medical Physics (XVI CBFM), 2011, Porto Alegre. CDProceedings of ICMP2011, 2011.

7. ANTONIO, P.L.; CALDAS, L.V.E. Application of a dosimetric system for calibration of ${ }^{90} \mathrm{Sr}+{ }^{90} \mathrm{Y}$ sources used in brachytherapy. In: 16th International Conference on Solid State Dosimetry, 2010, Sydney - Austrália. Abstract Book, 2010.

8. PINTO, T.C.N.O.; ANTONIO, P.L.; CALDAS, L.V.E. Measuring TL and OSL of beta radioisotopes inside a glove box at a Radiopharmacy Laboratory. In: 16th International Conference on Solid State Dosimetry, 2010, Sydney - Austrália. Abstract Book, 2010. 